New Science Institutions for Global Sustainability

Sandra van der Hel 
Design by Barend Wilschut

Language editing by Daya Berendse

Printed by Ridderprint

ISBN: 978-94-6416-048-2

DOI: https://doi.org/10.33540/39

Copyright (C) 2020 S.C. van der Hel 


\title{
New Science Institutions for Global Sustainability
}

\author{
Nieuwe Wetenschappelijke Instituties voor Mondiale Duurzaamheid \\ (met een samenvatting in het Nederlands)
}

\section{Proefschrift}

ter verkrijging van de graad van doctor aan de

Universiteit Utrecht

op gezag van de

rector magnificus, prof.dr. H.R.B.M. Kummeling,

ingevolge het besluit van het college voor promoties

in het openbaar te verdedigen op

vrijdag 11 september 2020 des middags te 2.30 uur

door

\section{Sandra Corine van der Hel}

geboren op 8 december 1988

te Rotterdam 
Promotoren: $\quad$ Prof. dr. F.H.B. Biermann

Prof. dr. A.C. Petersen 
Other members of the doctoral committee:

prof.dr. H. Bulkeley

prof.dr. P.P.J. Driessen

prof.dr. M.A. Hajer

dr. E. Lövbrand

prof.dr. E. Turnhout

This research was supported by the Dutch Research Council (NWO) as part of the Graduate Programme on "Complex dynamics in human-environment systems" (grant no. 022.003.009) and conducted under the auspices of the Graduate School for Socio-Economic and Natural Sciences of the Environment (SENSE). 


\section{TABLE OF CONTENTS}

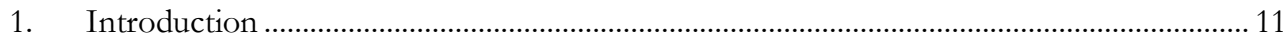

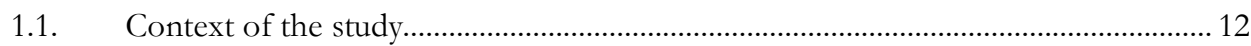

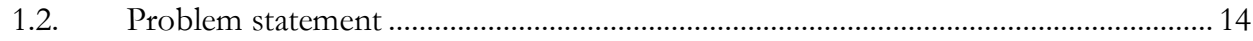

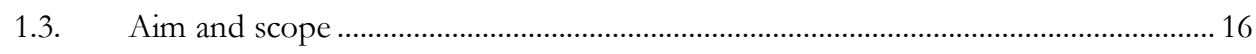

1.4. Empirical focus and research approach ....................................................................... 19

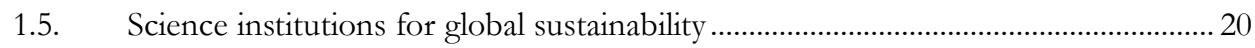

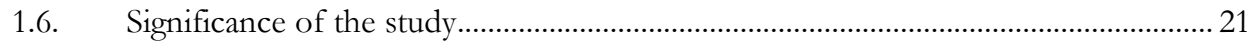

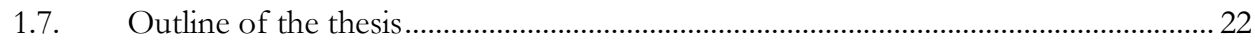

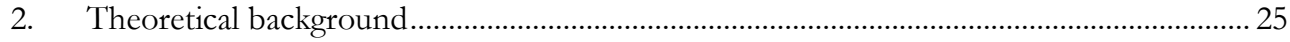

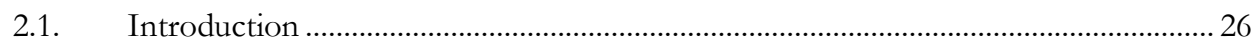

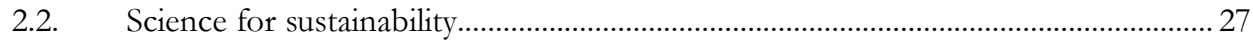

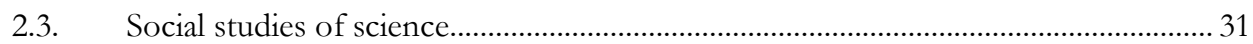

2.4. Science in environmental governance ......................................................................... 35

2.5. Integration: politics of science institutions for sustainability ..................................... 38

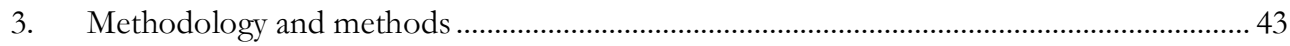

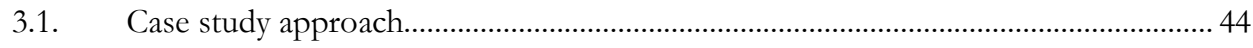

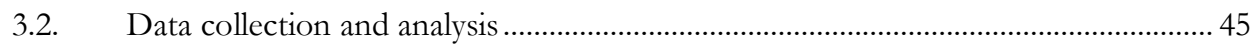

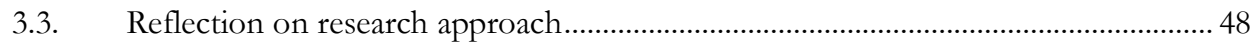

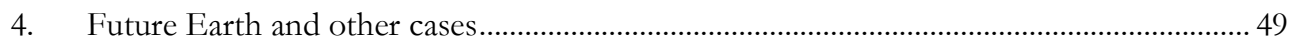

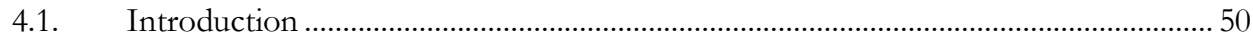

4.2. From global change science to science for sustainability …...................................... 50

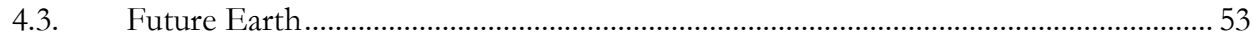

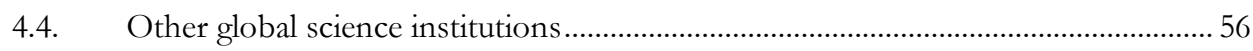

5. Institutionalising co-production in Future Earth.................................................................... 59

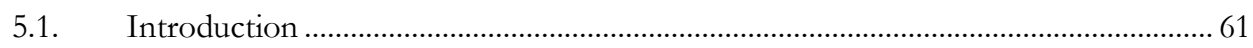

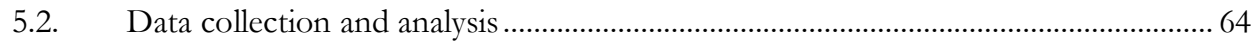

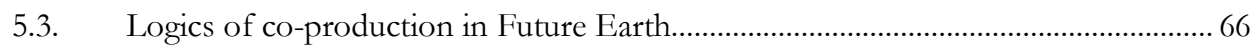

5.4. Institutionalising co-production in Future Earth.......................................................... 70

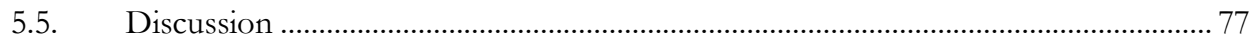




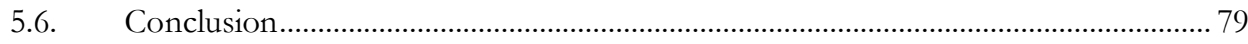

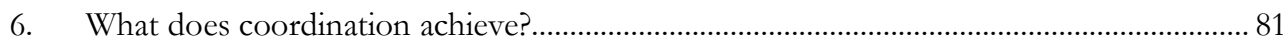

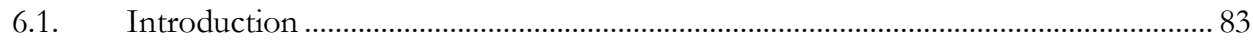

6.2. Research programmes as coordination mechanisms................................................... 84

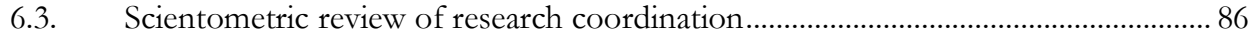

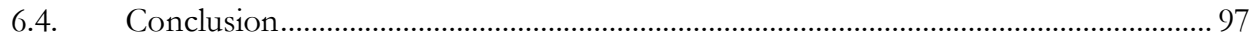

7. Normative and political dimensions of science for sustainability …................................... 99

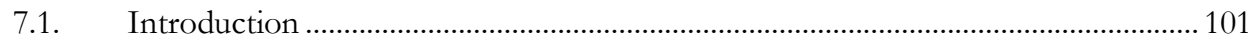

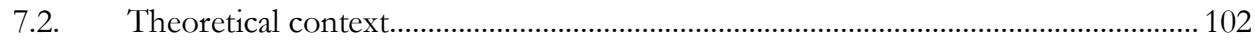

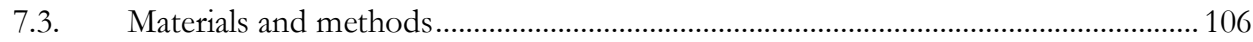

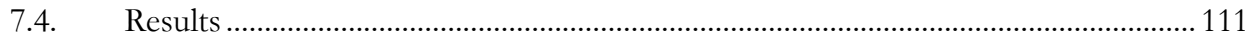

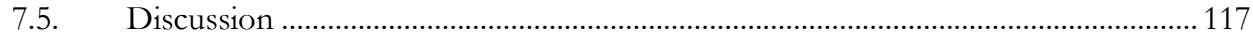

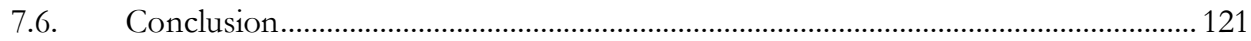

8. The authority of science in sustainability governance......................................................... 123

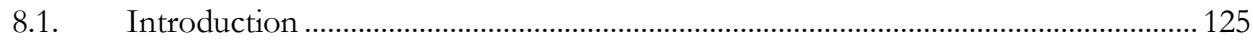

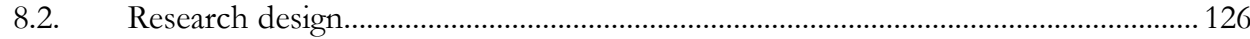

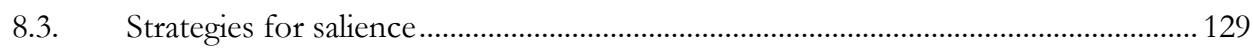

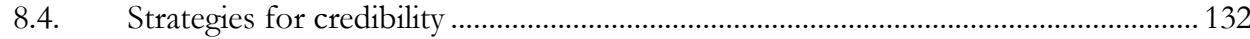

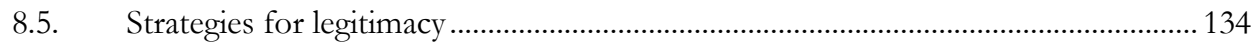

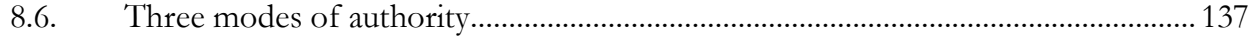

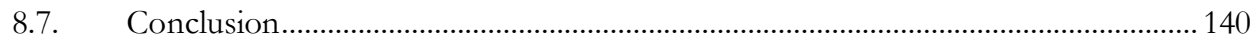

9. Epistemic authority and institutional design ....................................................................... 145

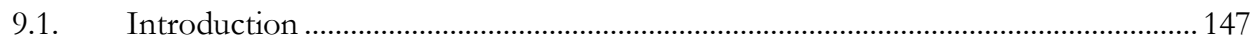

9.2. Knowledge platforms for sustainability ……............................................................. 149

9.3. Epistemic authority in global environmental politics............................................... 150

9.4. Studying institutional designs of participation ........................................................... 151

9.5. Institutional designs of participation in IPBES and Future Earth ........................... 152

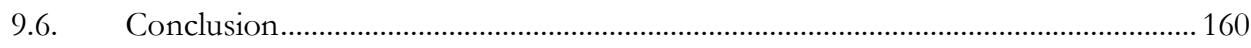

10. Conclusion, discussion and future directions................................................................. 163

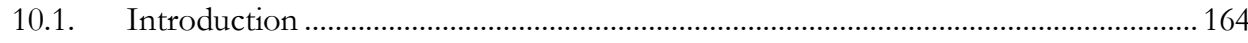

10.2. Summary of findings for research sub-questions ..................................................... 165 
10.3. Answer to main research question........................................................................... 169

10.4. The politics of transformative science for sustainability ......................................... 171

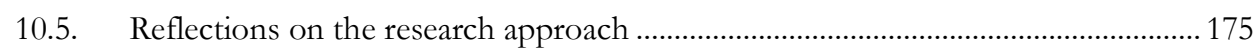

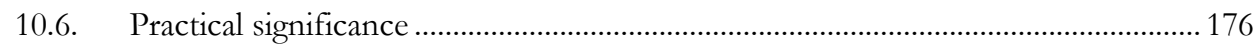

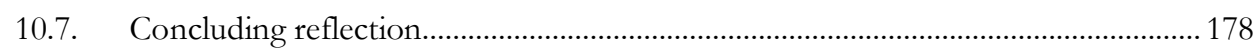

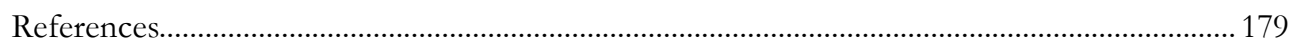

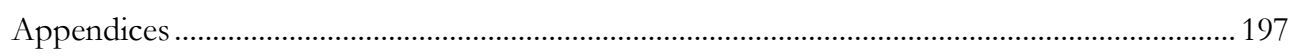

Appendix A: Interview respondents................................................................................ 199

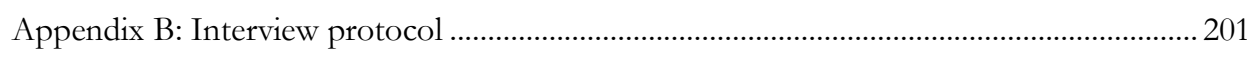

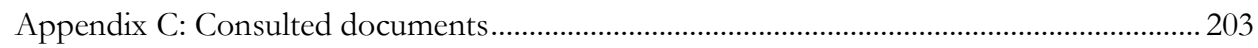

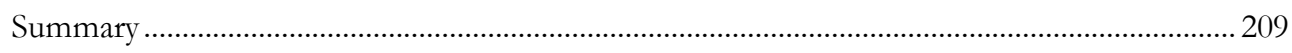

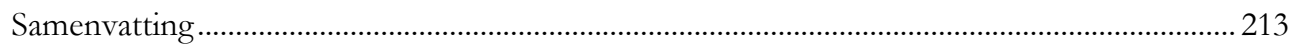

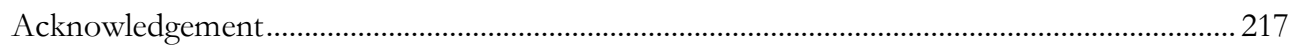




\section{LIST OF ACRONYMS}

ECOSOC United National Economic and Social Council

ESSP Earth System Science Partnership

GEO Global Environmental Outlook

GSDR Global Sustainable Development Report

ICS International Science Council

ICSU International Council for Science

IGBP International Geosphere-Biosphere Programme

IGFA International Group of Funding Agencies

IHDP International Human Dimensions Programme on Global Environmental Change

IPBES Intergovernmental Science-Policy Platform on Biodiversity and Ecosystem Services

IPCC Intergovernmental Panel on Climate Change

IR International Relations

IRDR Integrated Research on Disaster Risk

ISSC International Social Sciences Council

IUCN International Union for the Conservation of Nature

KAN Knowledge Action Network

SAB Scientific Advisory Board of the UN Secretary General

SDSN Sustainable Development Solutions Network

STS Science and Technology Studies

STC Scientific and Technological Major Group

UN DESA United Nations Department of Economic and Social Affairs

UNEP United Nations Environment Programme

WCED World Commission on Environment and Development

WCRP World Climate Research Programme

WMO World Meteorological Organisation 


\section{1 - Introduction}

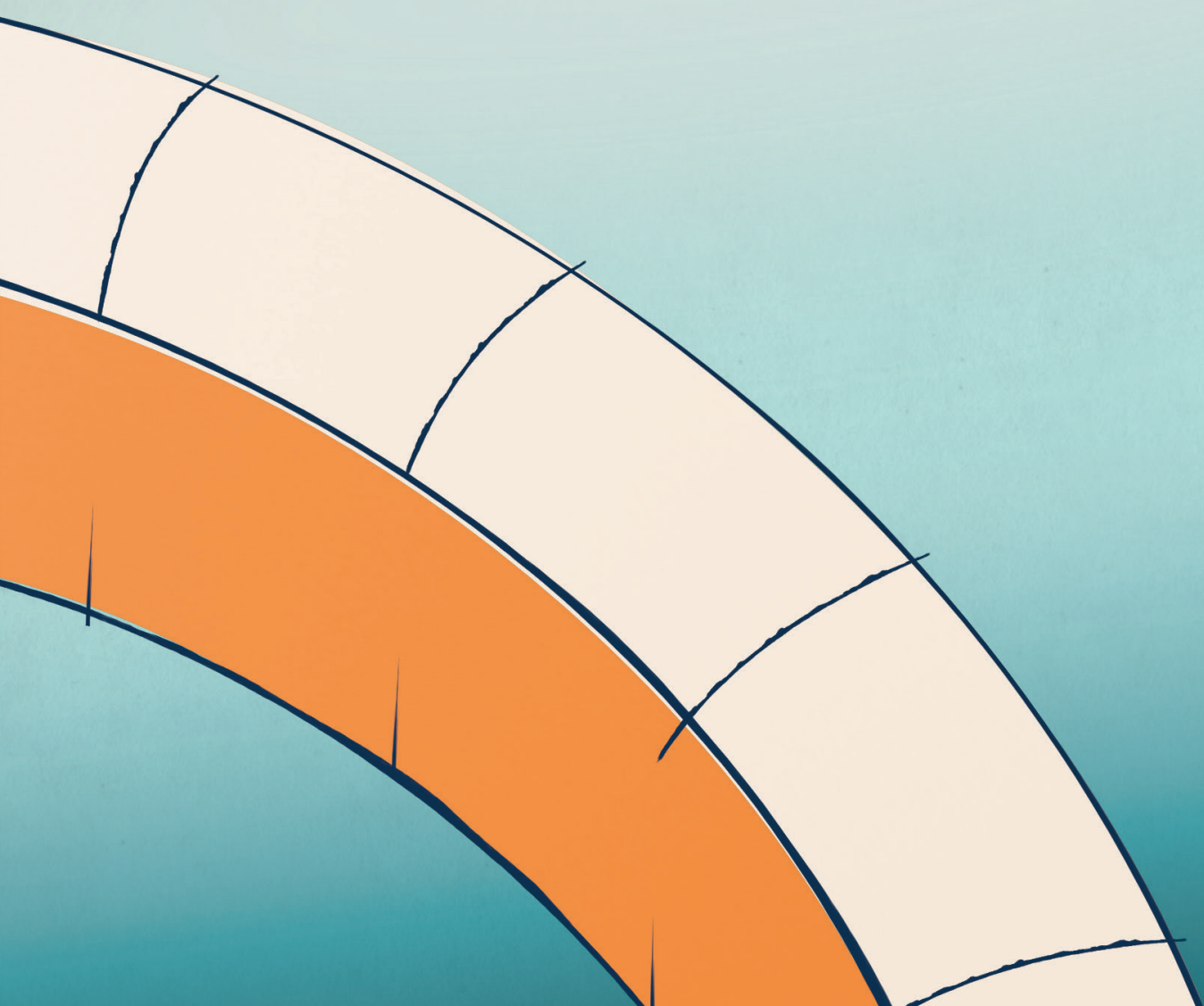




\subsection{CONTEXT OF THE STUDY}

The complex, urgent and contested nature of sustainability problems and potential solutions poses unprecedented challenges for both science and governance. Interconnected dynamics in human-environmental systems shape climate change, food security, rapid urbanisation, desertification, chemical pollution and other sustainability challenges, which leads to high uncertainty and the absence of one optimal path forward. This complexity is aggravated by the urgency to address sustainability challenges and a call for rapid transformations to sustainability. Yet, responses to sustainability challenges are also contested. These contestations centre the nature of possible and desirable sustainable futures and appropriate pathways to achieve these futures. Both science and governance are essential for sustainability transformations, yet both also struggle to deal with the complex, urgent and contested nature of sustainability challenges. In dealing with these challenges, developments in science and governance for sustainability are strongly intertwined.

Without science, we would know little about the sustainability challenges faced by modern-day societies. Starting with a few pioneers in the 1960s, researchers increasingly turned their attention to environmental problems, ranging from chemical pollution (Carson, 1962) to resource depletion (Meadows, Meadows, Randers, \& Behrens III, 1972) to global climate change (IPCC, 1990). This raised awareness of the often detrimental human influence on environmental systems and slowly put issues of sustainability on the global political agenda (WCED, 1987). Scientific knowledge of global environmental change and sustainability increased exponentially over the subsequent decades, supported by the development of global research programmes and global research infrastructure for data sharing and modelling (Edwards, 2010). These developments augmented the scientific understanding of global environmental change. They also informed and supported the development of a global governance infrastructure to attempt to address global sustainability challenges (Biermann, 2014; Jasanoff, 2004; C. A. Miller \& Edwards, 2001).

Today, the efforts and resources invested in the science of global change and sustainability have sparked a vast range of scientific research on socio-environmental change. Yet, scientific knowledge has hardly led to a decrease of the challenge. Human-induced environmental change has aggravated over the past decades with tremendous risks for societies worldwide. Few of these challenges have been successfully mitigated and communities across the globe struggle to adapt to changing environments. The governance infrastructures developed to address these challenges - from local to global scales - are often perceived as ineffective (Biermann et al., 2016). Moreover, scientific institutions that aim to inform and support environmental governance appear to have limited influence. Of course, there are exceptions, notably the Montreal Protocol, which, building on scientific evidence of damage to the ozone layer, has been considered largely successful in phasing out the production of ozone depleting 
substances (Litfin, 1994) ${ }^{1}$. However, overall, the expectation that more and better knowledge of environmental change would lead to solutions for sustainability challenges has not been met.

In response to this apparent disconnection between science and governance, analysts have come to reconsider the kind of science required to address sustainability challenges. Since the professionalisation of scientific institutions in the mid-19th century, science has been shaped by disciplinary institutions and ideals of autonomy and independence (Rip, 2011). Yet, this specialisation and compartmentalisation of science is increasingly called into question. From various angles, scholars have critiqued the mono-disciplinary and curiosity-driven mode of knowledge production for its apparent inability to provide a satisfactory response to societal needs. Instead, alternative modes of scientific knowledge production have been proposed. Prominent examples include Mode 2 knowledge production, introduced by Michael Gibbons, Helga Nowotny and colleagues, who argue that scientific knowledge production is undergoing profound transformations and becomes increasingly generated 'in the context of application' (Gibbons et al., 1994; Nowotny, Scott, \& Gibbons, 2003). Another example is post-normal science, a concept developed by Silvio Funtowicz and Jerome Ravetz, proposing that the nature of many current societal problems - where the stakes are high and values are contested - requires a scientific approach that involves stakeholders in the production and evaluation of knowledge (Funtowicz \& Ravetz, 1993). A third example is formed by the increasingly prominent notion of transdisciplinarity, which focuses on 'transcending' disciplinary perspectives and collaboration between scientists and non-scientists (Hadorn et al., 2008; Pohl, 2008). What these examples have in common is a call for changing practices and institutions of science to make scientific knowledge more relevant and responsive to societal needs.

The domain of sustainability research forms a focal point for the development and application of new modes of knowledge production. Commentators call for a new social contract between science and society for sustainability. Such science for sustainability should not only provide scientific insights into the problems of sustainability, but should also actively contribute to sustainability governance and sustainability transformations (Hessels, van Lente, \& Smits, 2009; Lang et al., 2012; Lubchenco, 1998). In order to achieve this goal, new modes of knowledge production are required that are better equipped to address complex, urgent and contested sustainability challenges. In other words, not more or better but different science is needed. This call for new modes of knowledge production for sustainability is increasingly supported by researchers, science managers, funding agencies and policy-makers (Cash et al., 2003; Cornell et al., 2013; Kueffer et al., 2012; Wiek, Farioli, Fukushi, \& Yarime, 2012).

\footnotetext{
${ }^{1}$ Liftin (1994) shows that while the availability of scientific knowledge was a necessary condition to achieve a policy solution in the Montreal Protocol, it was far from a sufficient condition. Instead, the alignment between scientific knowledge and public and private interests shaped the proposed policy solution. In other words, the development of the Montreal Protocol was shaped through an interactive relationship between science and politics.
} 
Although a variety of perspectives on science for sustainability exists (see Chapter 2 for more details), the following principles form a common ground:

- Science for sustainability is interdisciplinary; that is, it brings together insights from multiple disciplines, including the natural sciences, social sciences and humanities.

- Science for sustainability is co-produced; that is, it is based on collaboration between scientists and extra-scientific actors ${ }^{2}$.

- Science for sustainability is inclusive; that is, it includes researchers with different backgrounds and from different countries globally.

- Science for sustainability is solutions-oriented; that is, it contributes to solutions for sustainability challenges.

In recent years, sustainability researchers have increasingly come to adopt these principles of science for sustainability. Some scholars even argue that these principles are no longer really 'new', but rather have become part of the common toolbox of sustainability researchers (Newig, Jahn, Lang, Kahle, \& Bergmann, 2019). Moreover, large-scale science-based initiatives, including research programmes, advisory bodies and global environmental assessment (henceforth: science institutions), often adopt principles of science for sustainability. These science institutions bring together large numbers of researchers and hold the promise to shape research practices as well as relationships between science and society. As such, they bring the idea of science for sustainability to the global level of scientific knowledge production and collaboration. Together, these developments signify that science for sustainability, at least in rhetoric, has reached the mainstream of global change and sustainability research.

\subsection{PROBLEM STATEMENT}

The developments sketched above suggest that science for sustainability and the relationship between science and governance are potentially undergoing far-reaching transformations. The ideal of science for sustainability challenges conventional ideas of what science is and what it is for. The principle of interdisciplinarity challenges the disciplinary organisation of scientific knowledge production. The principle of co-production challenges the separation between science and society. The principle of inclusiveness challenges the idea that scientific knowledge is unaffected by the place and person who creates it. And the principle of solutions-orientation challenges the disinterested position of science in society. Overall, the ideal of science for sustainability implies that researchers move from a position of distant observers to active participants in shaping and steering societal change. With science institutions increasingly adopting science for sustainability, these ideals about science and its role in society move from the margin to the mainstream of scientific knowledge production. That is, where principles of

\footnotetext{
2 The principle of co-production is often referred to as participatory or transdisciplinary knowledge production. In this thesis, I use the term co-production because this term is used by Future Earth (the main case study of this thesis). I refer to literature on co-production as well as participation and transdisciplinarity to understand this principle.
} 
science for sustainability used to represent a niche idea, they can now potentially shape research practices on a much larger scale.

And yet, we do not know how, in what way and with what effects science for sustainability becomes institutionalised in global science institutions. The institutionalisation of science for sustainability at a global level is a relatively new and ongoing process which means that the potential to study this phenomenon has thus far been limited. The existing literature on science for sustainability is mostly theoretical, with little empirical research that documents how ideals of science for sustainability are confronted in practice. Moreover, the literature on science for sustainability is largely aspirational, documenting what science systems should look like as well as the barriers to achieving these changes. When this literature attends to the institutional dimensions of science, it is to show that existing institutions of science are unfit to support science for sustainability and that institutional change is urgently needed. Yet, little attention has been paid to what such institutionalisation of science for sustainability would look like and what effects it would have. This means that we do not know whether the attention for science for sustainability is simply rhetorical or actually changes the operation of global science institutions. And if the latter is true, we do not know which research practices are supported by institutional change nor how it affects the kind of knowledge that gets produced.

The lack of attention for the institutionalisation of science for sustainability is striking given the potential major transformation of the science system and its consequences. The institutionalisation of science for sustainability is how new principles of science become durable. That is, they become part of the norms, rules and structures of scientific knowledge production. The specific way in which principles of science for sustainability become durable matters for the kind of knowledge that gets produced. It shapes which knowledge is considered relevant, which perspectives are considered credible and which actors can legitimately engage in scientific knowledge production. Moreover, institutionalised science, implicitly or explicitly, demarcates ways forward in society by making possible certain ways of understanding and responding to socio-environmental changes. The kind of science that gets produced and the actors that are involved thus shape the governance and politics of transformations to sustainability.

While researchers, research managers and funders tend to agree on the objective to support science for sustainability through global science institutions, a closer look reveals multiple and sometimes conflicting perspectives on what science for sustainability really means and how the relationship between science and governance should be organised. These different perspectives attend to the kind of knowledge that should be produced, who should be involved and how science institutions can and should support sustainability transformations. Multiple actors with different interests are engaged in the global organisation of science, including science unions, funding agencies, governments, multinational organisations and private actors - each with their own interests in shaping global science institutions. The process and eventual outcome of institutionalising science for sustainability reflects the relative power of these different actors, while also supporting certain practices of science for sustainability and constraining others. The 
institutionalisation of science for sustainability is thus not a neutral act, but rather reproduces and potentially changes relationships of power in science and society.

While the rhetoric of science for sustainability is strong and is adopted more and more broadly, it is as of yet unclear if and how this rhetoric is translated into changes in science institutions and what this means for the relationship between science and governance for sustainability. With researchers seeking to make a positive impact on sustainability transformations through science for sustainability and these ideals increasingly being adopted by funding agencies and research organisations, it is important to direct our attention to the institutions and politics that shape these ideals.

\subsection{AIM AND SCOPE}

The question addressed in this thesis is as follows:

How are new principles of science for sustainability institutionalised and how does this shape the relationship between science and governance for sustainability?

This overarching question is addressed through four specific research questions that attend to different aspects of the institutionalisation of science for sustainability (questions 1-3) and the relationship between science and governance (question 4). For each question, I am focusing on a specific principle or combination of principles of science for sustainability. I address these four research questions in the five empirical chapters of this thesis (see Figure 1.1 for an overview).

Research question 1: How do new principles of science for sustainability shape global science institutions?

The first question concerns the institutionalisation of science for sustainability in global science institutions. While global science institutions such as research programmes, global environmental assessments and advisory committees increasingly adopt principles of science for sustainability, perspectives differ with respect to the way in which these principles should be brought into practice. Research managers, science councils, funding agencies, intergovernmental organisations and private actors are all involved in designing global science institutions and negotiate organisational structures, rules and procedures of knowledge production and assessment. In doing so, they play a role in moving principles of science for sustainability from the margin to the mainstream and shape how these principles become durable. To understand how science for sustainability is institutionalised, I studied the process and outcome by which ideals of science for sustainability shape the organisational structures, rules and procedures of global science institutions.

In addressing this question, I am focusing specifically on the principle of co-production and related participatory ideals. The principle of co-production is relatively novel and different perspectives on its meaning, desirability and implementation exist. This allows me to study how different perspectives shape the development of global science institutions. I will address this question in Chapter $\mathbf{5}$ and Chapter $\mathbf{9 .}$ 


\section{Research question 2: What is the influence of global science institutions on scientific knowledge production?}

The second question concerns the influence of global science institutions on scientific knowledge production. Global science institutions aim to bring together researchers around a common issue of concern. They hold the promise to support collaboration between researchers from different disciplines and countries globally. In doing so, they have the potential to shape research agendas and practices and move research in new directions. And yet, we know relatively little about their actual influence on scientific knowledge production. This means that we do not know whether and how the adoption of science for sustainability in global science institutions - even if this moves beyond rhetoric and shapes institutional structures, rules and procedures (question 1) - has actual effects on the production of scientific knowledge for sustainability. Thus, to better understand the actual influence of science institutions on global sustainability, I studied if and how global science institutions shape the kind of knowledge produced under their umbrella.

In addressing this question, I am focusing on the principles of interdisciplinarity and inclusiveness. These principles have a longer history in global change and sustainability research which allows me to study how support for these principles by global science institutions has shaped scientific knowledge production over time. I will address this question in Chapter 6.

Research question 3: What are the perspectives of researchers on the transformative ambition and politics of science for sustainability?

The third question focuses on the perspectives of researchers engaged in science for sustainability. It thus takes the question of institutionalisation from the formal structures, rules and procedures of global science institutions (question 1 and 2) to the shared norms and values of sustainability researchers. Science for sustainability puts forward the ambitious objective to inform and shape sustainability transformations. This takes researchers out of the scientific comfort zone of independence and neutrality, and rather advances an ideal of science that directly addresses societal concerns. Moreover, transformations towards sustainability inevitably involve normative and political decisions of what sustainable futures look like and how they can best be achieved. This raises the question how sustainability researchers perceive and engage with these normative and political dimensions of their work. Thus, to better understand shared norms and values that shape science for sustainability, as well as possible tensions between new principles of knowledge production and conventional scientific norms, I studied how sustainability researchers perceive normative and political concerns raised by the transformative objective of science for sustainability.

In addressing this question, I am focusing specifically on the principle of solutions-orientation. The principle of solutions-orientation brings the transformative objective of science for sustainability to the fore and thus draws attention to the interrelationship between science and normative and political concerns. I will address this question in Chapter 7. 
Research question 4: How does science for sustainability affect epistemic authority in sustainability governance?

The fourth question concerns the relationship between science and governance for sustainability. Global science institutions have become a well-established part of the global landscape of sustainability governance. Yet, as it has become evident that more and better knowledge of sustainability has not resulted in solutions for major societal challenges, the effectiveness of science institutions in supporting sustainability governance is also questioned. This is one of the reasons that the ideal of science for sustainability has found increasing support. Science for sustainability holds the potential to increase the relevance, credibility and legitimacy of science in governance for sustainability. However, the ideal of science for sustainability also challenges conventional foundations of epistemic authority based on scientific independence and neutrality. Thus, paradoxically, science for sustainability both holds the potential to reshape the authority of science in sustainability governance and undermines its conventional foundations. To better understand the relationship between science and governance for sustainability, I studied how science for sustainability and it is institutionalised in global science institutions affects the authority of science in sustainability governance.

In addressing this question, I am focusing on the four principles of co-production, interdisciplinarity, inclusiveness and solutions-orientation that together represent the ideal of science for sustainability. I will address this question in Chapter $\mathbf{8}$ and Chapter $\mathbf{9 .}$

\begin{tabular}{|l|l|l|}
\hline Research question 1 & $\begin{array}{l}\text { Chapter } 5 \\
\text { Institutionalising co-production } \\
\text { in Future Earth }\end{array}$ \\
\hline Ro-production & $\begin{array}{l}\text { Chapter } 6 \\
\text { What does coordination achieve? }\end{array}$ \\
\hline $\begin{array}{l}\text { Ro-production, interdisciplinarity, } \\
\text { inclusiveness, solutions-orientation }\end{array}$ & $\begin{array}{l}\text { Chapter } 7 \\
\text { Normative and political dimensions } \\
\text { of science for sustainability }\end{array}$ \\
\hline $\begin{array}{l}\text { Chapter } 8 \\
\text { The authority of science in } \\
\text { sustainability governance }\end{array}$ \\
\hline $\begin{array}{l}\text { Chapter } 9 \\
\text { Epistemic authority and } \\
\text { institutional design }\end{array}$ \\
\hline
\end{tabular}

Figure 1.1 Research questions, principles and corresponding chapters 


\subsection{EMPIRICAL FOCUS AND RESEARCH APPROACH}

The main empirical focus of this thesis is the research platform Future Earth: research for global sustainability. Future Earth was initiated in response to calls for fundamental change in the practice, content and organisation of global change research. It sets forth an ambitious mission of advancing science that shapes societal transformations to sustainability (Future Earth, 2013; ICSU, 2010; Mauser et al., 2013). As such, it provides an exemplary case of the institutionalisation of new principles of science for sustainability.

As a global science institution, Future Earth is unprecedented in its scope and ambition to transform global change research towards 'new science for global sustainability'. Future Earth is supported by an international alliance of science councils, science funders and UN organisations, and its network includes dozens of research initiatives each involving hundreds of scientists. This gives it the potential to shape research agendas and modes of knowledge production, and to structure the relationship between science and society on issues of sustainability.

Future Earth was officially launched in 2012 at the United Nations Conference on Sustainable Development in Rio de Janeiro and the preceding major academic conference Planet Under Pressure. Between 2012 and 2014, a multi-stakeholder Transition Team developed an initial design for Future Earth and an interim secretariat worked on the implementation of the programme. Future Earth became fully operational in 2015, with the establishment of an internationally distributed secretariat and appointment of its first Executive Director. For this thesis, I followed these developments, with a specific focus on the discussions and negotiations that went into the design of Future Earth. This early stage of development of a global science institution provides an opportunity to study the multiple and sometimes conflicting perspectives on science and its role in society. The negotiating of institutional structures and rules opens up discussions that would otherwise remain hidden from view.

The emergence of Future Earth marks a major development in global change and sustainability research. However, this development does not stand on its own. In this thesis, Future Earth is presented as a paradigmatic case which provides unique insights in the broader phenomenon of science for sustainability and its institutionalisation and politics. The development of Future Earth provides an opportunity to study tensions and politics of science for sustainability that become explicit in the process of designing a new global science institution. Across the chapters of this thesis, I have complemented the in-depth case study of Future Earth with six other case studies of science institutions in governance for sustainability (see Chapter 4). Contrasting and comparing the developments of Future Earth with other cases contributes to a better understanding of the meaning of science for sustainability and its significance for sustainability governance. Methodologically, this inquiry requires an integrated approach that is best achieved by a mixed-methods design. I have therefore combined expert interviews, document analysis, participant observation, scientometric analysis and a survey to understand the various dimensions of science institutions for global sustainability. 


\subsection{SCIENCE INSTITUTIONS FOR GLOBAL SUSTAINABILITY}

Throughout the chapters of this thesis, I am looking at science institutions for sustainability from different angles. Here, I will define what I mean by science institutions and clarify the terms used to refer to science institutions for sustainability in this thesis and the broader literature.

Broadly speaking, institutions are social structures. Institutions exist in many forms, including organisational structures, rules and regulations, shared norms and cultural practices (Scott, 2014). Institutions bring stability and meaning to social life. In the domain of science, institutions shape what is considered credible scientific knowledge and how such knowledge can be achieved. For example, formalised systems such as peer review are meant to maintain standards of scientific knowledge production. Scientific disciplines are another form of institutionalisation in science, with disciplinary training and career trajectories shaping what is shared and taken for granted among a community of scientists in terms of suitable research problems, conceptual approaches and methodological standards (Rip, 2011). Yet, while institutions seem like stable entities, they are constantly being reconstructed and reshaped by the actors involved. When scientific institutions change, the process of generating scientific understanding does too (Vaughan, 1999). In other words, "science, as we know it now, is also the convergence ... of different activities, their institutionalization at particular times and places, and their further co-evolution" (Rip, 2011, p. 197).

In this thesis, I am interested in the way in which new ideas about science and its role in society inform and shape institutions and are in turn affected by these institutions. I have been studying science institutions in two distinct but interrelated ways.

Firstly, I focused on the institutionalisation of science for sustainability in science institutions such as Future Earth. I am interested in the way in which abstract aspirations and intentions are translated into actual organisational designs, rules and procedures, and how these designs are in turn legitimised in reference to ideas about science and its role in society. I thus understand the development of formal structures and rules of science institutions as part of a process of institutionalisation (Pinheiro \& Stensaker, 2013). Moreover, I am interested in the informal rules, norms and values that shape scientific knowledge production (Thune \& Gulbrandsen, 2011). These informal elements are also part of science institutions. Hence, my focus on Future Earth goes beyond studying Future Earth as a research organisation and also considers the institutional processes, norms and values that shape science institutions for sustainability.

Secondly, I focused on global science institutions as actors in sustainability governance. Future Earth is one among multiple science-based initiatives that aim to inform and shape governance for sustainability. This includes global environmental assessments, scientific advisory bodies, knowledge platforms and formal research programmes. These institutions are diverse in their organisational designs and mode of operation. My reasons for capturing them here under the common heading of global science institutions is to capture how these diverse science-based 
initiatives shape and are shaped by their relationship to governance for sustainability. Yet, it is important to note that these institutions are not unitary actors that speak with one voice but rather a conglomeration of actors and practices (Gupta, Andresen, Siebenhüner, \& Biermann, 2012). My reason for referring to these science-based initiatives as institutions and not organisations is that the term institutions captures both the organisational dimension and the informal structures, norms and networks that these initiatives represent. Understanding these initiatives as science institutions, and not simply a collection of individuals within an organisation, allows for studying how changing structures, norms and practices of science challenges and reshapes the relationship between science and governance.

It is important to note that the qualification 'global' refers to the ambition of global science institutions to operate at the transnational or even planetary scale. It refers to the stated focus of science institutions for sustainability to address global sustainability challenges (for Future Earth the mission 'research for global sustainability' is reflected in its full name), rather than being a reflection of the actual global representation of these institutions. In fact, what it means for science institutions to be global is an important empirical question that has received ample critical scrutiny (Jasanoff \& Martello, 2004). I get back to this in Chapter 2.

\subsection{SIGNIFICANCE OF THE STUDY}

This thesis focuses on science institutions in the context of complex dynamics in humanenvironmental systems. It understands science as being part of the system it seeks to understand. By investigating the institutionalisation of science for sustainability and the changing relationship between science and governance, I aim to make visible and reflect on the politics of science institutions for sustainability. As various scholars have argued: when science becomes directly concerned with action, societal change and sustainability transformations, questions of power and politics can no longer be ignored (Fazey et al., 2018; Lövbrand et al., 2015; Turnhout, Dewulf, \& Hulme, 2016; van Kerkhoff \& Lebel, 2006; West, 2016). In seeking to inform and shape transformations to sustainability, science for sustainability engages in conversations about desirable sustainable futures and required societal, political and economic changes to achieve such futures. It takes science out of its role of neutral and distant observer and rather advances an understanding of science directly concerned with the question 'what needs to be done?' (Sarewitz, 2011). Science for sustainability, in other words, becomes inseparable from the governance and politics of sustainability transformations.

Science institutions for sustainability are thus about politics. Firstly, science for sustainability has political origins and effects. Here, the term politics signifies the relevance of science for collective decision-making (Pielke, 2007) as well as the ways in which science is shaped by and shapes the material and discursive power structures of the society in which it is set (Brown, 2015). Secondly, science institutions themselves can be understood as sites or objects of politics. As the empirical chapters in this thesis will show, science institutions are subject to political activity such as negotiations and power struggles. As argued by Brown (2015), in negotiating appropriate designs of science institutions, actors "persistently and effectively 
challenge established practices and institutions, thus transforming them into sites or objects of politics" (p.7). In this context, the politicisation of science, which is often presented as a negative outcome, might actually be considered desirable as it allows for contesting established power relations and rethinking the relationship between science and governance for sustainability.

This thesis contributes to debates at the interface of academic literature on science for sustainability, social studies of science and science in environmental governance. Each of these perspectives (unpacked in more detail in Chapter 2) provide relevant insights to understand the institutions and politics of science for sustainability. However, a perspective on the politics of science for sustainability that bridges these different bodies of literature is so far missing. I bring together these bodies of literature in a nested conceptualisation of the politics of science for sustainability that attends to the transformative ambition of science for sustainability, the institutionalisation of this ambition in global science institutions and eventual effects on the authority of science in sustainability governance.

On a practical level, this thesis provides relevant insights for researchers, research managers and research funders engaged in science for sustainability. My aim is to help readers understand the implications of current developments in science for the way we understand and govern transformations to sustainability. Moreover, I aim to support readers in reflecting on the politics of science for sustainability and provide relevant insights for redesigning knowledge systems and practices accordingly.

\subsection{OUTLINE OF THE THESIS}

This thesis continues as follows: Chapter 2 to 4 lay out the theoretical, methodological and empirical foundations of the thesis. Chapter 2 introduces the three bodies of literature that are brought together in this thesis: literature on science for sustainability (Section 2.1); literature from the social studies of science (Section 2.2); and literature about science in environmental governance (Section 2.3). Chapter 3 introduces the research approach and methods of data collection and analysis. Chapter 4 discusses the history and development of Future Earth - the main case study of this thesis - and briefly introduces the other science institutions for sustainability discussed in this thesis. Subsequently, Chapter 5 to $\mathbf{9}$ present the research conducted for this thesis. Chapter $\mathbf{5}$ discusses the institutionalisation of the principle of coproduction in Future Earth, focusing specifically on the contestations and tensions that emerged in translating this aspirational principle into specific institutional structures, rules and procedures. Chapter 6 then moves the focus to the impact of research programmes such as Future Earth on geographical inclusiveness and interdisciplinarity in scientific knowledge production. Chapter 7 delves into what transformative research as proposed by Future Earth means for sustainability researchers, focusing specifically on the normative and political dimensions of science for sustainability. Chapter $\mathbf{8}$ turns the focus to the relationship between science and governance for sustainability, discussing how science institutions for sustainability, including Future Earth, seek authority in this crowded space of science engagement. Chapter 
9 further develops this perspective on science in governance for sustainability by explaining how the pursuit of epistemic authority shapes institutional designs of science institutions. Chapter 10 brings together the insights from the preceding chapters. I conclude by presenting my thoughts on the need to rethink the relationship between science and politics for sustainability. 


\section{2 - Theoretical background}

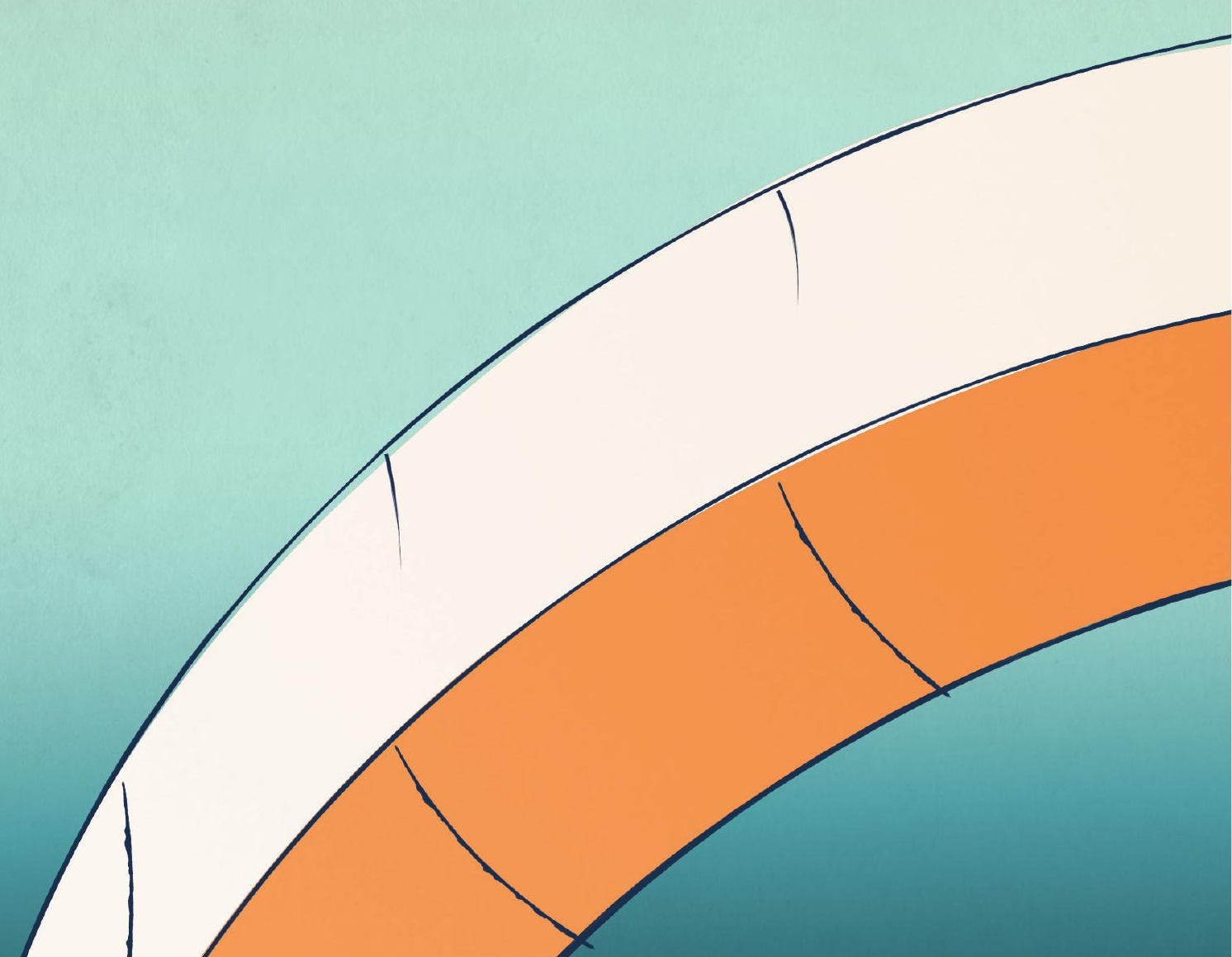




\subsection{INTRODUCTION}

This thesis brings together insights from three bodies of literature: literature on science for sustainability, literature on social studies of science, and literature on science in environmental governance. Each body of literature highlights different aspects that are relevant for understanding the institutionalisation and politics of science for sustainability. Each body of literature also has some blind spots; aspects that remain hidden from view when following the reasoning and focus of this academic tradition. Therefore, by combining and contrasting relevant insights of these different bodies of literature, I aim to provide a more comprehensive and novel view.

The first body of literature that I use is literature on science for sustainability. This literature discusses how research should be conducted to address sustainability challenges and support transformations to sustainability. Thus, the main question that this body of literature addresses is how science can advance sustainability. This literature is relevant for this thesis because it puts forward and reflects on principles of science for sustainability that form the rationale for Future Earth. There is a strong call within this body of literature for better institutional support of interdisciplinary, co-produced, inclusive and solutions-oriented research. Yet, the literature on science for sustainability provides limited depth in understanding the social and institutional processes that shape science for sustainability. Moreover, there is little attention for normative and political questions raised by the ideal of transformative science.

The second body of literature that I use is literature from the social studies of science. This literature attends to the social, institutional and political processes of scientific knowledge production. Scholars working in this tradition have studied scientific knowledge production as a social process that shapes and is shaped by institutions of science. Moreover, this literature attends to the interrelationships between science and its societal context, including the way in which science is both shaped by and shapes global political order. Thus, the main question that this body of literature addresses is how science functions as social, institutional and political process. This literature is relevant for this thesis because it highlights the social and institutional processes that shape ideas and practices of science. Moreover, it shows that science institutions have political causes and consequences. Yet, the social studies of science literature is less directly concerned with the influence of science and science institutions for sustainability governance. There is also limited engagement with the ideal of transformative science as put forward in the literature on science for sustainability.

The third body of literature that I use is literature on science in environmental governance. This literature focuses on the influence of science and science institutions in governance, specifically in relation to environmental change and sustainability. It is concerned with the principles and structures that shape whether and how science informs the behaviour of international organisations and other governance actors and the formation of governance regimes. Thus, the main question that this body of literature addresses is how science influences environmental and sustainability governance. This literature is relevant for this thesis because it helps to understand if and how science institutions for sustainability reshape the relationship between 
science and governance. Yet, environmental governance scholars have so far paid limited attention to the ideal of science for sustainability. Another limitation of this body of literature is that it tends to focus on the output of science, rather than the social and institutional process of scientific knowledge production.

I bring together these three bodies of literature to address some of the limitations of each individual perspective and contribute to a richer understanding of science institutions for sustainability. The literature on science for sustainability puts forward the rationale of science for sustainability. Yet, this body of literature provides limited depth in understanding how these ideas shape science institutions or the relationship between science and governance. The social studies of science literature, through its focus on the social, institutional and political dimensions of scientific knowledge production, helps to unpack the challenges and tensions that shape science institutions for sustainability. The literature on science in environmental governance extends this perspective by its focus on the institutional structures that shape the influence of science in governance for sustainability. So far, neither the social studies of science literature nor the literature on science in environmental governance have extensively engaged with debates and challenges of science institutions for sustainability.

In the remainder of this chapter I discuss relevant insights from each body of literature. I pay attention to key concepts and developments related to the topic of this thesis as well as emerging questions and knowledge gaps. Where relevant, I highlight overlaps and crossfertilisation between the different bodies of literature. I wrap up this section by discussing how the three bodies of literature together provide insights in the politics of science institutions for global sustainability.

\subsection{SCIENCE FOR SUSTAINABILITY}

\subsubsection{Introduction}

The literature on science for sustainability emerged alongside the call for new modes of knowledge production to address complex, urgent and contested challenges of sustainability (as described in Chapter 1). This literature describes, prescribes, explains and evaluates changes towards new modes of knowledge production in science for sustainability. It discusses the required 'paradigm shift' to make science more relevant and responsive to sustainability challenges. It also draws attention to persistent barriers to new modes of knowledge production and calls for institutional support. Recent contributions to this body of literature are concerned with normative and political questions raised by the transformative objective of science for sustainability. I discuss these developments below.

\subsubsection{What is science for sustainability?}

I use the term science for sustainability to capture various perspectives on how science can and should support sustainability. A prominent perspective on science for sustainability has framed this as 'sustainability science'. Sustainability science is presented as a new type of science that focuses on interactions between nature and society and aims to support society in seeking sustainable trajectories (Kates, 2011; Kates et al., 2001). Its proponents argue that sustainability 
science "differs to a considerable degree in structure, methods, and content from science as we know it" (Kates et al., 2001, p. 641). Across the various writings that define sustainability science, three core characteristics stand out. Firstly, sustainability science has a problem-solving focus and aims to link knowledge to action. Secondly, sustainability science combines and integrates insights from natural and social sciences. Thirdly, sustainability science encourages collaboration between scientists and non-academic stakeholders in a transdisciplinary approach (Clark, 2007; Clark \& Dickson, 2003; Jerneck et al., 2011; Kates et al., 2001; Lang et al., 2012; T. R. Miller, 2013; Spangenberg, 2011; van der Leeuw et al., 2012; Wiek et al., 2012). These three characteristics resonate with the principles of 'new science for global sustainability' as put forward by Future Earth. The principle of geographical inclusiveness, also raised by Future Earth, is less prominent in the sustainability science literature.

Other scholars would not necessarily subscribe to the 'emerging discipline' of sustainability science, but follow similar ideals. For example, Cornell and colleagues (2013) argue that there is an urgent need for knowledge systems change in an age of unprecedented environmental change. They state that more open knowledge systems are needed to link knowledge with action for sustainability. Open knowledge systems are based on collaboration between different science communities, as well as between scientific communities and other actors, communities and networks (Cornell et al., 2013). The rationale is thus similar as proposed in the sustainability science literature: to bring together knowledge holders and stakeholders in a concerted effort to address global sustainability challenges. This requires joint problem framing, knowledge integration and collaborative implementation in a process often referred to as knowledge co-production. Mauser and colleagues (2013) also advocate knowledge integration through knowledge co-production. They state that "in societally relevant research, the gap between science as the active knowledge producer and society as the passive recipient in the knowledge production process will need to be replaced by a process of co-design and co-production of knowledge" (Mauser et al., 2013, p. 4). These perspectives put forward by Cornell and colleagues (2013) and Mauser and colleagues (2013) featured prominently in discussions over the design of Future Earth (see also Chapter 4).

Overall, whether captured as a new discipline of sustainability science, or more broadly as a variety of approaches to support science for sustainability, the perspective that science can and should be done differently in support of sustainability is shared widely. Principles of interdisciplinarity, co-production, inclusiveness and solutions-orientation were novel and contested just two decades ago (Clark \& Dickson, 2003; Kates et al., 2001). Today, these principles receive broad support across academic traditions, universities, funding agencies and science councils. And yet, the rhetoric of science for sustainability seems to surpass actual practice.

\subsubsection{Institutional change to support science for sustainability}

Most of the literature on science for sustainability is aspirational. It describes what research practices and research systems should ideally look like - rather than what they look like today. A common argument in this body of literature is that the conservative nature of academic 
institutions hampers efforts to make research more relevant to sustainability (Dedeurwaerdere, 2013; Horlick-Jones \& Sime, 2004; Kueffer et al., 2012; Schneidewind \& Augenstein, 2012; Spangenberg, 2011). As Dedeuwaerdere (2013) puts it “...both Noble prize laureates and highlevel science officials have stressed the need of an in depth transformation of the modes of organization of scientific research for governing the transition to sustainable societies. However, existing analyses of on-going initiatives show that most of the barriers to a major, consolidated effort in sustainability science will not be removed without far-reaching institutional change" (p. 3783). Institutional barriers appear to keep the research system from transitioning to a mode of operation that is more interdisciplinary, co-produced, inclusive and solutions-oriented. These barriers include funding mechanisms, career trajectories and other reward systems that are unsupportive of science for sustainability, as well as academic norms and cultures that maintain disciplinary systems.

Thus, many scholars calls for institutional change in support of science for sustainability (Cornell et al., 2013; Dedeurwaerdere, 2013; Kueffer et al., 2012; Robinson, 2008; Schneidewind \& Augenstein, 2012; Spangenberg, 2011; van der Leeuw et al., 2012; Yarime et al., 2012). Such institutional change may take many forms, and may include, for instance, changes in funding mechanisms, educational programmes, evaluation and career trajectories. Scholars also call attention to the potential of (international) research programmes and collaborative networks to provide systematic support for new modes of knowledge production. Yet, they also note that this potential can only be achieved when combined with structural changes in funding, training and career trajectories (Dedeurwaerdere, 2013; Trencher, Yarime, \& Kharrazi, 2013). Talwar and colleagues (2011) argue that institutional change is not an easy task, and that "new requirements, standards and organisational structures which need to be defined, negotiated and implemented" (Talwar, Wiek, \& Robinson, 2011, p. 388). Thus, they highlight that the institutional change is always contested. Overall, calls for institutional reform of academia in support of new modes of knowledge production are increasingly prominent and loud. Yet, there is limited attention for the politics of institutional change. Moreover, given the repeated calls for institutionalisation of science for sustainability, there is a surprising absence of studies that investigate whether and how institutionalisation is taking place (Yarime et al., 2012).

\subsubsection{Transformative science and its politics}

A driving factor behind the development of science for sustainability is the objective to make science more responsive to complex, urgent and contested sustainability challenges. Recent contributions draw attention to the transformative aim of science for sustainability (Blythe et al., 2018; Fazey et al., 2018; Schneidewind, Singer-Brodowski, Augenstein, \& Stelzer, 2016; West, van Kerkhoff, \& Wagenaar, 2019). That is, science for sustainability can and should initiate and catalyse systemic societal change towards sustainability (Schneidewind et al., 2016). As a transformative science, science for sustainability is concerned with the structural societal transformations required to support sustainability. This 'transformative turn' in science for sustainability (Blythe et al., 2018) puts science for sustainability in the centre of the deeply 
social, normative and political terrain of sustainability problems and potential solutions (Fazey et al., 2018; T. R. Miller, 2013).

Sustainability transformations concern normative and political questions about what sustainable futures look like and how sustainable transformations can best be achieved. While win-win solutions in support of sustainability are possible, they only represent the low hanging fruit and will not be enough for the structural, systemic changes that many argue are urgently needed to further sustainability (Blythe et al., 2018; Fazey et al., 2018; Patterson et al., 2016). System transformations to sustainability cannot be achieved without breaking down incumbent systems and the interests that they support. Thus, sustainability transformations are "deeply and unavoidably political, and need to be recognised as such" (Patterson et al., 2016, p. 2). This puts the principle of solutions-orientation in a new perspective. As several scholars have argued, solutions-oriented science is not necessarily transformative. Some short-term solutions to sustainability in fact may engrain practices and structures that are unsustainable in the long run (Jagannathan et al., 2019). Instead, scholars supporting the transformative ambition of science for sustainability call for sustainability solutions to address long-term, structural and systemic changes (Jagannathan et al., 2019; T. R. Miller et al., 2014; Schneidewind et al., 2016).

Recent contributions to the science for sustainability literature are concerned with the question how sustainability researchers can and should position themselves vis-à-vis the normative and political context of their work. Specifically, the question is raised whether it is possible and desirable for sustainability researchers to operate from the 'academic comfort zone' of objectivity and independence (T. R. Miller et al., 2014; Wittmayer \& Schäpke, 2014). Extending the perspective on the politics of transformations put forward above, Fazey et al (2018) argue that transformative science itself is inherently political. Not recognising this political dimension, they warn, creates the danger that research becomes "a powerful de-politicizing practice, unintentionally reproducing unfavourable market settings, social inequalities and exploitive institutional relations inherent in the systems and structures of society that continue to contribute to climate change" (Fazey et al 2018). The question though remains how to engage with the politics of science for sustainability in a reflexive and productive way, especially in a research system deeply engrained with the assumption that knowledge creation is and should be independent from politics.

\subsubsection{Relevance for this thesis}

Altogether, the literature on science for sustainability provides a context for understanding the emergence and development of Future Earth. Indeed, multiple scholars involved in Future Earth (as members of research projects or advisory committees) are key contributors to this body of literature (e.g. Cornell et al., 2013; Mauser et al., 2013; Moser, 2016; O’Brien, 2012). In this thesis I build on this body of literature to illustrate the tensions between different perspectives on principles of science for sustainability and the way they become institutionalised (Chapter 5) and in unpacking how researchers engaged in science for sustainability understand and deal with the normative and political dimensions of their work

\section{(Chapter 7).}




\subsection{SOCIAL STUDIES OF SCIENCE}

\subsubsection{Introduction}

A second body of literature that is relevant for this thesis is here captured under the broad heading of social studies of science (Demeritt, 2006; Hess, 1997). The social studies of science form a heterogeneous domain of research. What the various perspectives have in common is that they recognise science as a social system, in which not only cognitive but also other social, institutional and political - factors determine how and which knowledge gets produced. While the literature on science for sustainability calls for institutional change, it provides limited depth in understanding the social, institutional and political processes that shape scientific knowledge production. In contrast, this is a core focus of the social studies of science. The social studies of science literature is thus relevant for this thesis to unpack the processes of social and institutional change that turn visions of science for sustainability into the everyday reality of research systems, norms, rules and practices. In this section I discuss two sets of literature from the social studies of science that carry particular relevance for this thesis. First, I discuss literature that considers how the (global) organisation and governance of science shape scientific practices and institutions. Second, I discuss perspectives that draw attention to the politics of knowledge production and institutionalisation.

\subsubsection{Governance and organisation of science}

A first set of relevant literature within the social studies of science focuses on the governance and organisation of science. This literature attends to the processes and forms of governance and organisation - from formal to informal, and from the level of the laboratory to the level of transnational research programmes - that shape science and science institutions (Hackett, Parker, Vermeulen, \& Penders, 2017). The broad premise in this body of literature is that the governance and organisation of science matter for the kinds of knowledge that get produced (K. Braun \& Kropp, 2010; Gläser \& Laudel, 2016; Hackett et al., 2017). Scholars also pointed to the relationship between science and its sponsors as an integral element to developments in science (Jasanoff, 2005; Miettinen, 1998; Rip, 2011).

Studies of the 'global' organisation of science became prominent at the turn of the century (Georghiou, 1998). These studies document and reflect on the rapid increase in reach and scale of scientific collaboration since the mid-20 $0^{\text {th }}$ century. An important factor in the evolving pattern of scientific collaboration on issues of global change and sustainability is the infrastructure of data collection, observation and modelling (Edwards, 2010). Understanding the climate as a global system, for example, involved the expansion of global climate models, the development of local observations into uniform data, and the establishments of global data sharing infrastructure. This global climate knowledge infrastructure both allowed for and required collaboration between climate scientists on larger scales than had been possible before (Edwards, 2010). This collaboration between scientist concerned with physical and geochemical processes of climate and global change, shaped by institutions of global knowledge making, informed the understanding of the Earth as an interconnected system that can be known, modelled and understood (Uhrqvist, 2014). Thus, the increasingly global 
organisation of science not only allowed for collaboration between scientists at an unprecedented scale, but also produced the climate and Earth System as global objects of concern (Uhrqvist \& Lövbrand, 2013). Importantly, studies of global knowledge making show that 'global' collaboration and networks are never truly global, but rather represent an amalgamation of perspectives that are inevitably situated and partial. The problem in seeking global consensual knowledge is that it "erases difference and allows the most powerful to determine what is "known"' (Hulme, 2010, p. 563). Scholars in this tradition have thus argued that more attention should be placed on the different ways and places in which knowledge get made and becomes part (or not) of global environmental knowledge (Hulme, 2010; Jasanoff \& Martello, 2004; Mahony \& Hulme, 2016). The literature on global knowledge making also shows how global knowledge system have helped to create institutions of governance (Jasanoff \& Martello, 2004; C. A. Miller \& Edwards, 2001). I further unpack this link between global science and governance in the next section (Section 2.3.3.).

The increasingly global organisation of science is partly a self-reinforcing process, but also shaped by governance of science. At the global level, international organisations, science councils and funding agencies shape the governance of science (Gläser \& Laudel, 2016; Lyall, Bruce, Marsden, \& Meagher, 2013; Shove, 2003; Shove \& Redclift, 2001). In recent years, governance of science at the global level has often evolved around so called 'grand challenges' (Hackett et al., 2017; Maasen \& Dickel, 2019). The promise of global science to address 'grand challenges' such as climate change, resource depletion, food security or health provides an important justification for the allocation of resources to global collaborative research programmes, including Future Earth (Keenan et al., 2012). Such research programmes have been characterised as coordination mechanisms that mediate between global trends and demands of science in society and the everyday practices of scientific knowledge production (D. Braun, 2003; Hessels, 2013; Wardenaar, Jong, \& Hessels, 2014). Elizabeth Shove's (2003) analysis of research programmes in action reveals the complex relationship between research programmes and the research community operating under its umbrella. Research programmes have the potential to affect scientific knowledge production, but not necessarily in the intended way. She argues that "the formation of a realistic and viable programme is already shaped not only by what programme managers want but by what research capacity exists and by the research community's active involvement in programme making” (Shove, 2003, p. 375).

In studying how new ideas about science shape and are shaped by the governance and organisation of science, formal institutions of science, such as global research programmes, are strategic sites for analysis. Analysis of the governance and organisation of such formal institutions points attention to rules and rule-making practise that distribute power and resources in support of particular actors, practices and purposes (Frickel \& Moore, 2006). Particularly relevant for this thesis is the core insight that institutions of science are never neutral arrangements. Purpose and politics of science are built into scientific institutions, specifically in the connections between science and other sectors in society (Hackett et al., 2017). The unavoidable question, of course, is whose purpose scientific institutions serve. Several authors have voiced concerns that the global governance and organisation of science is 
increasingly tightly coupled to the political and economic needs of only a small group of actors; leaving little room for critical approaches or science that serves the needs of the less privileged (Demeritt, 2001; Frickel \& Moore, 2006; Hackett et al., 2017).

\subsubsection{Boundary work and co-production}

Extending the previous point on the purpose served by global science, the social studies of science literature is also relevant for this thesis in its attention to the politics of science and science institutions. Specifically, scholars working in the tradition of Science and Technology Studies (STS) have drawn attention to the ways in which science is inescapably political. Two core concepts that engage with the politics of science in different ways are the concepts of boundary work and co-production. The literature on boundary work shows that boundaries between science and politics are not given a priori but are actively constructed by actors involved. The literature on co-production is concerned with the mutual co-shaping relationship between science and politics. I briefly discuss each concept below paying attention to how it is relevant for understanding the politics of science institutions for global sustainability.

The concept of boundary work points to the social processes by which demarcations between science and non-science are actively made and maintained (Gieryn, 1999). Boundary work determines which actors and practices form a legitimate part of science, as well as which actors and practices lack the authority to speak for science. Over the course of history scientists have worked hard to have society appreciate science, recognise its special status and be grateful for its outcomes (K. Moore, 2008). Yet, the socially constructed nature of boundaries also means that they can be challenged, which is, as several authors have observed, what happens when imperatives of participatory and solutions-oriented science reach the core of science institutions (K. Braun \& Kropp, 2010; De Pryck \& Wanneau, 2017; K. Moore, 2008). From this perspective, designing institutions of science for sustainability involves reorganising boundaries between science and extra-scientific actors and between concerns that can and cannot be legitimately addressed by science. The design of science institutions delineates responsibilities and procedures for producing scientific knowledge. For science institutions for sustainability, this means that boundary work affects how and by whom knowledge of sustainability problems and potential solutions get produced (Beck, Forsyth, Kohler, Lahsen, \& Mahony, 2017). The concept of boundary work also draws attention to the processes and criteria through which actors discern between science and politics, and the way in which these processes and criteria may change over time. As such, it positions boundary work itself as a political process, and highlights the political choices embedded in (contested) boundaries between science and politics (Brown, 2015; Gieryn, 1999).

The concept of co-production provides another important lens by which scholars in science and technology studies understand the politics of science. Here, the analysis of politics focuses not on the social process of delineating science but rather on the inevitable condition of coproduction that shapes both science and politics. The lens of co-production points attention to the mutual constitution of science and social order (Jasanoff, 2004). Analyses of co-production make visible how "particular scientific framings of problems call forth certain kinds of 
response and of how such framings themselves do not emerge in a social vacuum but through social processes, which shape the content and direction of scientific work" (Beck et al., 2017, p. 1066). Science and science institutions co-create certain framings of sustainability issues and potential solutions but are also themselves shaped by social processes that connect science and society. Thus, science institutions are both agent and results of co-production. Scholars have critically reflected on co-production processes that shape global institutions of knowledge making, and, for example, point out how concerns from the Global South struggle to find their way in to global representations of climate change such as put forward by the Intergovernmental Panel on Climate Change (Miller, 2004). It is important to note that this understanding of co-production is different from the imperative of co-production of knowledge as put forward in the literature on science for sustainability (Lövbrand, 2011). Science for sustainability advances the aspiration to co-produced knowledge with users, which can be applied in certain projects but not others; rather than seeing co-production as a de facto reality of any science project. These two perspectives on co-production are not necessarily in conflict. Yet, the emphasis on power and politics of knowledge production is largely absent from the science for sustainability understanding of co-production (C. A. Miller \& Wyborn, 2018).

Beck and colleagues write that "[i]f there is one takeaway message about STS research on global environmental problems, it is that knowledge about these problems is inescapably political” (Beck et al., 2017, p. 1077). Perspectives from STS show that actors actively draw boundaries between science and politics in seeking scientific authority (boundary work) and that politics is always part of science (co-production). STS understands science institutions as sites of politics. That is, science institutions are the locus where, through co-production of science and politics, certain processes of knowledge production, framings of issues and societal responses gain legitimacy. Attention to such co-production in science institutions is particularly important when, as in the case of science for sustainability, scientific knowledge production is driven by the objective to change social order towards sustainability (Beck et al., 2017; C. A. Miller \& Wyborn, 2018).

\subsubsection{Relevance for this thesis}

Overall, literature from the social studies of science forms an important foundation for the analytical perspective of this thesis on the institutions and politics that shape science for global sustainability. Literature on the governance and organisation of science informed the analysis of research programmes as coordination mechanisms in Chapter 6. Literature on coproduction (analytical concept) and boundary work informed the analysis on the institutionalisation of co-production (practical imperative) in Chapter $\mathbf{5}$ and the analysis of changing foundations of epistemic authority in Chapter 9. 


\subsection{SCIENCE IN ENVIRONMENTAL GOVERNANCE}

\subsubsection{Introduction}

The third body of literature that I use in this thesis is literature on environmental governance, particularly where the focus is on the role of science. Environmental governance scholarship provides an analytical perspective on the multiple actors and institutions that steer socioenvironmental interactions. An important subset of this literature focuses on the relationship between science and governance. In contrast to the social studies of science literature, the environmental governance literature is concerned less with the workings of science itself, but rather with the influence and role of science in environmental governance. The main analytical focus of this body of scholarship are the networks of actors, formal procedures and institutional designs of science in environmental governance. As such, it complements perspectives from the social studies of science discussed in the previous section by focusing specifically on the actors, procedures and designs that shape interactions (or construct boundaries) between science and politics (Pregernig \& Böcher, 2012). At the same time, the environmental governance literature has been criticised by STS scholars for providing a narrow perspective on how and when science and politics influence each other, and for focusing on the output of science rather than the process of its production (Kohler, 2019; Lidskog \& Sundqvist, 2015). Yet, specifically when it comes to issues of science for sustainability - as discussed in this thesis - perspectives from the social studies of science and environmental governance tend to find common ground (C. A. Miller \& Wyborn, 2018). In this section I discuss how the environmental governance literature has developed from understanding science as an external input to an inherent part of environmental governance. Based on the latter perspective (science as part of environmental governance), I then discuss how the ideal of science for sustainability affects the relationship between science and governance, drawing on contributions that bring perspectives from the social studies of science into environmental governance scholarship.

\subsubsection{The influence of science in environmental governance}

Within the environmental governance literature that deals with science, two different perspectives can be distinguished. The first perspective considers science as an input in environmental governance and studies its influence in terms of the effectiveness of scientific knowledge in decision-making. The second perspective considers science and science institutions as inherent part of environmental governance and studies how science shapes and is shaped by authority and power in environmental governance. A prominent perspective within the first strand of research is that of epistemic communities. The epistemic community concept is generally recognised as the first systematic account of the influence of science in environmental governance (Hughes, 2012). It presents scientific consensus as key factor in the effective uptake of environmental knowledge in international institutions (Adler \& Haas, 1992; Haas, 1989, 2004). An epistemic community is "a network of individuals or groups with an authoritative claim to policy-relevant knowledge in their domain of expertise" (Adler \& Haas, 1992). The members of an epistemic community share scientific knowledge about social and physical phenomena in a given subject area, but also a common set of normative beliefs. This 
allows them to speak with one voice and thus acquire authority to define the problem at hand as well as possible solutions. Yet, the concept of epistemic authority has also received critique. Critics suggest that it overestimates the authority of experts, wrongly assumes that it is both possible and preferable to separate scientific knowledge from political processes, and overlooks the interests of the epistemic community and competition between expert groups (as summarised in Hughes, 2012).

An alternative and equally influential perspective on the influence of science in environmental governance responds to some of these critiques by proposing three criteria for the effective uptake of scientific knowledge by decision-makers: credibility, salience and legitimacy (Cash et al., 2003; Mitchell, Clark, Cash, \& Dickson, 2006). Credibility is defined as the perceived scientific adequacy of knowledge, salience refers to the perceived relevance for the selected audience, and legitimacy attends to the perceived fairness, inclusiveness and transparency (Cash et al., 2003). The main argument is that science and science institutions should be perceived as credible, salient and legitimate by decision-makers in order to be influential. Thus, the framework moves beyond a focus on consensus and rather considers the social context of knowledge production and assessment as relevant factor in explaining influence. The criteria of credibility, salience and relevance were first introduced and applied in the Global Environmental Assessment Project hosted at Harvard University (1995-2005), which also formed the home of early discussions on Sustainability Science and involved several STS scholars. These bodies of scholarship thus have a common root, although they developed largely independently from each other in subsequent years. The Global Environmental Assessment framework has had a lasting influence in environmental governance scholarship. It is not only used in a burgeoning literature that evaluates the influence of science in decisionmaking (Kowarsch \& Jabbour, 2017; Reinecke, 2015; Sarkki et al., 2015), but also directly adopted by global environmental assessments and other science institutions as part of their institutional strategy. For example, the Intergovernmental Science-Policy Platform on Ecosystem Services (IPBES) refers directly to the principles of salience, credibility and legitimacy in its founding documents (Kohler, 2019).

Overall, the epistemic communities and global environmental assessment literature see science as an input to environmental governance that can be more or less effective depending on, among other things, the level of consensus (epistemic communities perspective) and the perceived credibility, salience and legitimacy (global environmental assessment perspective). Science and governance are thus seen as two relatively separate spheres.

\subsubsection{Science as part of environmental governance}

Other scholars have argued that processes of knowledge making and governance are more strongly intertwined than suggested by the concept of epistemic communities or global environmental assessment literature. These scholars understand science and science institutions as an inherent part of environmental governance rather than an independent input (Kohler, 2019). Researchers drawing on discursive approaches have demonstrated that science plays and important role in political struggles to frame environmental issues and desirable responses 
(Allan, 2017; Hajer, 1995; Litfin, 1994). Not the independent input of science but the interaction between science and politics shapes governance problems and responses. It follows that the epistemic authority of science and science institutions cannot be understood separately of others forms of power and authority in the construction of environmental issues (Allan, 2017; Hughes, 2012; Keller, 2009). From an institutional perspective, Biermann (2002) argues that the "immense networks of scientists, experts, national governments, private bodies, and international organisations" engaged in environmental knowledge making and assessments can themselves be understood as international political institutions (Biermann, 2002). Science institutions bring issues to the political agenda, shape the framing of problems and possible responses, and affect the distribution of power and authority. Hence, they can be understood as actors in environmental governance (Gupta et al., 2012). Overall, scholars that understand science and science institutions as part of environmental governance pay attention to the way science institutions, directly or indirectly, shape political debates and actions from the local to the global level (Bauer \& Stringer, 2009; Eimer, 2014; Gupta \& Möller, 2019; Hughes \& Vadrot, 2019; van der Molen, van der Windt, \& Swart, 2016). These perspectives show that science and governance are always intertwined, even if organised as separate activities (Lidskog \& Sundqvist, 2015; Milkoreit, Bansard, \& van der Hel, 2020).

In the realisation that science and governance for sustainability are strongly intertwined, scholars drawing on environmental governance and STS find common ground (Bäckstrand, 2003, 2004; Edwards et al., 2013). As argued above, science institutions not only shape what is considered relevant knowledge but also affect the distribution of authority and power in environmental governance. It follows that, as Miller and Edwards argue (2001), "if we are to understand how and why global policymaking comes to be based on certain kinds of knowledge and not others, it is essential that we understand how scientific networks and institutions form, how they come to speak with one voice, and how they acquire political influence" (p. 24). Thus, the workings of science institutions themselves, and not just their output or influence, becomes an important object of study for environmental governance scholars. In this context, Bäckstrand calls attention to the "normative aspects of scientific expert advice, including the issues of representation, transparency, participation, accountability and legitimacy" (Bäckstrand, 2003). Moreover, the difference in knowledge production capacity between countries globally is an important issue of concern. Several studies have pointed to the dominance of scholars from the Global North in assessment bodies and advisory committees, and associated consequences for the political legitimacy these institutions carry in the Global South (Biermann, 2001, 2002; Karlsson, Srebotnjak, \& Gonzales, 2007; Montana, 2017; Pasgaard, Dalsgaard, Maruyama, Sandel, \& Strange, 2015). More recently, scholars in environmental governance have urged researchers to direct attention to normative questions of sustainability governance, including the orientation of science institutions towards questions of equity and justice (Burch et al., 2019; Lahn, 2018).

The call for participatory and solutions-oriented science for sustainability has not gone unnoticed in the environmental governance literature (Garard \& Kowarsch, 2016; Haas, 2017; Kowarsch \& Jabbour, 2017). Recent literature has directed attention to the link between 
stakeholder participation in science and criteria of credibility, salience and legitimacy (Garard \& Kowarsch, 2017; Kunseler, Tuinstra, Vasileiadou, \& Petersen, 2015). Other scholars have asked what solutions-oriented approaches mean for the role of science in in policy making and implementation (Beck \& Mahony, 2017; Haas, 2017; Kowarsch \& Jabbour, 2017). The question that remains unanswered is what kind of epistemological, normative and institutional changes are required and perhaps already underway to redesign science and governance for sustainability transformations (Bäckstrand, 2003; Wyborn et al., 2019).

\subsubsection{Relevance for this thesis}

The environmental governance literature is thus relevant for this thesis because it draws attention to the interconnected nature of global institutions of science and governance for sustainability. Drawing on environmental governance and STS scholarship, I understand science and science institutions as inherent parts of sustainability governance. I build on this literature in Chapter 8 and Chapter 9 where I focus on the ways in which global science institutions seek authority in environmental governance.

\subsection{INTEGRATION: POLITICS OF SCIENCE INSTITUTIONS FOR SUSTAINABILITY}

This study addresses the question how new principles of science for sustainability become institutionalised and what this means for the relationship between science and governance. The three bodies of literature discussed above are relevant for this question in different ways. Literature on science for sustainability provides insights in the ideal and ambitions of science for sustainability that is interdisciplinary, co-produced, inclusive and solutions-oriented, and calls for a focus on the required institutional changes to support these ambitions. Literature from the social studies of science draws attention to the social and institutional processes that shape scientific knowledge production and highlights how science and governance are inevitably co-produced. Literature on science in environmental governance points to the role and influence of global science institutions in sustainability governance. Together, these three bodies of literature provide relevant insights on the ambitions, institutions and effects of science for sustainability (see Figure 2.1).

The discussion above already pointed out some common roots and cross-cutting influences between these three bodies of literature. In particular, scholars working from traditions of STS and environmental governance tend to find common ground in a perspective of science as inherent part of environmental governance (Beck, Borie, Chilvers, \& Esguerra, 2014; Gupta \& Möller, 2019; Kohler, 2019; Lidskog, 2008, 2014; Turnhout et al., 2016). There is less work that directly connects social studies of science and sustainability research (but see Cornell et al., 2013; C. A. Miller \& Wyborn, 2018; T. R. Miller, 2013), although several STS scholars have reflected critically on the ambitions and institutionalisation of science for global sustainability (De Pryck \& Wanneau, 2017; Lövbrand et al., 2015). Only few studies directly connect literature from science for sustainability and environmental governance (Luks \& Siebenhüner, 2007; Uhrqvist \& Lövbrand, 2013), or bring together all three bodies of literature (Bäckstrand, 2003). 


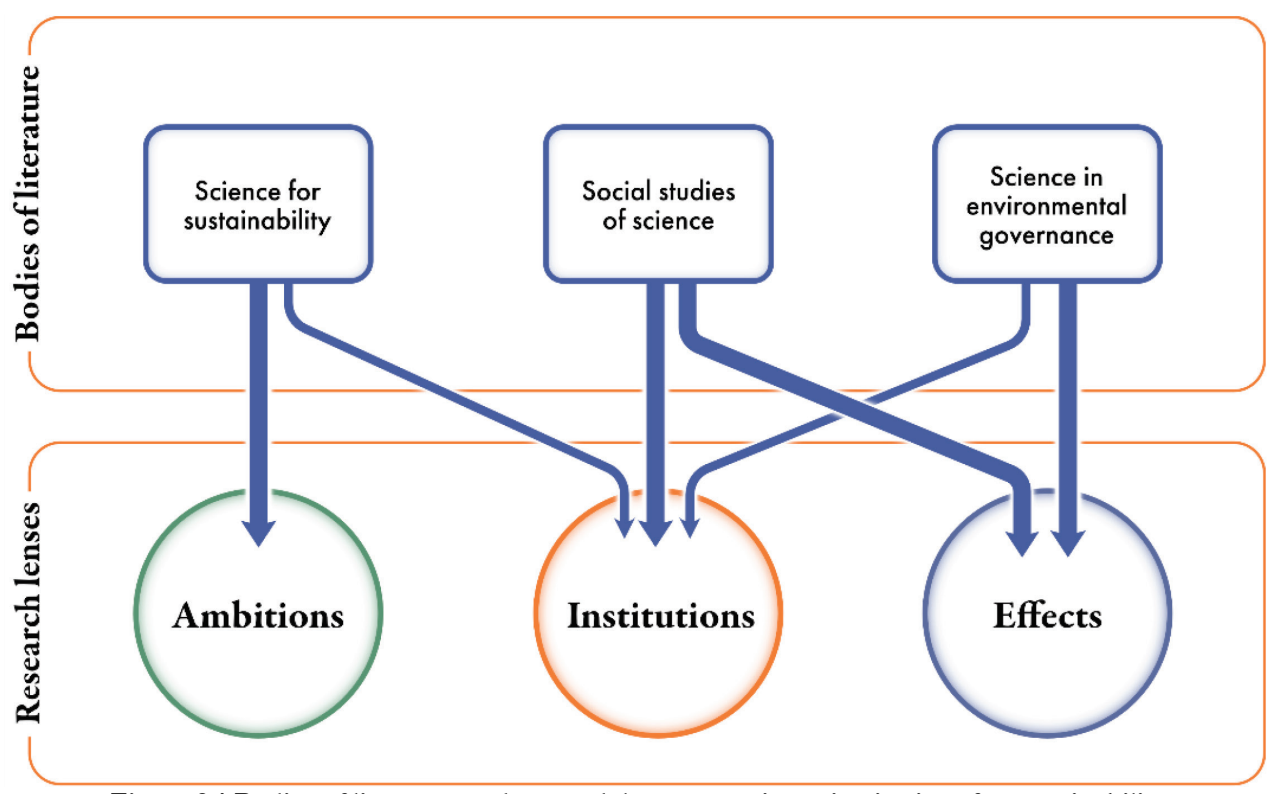

Figure 2.1 Bodies of literature and research lenses on science institutions for sustainability

Nevertheless, there is an important common thread that runs through these three bodies of literature. All three bodies of literature draw attention to the politics of science institutions for sustainability, albeit in different ways (Figure 2.1). These insights can be combined in a nested conceptualisation of the politics of science institutions for sustainability (Figure 2.2). First, in the literature on science for sustainability, attention to politics of science, while still a marginal topic, is directed at the ambition of science for sustainability. Through its ambition to inform and shape societal transformations, science for sustainability becomes inevitably entangled with normative and political concerns. Sustainability scholars increasingly call attention to the questions this raises for the role and responsibility of researchers in shaping societal change. I contribute to these discussions in Chapter 7 where I examine how sustainability researchers perceive their own role between science and politics. Second, this raises the question how ambitions of science for sustainability become institutionalised. The social studies of science literature attends to the politics inherent in the institutional dimension of science. While the politics of science is a new topic in the sustainability literature, it is an 'old' topic in the social studies of science. Traditions in the social studies of science, and STS in particular, perceive science and science institutions as inevitably political. Yet, questions of the politics of science gain new relevance in relation to the ambitions and institutionalisation of science for sustainability. If science institutions are sites of politics, who gets to shape science institutions for sustainability, in what way, and with which effects? I contribute to this perspective by discussing how institutional designs of 'new science for global sustainability' are negotiated in Future Earth (Chapter 5) and how the organisation of science in large international research programmes shapes the kind of knowledge that gets produced (Chapter 6). Third, combined perspectives from environmental governance and STS direct attention to the political origins, 
implications and effects of science institutions for sustainability. These perspectives see science and science institutions as inherent part of governance for sustainability. This raises questions about the authority of science institutions in governance for sustainability, the actors and perspectives that are (dis)empowered, and the kind of transformations to global sustainability that science for sustainability supports. I unpack this relationship between science and governance for sustainability in Chapter $\mathbf{8}$ and Chapter $\mathbf{9 .}$

Overall, perspectives from the three bodies of literature discussed here shows that a separation of science from politics is not only impossible (social studies of science), but also not necessary for science to have an influence (environmental governance), and perhaps undesirable for science that wants to inform and shape societal transformations to sustainability (science for sustainability). This raises the question how science institutions for sustainability respond to these challenges at the interface between science and politics, and what it means for the relationship between science and governance for sustainability. The chapters of this thesis contribute to literature on science for sustainability, social studies of science and environmental governance in investigating how science and politics are entangled in the ambitions, institutions and effects of science for sustainability. In Chapter $10 \mathrm{I}$ draw together the contributions from the different chapters by considering whether and how the politics of science for sustainability are addressed directly in science institutions for sustainability, or remain hidden from view, and discuss how this affects the ability of science for sustainability to shape sustainability transformations. 


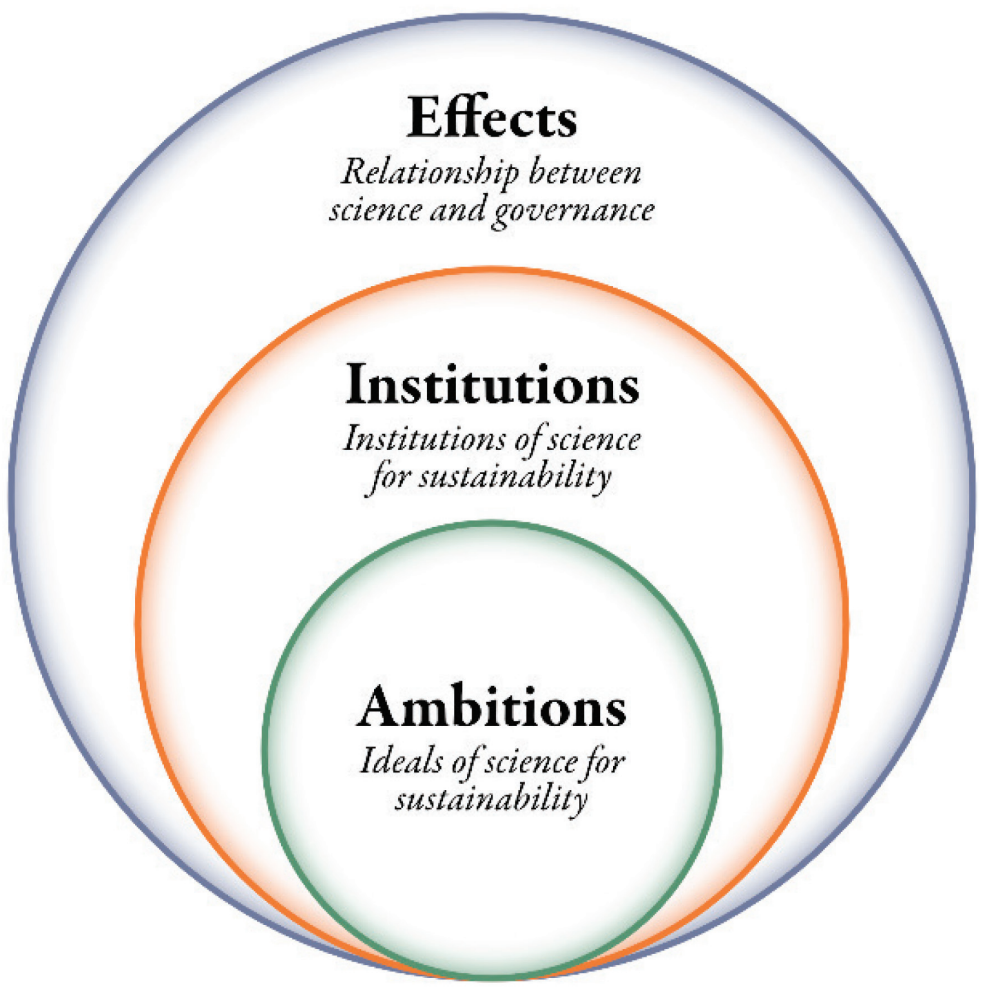

Figure 2.2. Nested conceptualisation of the politics of science for sustainability. 
3 - Methodology and methods

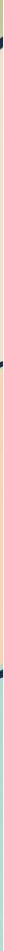




\subsection{CASE STUDY APPROACH}

The main case study of this thesis is the global research platform Future Earth: research for global sustainability. The development of Future Earth represents the trend towards new modes of knowledge production in science for sustainability (as discussed in Chapter 2, section 2.2.). I therefore identify Future Earth as a paradigmatic case (Flyvbjerg, 2001). The aim of this type of case study is to understand a more general social phenomenon (science for sustainability) through a specific case (Future Earth). Future Earth presents a relevant paradigmatic case because it reveals key elements of the phenomenon of science for sustainability and its institutionalisation. In institutionalising science for sustainability, discussions over what science for sustainability should look like, what it's purpose should be, and who should be involved are made specifically visible in Future Earth. As such, Future Earth provides an opportunity to study the institutionalisation and politics of science for sustainability.

By focusing specifically on the development and early years of operation of Future Earth, this thesis provides a study of a global science institution 'in the making' (Latour, 1987). This approach loosely builds on traditions in the social studies of science that study the practices, processes and techniques involved in the creation of scientific facts, yet here specifically focuses on the making of science at the level of global science institutions. The design-phase of a new global science institution and active transformation of the institutional context opens up discussions about rules, norms, goals and practices of scientific knowledge production that are otherwise taken for granted. The exact nature of the research programme still needs to be worked out, as are the organisational structures, participating actors and their roles. Studying scientific institutions while they are 'in the making' thus allows for investigating the underlying rationales and logics of scientific knowledge production and makes visible contested relationships between the various actors involved. I followed the premise that the people who are 'doing science' are not only the people 'in the lab', but all the people (funders, governments, private actors, etc.) that make scientific knowledge production possible (Latour, 1987). Therefore, this thesis is not restricted to studying the ideas and practices of scientists but includes also other actors - such as science unions, funders and UN organisations engaged in shaping research for global sustainability in Future Earth and beyond.

As defined in the introduction, the institutionalisation of science for sustainability encompasses both formal institutions (organisations, rules and procedures) and informal institutions (shared understandings, values, norms). I operationalise formal institutions of science for sustainability as the design of Future Earth, including its organisational structure, rules and procedures. I operationalise informal institutions of science as the shared norms and understandings held by researchers engaged in Future Earth. To gain a deeper understanding of the institutionalisation and politics of science for sustainability, I also compare and contrast the development and operations of Future Earth to other global science institutions (see Chapter 4, section 4.4. for a brief introduction to these cases). Comparing the ambitions, structure and impact of Future Earth to other science institutions allows me to uncover which aspects are unique to Future Earth and which aspects represent more general trends in science for sustainability. 


\subsection{DATA COLLECTION AND ANALYSIS}

I combine document analysis, participant observation, expert interviews, scientometric analysis and quantitative and qualitative analysis of survey data. These methods are each discussed below. Through the triangulation of data and methods I aim to provide a more comprehensive understanding than would have been possible based on a single approach. For example, through document analysis I gained understanding of the vision of 'new science for global sustainability' as put forward in formal documents on Future Earth, while a survey among sustainability researchers allowed me to contrast some of these insights with the perspectives of the broader research community. Similarly, participant observation at formal meetings brought out insights on how Future Earth's leadership sees its role vis-à-vis the research community, while the scientometric analysed focused on the extent to which similar research programmes were able to shape research conducted under their umbrellas. Thus, the various methods used in this thesis allow me to look at the phenomenon of science for sustainability and its institutionalisation in different ways.

I received formal permission from the (interim-)secretariat of Future Earth to study the development and operations of the platform. I was given access to internal documentation and pre-final versions of formal documents (see Section 3.2.1) and was able to participate in several high-level meetings (see Section 3.2.3). In addition, the Future Earth secretariat helped me to distribute my survey among its members (see Section 3.2.5).

\subsubsection{Document analysis}

For the document analysis, I collected documents that reflect ambitions of science for sustainability and its institutionalisation in Future Earth and other science institutions. This includes formal documents such as designs reports, vision documents and evaluations as well as unpublished documents such as meeting minutes and drafts reports. I also included selected news items about Future Earth and other science institutions. Finally, I included several scientific publications as empirical material. These publications discuss institutional changes in global change and sustainability research and often advocate particular future directions. As such, they provide insights in the different rationales that guide science for sustainability and its institutionalisation. These documents are listed as supplementary material in Appendix C.

I analysed these documents through qualitative coding. The specific coding scheme differed based on the questions raised in the respective chapter but was in all cases a combination of open and closed coding. That is, I developed the initial coding schemes based on key themes or concepts and further defined these codes through an iterative coding process. I used the software programmes ATLAS.ti and NVivo for coding.

Document analysis allowed me to distinguish different rationales shaping the vision of 'new science for global sustainability' in Future Earth (Chapter 5) and to trace the process and eventual outcomes of institutionalisation (Chapter $\mathbf{5}$ and Chapter 9). I also used document analysis to unpack and compare the strategies by which science institutions seek authority in sustainability governance (Chapter 8 and Chapter 9). Moreover, document analysis informed 
the case descriptions of Future Earth and other science institutions (Chapter 4) and aided the interpretation of findings from the scientometric analysis and survey (Chapter $\mathbf{6}$ and Chapter 7).

\subsubsection{Expert interviews}

I conducted in-depth, semi-structured expert interviews to learn from the experiences and perspectives of experts in the domain of global change and sustainability research (Bogner, Menz, \& Littig, 2009; Desmond, 2004). The expert interviews allowed me to gain a rich understanding of the socio-political context and institutions in which these experts are embedded. I interviewed 22 experts involved in global change research and the development of Future Earth. These interview respondents hold or have held different positions in Future Earth or other organisations in global change and sustainability research. In order to gain insights in the context for the development of Future Earth, I interviewed experts that held leadership positions in the global change research programmes that preceded Future Earth. In order to gain insights in the development and operations of Future Earth itself, I interviewed experts involved in Future Earth's advisory committees, governing bodies and the alliance of funding agencies, science councils and governmental organisations supporting Future Earth. Interviews were conducted in person or via Skype and lasted between 45 minutes and 2 hours. I transcribed all interviews and analysed these transcripts together with the documentary material as described above. Direct quotes used in this thesis were verified with the respective respondents. The interview respondents are listed in Appendix A (all interviewees agreed to be listed by name), the interview scheme is provided in Appendix B.

The expert interviews informed my analysis of the institutionalisation of science for sustainability (Chapter 5) and how this institutionalisation shapes epistemic authority (Chapter 9). I also used insights from the interviews to enrich the case descriptions of Future Earth (Chapter 4) and to interpret the findings of the scientometric analysis (Chapter 6).

\subsubsection{Participant observation}

As a participant observant, I participated in a 2-day meeting in Paris, France in November 2012, a 1-day meeting in Brussel, Belgium in February 2015, and a 3-day meeting in Bern, Switzerland in June 2016. The Paris meeting took place during the development phase of Future Earth and focused on the aspirations and organisational design of the programme. The meeting in Brussel was a meeting between Future Earth and several representatives of the European Commission. The meeting in Bern was an annual meeting where the executive secretariat, advisory committees, project representatives and alliance members met to discuss the progress and strategic directions of Future Earth. I participated in plenary meetings and side meetings as well as several of the social events organised alongside. My informal talks with many of the participants informed my understanding of the rationales and tensions shaping Future Earth. At the Paris meeting I supported the ICSU secretariat by taking minutes at some of the meetings. At the Bern meeting I organised a workshop on the normative and political dimensions of sustainability research. As part of this workshop I asked participants for their feedback on a set of statements that I later used - modified based on the input from this 
workshop - in the survey among sustainability researchers (see Section 3.2.5). I also assisted with a session organised by the Early Career Network of Networks (ECR NoN), which is a network of early career scholars across the projects engaged in Future Earth, including the Earth System Governance project of which I am a member.

Participant observation informed the analysis of institutionalisation (Chapter 5) and epistemic authority (Chapter 9) as well as the case descriptions of Future Earth (Chapter 4) and my interpretation of the finding from the scientometric analysis and survey (Chapter 6 and Chapter 7).

\subsubsection{Scientometric analysis}

Where the other methods allowed me to gain insights on the rationales and actors shaping Future Earth, I conducted a scientometric analysis to study the influence of formal research programmes on the research conducted under their umbrella. Scientometric analysis is a method for studying the development of a research domain based on meta-data of scientific publications (such as field of publication, references and author affiliation) (Hellsten \& Leydesdorff, 2015; Wagner et al., 2011). It is a well-accepted method for studying scientific impact, although it should be noted that scientometric data reflects only the influence of research programmes on scientific publications, and not, for example, influence on sciencepolicy or science communication (Koier \& Horlings, 2015). Because it would be too early to see the influence of Future Earth on scientific publications, I instead looked at two of its predecessors: the International Geosphere Biosphere Programmes (IGBP) and the International Human Dimensions Programme on Global Environmental Change (IHDP). I analysed the development of their scientific output over time and reviewed whether this output reflects principles of interdisciplinarity and inclusiveness. My analysis was based on a dataset of 398 scientific publications and 21.509 references to these publications. I used the software SAINT to parse and analyse the data, UCINET for network analysis and VOSviewer for visualisations.

Scientometric analysis informed my study of the impact of science coordination through formal research programmes (Chapter 6).

\subsubsection{Survey}

Finally, I conducted a survey to gain insight in the different perspectives within the community of sustainability researchers. Through the previously discussed methods of data collection I mainly had access to 'elite' actors, who, as members of governing and advisory bodies, get to shape institutional rules and structures, develop core documents, and publish their perspective in opinion pieces and academic articles. The survey approach allowed me to see to what extent these perspectives are shared within the broader research community. Moreover, I was interested to know how challenges of dealing with normative and political concerns were perceived by sustainability researchers. In order to do so, I developed a survey in which participants were asked to rank and explain their (dis)agreement on several sets of statements pertaining to different normative and political dimensions of sustainability research. The formulation of these statements was informed by insights from the literature review, document 
analysis, interviews and participant observation. At the 2016 Future Earth meeting in Bern I received feedback on these statements and adjusted them accordingly. The survey was distributed online among networks of researchers involved in Future Earth and received 284 responses. I analysed the responses to the statements through a quantitative cluster analysis in SPSS which allowed me to distinguish four positions on the normative and political dimensions of sustainability research. I complemented this quantitative part of the analysis with qualitative analysis of the responses to open questions in the survey.

The survey informed my analysis of the normative and political dimensions of science for sustainability as perceived by sustainability researchers (Chapter 7).

\subsection{REFLECTION ON RESEARCH APPROACH}

This thesis builds on the premise that science is part of the system it seeks to understand. This also holds true for my own relationship to the subject of this thesis. I did not approach my study subject from a singly disciplinary or methodological perspective. In that sense, my research process can be characterised as an 'undisciplinary journey' (Haider et al., 2017; Robinson, 2008). For me this meant developing the ability to orient my research between different disciplinary perspectives and epistemologies, as well as my personal experiences.

My first encounter with academia as a bachelor student in sustainability studies imprinted me with ideals of transdisciplinary research, including interdisciplinarity and solutions-orientation. I support many of the ambitions of science for sustainability. Yet, my experience as a student and later as researcher also makes me aware of the multiple and sometimes conflicting perspectives on what science for sustainability ought to be, and the gap between ambition and reality. As a fellow of the Earth System Governance project, which is part of Future Earth, I am one of the researchers 'operating under the umbrella of Future Earth'. My involvement in the Earth System Governance project helped me to get access to meetings and set up interviews, and, I believe, gave me a certain credibility as an early-career researcher. It also framed the position from which I was able to study Future Earth. Questions about the desirability and challenges of science for sustainability that I put to my respondents were often questions that I also asked myself.

These entanglement between my personal position and research subject sometimes proved challenging to navigate, especially on occasions that I found myself caught in heated discussions on the promises and perils of Future Earth. Yet, it simultaneously provided me with opportunities for reflection on how institutions and politics of science for sustainability matter, also for my own research. As such, I am convinced that these multiples perspectives and personal experiences in the sustainability research domain enriched my findings in this thesis. 


\section{4 - Future Earth and other cases}




\subsection{INTRODUCTION}

In this section I further introduce the main case study of this thesis, Future Earth: research for global sustainability. Future Earth is set in the context of global change research and builds on the foundation of previous global change research programmes. I briefly describe the history of science coordination in global change research as it explains some of the rationales as well as tensions that shape Future Earth (Section 4.2). The development of Future Earth itself builds on several years of visioning, designing and negotiating. I discuss this process as well as the four design principles put forward by Future Earth (Section 4.3). While Future Earth is unique in its scope and ambitions, it is far from the only science institution that aims and claims to inform sustainability transformations. I conclude this section by introducing the other science institutions that are discussed in this thesis in order to get a better grasp of the institutionalisation of science for sustainability and consequences for the relationship between science and governance (Section 4.4).

\subsection{FROM GLOBAL CHANGE SCIENCE TO SCIENCE FOR SUSTAINABILITY}

Future Earth builds on a long history of research coordination in global change research. This history can be traced back to at least the 1950s, which saw the development of multiple international research initiatives focused on geophysical research, such as the International Geophysical Year (1957-58) led by the International Council of Scientific Unions (ICSU) 3 . These international collaborations formed the basis for the development of data sharing infrastructure, satellite observation systems, and global circulation models, which in turn supported increased international collaboration (Edwards, 2010; C. A. Miller \& Edwards, 2001). To further strengthen climate research, the World Climate Research Programme (WCRP) was established in 1980. The International Geosphere Biosphere Programme (IGBP) followed in 1987. Both programmes grew quickly to become important actors shaping global science collaboration. WCRP focused specifically on physical and metrological understandings of the global climate systems. IGBP focused on physical, biological and geochemical perspectives on earth system change. Within the IGBP, the concept of the Earth System and Earth System Science were important framing devices bringing together researchers from different disciplines (Uhrqvist, 2014). In its early years of operation, the IGBP was strongly situated within the natural sciences. Over the course of its development, efforts were undertaken to reach out to the social sciences, albeit with mixed success (Seitzinger et al., 2015; Will Steffen et al., 2004).

\footnotetext{
3 The International Council of Scientific Unions (ICSU) was later renamed the International Council for Science, keeping the acronym of ICSU. In July 2018, the International Council for Science (ICSU) together with the International Social Sciences Council (ISSC) merged to form the International Science Council (ISC).
} 


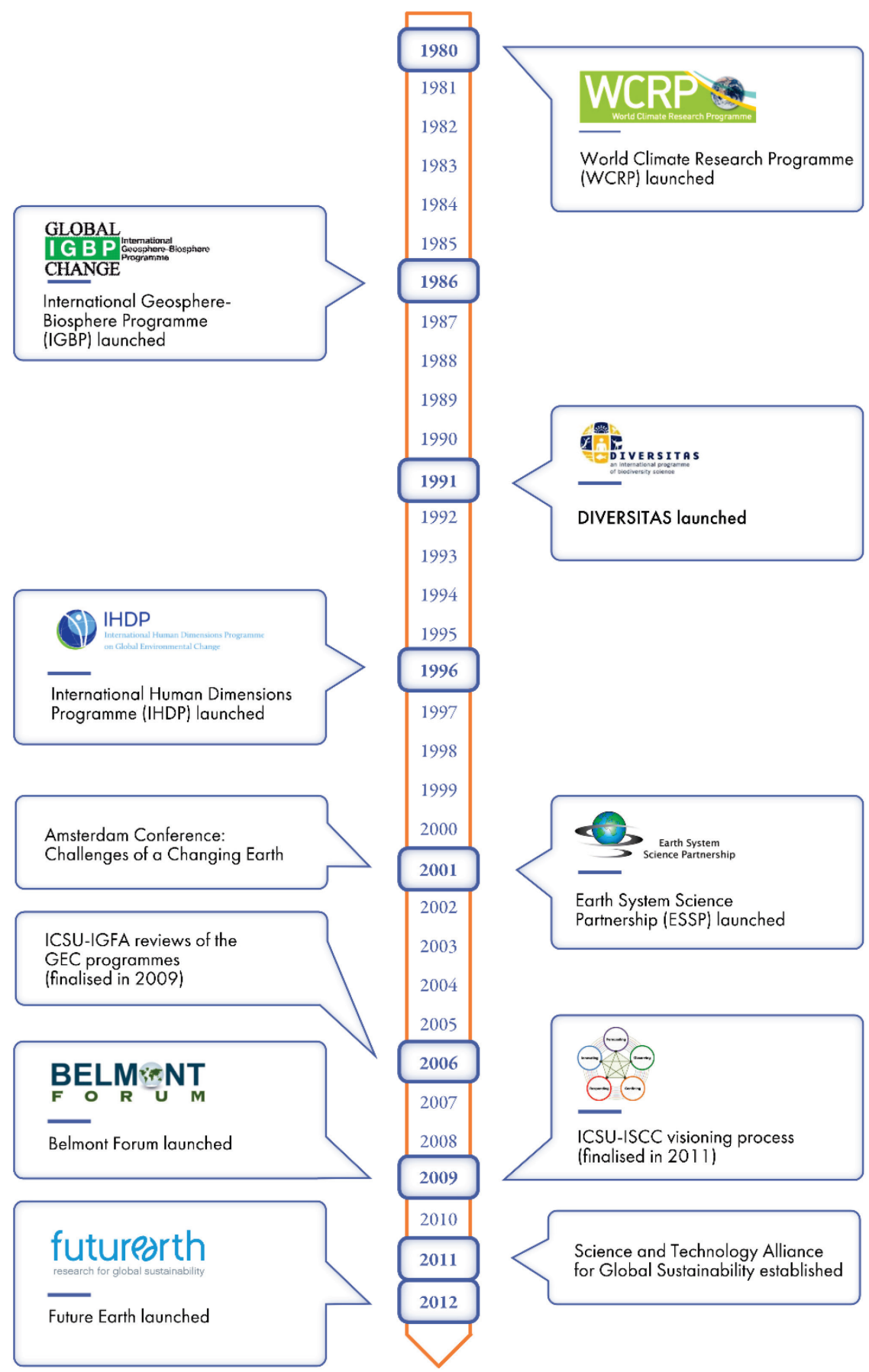

Figure 4.1 Timeline of developments in global change research up to the launch of Future Earth 
In the 1990s, another two global change programmes were established. DIVERSITAS, a programme on biodiversity sciences, was launched in 1991. DIVERSITAS focused on bringing together the community of researchers working on biodiversity and ecosystem services (Mooney, Duraiappah, \& Larigauderie, 2013). The International Human Dimensions Programme on Global Environmental Change (IHDP) was launched in 19964. IHDP's aim was to bring together social science research from various disciplines in a common focus on the human dimension of global environmental change. Key research themes included institutional change, industrial transformations, governance, learning and adaptation and the human-security dimensions of global environmental change (Jäger, 2003; Mooney et al., 2013).

By the end of the 1990s, voices went up to strengthen the connections between the four global change programmes (WCRP, IGBP, DIVERSITAS and IHDP) and work towards and integrated science of global change. In 2001 the four programmes joined in Amsterdam for the Global Change Open Science Conference 'Challenges of a Changing Earth'. In the Amsterdam Declaration that proceeded the conference, the programmes agreed that their "... common goal must be to develop the essential knowledge base needed to respond effectively and quickly to the great challenge of global change" (B. Moore, Underdal, Lemke, \& Loreau, 2001). To meet this common goal, the four programmes set up the Earth System Science Partnership (ESSP). The ESSP aimed to integrated research across the different areas of global change research and make global change research more relevant for addressing societal challenges (Ignaciuk et al., 2012; Leemans, 2016). Yet, the ESSP, and with it the four global change programmes, struggled to live up to the high expectations.

Between 2006 and 2009, ICSU together with some of the other core sponsors of the global change programmes commissioned a series of organisational reviews. These reviews highlighted the excellent science across the global change programmes but also pointed out that the programmes had limited influence beyond the scientific realm (Hordijk, Marcus, Pearman, Sinha, \& Torrey, 2006; ICSU-IGFA, 2008, 2009). One of the reviews concluded that "fundamental rethink and reprioritization of [global environmental change] research" was required to address the challenges of global environmental change and sustainability (ICSUIGFA, 2008, p7). These reviews formed the starting point of a decade of major restructuring in global change research. The reviews justified the decision of the sponsors of the global change programmes, including some major funding agencies (such as the National Science Foundations of the United States and the National Environmental Research Council of the United Kingdom), to push for organisational change towards a new integrated research platform that would enhance societal relevance and influence.

In 2009, the International Council for Science (ICSU) together with the International Social Science Council (ISSC), launched a 'visioning process' to explore the research priorities for the

\footnotetext{
${ }^{4}$ IHDP built on the Human Dimensions Programme (HDP) which was set up in 1991 but lacked resources and institutional support (Kwa, 2006).
} 
next decade of global change research and investigate possible new institutional structures. Participants in the visioning process concluded that there was an 'urgent need' for the scientific community to reorganise and join forces in working together towards a future of global sustainability (ICSU, 2010). Parallel to this visioning process, some of the major funders of global change research started their own discussions on required changes in global change research. They created a new platform for international cooperation of global change funding agencies, the Belmont Forum, with the aim to "mobilise international resources ... in order to catalyse delivery of the environmental science-derived solutions that society needs" (Belmont Forum, 2011, p. 1). At a meeting in Cape Town in October 2010, ICSU, ISSC and the Belmont Forum decided to work together towards what they formulate as their common goal: a single united framework for solutions-orientated global change research. In their common statement, ICSU, ISSC and the Belmont Forum defined the challenge as follows:

"In recent decades the global research community has developed valuable understandings of and predictions about, how humans are changing the world's environment and how these changes are affecting, and will affect, human and societal wellbeing. For the 21 st century, societies urgently require innovative solutions to these challenges, based on significant advances in combined natural and social sciences" (Belmont Forum, ICSU, \& ISSC, 2011, p. 1)

To support the aim of providing innovative solutions to sustainability challenges and bring about the required 'step change' in global change research, they initiated a new 'Research Initiative for Global Sustainability' that would succeed the global change programmes. This new research initiative eventually developed into Future Earth (see Figure 4.1 for an overview of the organisational developments leading up to the launch of Future Earth).

\subsection{FUtURE EARTH}

ICSU, ISSC and the Belmont Forum set up a Transition Team to facilitate the development of the new research initiative for global sustainability. The Transition Team consisted of prominent scientists from the global change community, public and private sector stakeholders, and representatives of the funding agencies. They were given the task to create an initial research framework and develop an institutional design for the new research programme (ICSU, 2011b). The Transition Team named the new initiative Future Earth: research for global sustainability (Future Earth, 2013).

Future Earth was launched at the Planet under Pressure conference in March 2012 and at the United Nations Conference on Sustainable Development (Rio+20) in the same year. This dual launch reflects the aim of Future Earth to not only shape science for sustainability but also partake in sustainability governance. Among insiders, Future Earth was presented as an Apollo Project: a concerted effort of research organisations, science councils and funders to mobilise global science for sustainability transformations. As one of the co-chairs of the Transition Team stated: "With humanity at a critical juncture, Future Earth has the potential to become the largest, most ambitious international research program ever undertaken" (Rockström, 
2016, p. 1). This concerted effort under the heading of Future Earth meant the closure of the IGBP, IHDP, DIVERSITAS and ESSP. Most of their research projects transitioned to Future Earth. The WCRP continued its operations under the sponsorship of the $\mathrm{WMO}^{5}$, and was said to work 'in strong partnership' with Future Earth (Future Earth, 2014d). Future Earth is sponsored by the Science and Technology Alliance for Global Sustainability, an alliance of science councils, funders and UN organisations.

The Initial Design Report of Future Earth, produced by the Transition Team, makes the case that to achieve the ambitions of Future Earth, a new kind of science is needed that is interdisciplinary, co-produced, inclusive and solutions-oriented (Future Earth, 2013). These four propositions can be understood as design principles for Future Earth ${ }^{6}$. They function as a means to position Future Earth and define the objectives and practices of 'new science for global sustainability'. Many of the ideas that underlie these four design principles are not new; they have been tried and applied in various settings inside and outside the global change community (see also Chapter 2). Yet, with the emergence of Future Earth, these principles were brought into the mainstream of global research coordination. This also means that they became subject to discussion and debate about good scientific practices, the roles and responsibilities of scientists, and the rightful place of science in society. Different perspectives on these principles, resulting tensions, and challenges of institutionalisation are explored in the chapters of this thesis. Here I briefly introduce the four principles, focusing on their history in global change research and the way they are presented in Future Earth's Initial Design Report (Future Earth, 2013).

- Interdisciplinarity - Interdisciplinarity is advanced by Future Earth as a core principle of science for sustainability. Future Earth aims to develop interdisciplinary collaborations that "draw on expertise in natural and social science, as well as engineering, the humanities and professions such as planning and law" (Future Earth, 2013, p. 22). The integration of science across different disciplines, especially across the natural and social sciences, is a long term theme in global change research (Castree et al., 2014; Mooney et al., 2013; Rice, 2013; Seitzinger et al., 2015; Weaver et al., 2014). An important point of debate is the balance between natural and social science perspectives. Some scholars caution that the focus on 'integrating' the human sciences in global change research may further entrenches the dominance of natural science disciplines (Klenk \& Meehan, 2015; Lahsen et al., 2015; Lövbrand et al.,

\footnotetext{
${ }^{5}$ WCRP was co-sponsored by ICSU (now ISC) and the World Meteorological Organisation (WMO), and the later hosts the WCRP secretariat. The sponsorship of the WMO provides the WCRP with a stable funding base which is one of the factors explaining the programme's stability over more than 40 years of operation (Kwa, 2006).

${ }^{6}$ The term 'design principles' is used in early documentation on Future Earth. A list of design principles for the new research initiative is provided in the guidance document for the Transition Team (ICSU, 2011b) and in preparatory documents for the Initial Design Report of Future Earth (Future Earth, 2013). The listed design principles vary across the different drafts, but the four principles listed here are consistently included. Thus, they are interpreted here as the core of the 'new science for global sustainability' advanced by Future Earth.
} 
2015). At the same time, scholars worry that the focus on interdisciplinarity comes at the expense of disciplinary perspectives, which are portrayed as foundational of the contributions of global change research (Future Earth, 2013).

- Co-production ${ }^{7}$ - Co-production is put forward as a second core principle of science for sustainability. Future Earth's states that its "research agenda and programmes should be co-designed and, where possible, co-produced by researchers in collaboration with various stakeholders in governments, industry and business, international organisations, and civil society" (Future Earth, 2013, p. 22). The principle of co-production is presented as a key feature distinguishing Future Earth from preceding initiatives in global change research. Although ideas of user participation in global change research had been raised before, this is the first time that the principle gained such a central place. Many different perspectives on the purpose and practice of co-production exist (Bremer \& Meisch, 2017), also in Future Earth (Cornell et al., 2013; Mauser et al., 2013). There is ongoing discussion on the desirability, form and implementation of co-production in Future Earth.

- Inclusiveness - Inclusiveness is a third core principle of science for sustainability in Future Earth. Discussions on inclusiveness in Future Earth specifically centre on geographical inclusiveness. The Initial Design Report states that Future Earth "must be inclusive, involving researchers from countries around the world and building capacity where needed, especially in the least developed countries" (Future Earth, 2013, p. 21). Similar to interdisciplinarity, geographical inclusiveness is a long-term theme in global change research. The imperative to overcome the North-South research divide is a long-standing challenge, with the unequal global distribution of resources and research capacity as a factor that consistently proves difficult to overcome (Blicharska et al., 2017). Critics argue that global science institutions have to do better to ensure inclusiveness in their design and outcomes (Karlsson et al., 2007; Pasgaard et al., 2015; Yamineva, 2017). Overall, the aim to create a global programme with equal representation from all world regions is prominent in rhetoric, yet there are many concerns about meeting this principle in practice.

- Solutions-orientation ${ }^{8}$ - Solutions-orientation is the fourth design principle of science for sustainability in Future Earth. The Initial Design Report states that " $[t]$ he emphasis of Future Earth will be on solution-oriented science that enables

\footnotetext{
${ }^{7}$ A distinction is sometimes made between the 'co-design of research agendas', the 'co-production of knowledge' and the 'co-dissemination of findings' (e.g. Mauser et al., 2014). In this thesis, I use the term co-production to refer to the general discussion on including extra-scientific actors in the process of knowledge production, specifying between codesign, co-production and co-dissemination only where necessary.

8 Documentation on Future Earth variably speaks of solution-oriented (singular) or solutions-oriented (plural) research. Here I decided to use the plural form as this better reflects the multiple possible 'solutions' for responding to sustainability challenges.
} 
fundamental societal transitions to global sustainability" (Future Earth, 2013, p. 13). Solutions-orientation is a relatively new principle in global change research that challenges institutionalised boundaries between science and society (De Pryck \& Wanneau, 2017; T. R. Miller et al., 2014; Suni et al., 2016). Contributing to solutions and transformations to global sustainability is presented as the ultimate aim of Future Earth. At the same time, some scholars worry that solutions-oriented research comes at the expense of scientific freedom and independence. The question that is raised is whether there is room for fundamental, basic, curiosity-driven or 'blue sky' research in Future Earth (Future Earth, 2013).

As a new global research platform with the ambition to fundamentally transform science for sustainability, Future Earth has received ample attention from scholars and commentators, both inside and outside the global change community, reflecting on, applauding or criticising its development and operations (Castree, 2017; Castree et al., 2014; De Pryck \& Wanneau, 2017; Hadley Kershaw, 2017; Hulme, 2015; Leemans, 2016; Lövbrand et al., 2015; Rice, 2013). Although 'global sustainability' is an image that many can agree on in the abstract, the pathways of getting there, and the role of science on these pathways, are disputed (O'Brien, 2012). Specifically, the fundamental restructuring towards science for sustainability in Future Earth was met with distrust by members of the global change community, who questioned the necessity and direction of envisioned changes. Eventually, most research projects that had earlier operated under the umbrella of one or more of the global change programmes transitioned to Future Earth (e.g. Biermann et al., 2019; de Bremond, Ehrensperger, Providoli, \& Messerli, 2019). Future Earth also set up several new types of initiatives, including Knowledge Action Networks, that are envisioned to contribute to interdisciplinary, coproduced and inclusive research providing solutions for sustainability (e.g. Martinez-Harms et al., 2018; Shrivastava et al., 2016). Future Earth became fully operational in 2015 with the establishment of a globally distributed secretariat with offices in Canada (Montreal), France (Paris), Japan (Tokyo), Sweden (Stockholm) and the USA (Boulder and Fort Collins, Colorado, and Fairfax, Virginia). In addition, the network includes regional offices and national platforms in different world regions (Suni et al., 2016; Wang, Zhou, Lin, \& Jin, 2015; Zhou et al., 2015). Together, Future Earth estimates that its projects and activities reach more than 50.000 sustainability researchers and other actors interested in its research (Future Earth, n.d.).

\subsection{OTHER GLOBAL SCIENCE INSTITUTIONS}

Future Earth is part of a complex landscape of global science institutions for sustainability. These institutions partly overlap and inform each other, and sometimes compete for attention. I discuss eight other cases in this thesis. Two of these cases are research programmes that preceded Future Earth. The first case is the International Geosphere-Biosphere Programme (IGBP). The second case is the International Human Dimensions Programme on Global Environmental Change (IHDP). Both cases have been briefly introduced above as global change research programmes preceding Future Earth. There are many similarities between the design of Future Earth and the IGBP and IHDP. I study these 
cases in Chapter 6 to get a better understanding of the coordination of science by global science institutions.

The other six cases are science institutions that, like Future Earth, are involved in sustainability governance, albeit in different ways and with different aims. They include global environmental assessments, scientific advisory bodies, knowledge platforms and research programmes. These cases serve as comparative cases for studying the changing dynamics of epistemic authority in Chapter 8 and Chapter 9. The first of these cases is the Scientific and Technological Major Group (STC) which represents the scientific community and provides expert input as part of the United Nations Major Group system for Sustainable Development. The second case is the Global Environmental Outlook (GEO), which is a long standing global environmental assessment of the state of the environment periodically produced by the United Nations Environment Programme. The third case is the Sustainable Development Solutions Network (SDSN), which is a network of experts, formally including academia, business, civil society and the private sector, that seeks to inform discussions on the Sustainable Development Goals. The fourth case is the Scientific Advisory Board of the UN Secretary General (SAB), which is a high-level expert group that provides advice on the role of science in achieving the Sustainable Development Goals. The Scientific Advisory Board was founded by Ban Ki-moon in 2013 and closed at the end of his tenure as UN Secretary General in 2016. The fifth case is the Global Sustainable Development Report (GSDR), which is a periodically produced assessment of scientific knowledge for sustainable development, and officially reports to the High-Level Political Forum on Sustainable Development. Finally, the sixth case is Intergovernmental Science-Policy Platform on Biodiversity and Ecosystem Services (IPBES) which is a global environmental assessment on biodiversity. Similar to Future Earth, IPBES was established recently and builds on principles of participation in its institutional design.

Together, these eight cases and Future Earth represent science institutions that differ in their structure, objectives, process and outputs, and yet share a common focus on global change and sustainability. Table 4.1 provides an overview of these eight cases based on four categories of attributes (Sarkki et al., 2015):

1. Structural characteristics

2. Specific objectives and function in relation to sustainability

3. Processes of acquiring, assessing and communicating knowledge

4. Intended outputs and engagement in sustainability governance

The cases are discussed in more detail in the respective chapters. 
Table 4.1 Case descriptions based on the framework of Sarkki et al. (2015)

\begin{tabular}{|c|c|c|c|c|}
\hline Case & STRUCTURES & FUNCTION & Processes & OUTPUTS \\
\hline IGBP & $\begin{array}{l}\text { Global research } \\
\text { programme with } \\
\text { multiple research } \\
\text { projects. Sponsored } \\
\text { by ICSU }\end{array}$ & $\begin{array}{l}\text { Coordinate research } \\
\text { on earth system and } \\
\text { global environmental } \\
\text { change }\end{array}$ & $\begin{array}{l}\text { Developing research } \\
\text { agenda; facilitating } \\
\text { collaboration; } \\
\text { synthesising findings; } \\
\text { etc. }\end{array}$ & $\begin{array}{l}\text { Research products, } \\
\text { incl. scientific } \\
\text { publications, scientific } \\
\text { tools, policy briefs, } \\
\text { etc. }\end{array}$ \\
\hline IHDP & $\begin{array}{l}\text { Global research } \\
\text { programme with } \\
\text { multiple research } \\
\text { projects. Sponsored } \\
\text { by ICSU and ISSC }\end{array}$ & $\begin{array}{l}\text { Coordinate research } \\
\text { on human dimensions } \\
\text { of global } \\
\text { environmental change }\end{array}$ & $\begin{array}{l}\text { Developing research } \\
\text { agenda; facilitating } \\
\text { collaboration; } \\
\text { synthesising findings; } \\
\text { etc. }\end{array}$ & $\begin{array}{l}\text { Research products, } \\
\text { incl. scientific } \\
\text { publications, scientific } \\
\text { tools, policy briefs, } \\
\text { etc. }\end{array}$ \\
\hline STC & $\begin{array}{l}\text { UN Major Group. } \\
\text { Coordinated by ICSU, } \\
\text { ISSC and the World } \\
\text { Federation of } \\
\text { Engineering } \\
\text { Organisations }\end{array}$ & $\begin{array}{l}\text { Represent the voice } \\
\text { and interest of the } \\
\text { scientific community }\end{array}$ & $\begin{array}{l}\text { Formal input in UN } \\
\text { through Major Group } \\
\text { system }\end{array}$ & $\begin{array}{l}\text { Formal statements at } \\
\text { international meetings; } \\
\text { formal reports by } \\
\text { members }\end{array}$ \\
\hline GEO & $\begin{array}{l}\text { Global environmental } \\
\text { assessment. Led by } \\
\text { UNEP }\end{array}$ & $\begin{array}{l}\text { Inform governments } \\
\text { and stakeholders of } \\
\text { the state of the global } \\
\text { environment }\end{array}$ & $\begin{array}{l}\text { Scientific assessment; } \\
\text { comprehensive peer } \\
\text { review by internal and } \\
\text { external stakeholders }\end{array}$ & $\begin{array}{l}\text { Assessment reports } \\
\text { published every 3-4 } \\
\text { years }\end{array}$ \\
\hline SDSN & $\begin{array}{l}\text { Expert network. } \\
\text { Universities, research } \\
\text { centres and other } \\
\text { knowledge institutes } \\
\text { as members }\end{array}$ & $\begin{array}{l}\text { Mobilise global } \\
\text { expertise to support } \\
\text { the implementation of } \\
\text { Agenda } 2030\end{array}$ & $\begin{array}{l}\text { Contribute to SDGs } \\
\text { through issue briefs, } \\
\text { workshops, expert } \\
\text { sessions, etc. }\end{array}$ & $\begin{array}{l}\text { Official reports; } \\
\text { guides for } \\
\text { stakeholders. }\end{array}$ \\
\hline SAB & $\begin{array}{l}\text { Advisory board. } \\
\text { Includes scientists } \\
\text { representing different } \\
\text { disciplines and regions }\end{array}$ & $\begin{array}{l}\text { Strengthen the } \\
\text { interface between } \\
\text { science and policy }\end{array}$ & $\begin{array}{l}\text { Providing advice to } \\
\text { UN Secretary-General } \\
\text { and Executive Heads } \\
\text { of UN organisations }\end{array}$ & $\begin{array}{l}\text { Official reports to UN } \\
\text { Secretary-General. }\end{array}$ \\
\hline GSDR & $\begin{array}{l}\text { Global environmental } \\
\text { assessment. Led by } \\
\text { the United Nations } \\
\text { Division for } \\
\text { Sustainable } \\
\text { Development }\end{array}$ & $\begin{array}{l}\text { Key instrument for } \\
\text { the High-Level } \\
\text { Political Forum to } \\
\text { strengthen the } \\
\text { science-policy } \\
\text { interface }\end{array}$ & $\begin{array}{l}\text { Assessment of existing } \\
\text { assessments and other } \\
\text { information relevant } \\
\text { to sustainable } \\
\text { development. }\end{array}$ & $\begin{array}{l}\text { GSDR } 2014 \\
\text { (prototype), } 2015 \text { and } \\
\text { 2016. Henceforth } \\
\text { published on } \\
\text { quadrennial basis. }\end{array}$ \\
\hline IPBES & $\begin{array}{l}\text { Global environmental } \\
\text { assessment. Secretariat } \\
\text { hosted by UNEP }\end{array}$ & $\begin{array}{l}\text { Science-policy } \\
\text { platform for } \\
\text { biodiversity and } \\
\text { ecosystem services }\end{array}$ & $\begin{array}{l}\text { Scientific assessment; } \\
\text { capacity building; } \\
\text { policy support }\end{array}$ & $\begin{array}{l}\text { Global, regional and } \\
\text { thematic assessment } \\
\text { reports }\end{array}$ \\
\hline
\end{tabular}


5 - Institutionalising co-production in Future Earth 
This chapter focuses on the principle of co-production as advanced by Future Earth. It explores how co-production becomes institutionalised in the emerging structure of Future Earth. The chapter points to the existence of three distinct rationales (logics) on the purpose and practice of co-production. Co-production is understood as a way to enhance scientific accountability to society ('logic of accountability'), to ensure the implementation of scientific knowledge in society ('logic of impact'), and to include the knowledge, perspectives and experiences of extra-scientific actors in scientific knowledge production ('logic of humility'). This heterogeneous conception of the principle of co-production provides helpful ambiguity allowing actors with different perspectives on science and its role in society to engage in Future Earth. However, in the process of designing an institutional structure for Future Earth tensions between the different logics of co-production become apparent. My research shows that logics of accountability and impact are prominent in shaping the development of Future Earth, while the logic of humility plays a more marginal role.

Published as:

van der Hel, Sandra. 2016. New Science for Global Sustainability? The Institutionalisation of Knowledge Co-Production in Future Earth. Environmental Science and Policy 61: 165-75. http://dx.doi.org/10.1016/j.envsci.2016.03.012 


\subsection{INTRODUCTION}

"The magnitude and urgency of the challenges facing humanity requires [...] a common coherent strategy of transdisciplinary research for global sustainability" (Belmont Forum et al., 2011, p. 1)

With the above statement, the International Council for Science (ICSU), the International Social Science Council (ISSC) and the funding agencies united in the Belmont Forum announced their ambition to fundamentally change the practice, content and organisation of global change research. These ambitions materialised in the major new global change research programme Future Earth: research for global sustainability. Future Earth merges three international research programmes - the International Geosphere-Biosphere Programme (IGBP), the International Human Dimensions Programme on Global Environmental Change (IHDP), and DIVERSITAS: a programme on biodiversity science - and their Earth System Science Partnership (ESSP), bringing together scientists from a wide variety of disciplines and organisations all over the world. The programme was launched at the United Nations Conference on Sustainable Development that took place in Rio de Janeiro, Brazil in June 2012 and intends to provide 'the knowledge and support to accelerate our transformations to a sustainable world' (Future Earth, n.d.). In doing so, Future Earth questions and potentially reforms commonly held perceptions of science and its role in society. In particular, the programme advocates the co-production of knowledge with societal actors as a new mode of knowledge production that is essential to address the challenge of 'global sustainability'.

The development of Future Earth can be placed in a larger discourse on the emergence of new modes of knowledge production (e.g. Hessels \& van Lente, 2008) and the changing role of science in society (Luks \& Siebenhüner, 2007). Many authors have commented on a trend, at least in rhetoric, from curiosity-driven, mono-disciplinary modes of scientific knowledge production towards interdisciplinary, participatory and solutions-oriented approaches (Funtowicz \& Ravetz, 1993; Julie Thompson Klein, 2001; Nowotny, Scott, \& Gibbons, 2001). New modes of knowledge production are proposed and advanced in a variety of contexts and settings, finding support as well as resistance among the scientific community. Yet, academic research on the practices, processes and particularities of this kind of 'epistemic work' is limited (Felt, Igelsböck, Schikowitz, \& Völker, 2012, p. 10). This study aims to make a contribution by investigating the process by which a new mode of 'science for global sustainability' is being negotiated and institutionalised in Future Earth.

The chapter draws attention to a core principle of Future Earth: the co-production of knowledge. Co-production is presented (in documents and personal communication) as the most innovative aspect of Future Earth and a key feature distinguishing the new research programme from existing initiatives in global change research. In the next section, I discuss the principle of co-production in the context of related accounts of participatory knowledge production. Subsequently, I provide a brief review of the literature on intermediary organisations in science, and their role in supporting new modes of knowledge production. 
Then, I lay out my methods of data collection and analysis. The empirical section of the chapter discusses, first, three co-existing logics that support a different interpretation and implementation of knowledge co-production in Future Earth and, subsequently, investigates how these different logics of knowledge co-production shape the process of developing an institutional structure for Future Earth. The chapter concludes by pointing to the tensions between different logics of co-production that become apparent in Future Earth's reorientation of global change research towards research for global sustainability.

\subsubsection{The principle of co-production}

The term co-production was originally coined in the Science and Technology Studies (STS) literature to account for the relationship between science, technology and society. This notion of co-production draws attention to co-evolvement and co-shaping of knowledge and social order, recognising that knowledge is both "a product of social work and, at the same time, constitutive of forms of social life" (Jasanoff, 2004, p. 274). In the context of Future Earth, however, co-production is used in a practical rather than analytical sense and refers to the intentional act of engaging extra-scientific actors in the process of scientific knowledge production?.

Co-production, in its practical orientation, is not a new idea. Similar ideas and objectives as captured by Future Earth's notion of co-production have been discussed in the academic literature under different terms, including participatory research (e.g. Lengwiller, 2007), interactive research (e.g. Lemos \& Morehouse, 2005), civic science (Bäckstrand, 2003), transdisciplinarity (e.g. Julie Thompson Klein, 2001) and joint knowledge production (Hegger, Lamers, Van Zeijl-Rozema, \& Dieperink, 2012). These approaches share a focus on the participation of extra-scientific actors in academic knowledge production. Often, participation is proposed as a way to go beyond the linear relationship between science and society - in which science is communicated to society after its production - towards more interactive and productive arrangements between scientific and extra-scientific actors.

However, as the literature points out, different ideas about the purpose and practices of engaging extra-scientific actors in scientific knowledge production prevail. Bäckstrand (2004), for example, distinguishes between participation pursued with the aim to restore public trust in science, to address the complexity of global environmental problems, or to extend the principle of democracy to scientific knowledge production. These perspectives build on different epistemic and normative understandings of science and its role in society and are not necessarily compatible. The first perspective retains the traditional model of top-down scientific expert knowledge, whereas the latter two perspectives suggest reforms of scientific norms, institutions and procedures, albeit in different ways (Bäckstrand, 2003). Similarly, Lövbrand's (2011) study of co-production in European climate science reveals a tension

\footnotetext{
${ }^{9}$ On the difference between the analytical understanding of co-production, and the more utilitarian interpretation of co-production in practical terms, see Kerkhoff and Lebel, 2015; Lövbrand, 2011.
} 
between narratives of usefulness, according to which science is expected to respond to the needs of decision-makers, and an emancipatory, critical and reflexive objective of participation in scientific knowledge production. Multiple authors have observed that participatory knowledge production tends to remain rooted in traditional structures and assumptions of science, providing an attractive label and legitimacy for scientific knowledge production while actual practices remain unchanged (Felt et al., 2012; Turnhout, Stuiver, Klostermann, Harms, \& Leeuwis, 2013).

\subsubsection{The role of research programmes}

Academic reflections on new modes of knowledge production point to the importance of the institutional context of science in supporting and encouraging new research practices (Dedeurwaerdere, 2013; Kueffer et al., 2012; Yarime et al., 2012). Historically developed institutional structures of modern science - such as the academic publishing system, career trajectories, department structures and criteria for evaluation and funding - are often unsupportive of new modes of knowledge production (Rip, 2011). Increasingly, though, research programmes, at national, regional and international level bring new modes of knowledge production to the core of their research strategies. Hessels (2013) identifies research programmes as 'intermediary organisations with a coordinating mission', that is, organisations that aim to coordinate research practices in a specific research domain, possibly steering research in new directions. These programmes operate between the macro structures of the science system and the micro level of daily research practices, thus providing a context for institutional support of new modes of knowledge production. Studies of existing research programmes and formal research networks have pointed out that, to support the engagement of extra-scientific actors in scientific knowledge production, it is important to "purposefully put into place structures and process" (Klenk \& Hickey, 2012, p. 370). Engagement of extrascientific actors in the early stages of programme design is considered particularly promising (Garrett-Jones, Turpin, Burns, \& Diment, 2005; Hessels, 2013; Klenk \& Hickey, 2013), since these early stages provide the opportunity to engage multiple actors in shaping the research programme and structure, and tend to give an indication of the way in which these actors participate in the coordination of research during later stages of the programme's development (Hessels, Wardenaar, Boon, \& Ploeg, 2014). Moreover, funding agencies are identified as important actors in stimulating and supporting research programmes based on new modes of knowledge production (Lyall et al., 2013). Intermediary organisations thus provide an opportunity to support new modes of knowledge production in the context of institutionalised macro-level structures of science. At the same time, these research programmes face the challenge of fitting organisational structures and governance models to the wide diversity of objectives and expectations that exist in a research community (Turpin, Garrett-Jones, Woolley, Garret-Jones, \& Woolley, 2011).

\subsubsection{Institutionalising co-production in Future Earth}

It seems plausible to assume that the principle of co-production gained prominence in the international institutional domain of global change research precisely because it allows for multiple interpretations, including more traditional perception of science-society relations and 
scientific practices (Turnhout et al., 2013). A flexible concept like knowledge co-production can provide a possibility to overcome conflict between different value positions as it is adaptable to multiple contexts, visions and perspectives (Bensaude-Vincent, 2014). In the process of institutional change, however, such multiple understandings might prove problematic as different notions of the purpose and practice of participation in scientific knowledge production may link to different ideas on the preferred form of institutionalisation (Turnhout et al., 2013). Institutional settings are not neutral instruments, but "embody certain intentions, aspirations and purposes" (Pinheiro \& Stensaker, 2013). This raises the question why institutional arrangements are established in a particular way, and how particular organisational structures and institutional rules are promoted and legitimised (ibid.). Moreover, we can expect that changes in the institutional structure of research will be "the subject of considerable debate and negotiation" (Turpin, 1997, p. 265), as particular knowledge producing practices may become supported at the expense of others.

Studies on the institutional aspects of new modes of knowledge production have mainly focused on institutions at the national or sub-national level; global networks of knowledge production - although promoted as appropriate institutional arrangements to support new modes of knowledge production in research for sustainability (Yarime et al., 2012) - have yet to be investigated sufficiently. This study asks how the principle of knowledge co-production becomes institutionalised in the new research programme Future Earth. Studying a research programme 'in the making' allows for explicit consideration on the vision, aims and purposes that guide the development of a new research programme, the tensions between different positions that become apparent in negotiating new institutional arrangements, and the processes through which new organisational structures and institutional rules are eventually established.

\subsection{DATA COLLECTION AND ANALYSIS}

The empirical part of this chapter presents a qualitative case study of the emergence and development of the new major research programme Future Earth. The results presented reflect events from early 2009 (with the start of the ICSU-ISSC visioning process, see below) until December 2015. I base my analysis on documentary material and interviews. The documentary material consists of 1) key documents of the organisations involved in global change research, including vision documents, strategic plans, annual reports, review documents, meeting minutes and newsletters and 2) academic publications reflecting on epistemic and institutional developments in global change research, and often advocating particular future directions (both types of documents included in Appendix C). Together, this documentary material provides and overview of the main events in global change research leading up to the development of Future Earth, as well as insights in the visions and rationales that shaped these developments.

The documentary material is complemented with 18 in-depth expert interviews with senior scientists and managers affiliated with different organisations involved in the global change 
community (see Appendix A; numbers between brackets in the text refer to the number of the interview). A first set of questions in these semi-structured interviews concentrated on the interviewees' perceptions of 'new science for global sustainability' proposed by Future Earth, and specifically the principle of co-production. I asked interviewees about their understanding of the principles, purposes and practices of this new mode of knowledge production, and the way it differs from 'traditional' modes of knowledge production in global change research. A second set of questions was directed at the process of negotiating and establishing a new institutional structure for global change research. Here I invited interviewees to reflect on their participation in this process, the challenges they encountered, and the eventual decisions that were made. Interviews were conducted in person or via Skype and lasted between 45 minutes and 2 hours. All interviews were recorded and transcribed.

In my analysis of documentary materials and transcribed interviews, I draw on the concept of 'logics' as an analytical tool (Barry \& Born, 2013; Barry, Born, \& Weszkalnys, 2008). Barry and colleagues employ the concept of logics to point to "a set of contemporary rationales about what the purposes of interdisciplinarity are and how it should be guided and justified" (Barry et al., 2008; p. 24) ${ }^{10}$. Here, I direct this analytical tool to the principle of co-production, focusing on different understandings of the purpose and practices of knowledge co-production as they are expressed in the context of Future Earth. The focus on logics allows me to disentangle different rationales of knowledge co-production in Future Earth, and asses how these logics shape the process of institutional design.

My analysis proceeded in two steps. First, I coded the empirical material focusing on the different understandings of the principle of knowledge co-production, based on the attributes listed in Table 5.1. Subsequently, I categorised the interview quotes and texts fragments according to the different interpretations of these five attributes of co-production. This allowed me to distinguish three rationales for knowledge co- production in Future Earth which provide different interpretations with respect to the purpose and practice of co-production. I refer to these three rationales as 'logics of co-production'. This part of the analysis is presented in Section 5.3 ('Logics of co-production in Future Earth').

\footnotetext{
${ }^{10}$ Barry et al., (2008) and Barry and Born (2013) distinguish three logics for the pursuit of interdisciplinarity, namely the logic of accountability, the logic of innovation and the logic of ontology. Although related, the logics identified by Barry et al. are not directly transferable to the case of knowledge co-production and the specific context of Future Earth. Instead, through an inductive process, I distinguish three logics that feature prominently in the text and talk on knowledge co-production in the context of Future Earth.
} 
Table 5.1 Coding scheme

\begin{tabular}{|c|c|}
\hline ATTRIBUTE & DESCRIPTION \\
\hline Why co-produce? & Reasons given for co-producing scientific knowledge with societal actors \\
\hline How to co-produce? & Description of co-producing practices \\
\hline With whom to co-produce? & $\begin{array}{l}\text { Actors, institutions, categories or sectors mentioned as potential partners in } \\
\text { the co-producing process }\end{array}$ \\
\hline Roles of scientists & Roles and responsibilities attributed to scientists in knowledge co-production \\
\hline Roles of non-scientists & $\begin{array}{l}\text { Roles and responsibilities attributed to non-scientific actors in knowledge co- } \\
\text { production }\end{array}$ \\
\hline
\end{tabular}

Second, I used this framework of three logics to analyse the institutionalisation of the principle of co-production in Future Earth. Based on the collected documents and interview material, I examined the process by which the institutional design for Future Earth came into being, focusing in particular on the rationales and justifications given for particular decisions and events, as well as the tensions between positions that surfaced during several moments in this process. The framework of three logics served to identify different rationales shaping the process of institutional design, and to assess which understandings of science and its role in society find support in the emerging institutional structure of Future Earth. I distinguish four phases in the development of Future Earth, where different combinations of logics are at play. This part of the analysis is presented in Section 5.4 ('Institutionalising co-production in Future Earth').

\subsection{LOGICS OF CO-PRODUCTION IN FUtURE EARTH}

In the following, I introduce the three logics of knowledge co- production that I distinguish in the text and talk on co-production in Future Earth. All three logics support Future Earth's central aim of a science that is firmly rooted in society and contributes to societal goals, yet differ in understanding of the purpose and practices of knowledge co-production, the type of societal actors that scientists are expected to engage with, and the roles attributed to societal actors as well as scientists themselves in the process of knowledge co-production (see also Table 5.2). These three logics of knowledge co-production are not mutually exclusive; they are sometimes combined in a single storyline and can be seen as interdependent. Nevertheless, it is useful to make a distinction between the logics of co-production as they represent different underlying motivations for knowledge co- production, imply different modes of practicing coproduction, and potentially lead to different institutionalisations of co- production in Future Earth (see Table 5.2 for an overview and selected quotes). 


\subsubsection{Logic of accountability}

The first logic of co-production that I distinguish is centred on the objective for science to be relevant and responsive to the needs of society. This 'logic of accountability'11 builds on the narrative of a social contract between science and society: science provides useful knowledge to society in return for the resources it receives. In contrast with earlier interpretations of the science-society contract in which science was expected to deliver societal returns through selfgovernance, the accountability logic of co-production assumes that active involvement of 'users' is required for science to provide useful insights and products for society. Coproduction is thus proposed as a way to ensure societal benefits of science. Public funding agencies are perceived as forming the link between societal demands and scientific knowledge production, and their involvement in science governance is expected to steer science towards improved accountability. In extension, the business community is identified as potential beneficiary of science and partner in co-production, with the expectation that a better response to the needs of businesses might increase private sector funding for science. Based on this logic, scientists are expected to be responsive to the needs of societal actors in setting research agendas and formulating research questions yet remain in control of scientific knowledge production and in this respect maintain a certain level of separation from society, which is considered essential to safeguard scientific credibility.

\subsubsection{Logic of impact}

A second logic that shapes the discourse of knowledge co-production in Future Earth proposes co-production as a practice to remedy the perceived gap between scientific knowledge and its implementation in society. This logic stresses that co-production is important " ... to ensure that proposed and established solutions are acceptable in actual societal contexts" (Future Earth, 2013, p. 51). The assumption is that engaging 'users' or 'stakeholders' throughout the research process will increase legitimacy of and reduce scepticism towards research and research results, thus enhancing the likelihood that scientific knowledge will contribute to societal change. The societal actors identified as possible partner in knowledge co-production are those actors that are in a position to 'make a difference in society'. The private sector in particular is often recognised as an engagement partner that has the potential to implement science-based solutions for a transition to global sustainability. Similar to the logic of accountability, the roles of scientific and extra-scientific actors in the various stages of scientific knowledge production are clearly differentiated. Scientists take the lead in the production of scientific knowledge, whereas the role of 'stakeholders' is to ensure that research questions are relevant to societal needs and that scientific knowledge finds implementation in society.

\footnotetext{
${ }^{11}$ Accountability in science can take many different forms, ranging from legitimation of existing scientific practices to radical reorientation of science (Barry et al., 2008). Here, I focus on the way accountability is expressed and institutionalised in the context of Future Earth, which is shaped by the central role of funding agencies in the development of the programme (see also section 5.4).
} 


\subsubsection{Logic of humility}

A third logic that shapes the discourse of knowledge co-production in Future Earth builds on the position that scientists need "to be humble and reflective about their own positions, recognising that their own views of the world and of what kinds of science and knowledge are appropriate are always positioned and partial" (Prof. Melissa Leach, Vice-Chair of the Future Earth Science Committee, as quoted in Sayer (2014)). This 'logic of humility'12 emphasises the relevance of societal norms, values and concerns in addressing issues of sustainability, and maintains that scientific knowledge production should not close down questions of meaning and value, but rather allow for inclusive and open deliberation of issues of societal concern. The assumption is that taking societal complexities into account in producing scientific knowledge for global sustainability will enhance the value of research in addressing issues of global change. Hence, co-production of knowledge is called for as an approach that includes the knowledge, perspectives and experiences of extra-scientific actors. Extra-scientific actors are perceived as legitimate knowledge holders and partners in the full process of scientific knowledge production. This means that the boundaries between science and other societal subsystems are blurred in the common pursuit of knowledge for global sustainability.

\footnotetext{
12 The name is inspired by Jasanoff's (2003) work on 'technologies of humility', in which she argues that coming to grips with the limits of scientific knowledge requires an "intellectual environment in which citizens are encouraged to bring their knowledge and skills to bear on the resolution of common problems" (p.227).
} 
Table 5.2 Logics of co-production

\begin{tabular}{|c|c|c|c|}
\hline & LOGIC OF ACCOUNTABILITY & LOGIC OF IMPACT & LOGIC OF HUMILITY \\
\hline $\begin{array}{l}\text { Purpose of } \\
\text { co-production }\end{array}$ & To be responsive to the needs of society & To ensure implementation of knowledge & $\begin{array}{l}\text { To be humble and reflexive about the role of } \\
\text { science in society }\end{array}$ \\
\hline $\begin{array}{l}\text { Motivation to } \\
\text { engage in } \\
\text { co-production }\end{array}$ & $\begin{array}{l}\text { Living up to societal demands to justify public } \\
\text { spending on research and possibly increase } \\
\text { funding by demonstrating utility of research }\end{array}$ & $\begin{array}{l}\text { Having an impact in society; supporting } \\
\text { transformations towards global sustainability }\end{array}$ & $\begin{array}{l}\text { Acknowledging the value of different ways of } \\
\text { knowing; taking into account different values, } \\
\text { norms, understandings in dealing with uncertain } \\
\text { and complex issues }\end{array}$ \\
\hline $\begin{array}{l}\text { How to } \\
\text { co-produce }\end{array}$ & $\begin{array}{l}\text { Engaging extra-scientific actors in the research } \\
\text { process, particularly in deciding on research } \\
\text { priorities, to ensure that research responds to } \\
\text { societal needs }\end{array}$ & $\begin{array}{l}\text { Engaging extra-scientific actors throughout the } \\
\text { research process to increase legitimacy, reduce } \\
\text { scepticism and create ownership. }\end{array}$ & $\begin{array}{l}\text { Recognising extra-scientific actors as legitimate } \\
\text { knowledge holders; creating knowledge together }\end{array}$ \\
\hline $\begin{array}{l}\text { With whom to co- } \\
\text { produce }\end{array}$ & $\begin{array}{l}\text { Those that provide funding for scientific } \\
\text { knowledge production (directly: funding agencies; } \\
\text { indirectly: governments and tax payers, possibly } \\
\text { private sector) }\end{array}$ & $\begin{array}{l}\text { Actors that can make a difference in society } \\
\text { (often interpreted as private sector and high-level } \\
\text { decision-makers) }\end{array}$ & $\begin{array}{l}\text { Actors who bring in different knowledges, } \\
\text { perspectives and experiences than scientific } \\
\text { actors }\end{array}$ \\
\hline Roles of science & $\begin{array}{l}\text { Providing the knowledge that society needs; } \\
\text { providing useful knowledge }\end{array}$ & $\begin{array}{l}\text { Inform and guide transition to global } \\
\text { sustainability; co-producing sustainable futures }\end{array}$ & $\begin{array}{l}\text { Facilitating knowledge production and } \\
\text { stakeholder cooperation; engage in reflexive } \\
\text { learning process }\end{array}$ \\
\hline $\begin{array}{l}\text { Roles of societal } \\
\text { actors }\end{array}$ & $\begin{array}{l}\text { Informing research directions and research } \\
\text { agendas }\end{array}$ & Implementing scientific knowledge in society & $\begin{array}{l}\text { Epistemic partner in knowledge production } \\
\text { process }\end{array}$ \\
\hline Illustrative quotes & $\begin{array}{l}\text { "... governments and society want a bigger say in the } \\
\text { formulation of the research questions and issues that they } \\
\text { want science to investigate and explore. Because } \\
\text { governments are making the investment, they want to have } \\
\text { more say in what the science priorities are and look. like" } \\
\text { [4] } \\
\text { "[Answering to major societal concerns] is the only way to } \\
\text { justify the money we have, and if we want to get some more } \\
\text { into our science, this is the only way to go." [11] }\end{array}$ & $\begin{array}{l}\text { "... you have to give [stakeholders] a role in the beginning } \\
\text { so that your questions are framed in the right way. But } \\
\text { also during the research, you actually have to check if their } \\
\text { needs aren't changing, if your insights aren't changing. } \\
\text { And in the end the big advantage is that, if you bave still } \\
\text { their buy in, they will actually communicate your results." } \\
{[1]} \\
\text { "There is [...] a greater chance of creating durable, } \\
\text { effective interventions if decision makers and other users of } \\
\text { the research are appropriately involved in the process of } \\
\text { designing and producing knowledge." (ISSC and Belmont } \\
\text { Forum, 2011, p. 21) }\end{array}$ & $\begin{array}{l}\text { "... like academics, non-academics are knowledge } \\
\text { producers as well as users, [and] they hold valid knowledge } \\
\text { that has to be part of framing the agenda and of research" } \\
\text { [6] } \\
\text { [Co-production of knowledge is a process] ... by which } \\
\text { scientific and societal actors negotiate how different sources } \\
\text { of knowledge can be brought together into new and mutual } \\
\text { understandings. Sustainable development requires } \\
\text { knowledge that is integrated in appropriate ways with } \\
\text { scientific and other forms of knowledge." (ISSC and } \\
\text { UNESCO, 2013,p.607) }\end{array}$ \\
\hline
\end{tabular}




\subsection{INSTITUTIONALISING CO-PRODUCTION IN FUTURE EARTH}

The three logics that shape the discourse on co-production in Future Earth imply different ways of institutionalising this principle in structures, rules and procedures. In this section, I discuss the development of Future Earth and analyse which logics we see 'at work' in the process of designing and negotiating a new institutional context of science for global sustainability. The section is structured along four phases in the development of Future Earth in which different combinations of logics shape the process of designing an institutional structure for the programme.

\subsubsection{The formation of an alliance}

Early 2009, following reviews of existing international research programmes in the global change community which pointed out that these programmes, although generally successful in their scientific objectives, had limited societal impact (ICSU-IGFA, 2008, 2009), the International Council for Science (ICSU) and the International Social Science Council (ISSC) engaged in a 'visioning process' to explore research priorities and new institutional frameworks for the next decade of global change research. The report that resulted from this process stresses that:

There is an "urgent need for the international scientific community to develop the knowledge that can inform and shape effective responses to . . . threats [resulting from human-induced global environmental change]" (ICSU, 2010, p. 5).

This statement illustrates the strong emphasis in the ICSU-ISSC visioning process on the societal role of global change research community. It is argued that, while the global change community has already played an important role in understanding the functioning of the Earth system, it now needs to step up to the challenges of 'informing and shaping' the societal response to global change. The report continues by stating that:

"Research will often be most useful, and the results most readily accepted by users, if priorities are shaped with the active involvement of potential users of research results and if the research is carried out in the context of a bi-directional flow of information between scientists and users. An effective response to global environmental change will be aided by the co-creation of new knowledge with a broad range of stakeholders through participatory practices" (ICSU, 2010, p. 6).

Here, again, the focus is on an effective response to global environmental change requiring effective interactions with stake-holders. Illustrating that, in this initial visioning process, objectives of scientific impact in society were central to the developments towards a new type of research and a new institutional framework.

Parallel to the ICSU-ISSC visioning process, some of the major funders of global change research, among them the US' National Science Foundation (NSF) and the UK's Environmental Research Council (NERC), created a new platform for international cooperation among national funding agencies: the Belmont Forum. The Belmont Forum 
intends to coordinate across national funding agencies in the domain of global change with the overarching aim "[t]o deliver knowledge needed for action" (Belmont Forum, 2011, p. 7). Here, again, the objective of societal impact is strongly represented. The constitutional White Paper of the Belmont Forum states the following:

"To maximise benefit to policy and business, provision of this information [i.e. the information that society needs to respond to the challenges of global environmental change] will need to be co-designed in partnership with influential societal decisionmaking systems, internationally and at regional scales." (Belmont Forum, 2011, p. 4)

The above statement emphasises the benefit of research for particular societal actors (policy and business) rather than societal effectiveness in general, and, to maximise benefit, the need to engage 'influential societal decision-making systems' in processes of co-design. Within the Belmont Forum and its constitutional White Paper there is a strong sense that the global change community needs to increase its accountability to its societal sponsors by stepping up to the challenge of providing the knowledge needed by governments and businesses.

Finding similarities in their missions, ICSU, ISSC and the Belmont Forum decided to join forces in the process of initiating a new research programme for global change research. In a joint statement of intent, the science councils and funders of global change research stated that:

"A step change in coordination and collaboration is required that will . . [e]ndeavour to collectively identify priorities, co-design research strategies and co-produce knowledge with users and key drivers of innovation and change, including the policy and business communities." (Belmont Forum et al., 2011, p. 1)

Whereas the notion of engagement and participation had been mentioned in both the ICSUISSC and Belmont Forum process, co-production now took centre stage as the principle where the science councils and funding agencies found common ground. Co-production was made a core objective of the new research initiative, as well as a principle for the design of the initiative itself (ICSU, 2011a). Together with the other institutional sponsors of global change research (UNESCO, UNU and UNEP), ICSU, ISSC and the Belmont Forum formed an alliance which was formalised as the Science and Technology Alliance for Global Sustainability (in short: 'the Alliance'). This alliance is identified as a 'strategic alliance', bringing together the relevant partners to co-produce the new research programme and to encourage and facilitate the co-production of knowledge in Future Earth [4,11,13]. Within this strategic alliance, the international science councils (ICSU and ISSC) represent the scientific community. A strong link to national funders of global change research is provided by the Belmont Forum, which is expected to ensure that Future Earth responds to the knowledge needs of its sponsors. This central role of the funding agencies with respect to co-production in Future Earth reflects the logic of accountability, with the funding agencies identified as key actors in ensuring the accountability of the new research programme to society. The presence of UN bodies in the Alliance (UNESCO, UNU and UNEP) is also justified through the logic of accountability, 
with these international agencies (indirectly) representing the 'users' of Future Earth. At the same time, including UN organisations as institutional sponsors is anticipated to provide the initiative with "political convening power" and to "build visibility and capacity for Future Earth at a global level [and] directly with governments" [13], thus supporting the societal influence of Future Earth and reflecting the logic of impact. The Alliance became the initiator and interim-Governing Council of Future Earth, taking responsibility for setting-up governance structures, appointing committees and running the secretariat in the early stages of Future Earth's development.

In sum, in this initial phase in the development of Future Earth, the principle of co-production acts as a bridging concept bringing together multiple actors in a common alliance to develop a new research initiative. Shared logics of impact and accountability shape and justify the establishment of the Alliance and the role of its members in co-producing Future Earth. The objective to enhance the effectiveness of global change knowledge in society features prominently in both the ICSU-ISSC visioning process and the Belmont Forum White Paper. The formation of a strategic alliance between science councils, funding agencies and UN organisations, co-producing the new initiative Future Earth, is expected to contribute to this objective (logic of impact). At the same time, the funding agencies bring in a focus on the 'users' of global change research (at this stage mostly simplified as policy and business communities) and the responsibility to respond to their needs (logic of accountability).

\subsubsection{Negotiating Future Earth's initial design}

The Alliance established a "Transition Team" tasked with the development of an initial research strategy and organisational design for Future Earth. Members of the Transition Team were selected to represent different scientific communities as well as the science councils, funders and 'users' of global change research (ICSU, 2011b), reflecting the objective to build the new initiative through a process of co-production ${ }^{13}$. The Transition Team agreed that an institutional innovation was necessary to support the principle of knowledge co-production in Future Earth. Yet, how to internalise the principles of co-production in the institutional design of Future Earth proved to be a point of disagreement.

One way in which the Transition Team decided to incorporate the principle of co-production in the design of Future Earth was by complementing the Science Committee (an established component of the governance structure of international research programmes) with an Engagement Committee. Where the Science Committee traditionally consists of respected members of the scientific community tasked with steering the research directions of a research programme, the Engagement Committee was considered an appropriate way to include extrascientific actors in shaping and steering research for global sustainability. However, perspectives differed with respect to the desired position of the Engagement Committee in the

\footnotetext{
${ }^{13}$ However, the executive team consisted of scientists; extra-scientific stakeholders fulfilled a more distant, advisory role. This illustrates that, as in other stages of Future Earth's development, ambitions of co-production were not always reflected in reality.
} 
organisational structure of Future Earth. Discussions within the Transition Team centred on the question whether priority should be given to the Science Committee (representing the scientific community) or the Engagement Committee (representing the 'stakeholders' or 'users' of Future Earth). This discussion reflected different positions with respect to the appropriate and desired relationship between scientific and non-scientific actors. Whereas some members argued that the new research programme should be driven directly by the needs of society and therefore the Engagement Committee should have priority in the organisational design, other members, while recognising the role of non-academic actors in advising on scientific priorities, pointed to the importance of scientific autonomy which would be safeguarded by the primacy of the Science Committee in Future Earth's organisational design.

“. . . there was lots of discussion [within the Transition Team] as to which one [i.e. which committee] would be on top - too put it crudely . . in the end we concluded that they had to be equal . . . I can remember a meeting were we actually beat this . . . we said, this is stupid! This whole discussion is really pointless. We've got to have both. And they need to be on the same level and they've got to interact with due respect for each other, they've got to interact properly. It says all that in the text [i.e. the Initial Design Report of Future Earth]. We spend ages getting this text right." [11]

Thus, in the organisational design that the Transition Team eventually settled with, the Science Committee and the Engagement Committee have "the same status and priority" (Future Earth, 2013, p. 82). Members of the Transition Team explain that this dual structure was developed to give stakeholders a strong voice in the governance of Future Earth and to avoid 'getting the science right first and doing the engagement later' $[1,11,16]$. Including extra-scientific actors from the start was considered important to ensure that Future Earth produces the knowledge that society needs (logic of accountability) while building relationships of trust and legitimacy and increasing the likelihood of implementation of scientific knowledge in society (logic of impact). At the same time, the dual structure is argued to be safe-guarding scientific autonomy:

"You want to have a certain independence of your science, in order to have your freedom and quality and all of that. And at the same time, you want to have policy relevance. It is difficult to do both at once. [The dual structure] was the solution that was found to both have a place where you have your policy-relevance and you have your stakeholders, and then at the same time scientists also have some space to meet separately.” [6]

Thus, whereas the governance structure of Future Earth, with its dual structure of a Science Committee and Engagement Committee, was meant to bring the principles of co-production at the core of the research programme, it also accommodates principles of scientific independence and autonomy.

The next step was to decide on the appropriate membership of the Engagement Committee. The profile for Engagement Committee members stresses the desirability of "[s]trong experience in addressing environmental change and sustainability issues at different scales, 
from the local to the global scale" (Future Earth, 2014a, p. 1), thus encouraging engagement of actors who, based on their experience in addressing environmental change and sustainability issues, have the potential 'to make a difference in society'. Indeed, members of the Engagement Committee represent high-level positions in various sectors of society, from international political bodies to multinational organisations. Here, again, we see the logic of impact at work, where co-production is proposed to ensure that scientific findings translate into societal change.

With the establishment of the Science and Engagement Committees, as well as various subcommittees at the regional and national scale, new actors and voices were brought into Future Earth. In this context, the dual structure of Science Committee and Engagement Committee became a point of discussion, not in the least by members of these committees themselves. The separation of 'science' from 'engagement' through the two distinct committees was strongly questioned based on the reasoning that both scientific and extra-scientific actors hold relevant knowledge as well as value positions with respect to research for global sustainability (logic of humility), making a separation of committees unnecessary and undesirable. Voices went up to reconsider this aspect of the governance structure of Future Earth and, rather than two committees with different mandates, establish a single committee in which scientists and stakeholders would work together in shaping research for global sustainability. Indeed, during this phase, most meetings of the Science Committee and Engagement Committee were held jointly, and tasks were carried out under common responsibility, diminishing the structural separation between the two committees.

In sum, during this second phase in the development of Future Earth, debates on the appropriate governance structure for the new research programmes expose tensions between different logics of co-production. The establishment of a dual structure of a Science and Engagement Committee institutionalises the co-production principle in the governance structure of Future Earth by allowing 'stakeholders' or 'users' to shape research directions (logic of accountability) and increasing the likelihood of implementation of knowledge in society (logic of impact), while also accommodation values of scientific independence and autonomy. At the same time, opening up the programme and its development to new actors with the establishment of the Science Committee and Engagement Committee strengthened the understanding of co-production based on the logic of humility, as reflected in internal criticism on Future Earth's dual governance structure.

\subsubsection{Developing institutional rules and procedures}

Future Earth was officially launched at the Planet under Pressure conference (London, March 2012) and the Rio+20 United Nations Conference on Sustainable Development (Rio de Janeiro, June 2012), reflecting its dual commitment to the scientific community and decisionmaking audiences. Future Earth's vision document (Future Earth, 2014c) and Strategic Research Agenda (Future Earth, 2014e), both again stress co-production as a central principle of Future Earth. The vision document states that, by 2025, Future Earth will have: 
"Pioneered approaches to co-design and co-produce solutions-oriented science, knowledge and innovation for global sustain-able development" (Future Earth, 2014c, p. 5), and

"Enabled and mobilised capacities to co-produce knowledge, across cultural and social differences, geographies and generations.” (Future Earth, 2014c, p. 6)

These statements, rather than focusing on the design of Future Earth itself, stress the role of the programme in supporting co-production of knowledge in the research projects and initiatives operating under Future Earth's umbrella. Next to the governance structure discussed in the previous section, institutional rules and procedures were developed with the intention to contribute towards this objective. One of these is the 'Memorandum of Understanding' that existing research projects are expected to sign when becoming part of Future Earth. In a statement addressed to the Science Committee of Future Earth, research projects are requested to describe how they meet, or will seek to meet the principle of co-production in their research strategy and practices. Co-production has also been made a key criterion for the establishment of new initiatives under the umbrella of Future Earth and the assessment of funding proposals by the Belmont Forum.

Particularly in the early stages of Future Earth's development, the design of assessment criteria and the actual assessment of the project and project proposals was taken up by academic actors represented in the Science Committee (partly because the Engagement Committee was not fully established yet at this point). More recently, the Engagement Committee has acquired an official role in the process of reviewing global change research projects that intend to become part of Future Earth, indicating that judging the value of science is no longer considered the exclusive task of the scientific community.

To aid a common vision and strategy on the principle of co-production, members of the Science Committee and Engagement Committee have been working on an 'Engagement Strategy'. Initially, this document was developed as a white paper - an authoritative document on engagement in Future Earth - yet, over time the document got the status of a green paper, intended to stimulate discussion on the topic of engagement, rather than an authoritative statement on the principles and practices of knowledge co-production [18]. Various drafts of the document point to the diversity of meanings associate with the principle of co-production. Indeed, the document acknowledges 'multiple interrelated objectives' and stresses that there is 'no one type fits all' when it comes to engagement. Instead, all initiatives within Future Earth are expected to develop their own tailored engagement strategy (Future Earth, 2014b).

Yet, a form of engagement supported by Future Earth in particular is that through Knowledge Action Networks (KANs). Knowledge Action Networks are new initiatives intended to bringing together researchers and extra-scientific actors in responding to key societal challenges (Future Earth, 2014c). A core objective of Knowledge Action Networks is to strengthen the link between scientific knowledge and societal change. Knowledge Action Networks are expected to support the production of 'actionable scientific knowledge' and 'inform solutions 
for global sustainability' (Future Earth, 2016b), reflecting a perspective on co-production based on the logic of impact.

Thus, the principle of co-production has been made a precondition for evaluation and funding of research under the umbrella of Future Earth. Early experiences with co-production as assessment criterion expose that what co-production exactly means in this context, how it can be evaluated and by whom, is open for debate and interpretation by both the scientists submitting a proposal and the actors conducting the review and assessment. An exception is formed by Knowledge Action Networks, the new flagship initiatives of Future Earth, which display a rationale of impact in their framing and operationalisation.

\subsubsection{Formalising structures and responsibilities}

In 2015, Future Earth appointed its first Executive Director, established a permanent secretariat, and decided on the final governance structure of the programme. According to the initial design of Future Earth developed by the Transition Team, the Alliance partners were expected to hand over their role as interim-Governing Council to an independent multistakeholder body. Although attempts were made to establish such a multi-stakeholder body, it was eventually decided that the Alliance would continue its role as Governing Council of Future Earth" ${ }^{14}$ This means that members of the Alliance form the "main decision-making body of Future Earth on all aspects of the Programme, including its strategic direction" (Future Earth, 2013, p. 44). As such, the position of funding agencies and UN organisations in steering the development and future direction of scientific knowledge production is further strengthened. The Governing Council is the ultimate decision-making body of Future Earth, responsible for the programme's strategic directions and the appointment of members of the Science Committee and Engagement Committee. The Science Committee and Engagement Committee have a primarily advisory role, with some implementing commitments ${ }^{15}$. The separate mandates of the two advisory committees have been reconfirmed in the final governance structure approved by the Governing Council. Within this formalised structure, the Science Committee advises and reports to the Governing Council on scientific matters, whereas the Engagement Committee advises on engagement, communication and fundraising strategies, and is responsible for developing a network of social partners willing to participate in the co-production of knowledge. Monitoring, supporting and evaluating research initiatives is the responsibility of the two committees together.

Thus, in this final stage of the development of Future Earth discussed here, with the Alliance partners reclaiming their central role in Future Earth as members of the Governing Council, and by formalising the dual structure of the Science Committee and Engagement Committee

\footnotetext{
${ }^{14}$ The Alliance was expanded with two new organisational members, the Sustainable Development Solutions Network (SDSN) and the Science and Technology in Society Forum, as well as one member of the Funders Consortium sponsoring Future Earth's secretariat.

15 This is different from the governance structure of the global change programmes preceding Future Earth (IGBP, IHDP, DIVERSITAS). In these programmes the Scientific Committee was the main decision-making body.
} 
(albeit in an advising role), the logics of accountability and impact are reinforced. However, it should be remembered that Future Earth is "a work in progress whose functioning and structure may evolve over time” (Future Earth, 2013, p. 81).

\subsection{Discussion}

The three logics of knowledge co-production identified in this chapter represent different normative positions on the appropriate relationship between science and society and the role of extra-scientific actors in scientific knowledge production. This heterogeneous conception of knowledge co-production within Future Earth may, on the one hand, be understood as providing helpful ambiguity allowing actors with different perspectives on science and its role in society to engage in Future Earth. On the other hand, certain tensions exist between the different logics of co-production. These tensions and their 'resolution' in the institutional structure of Future Earth reflect the politics of reorienting global change research to research for global sustainability.

As the above analysis has shown, tensions between logics of co-production surface at several moments in the development of Future Earth. A first set of tensions relates to the role of extra-scientific actors in (the governance of) research for global sustainability. Based on divergent objectives (see Table 5.2), different roles of extra-scientific actors are regarded as most desirable, ranging from a primarily advisory role towards active engagement in processes of knowledge production. These tensions shaped discussions on the appropriate governance structure of Future Earth, particularly with respect to the dual structure of the Science Committee and Engagement Committee, and the appropriate role of the Alliance partners in the governance of research through Future Earth.

A second set of tensions between logics of co-production relates to the type of extra-scientific actors perceived as most relevant and legitimate to engage with. Priorities range from engaging influential societal actors, to engaging actors that bring different knowledge and values into the process of knowledge production. This tension is important with respect to the composition of Future Earth's governance bodies, particularly the Governing Council and the Engagement Committee. Yet, it also speaks to the rules and procedures for monitoring, supporting and evaluating co-production in the research projects that operate under the umbrella of Future Earth, as these rules and procedure are meant to facilitate and encourage the engagement of extra-scientific actors in co-production of knowledge.

The current institutional structure of Future Earth is primarily shaped by logics of accountability and impact. The importance of these logics in shaping the governance of Future Earth is evident in the institutionalised role of funding agencies and high-level political actors in the governance structure of Future Earth, the composition of the Engagement Committee with actors 'that can make a difference in society', the dual structure of Science Committee and Engagement Committee which allows for engagement of extra-scientific actors while safeguarding scientific autonomy, and the establishment of impact-driven Knowledge Action Networks as Future Earth's flagship initiatives. The institutionalisation of the logics of 
accountability and impact in Future Earth's institutional structure can be explained by the centrality of these logics in early stages of Future Earth's development, when ICSU, ISSC and the Belmont Forum took a leading role. Moreover, both logics of co-production are accommodative of ideas and values of scientific independence and autonomy, thus resonating with 'traditional' perceptions of science and its role in society. Hence, these logics of coproduction find less resistance within the scientific community, advancing their institutionalisation in Future Earth.

The logic of humility became a more central component of the discourse on co-production in Future Earth only after the initial foundations of Future Earth was established by the alliance between science councils, funding agencies and UN organisations. Particularly the ISSC had been pointing to the value of a humble and reflexive perspective on the role of science in society in early talks on the principle of co-production. The logic of humility gained ground in the institutional process with Future Earth opening up to new actors through, for example, the establishment of the Science and Engagement Committees. The increased questioning of the institutional separation of 'science' and 'engagement' in the dual governance structure of Future Earth reflects the presence of this logic of co-production in discussions on the appropriate institutional design. Moreover, the flexibility of Future Earth's rules and procedures accommodates co-production based on the logic of humility, although no particular mechanisms for encouraging new knowledge traditions and communities to engage in Future Earth exist at this stage. In the final design of the governance structure of Future Earth, with the formalisation of the Alliance partners as Governing Council, the initial dominance of the logic of accountability and impact is reinforced. An explanation for the marginal role of the humility logic in shaping the governance structure of Future Earth could be that this logic of co-production is less accommodative of the traditional values of scientific independence and autonomy. As such, co-production based on the logic of humility is met with misunderstanding and resistance by some members of the scientific community, hindering the institutionalisation of this logic in Future Earth. Ironically, this defiance from traditional ideas about science and its role in society also makes that co-production based on a logic of humility, to flourish, requires strong institutional support.

In sum, tensions in the process of institutionalising co-production in Future Earth centre on the question who is allowed and able to shape research for global sustainability and thus engage in "conversations about the future of Earth" (Lövbrand et al., 2015). Future Earth institutionalises the role of funding agencies, high-level policy bodies and prominent public and private sector actors in the governance of research for global sustainability. The programme's institutional rules and procedures open up possibilities for engaging extra-scientific actors in knowledge production in various types and forms. Yet, Future Earth's flexible rules and procedures - which allow multiple logics of co-production to co-exist - may also hold the programme from encouraging scientists to change their research practices, allowing the gap between principles and practices of co-production to go unchallenged. 


\subsection{CONCLUSION}

The process of designing a new research programme opens up discussions on values and believes which are otherwise taken for granted. This research has illustrated how the existence of multiple rationales on the principle of co-production shapes the process of institutional design, leading, in some cases, to the manifestation of tensions and intense negotiations about appropriate governance structures and institutional rules in support of research for global sustainability. A final tension which shapes the institutionalisation of new modes of knowledge production in research programmes resides in the need to accommodate the diversity of values and perspectives on science and its role in society, while also encouraging and advancing a new mode of knowledge production. In navigating this tension between being inclusive and transformative, research programmes operate on a precarious balance between doing more of the same under a different name, and supporting and steering research communities towards new modes of knowledge production. 
Chapter 5 


\section{6 - What does coordination achieve?}
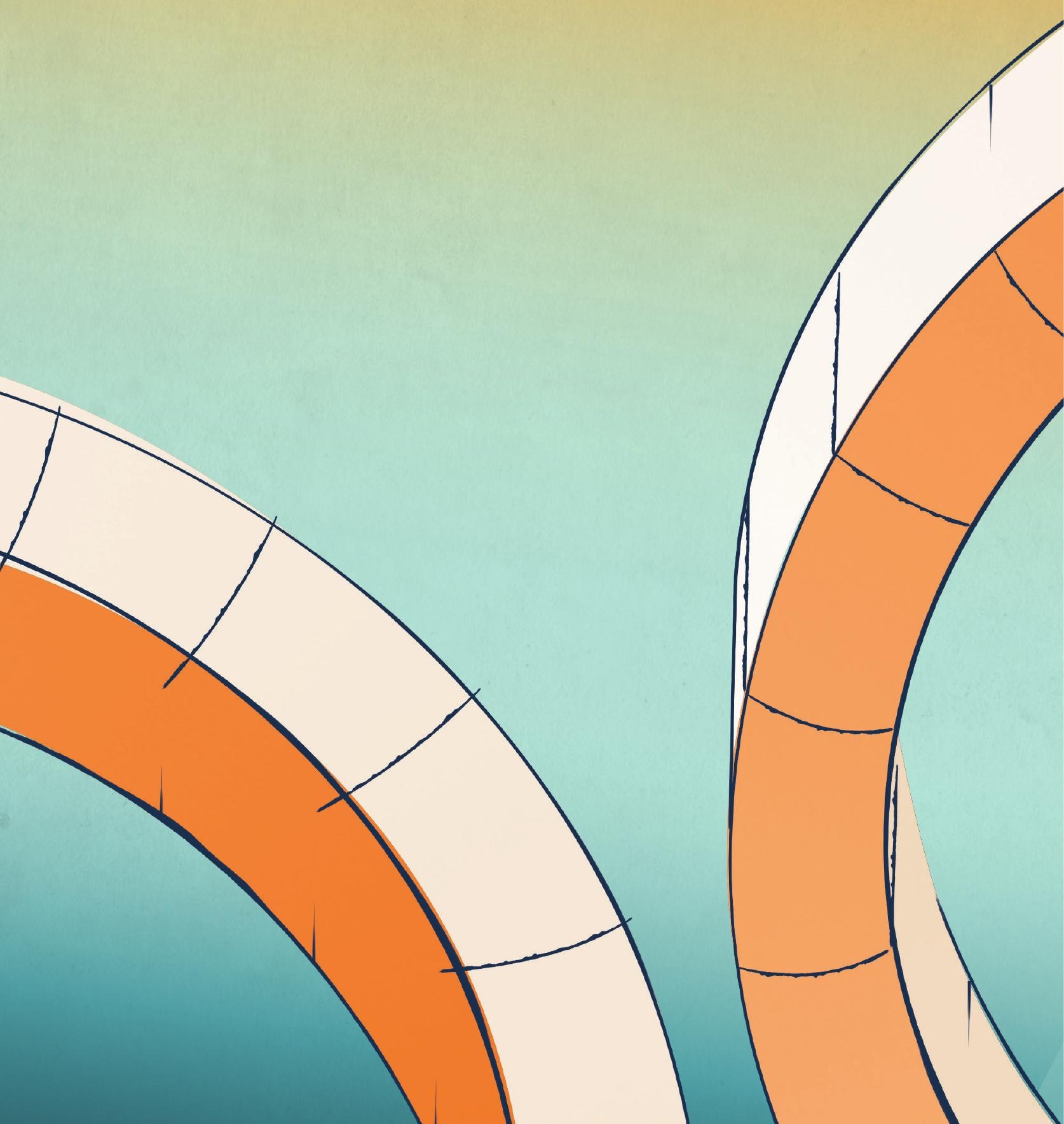
This chapter focuses on the principles of interdisciplinarity and inclusiveness. It looks at the role of science institutions as coordination mechanisms that aim to bring together researchers with different topical, disciplinary and geographical backgrounds around common issues of concern. Global science coordination by formal research programmes and networks is an increasingly prominent feature of global change and sustainability research that requires significant investment of buman and financial resources. Nevertheless, it is largely unclear whether and how research programmes and networks contribute to collaboration across disciplinary and geographical boundaries. This raises the question: 'what does coordination achieve?' I address this question based on a literature review and scientometric analysis of the International Geosphere-Biosphere Programme (IGBP) and the International Human Dimensions Programme on Global Environmental Change (IHDP). Insights from this study are relevant for identifying possible bottlenecks of science coordination as well as lessons for Future Earth.

Published as:

van der Hel, Sandra. 2019. What does coordination achieve? A scientometric analysis of large scale research programmes in global change and sustainability research. Current Opinion in Environmental Sustainability 39: 135-146. https://doi.org/10.1016/j.cosust.2019.07.006 


\subsection{INTRODUCTION}

Scientific collaboration is necessary to address research problems that stretch beyond a single disciplinary or geographical domain. However, such collaboration does not always arrive spontaneously. Instead, an increasing number of formal arrangements aim to enhance and steer research collaboration beyond national jurisdictions and disciplinary silos.

This development is particularly prominent in the domain of global change and sustainability research. Problems of global change and sustainability are inherently complex, multidisciplinary and cross local to global scales. Addressing such problems requires collaboration across topical, disciplinary and geographical boundaries (Belmont Forum, 2011; Clark \& Dickson, 2003; Future Earth, 2013; ICSU, 2010). Yet, although scientific research on issues of global change and sustainability is relatively internationalised (Engels \& Ruschenburg, 2008; Yarime et al., 2012), international collaboration mostly takes place between developed countries (Engels \& Ruschenburg, 2008; Hassan, Haddawy, \& Zhu, 2014), excluding large parts of the world and depriving the scientific community of considerable intellectual capacity (Karlsson et al., 2007; Pasgaard et al., 2015). Moreover, collaboration and integration across disciplinary perspectives, although increasing, tends to be focused on related disciplines and specific issue areas (Bettencourt \& Kaur, 2011; Kajikawa, Tacoa, \& Yamaguchi, 2014; Schoolman, Guest, Bush, \& Bell, 2011).

Global research coordination is recurrently proposed as a promising mechanisms to address these deficits (Berkhout, 2014; Cornell et al., 2013; ICSU, 2010; Kauffman \& Arico, 2014; Leemans et al., 2009; Yarime, Takeda, \& Kajikawa, 2010). Over the past decades, many largescale research programmes, platforms and networks have been developed with the aim to support collaboration across national and disciplinary boundaries. Examples include global change research programmes such as the International Geosphere Biosphere Programme (IGBP) and International Human Dimensions Programme (IHDP) (which are discussed in more detail later in this chapter), the Man and Biosphere programme of UNESCO (Bridgewater, 2015), the Resilience Alliance (Janssen, Schoon, Ke, \& Börner, 2006), and more recently the Sustainable Development Solutions Network (SDSN, 2018; see also Chapter 8) and the global research platform Future Earth: research for global sustainability (Future Earth, 2013). These programmes and networks are different in scale, focus, level of formality and funding base. What they have in common is the promise to advance global change and sustainability research by supporting global collaboration.

It is a common assumption that global research coordination can and should improve the performance of global change and sustainability research (Berkhout, 2014; Future Earth, 2013; Holm et al., 2013; Rice, 2013; Withycombe Keeler et al., 2015). However, global coordination also comes at a cost, as it requires substantial investments of both financial as well as intellectual and human resources (Cummings \& Kiesler, 2007; Hessels, 2013). Given the major promises as well as costs involved, it is surprising that the influence of global research programmes, platforms and networks has received little critical scrutiny. Addressing this deficit, the current chapter asks whether and how global research programmes manage to 
shape the disciplinary, geographical and conceptual composition of research undertaken under their umbrella. In other words, it addresses the question: 'what does science coordination achieve?' 16

The chapter addresses this question in two ways. First, it presents a literature review focused on the influence of large-scale research programmes and networks in global change and sustainability research. Second, it presents a scientometric review of the influence of two global research programmes on the research undertaken under their umbrella. Based on combined insights from the literature review and scientometric analysis, the chapter concludes by reflecting on the question 'what does global science coordination achieve?' and identifies critical issues for consideration by global research programmes that aim to facilitate international and interdisciplinary collaboration.

\subsection{RESEARCH PROGRAMMES AS COORDINATION MECHANISMS}

Large-scale research programmes and networks are increasingly viewed as a vehicle for supporting international and interdisciplinary collaboration (Georghiou, 1998; Hird \& Pfotenhauer, 2016; Klerkx \& Leeuwis, 2008). For the purpose of this study, it is important to make a distinction between research programmes as funding mechanisms and research programmes as coordination mechanisms. Research programmes as funding mechanisms have the primary aim to allocate funding to collaborative research projects that meet the stated aim of the programme. In contrast, research programmes as coordination mechanisms do not have a large funding base at their disposal and rather aim to steer research directions by other means. The academic literature that investigates the role and effectiveness of research programmes mostly focuses on funding programmes such as the European Framework Programmes (Luukkonen, 2001) or research centres and networks funded by the National Science Foundation (Garner, Porter, Newman, \& Crowl, 2012). Additionally, existing research evaluates collaborative initiatives at the national level, such as Centres of Excellence or University Research Centres (Schröder, Welter, Leisten, Richert, \& Jeschke, 2014; Smith, Lai, Bea-Taylor, Hill, \& Kleinhenz, 2016). This leaves the phenomenon of global research programmes as coordination mechanisms - i.e. without a large funding base - relatively unexplored. In contrast, this study focuses specifically on global research programmes, platforms and networks with a coordinating mission. Building on the existing literature, the current review points out the unique features of coordinating research programmes, focusing on how they function and what they may achieve.

How does coordination through research programmes work? Coordinating research programmes and networks hold the promise to advance science by bringing together researchers with different disciplinary, geographical and institutional backgrounds around a common theme or question of concern. According to Hessels (2013), large-scale research programmes can be understood

\footnotetext{
${ }^{16}$ This question was raised in a blog post by interim Director of Future Earth Frans Berkhout (Berkhout, 2014).
} 
as "intermediary organisations with a coordinating mission" (Hessels, 2013, p. 317). They are formally established and mandated organisations that aim to establish or strengthen relationships among researchers and research systems in order to enhance their common effectiveness (Hessels, 2013; Jappe, 2009; Withycombe Keeler et al., 2015; Wixted \& Holbrook, 2012). The term 'intermediary' refers to the position of these organisations mediating between the daily practices of researchers and the (inter)national research environments in which these practices take place (Hessels, 2013). This definition of research programmes is useful because it focuses on the coordination function of research programmes and thus allows to study research programmes that do not function as funding mechanisms per se. Instead, it recognises that coordination through research programmes may be based on a range of different tools and activities that potentially contribute to establishing or improving relations among researchers and research teams and may improve the coherence and effectiveness of a certain domain of research (Bernard de Raymond, 2018; Klerkx \& Leeuwis, 2008).

Coordinating research programmes have multiple strategies at their disposal, including setting a common research agenda, sharing resources, mobilising capacity, facilitating knowledge transfer and shaping funding priorities (Cummings \& Kiesler, 2007; Wixted \& Holbrook, 2012). Doing so, they may enhance interdisciplinary collaboration, shape global research agendas and practices, contribute to the development of research domains and share research insight and solutions across different contexts (Hessels, 2013; Jappe, 2009; Withycombe Keeler et al., 2015; Wixted \& Holbrook, 2012).

A common model to describe science coordination through formal research programmes is the principal-agent model which identifies research programmes as principals that delegate tasks to researchers as agents (Shove, 2003). Yet, it is increasingly argued that that this delegation model does not suffice for understanding the complex relationship between coordination agencies and the actors operating under their umbrella (Bernard de Raymond, 2018). Instead, researchers recognise different models and mechanisms of coordination that go beyond the delegation of tasks or funding (Bernard de Raymond, 2018; Klerkx \& Leeuwis, 2008; Shove, 2003; Wardenaar et al., 2014). Wardenaar and colleagues (2014) distinguish three ideal typical forms of research coordination: coordination by participants, when participants in the research programme or network interact on an equal basis and make decisions collectively; coordination by a lead organisation, when activities and decisions are coordinated through a single participating member; and coordination by administrators, when a separate entity is set up to coordinate activities, typically including an executive director, staff and board (Wardenaar et al., 2014).

What does research coordination achieve? While there is a strong believe in the benefits of large-scale research programmes among policy-makers and research managers, only a hand full of studies have assessed whether research programmes serve the goals for which they are created (Smith et al., 2016). Overall, these studies find that research programmes and networks, also without a large funding base, have the potential to enhance collaboration (Bernard de Raymond, 2018; 
Bridgewater, 2015; Jappe, 2009; Johnson, Christian, Brunt, Hickman, \& Waide, 2010; Klenk, Hickey, \& MacLellan, 2010; Smith et al., 2016). Yet, there are some important factors to consider. First, the nature of a research domain is an important element in research coordination. Specifically, research domains where mutual dependence between scientists is high (i.e. dependence on data, ideas and research infrastructure developed by other scientists) are more conducive to coordination by formal research programmes than research domains where mutual dependence is lower, such as research domains that build on local or regional case studies (Jappe, 2009). Thus, while integrating research across multiple place-based projects is highly valued in global change and sustainability research, this type of collaboration often proves to be particularly challenging (Bridgewater, 2015; Withycombe Keeler et al., 2015). Second, collaboration within research programmes tends to be based on pre-existing communities and networks (Smith et al., 2016). This finding is supported by several case studies that found that outcomes of research programmes could at least partly be explained by self-organisation rather than coordination (Janssen et al., 2006; Jappe, 2009; Johnson et al., 2010). In general, it appears that research programmes and networks often have difficulties achieving their mission when this involves steering the research domain in a new direction, e.g. towards further interdisciplinary collaboration (Bernard de Raymond, 2018; Bjurström \& Polk, 2011; Kloet, Hessels, Zweekhorst, Broerse, \& Buning, 2013). This means that not only patterns of collaboration but also patterns of segregation tend to get reproduced by large-scale research programmes and networks (Bjurström \& Polk, 2011; Vasileiadou, Heimeriks, \& Petersen, 2011). Drawing on the above, a main challenge for research coordination is to encourage collaboration beyond established networks while also achieving a certain level of coherence and cohesion among previously disconnected individuals and organisations (Bernard de Raymond, 2018; Johnson et al., 2010).

Overall, while the literature review provides insights on the role and relevance of research programmes as coordination mechanisms, knowledge of the actual effects and outcomes of research coordination is limited. This review is therefore extended with a scientometric analysis of two major research programmes in order to get further insights on the question 'what does science coordination achieve?'

\subsection{SCIENTOMETRIC REVIEW OF RESEARCH COORDINATION}

The International Geosphere-Biosphere Programme (IGBP) and International Human Dimensions Programme on Global Environmental Change (IHDP) are two of the four international global change programmes directed at coordinating and integrating research on different dimensions of global environmental change ${ }^{17}$. IGBP operated between 1987 and

\footnotetext{
${ }^{17}$ The other two global change programmes are the World Climate Research Programme (WCRP; 1980-present) and DIVERSITAS, a programme on biodiversity research (1991-2014). Between 2002 and 2012, the four programmes collaborated through the Earth System Science Partnership (ESSP), which aimed to contribute to further interdisciplinary integration in the study of global change. See also Chapter 4.
} 
2015 under the auspices of the International Council for Science (ICSU) and aimed to stimulate international research collaboration in the domain of earth system science (Seitzinger et al., 2015). IHDP ran between 1996 and 2014, sponsored by the International Council for Science (ICSU) and the International Social Science Council (ISSC), with the aim to mobilising the social sciences and contribute to a better understanding of the human dimensions of global environmental change (Hordijk et al., 2006). Coordination of research through IGBP and IHDP roughly followed the 'coordination by administrators' model (Wardenaar et al., 2014), both programmes were supported by a Scientific Committee which acted as the main decisionmaking body and set out strategic directions. Further, both programmes consisted of multiple international Core Projects focusing on specific dimensions of global environmental change research, ranging from atmospheric chemistry (Integrated Global Atmospheric Chemistry Project), to land-use change (Global Land Project), to urbanisation (Urbanization and Global Environmental Change Project) ${ }^{18}$. An international secretariat coordinated the activities of the programme and facilitated information exchange and scientific collaboration.

IGBP and IHDP provide exemplary cases of coordination in global change and sustainability research. They are selected as case studies because they share sufficient characteristics to allow for meaningful comparison, while they also differ in their respective research domain, membership and development. IGBP and IHDP shared three core objectives: first, both programmes aimed to bring together researchers from different disciplines in a coordinated effort to address issues of global environmental change; second, both programmes aimed to enhance international collaboration among multiple countries and regions globally, with a particular emphasis on including researchers from the global South; and, third, both programmes aimed to achieve integration and synthesis of research from various domains of research and multiple world regions (Mooney et al., 2012; Seitzinger et al. 2015; Von Falkenhayn et al., 2011).

The remainder of this section reviews research coordination through IGBP and IHDP based on a scientometric analysis. Scientometric analysis is a quantitative approach to the study of science. Scientometric studies are based on meta-data of scientific publications (also called bibliometric data), such as journal of publication, research field, number of citations and author affiliation. The approach is widely employed to map, visualise and review developments and impacts of scientific research. Scientometric analysis is employed in this study in order to review the development of research coordination over time by assessing the scientific output of these research programmes vis-à-vis their core objectives. Although an analysis of scientific publications does not account for all possible outcomes of science coordination, bibliometric data are widely regarded as revealing and accessible records of scientific output (Koier \& Horlings, 2015). Bibliometric data are retrieved from the list of core publications provided in the annual reports of IGBP and IHDP. It is assumed that these self-selected core publications represent the main scientific output of the programmes. To be able to track developments over

\footnotetext{
${ }^{18}$ After the closure of IGBP and IHDP, most Core Projects continued under the umbrella of Future Earth.
} 
time, publications were retrieved for different periods over the course of operation of the two programmes. This resulted in a dataset of 398 scientific publications. The main focuses of the analysis are the three core objectives of global research programmes identified above: to bring together knowledge from multiple disciplines, to enhance international collaboration, and to contribute to integration and synthesis of research. The analysis combines multiple indicators in order to assess to what extent IGBP and IHDP managed to shape the composition of research undertaken under their umbrella (see Table 6.1 for an overview). Results are compared to a control set of publications that represent the research domains of these programmes. The results are interpreted by taking into account contextual developments and the (changing) mission of both programmes ${ }^{19}$.

Table 6.1 Overview of core objectives reviewed in this chapter

\begin{tabular}{|c|c|c|c|}
\hline & $\begin{array}{l}\text { DISCIPLINARY } \\
\text { DIVERSITY }\end{array}$ & $\begin{array}{l}\text { GEOGRAPHICAL } \\
\text { DIVERSITY }\end{array}$ & $\begin{array}{l}\text { CONCEPTUAL } \\
\text { INTEGRATION }\end{array}$ \\
\hline Definition & $\begin{array}{l}\text { Bringing together } \\
\text { knowledge from different } \\
\text { disciplinary perspectives, } \\
\text { including both natural and } \\
\text { social sciences }\end{array}$ & $\begin{array}{l}\text { Bringing together } \\
\text { researchers from different } \\
\text { countries globally }\end{array}$ & $\begin{array}{l}\text { Developing a shared } \\
\text { conceptual language based } \\
\text { on the integration of } \\
\text { research from different } \\
\text { perspectives }\end{array}$ \\
\hline Operationalisation & $\begin{array}{l}\text { Disciplinary diversity of } \\
\text { the knowledge base of core } \\
\text { publications }\end{array}$ & $\begin{array}{l}\text { Geographical diversity of } \\
\text { authorship of core } \\
\text { publications }\end{array}$ & $\begin{array}{l}\text { Shared conceptual } \\
\text { language across core } \\
\text { publications }\end{array}$ \\
\hline Data & $\begin{array}{l}\text { References of core } \\
\text { publication }\end{array}$ & $\begin{array}{l}\text { Authors of core } \\
\text { publications (country) }\end{array}$ & $\begin{array}{l}\text { Abstracts of core } \\
\text { publications }\end{array}$ \\
\hline Indicator(s) & $\begin{array}{l}\text { - } \text { Rao-Stirling diversity } \\
\text { - } \text { Overlay maps of science } \\
\text { - } \text { Comparison to control } \\
\text { set }\end{array}$ & $\begin{array}{l}\text { - Shannon's diversity } \\
\text { index } \\
\text { - Authorship by } \\
\text { OECD/non-OECD } \\
\text { countries }\end{array}$ & $\begin{array}{l}\text { - Co-word network } \\
\text { - Network density }\end{array}$ \\
\hline
\end{tabular}

\subsubsection{Disciplinary diversity}

One of the main aims of both IGBP and IHDP was to bring together and integrate research from different disciplinary domains. This objective is reviewed here based on the diversity of cited references, which is a commonly used scientometric indicator for interdisciplinarity. The diversity of cited references reflects the breadth of knowledge on which scientific publications are based (Rafols, Leydesdorff, O’Hare, Nightingale, \& Stirling, 2012; Stirling, 2007).

For IGBP, disciplinary diversity was low in its initial period of operation, increased substantially in the period thereafter, and then stabilised at a level similar to its respective

\footnotetext{
${ }^{19}$ A more detailed description of data collection and analysis is available in the online supplementary material for the published article. https://doi.org/10.1016/j.cosust.2019.07.006
} 
research field (see Table 6.2 and Figure 6.1). This reflects the developments in research coordination by the IGBP. In its initial period of operation, IGBP was largely community driven, with the programme supporting collaborations that emerged from the existing community of global change researchers (Seitzinger et al., 2015). Towards the end of the 1990s, IGBP began to take a more active, steering role, with the explicit objective to increase the diversity of disciplines included in the programme, particularly towards the social sciences (Will Steffen et al., 2004). This is reflected in the development of the knowledge base, which includes a sizable share of literature from social science research domains such as geography, political science, development studies and ecological economics in the period 2002/3. Yet, disciplinary diversity decreased thereafter, as the focus of the knowledge base returned to natural sciences disciplines. This may be partly explained by the growth of the IHDP and development of the interdisciplinary Earth System Science Partnership, which made inclusion of the social sciences less of a priority of the IGBP. At the same time, this indicates that the expected diversification through partnership with these programmes did not materialise.

For IHDP, the diversity of the knowledge base steadily increased over the studied period, including a larger and more diverse set of publications from both the natural and social sciences for each subsequent period (see Table 6.3 and Figure 6.2). IHDP was established with the aim to strengthen the social science perspective in the traditionally more natural sciences oriented domain of global environmental change research (von Falkenhayn, Rechkemmer, \& Young, 2011). This position between the natural and social sciences is reflected in the relatively diverse knowledge base of IHDP, which shows a balance of references from the natural and social sciences. However, the diversity of IHDP's knowledge base is lower than its respective research field (i.e. the journals IHDP core publications are most frequently published in), raising the question to what extent disciplinary diversity of IHDP can be attributed to coordination or reflects broader developments in research on the human dimensions of global change.

\subsubsection{Geographical diversity}

A second core objective of both IGBP and IHDP was to stimulate international collaboration, with a particular emphasis on supporting participation of researchers from the Global South. Geographical diversity is here reviewed based on the authorship of core publication, taking into account the country of residence of these authors, the distribution of authorship across countries and the balance between authors from OECD and non-OECD countries.

For both IGBP and IHDP, geographical diversity increased over time, yet participation of non-OECD countries, particularly in relative terms of authorship, remained behind (see Table 6.2 and Table 6.3). For IGBP, geographical diversity is noticeably low in the period 2002/3. This coincides with the substantial diversification of IGBP's knowledge base in the same period, raising the question whether the focus for this period on steering IGBP towards a more diverse and interdisciplinary community limited efforts to enhance geographical diversity. For IHDP, an external review of the programme in 2006 noted the "disproportionate participation of scientists from developed countries in IHDP scientific activities", urging 
IHDP to direct strategic effort to enhance "the capacity of researchers in the South to shape and direct global change research through their participation as equal and active partners" (Hordijk et al., 2006, p. 2). In terms of authorship of core publications, these strategies proved of limited success.

\subsubsection{Conceptual integration}

Finally, both programmes shared the objective to integrate research from multiple disciplines and world regions and develop a common conceptual language. A co-word network that maps the connection between frequently used terms and concepts in the abstracts of core publications provides insights in the conceptual development of research programmes over time. A higher density of the co-word network indicating a more coherent research output, although it is important to note that integration presumes diversity of the knowledge base (Hellsten and Leydesdorff, 2015).

Over the course of their operation, the coherence of research output increased for both IGBP (see Table 6.2 and Figure 6.3) and IHDP (see Table 6.3 and Figure 6.4), suggesting that both programmes managed to work towards a common language. From its early operating phase, IGBP advanced the notion of the Earth System as a conceptual framework for studying the combined physical, chemical, and biological aspects of the planet (Uhrqvist, 2014). This is reflected in the relatively high conceptual integration. Nevertheless, the diversification of the knowledge base during the period 2002/2003 period coincided with a less coherent research output. This is recognised in a major synthesis of IGBP's work published in 2004, which applauds the success of IGBP in bringing together multiple disciplinary perspectives on global environmental change, yet also points out that IGBP's coordinated research effort "falls short [...] of reaching the level of integration required to understand the dynamics of the Earth System in a holistic way" (Will Steffen et al., 2004, p. 284). Over the subsequent years integration increased, while this period also saw a decrease in disciplinary diversity. For IHDP, conceptual integration was relatively low in its initial period of operation, which reflects the structure of individual Core Projects that operated relatively independently. With its 2007 Strategic Plan, IHDP turned its attention to integration of social science research on global change (von Falkenhayn et al., 2011). This resulted in several synthesis and review publications on cross-cutting research themes (Janssen \& Ostrom, 2006), and is reflected in the semantic maps (Figure 6.4) which indicate that IHDP developed an increasingly integrated research portfolio over the studied period. 
Table 6.2 IGBP: disciplinary diversity, geographical diversity and conceptual integration

\begin{tabular}{|c|c|c|c|c|}
\hline & $1997 / 1998$ & $2002 / 2003$ & $2007 / 2008$ & $2012 / 2013$ \\
\hline \multicolumn{5}{|l|}{ CORE PUBLICATION } \\
\hline $\mathrm{Nr}$ of publications & 29 & 62 & 86 & 131 \\
\hline $\mathrm{Nr}$ of references & 1014 & 2860 & 5489 & 8127 \\
\hline \multicolumn{5}{|l|}{ DISCIPLINARY DIVERSITY } \\
\hline Nr of journals & 56 & 165 & 234 & 326 \\
\hline Rao-Stirling & 0.083 & 0.132 & 0.102 & 0.106 \\
\hline Rao-Stirling (control) & 0.094 & 0.093 & 0.102 & 0.103 \\
\hline \multicolumn{5}{|l|}{ GEOGRAPHICAL DIVERSITY } \\
\hline Number of countries & 29 & 26 & 42 & 53 \\
\hline Shannon's H & 2,92 & 2,66 & 3,15 & 3,17 \\
\hline Non-OECD countries & $15(52 \%)$ & $7(27 \%)$ & $16(38 \%)$ & $23(43 \%)$ \\
\hline Non-OECD authorship & $17(21 \%)$ & $10(7 \%)$ & $23(10 \%)$ & $57(12 \%)$ \\
\hline \multicolumn{5}{|l|}{ CONCEPTUAL INTEGRATION } \\
\hline Density & 0,73 & 0,65 & 0,79 & 0,81 \\
\hline
\end{tabular}

Note: Disciplinary diversity is based on the references of core publications. The Rao-Stirling measure provides an index between 0 and 1, with a higher value indicating a larger diversity of cited references (see also Figure 6.1). Geographical diversity is based the country of authors of core publications. Shannon's H provides a measure of diversity taking into account number and balance of countries, with a higher value representing a higher diversity. In addition, the number of countries and authorships from outside the OECD was calculated. Conceptual integration is based on the density of the co-word maps of abstract words (see Figure 6.3). 
Table 6.3. IHDP: disciplinary diversity, geographical diversity and conceptual integration

\begin{tabular}{|llll|}
\hline & $\mathbf{2 0 0 2 / 2 0 0 3}$ & $\mathbf{2 0 0 7 / 2 0 0 8}$ & $\mathbf{2 0 1 2 / 2 0 1 3}$ \\
\hline CORE PUBLICATION & 23 & 22 & 45 \\
Nr of publications & 731 & 881 & 2407 \\
Nr of references & & & 157 \\
DISCIPLINARY DIVERSITY & 38 & 68 & 0.191 \\
Nr of journals & 0.173 & 0.186 & 0.222 \\
Rao-Stirling & 0.225 & 0.215 & 32 \\
Rao-Stirling (control) & & 16 & 2,96 \\
GEOGRAPHICAL DIVERSITY & 8 & 2,45 & $10(31 \%)$ \\
Number of countries & 1,59 & $7(44 \%)$ & $17(10 \%)$ \\
Shannon's H & $2(25 \%)$ & $8(24 \%)$ & 0,80 \\
Non-OECD countries & $2(7 \%)$ & & \\
Non-OECD authorship & & 0,75 & \\
\hline CONCEPTUAL INTEGRATION & 0,59 & & \\
Density & & & \\
\hline
\end{tabular}

Note: Disciplinary diversity is based on the references of core publications. The Rao-Stirling measure provides an index between 0 and 1, with a higher value indicating a larger diversity of cited references (see also Figure 6.2). Geographical diversity is based the country of authors of core publications. Shannon's H provides a measure of diversity taking into account number and balance of countries, with a higher value representing a higher diversity. In addition, the number of countries and authorships from outside the OECD was calculated. Conceptual integration is based on the density of the co-word maps of abstract words (see Figure 6.4). 


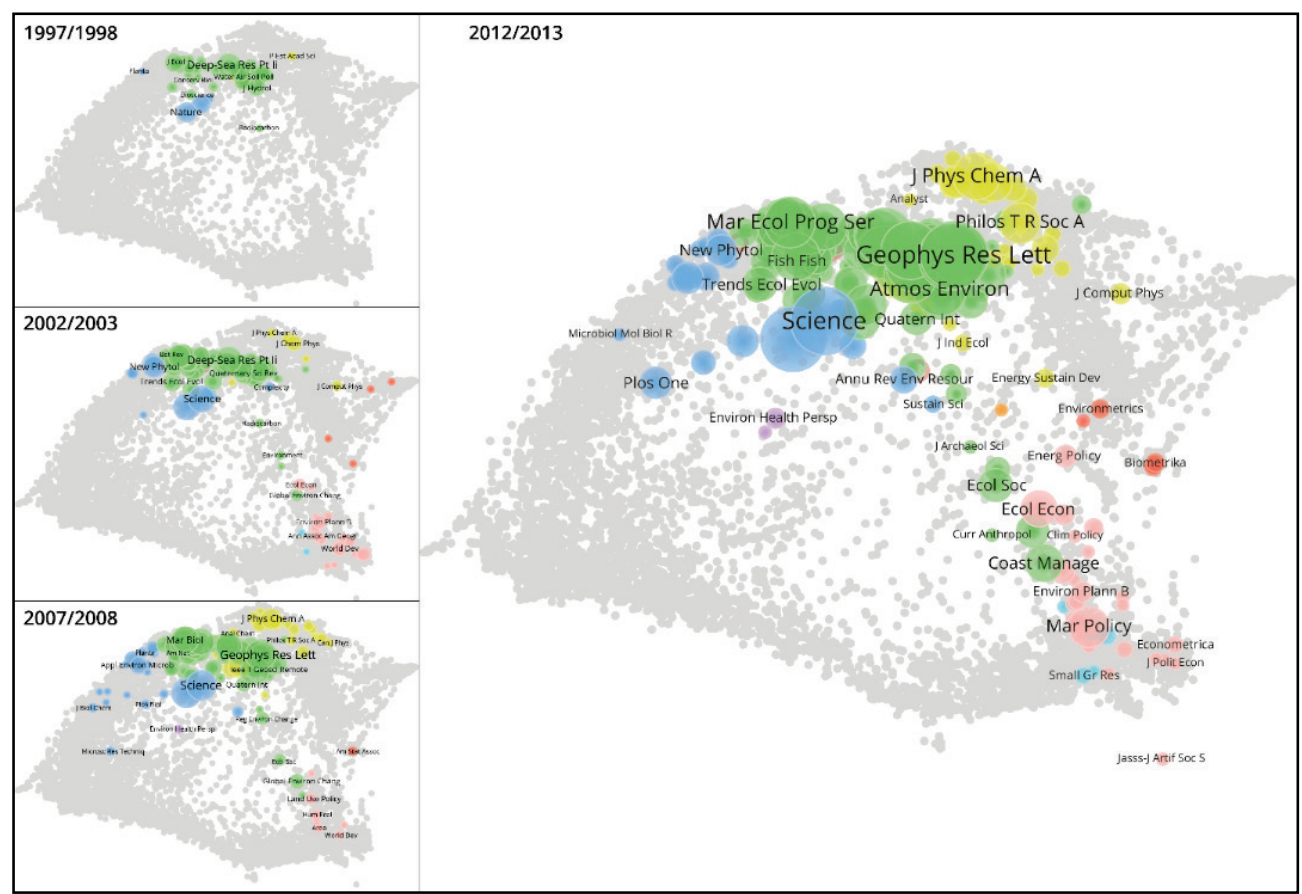

\section{Figure 6.1 References of IGBP core publications projected on global journal map}

Projection of IGBP references on a global map of scientific journals. Areas on the map represent different (disciplinary) domains of science (Leydesdorff et al., 2013; Leydesdorff and Rafols, 2012). The overlay maps were produced using VOSviewer. The colours represent clusters of journals. Broadly speaking, the green cluster contains journals concerned with environmental issues, including geosciences and ecology; yellow contains chemistry and physics; blue contains multi-disciplinary journals such as Science and Nature; pink contains management, economics, and policy-oriented journals. The size of the circles reflects the number of references. 


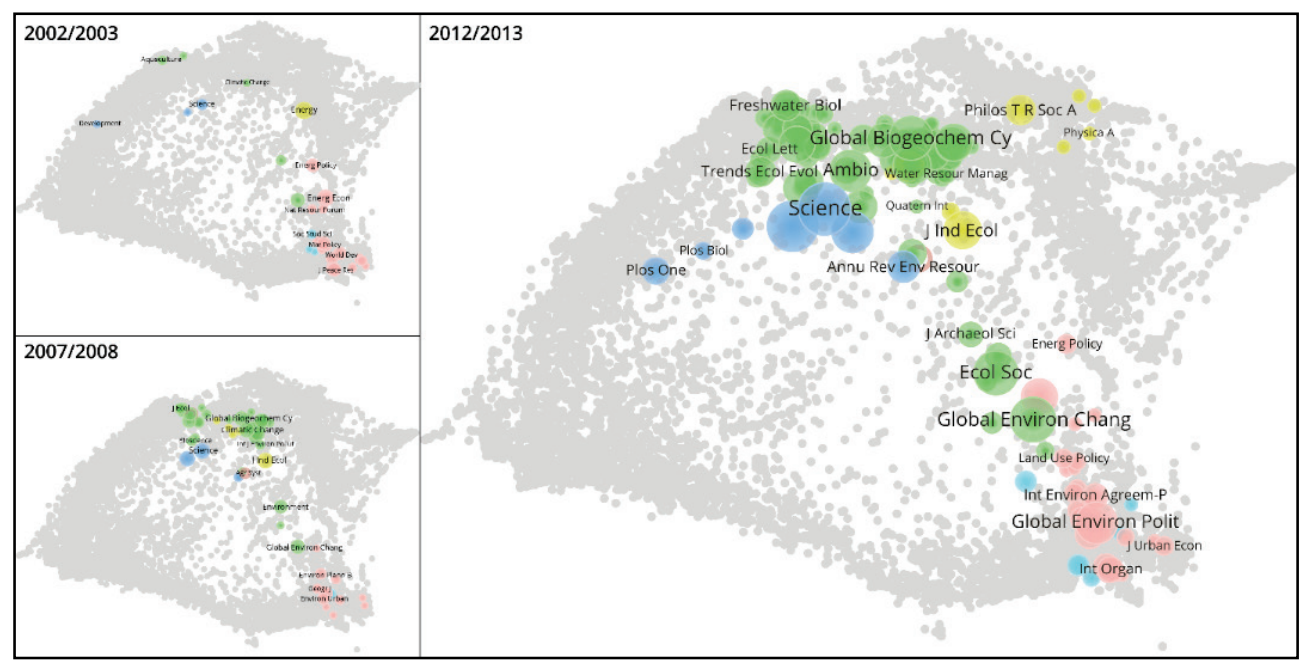

Figure 6.2 References of IHDP core publications projected on global journal map

Projection of IHDP references on a global map of scientific journals. Areas on the map represent different (disciplinary) domains of science (Leydesdorff et al., 2013; Leydesdorff and Rafols, 2012). The overlay maps were produced using VOSviewer. Colours represent clusters of journals. Broadly speaking, the green cluster contains journals concerned with environmental issues, including geosciences and ecology; yellow contains chemistry and physics; blue contains multi-disciplinary journals such as Science and Nature; pink contains management, economics, and policy-oriented journals. The size of the circles reflects the number of references. 


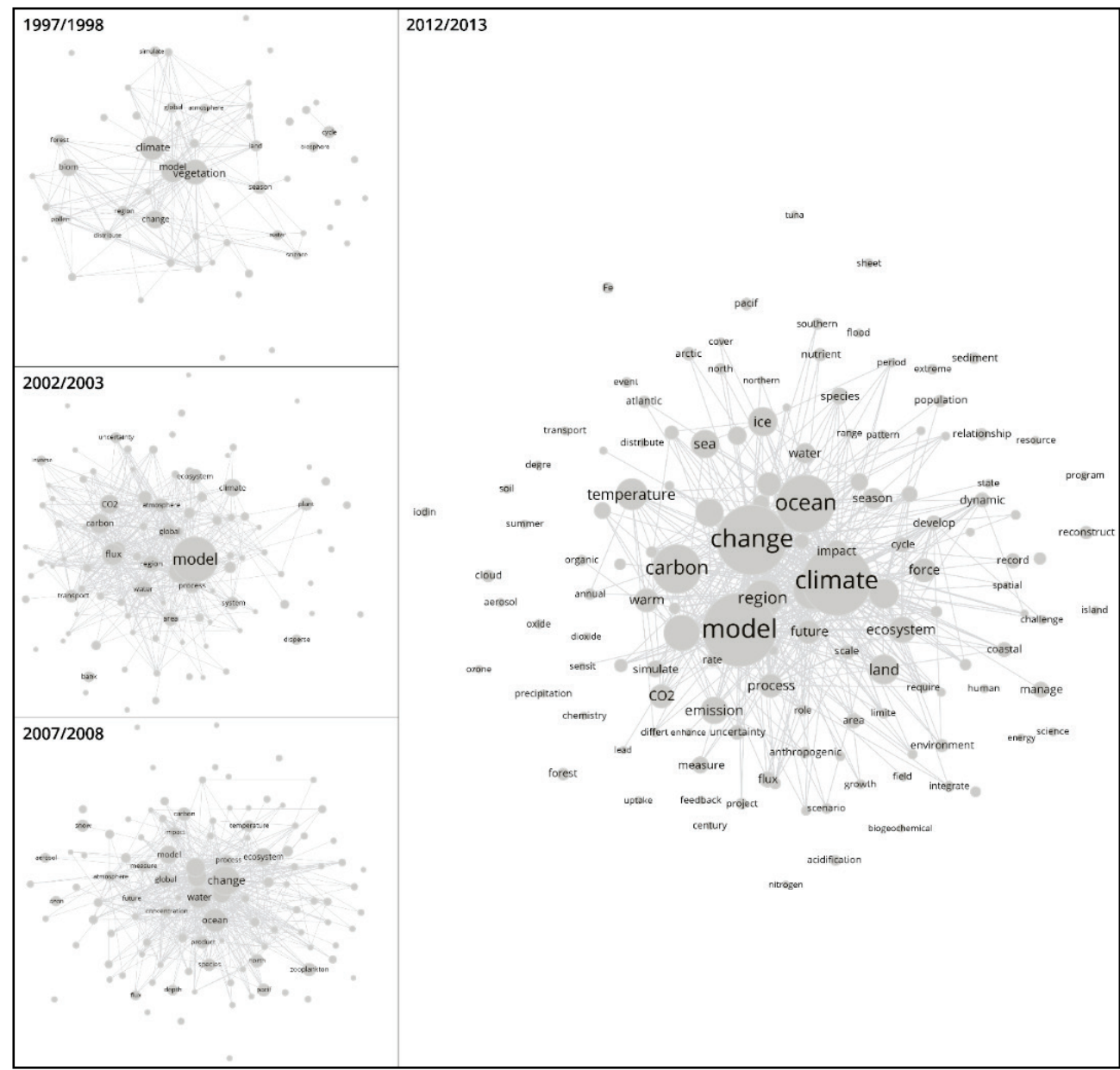

Figure 6.3 Co-word maps of abstract words of IGBP core publications

Semantic mapping of abstracts based on the $5 \%$ most frequently used words. The software programme UCINET 6 for Windows was used to compute the networks and VOSviewer was used to produce the visualisations. Lines connect word pairs that occur in the same abstract. Size of the circles represents frequency of occurrence. 


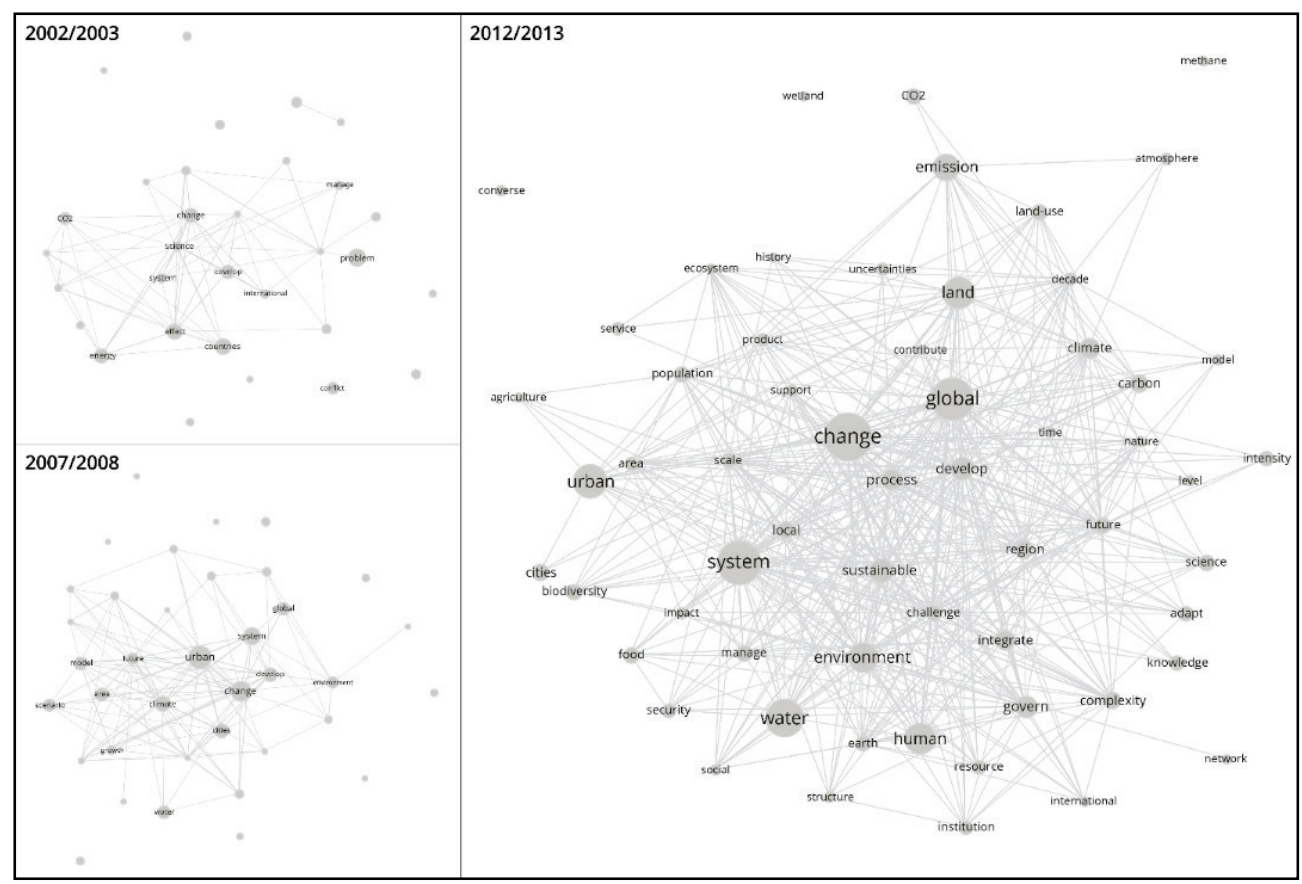

Figure 6.4 Co-word maps of abstract words of IHDP core publications

Semantic mapping of abstracts based on the $5 \%$ most frequently used words. The software programme UCINET 6 for Windows was used to compute the networks and VOSviewer was used to produce the visualisations. Lines connect word pairs that occur in the same abstract. Size of the circles represents frequency of occurrence. 


\subsubsection{Discussion of scientometric review}

This scientometric analysis of two major research programmes in global environmental change research explored whether research coordination has been conducive to disciplinary diversity, international collaboration, and the integration and synthesis of research. The results paint a mixed picture. Both programmes managed to develop a shared conceptual language over the studied period. Yet, diversification of the knowledge base occurred only with limited success, and in most cases reflected broader developments in the research field. This raises the question whether the observed diversification can be attributed to research coordination. Moreover, regardless of the repeatedly stated intention to build a global research programme, participation of non-OECD authors remained limited in both programmes.

There are some notable limitations to the insights that a scientometric analysis can provide on research coordination. First, this scientometric analysis focused exclusively on the influence of science coordination on scientific knowledge production. Other important functions of science coordination mechanisms, such as communication of science to a non-academic audience or facilitation of collaboration between scientists and non-scientists, where not included in the analysis. Second, the question remains to what extent developments in scientific output can be attributed to steering by science coordination mechanism or are the results of external developments. This study included a control set in order to account for the differences in development of the research programme and the broader research field. Nevertheless, it is important to remain careful when making causal claims. Future work could overcome some of these limitations by including more indicators to increase the sensitivity of the analysis, and by complementing scientometric insights with non-bibliometric methods such as interviews.

\subsection{CONCLUSION}

This chapter has critically reflected on the assumption that global coordination improves the performance of global change and sustainability research. The review of the literature pointed out that global research programmes, also without a large funding base, can be seen as coordination mechanisms that have the potential to shape research collaboration. Yet, knowledge on their actual outcomes and effects remains limited. The scientometric analysis of IGBP and IHDP built on and complemented these insights, and revealed that while science coordination contributed to interdisciplinary collaboration and conceptual integration, the objective of global collaboration was met with limited success. While IGBP and IHDP are now closed, coordination of global change and sustainability research continues under the new global research platform Future Earth (Berkhout, 2014; Future Earth, 2013). Based on the dual review in this chapter, I highlight some important aspects of global science coordination that warrant further reflection.

First, science coordination often aims to support multiple objectives which are not necessarily aligned. Prioritising a specific objective might, unwillingly and unintentionally, divert interest and resources from other functions of science coordination. This is reflected in the case of IGBP, where the focus on interdisciplinary collaboration and integration, appeared to come at 
the expense of international inclusiveness. Thus, careful reflection on potentials for conflict and synergies among the multiple objectives of science coordination is required. Second, the presence of a shared research approach can be both a blessing and a curse, as it shapes the contribution of research programmes and networks but might also constrain the involvement of research with disciplinary perspectives or geographical backgrounds not aligned with this shared approach. Related to this, there appears to be a tension between the importance of a strong and committed core community and the ability to attract and open up to new members and approaches. Finally, third, it is important to consider who participates in and shapes global research programmes (Lövbrand et al., 2015; chapter 5). Interdisciplinary and global inclusiveness are core objectives of science coordination mechanisms concerned with the future of our planet, yet particularly the later has only been addressed with limited success. At the same time, coordination mechanisms have the potential to make important conceptual contributions and shape the direction of a research domain. To support a meaningful contribution by global research programmes, platforms and networks, it is vital to ensure that such coordination builds on balanced and inclusive participation.

Given the large amount of energy and resources directed at science coordination today, the increasing prominence of science coordination mechanisms in multiple domains of research, and the need for greater collaboration across disciplinary and geographical boundaries, the benefits as well as limitations of global science coordination deserve to receive more careful scrutiny. Further in-depth study should provide insights into which coordination strategies work and which don't, under which conditions, and in which context. 


\section{7 - Normative and political dimensions of science for sustainability}

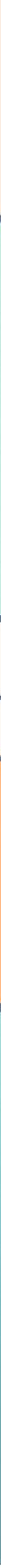


This chapter focuses on the solutions-oriented principle of science for sustainability. The ambition to provide solutions and support transformations to sustainability raises questions about the normative and political dimensions of science for sustainability. This chapter asks how sustainability researchers perceive and engage with these dimensions of their work. The chapter is based on a survey completed by 284 sustainability researchers. Based on the analysis of survey data, four groups of respondents are distinguished and classified by the following broad narratives: transformative research as speaking truth to power, transformative research as political act, responsibility for rigorous science, and humility on solutions potential. Several tensions within and between these perspectives exist, pertaining to the role of sustainability researchers in supporting societal transformations, the possibility and desirability of scientific independence and impartiality, and the appropriate relationship between science and politics. The chapter concludes by pointing to the need for more explicit engagement with the normative and political dimensions of science for sustainability.

Published as:

van der Hel, Sandra. 2018. Science for change: A survey on the normative and political dimensions of global sustainability research. Global Environmental Change, 52: 248-258. https://doi.org/10.1016/j.gloenvcha.2018.07.005 


\subsection{INTRODUCTION}

What is the appropriate relationship between science and politics? This question has triggered public and academic debates as old as the history of science itself. It surfaces yet again when we come to think about the role of science in supporting and enabling societal transformations towards sustainable futures.

Global change research has played a major role in advancing our understanding of the earth system and the major socio-environmental challenges faced by humanity today. In recent years, multiple interlinked processes have pushed the research community to shift its focus from understanding global environmental problems towards advancing solutions for sustainable futures (Belmont Forum et al., 2011; De Pryck \& Wanneau, 2017; European Science Foundation, 2012; Kowarsch \& Jabbour, 2017). A key example is the international research platform Future Earth: research for global sustainability which aims to support scientific knowledge production in pursuit of sustainability (Future Earth, 2014c; Moser, 2016). However, the ambitious objective to link scientific knowledge production to societal transformations requires not only a change in research practices and the organisation of knowledge systems (Cornell et al., 2013; Chapter 5), but also involves direct engagement with normative questions of what sustainable futures look like and how they can best be achieved (Kläy, Zimmermann, \& Schneider, 2015; T. R. Miller, 2013; Patterson et al., 2018; Schlaile et al., 2017; Schneidewind et al., 2016; Tschakert, Tuana, Westskog, Koelle, \& Afrika, 2016). In this context, the classic distinction between science and politics - where science attends to matters of facts and truth, whereas politics is about values, interests and power - appears misplaced (Lövbrand et al., 2015; Turnhout et al., 2016). Yet, how can and should researchers engage with the deeply normative and political dimensions of sustainability?

The answer to this question is anything but trivial. The ideal of global sustainability is filled with normative and political choices concerning possible and desirable futures as well as the pathways of getting there. With sustainability research taking an increasingly active and explicitly interventionist perspective on achieving sustainable futures, questions of values and politics thus become an inevitable component of science. Ignoring such dimensions restricts the ability of sustainability research to make a meaningful contribution to society.

Yet, although arguably at the core of a transformative approach to sustainability, questions of values and power in sustainability research have received limited attention in the academic literature (Lövbrand et al., 2015; Turnhout et al., 2016; van Kerkhoff \& Lebel, 2006; West, 2016). There are some notable exceptions, such as a study by Milkoreit and colleagues (2015) discussing values in resilience scholarship and by Miller (2013) discussing normative dimensions of sustainability science. However, we do not know how the vastly increasing and diverse community of sustainability researchers grapples with the normative and political dimensions of their work. Given the transformative potential of science for sustainability, this lack of attention to questions of values and politics is highly surprising and reason for concern (Rosendahl, Zanella, Rist, \& Weigelt, 2015). Therefore, this chapter aims to make these pertinent dimensions explicit and explore perspectives among sustainability researchers with 
respect to the normative orientation of science, the relationship between science and politics, and the role of sustainability research in society.

The research question for this chapter is therefore as follows: how do sustainability researchers perceive and engage with normative and political dimensions of their work? Normative dimensions, in this study, refer to the value-laden context, processes and consequences of science for sustainability. Political dimensions refer to the related implicit and explicit choices that shape both science for sustainability and its consequences for the way sustainability problems are understood and governed.

The chapter builds on the result of a survey conducted among researchers engaged in the global research platform Future Earth. The survey was informed by a literature review identifying different ways in which normative and political aspects are entangled in science for sustainability (Section 7.2). The survey approach was adopted with the aim to get an overview of different perceptions and attitudes within a diverse community of researchers (Section 7.3). Combining quantitative and qualitative analysis, four distinct clusters of respondents are identified reflecting different perceptions on science for sustainability (Section 7.4). The discussion elaborates on several core tensions (Section 7.5) and the conclusion encourages more explicit engagement with the normative and political dimensions of science for sustainability (Section 7.6).

\subsection{THEORETICAL CONTEXT}

\subsubsection{Action, solutions and societal change in science for sustainability}

Global change and sustainability research have become increasingly concerned with action, solutions and societal change (Lahsen, 2016; van Kerkhoff \& Lebel, 2006; West, 2016). As such, the focus of research is, at least in rhetoric, shifting from research on sustainability to research for sustainability (Jerneck et al., 2011; T. R. Miller, 2013; Schneidewind et al., 2016). That is, whereas global change and sustainability research build on a long tradition of describing and explaining major earth system transformations and societal processes, researchers are today increasingly challenged to advance the resolution of pressing sustainability problems and inform transformations towards sustainability (De Pryck \& Wanneau, 2017; T. R. Miller et al., 2014; Wiek et al., 2012). This shift in focus is accompanied with the normative claim that the responsibility of researchers should be extended from producing rigorous knowledge to the implementation of knowledge in society (Fazey et al., 2014; Mauser et al., 2013). In that sense, science for sustainability is recognised as an active process of intervention where science informs and facilitates societal transformations in order to avoid catastrophic environmental change (Fazey et al., 2018).

The turn towards transformative and solutions-oriented science for sustainability does not stand on its own. This development should be understood in a broader perspective of debates about the role of science in society. Notions of Mode- 2 knowledge production (Nowotny et al., 2003), transdisciplinarity (e.g. Julie Thompson Klein, 2014) and post-normal sciences (Funtowicz \& Ravetz, 1993) are influential descriptions of changes in science towards a system 
where knowledge production is more socially robust, increasingly interdisciplinary, oriented towards real world problems, co-produced with societal actors and more reflexive. The expanding literature around these and other concepts of changing modes of scientific knowledge production points towards changes in the relationship between science and society and the changing role of values in scientific knowledge production. Such perspectives on scientific knowledge production, however, stands in tensions with historically developed norms of science as objective, universal, value-free, and independent. The boundary between universal science (objective, autonomous, disinterested) and societal context (values, norms, interests) drawn by such norms is difficult to uphold for knowledge production that directly engages with complex, value-laden and urgent real-word issues (Caniglia et al., 2017; Funtowicz \& Ravetz, 1993; Lang et al., 2012)

Relating to these broader debates, scholars have argued that solutions-oriented and transformative research requires that researchers 'step out of their academic comfort zone' of objectivity and independence (Miller et al. 2014; Wittmayer and Schäpke 2014). Instead, sustainability researchers should directly and reflexively engage with the normative and political dimensions of their work. In this context, Fazey and colleagues (2018) argue that approaches to knowledge production "need to be able to take into account normative aspects, inequalities, politics and power, and work more directly across the interface of science and practice" (Fazey et al., 2018). Moreover, they state that conducting research that aims to be transformative (i.e. contributing to sustainable futures) places greater responsibility on the researcher to make explicit values and motivations and "actively seeks ways to work with [normativity] in a meaningful way" (Fazey et al., 2018). At the same time, concerns exist about the ambitious objectives and promises contained in the narrative of transformative and solutions-oriented science for sustainability. In particular, scholars have identified the need to be humble about the capacity of science to provide solutions for complex societal challenges (Kläy et al., 2015; Lövbrand et al., 2015; Stirling, 2014), and warn about the dangers of solutionism, where every problems appears to have a single solution and the role of values and power is ignored (Strohschneider, 2014). Moreover, some scholars have expressed concerns that the credibility and authority of science could be undermined by its direct engagement with value-laden discussions and political debates (Clark, van Kerkhoff, Lebel, \& Gallopin, 2016; Lacey, Howden, Cvitanovic, \& Dowd, 2015; Milkoreit et al., 2015).

The question that arises is how sustainability researchers make sense of the tension between historically developed scientific norms (such as objectivity and independence) and new objectives to inform and shape societal transformations to a more sustainable future. Although this question has been explored in conceptual and theoretical accounts, an understanding of how the research community engages with these tensions in day to day practices is lacking. The next section distinguishes different ways in which values and politics are entangled in science for sustainability, which are subsequently explore through empirical analysis. 


\subsubsection{Normative and political dimensions of science for sustainability}

The solutions-oriented and transformative focus of science for sustainability foregrounds the importance to take into account normative and political concerns. Yet, what are the different ways in which normative and political concerns are entangled with science for sustainability? Drawing on sustainability science, science and technology studies, science and policy studies and governance studies, I distinguish four ways in which normative and political dimensions are entangles in science for sustainability. In the remainder of this section I briefly discuss each dimension and its relevance for sustainability researchers (see Table 7.1 for an overview).

First, science for sustainability is set in a normative and political context. Although sustainability is well accepted in its general meaning, it is often strongly disputed when it comes to concrete terms and implementation. Sustainability is fundamentally a normative assertion concerning environmental and social values, conceptions of justice and ideals of desirable futures (Anderson, Teisl, \& Noblet, 2016). Moreover, transformations towards sustainability take place in a context of competing interests and power asymmetries (O'Brien, 2011; Patterson et al., 2016). Scholars have argued that sustainability researchers should take this normative and political context into account when addressing complex problems of sustainability and identifying possible solutions (T. R. Miller et al., 2014; Pohl et al., 2010; Wiek $\&$ Kay, 2015). Yet, as previous studies have pointed out, researchers may prefer different ways to engage with political debates and societal controversy (Turnhout, Hisschemöller, \& Eijsackers, 2008) and find different ways to balance normative aspirations with epistemic concerns (Milkoreit et al., 2015; T. R. Miller, 2013).

Second, as social studies of science have long held, it is important to pay attention to the socially situated and normative position of the researcher, as the standpoint of the researcher influences the research process and outcome, regardless of whether researchers are aware of these biases and make them explicit (Milkoreit et al., 2015; Rosendahl et al., 2015; West, 2016). While transparency about values and assumptions is a widely shared norm, it is often argued that sustainability researchers need to go further and take a reflexive stance with respect to personal and collective value-commitments and the way in which these affect knowledge claims (Mukhtarov, 2016; Pasgaard, Van Hecken, Ehammer, \& Strange, 2017; Popa, Guillermin, \& Dedeurwaerdere, 2014; Wittmayer \& Schäpke, 2014). Such an attitude increases researchers' awareness of their epistemic and normative positionality, which not only shape research priorities and questions but also affect which research approach will be taken and which stakeholders will be involved (Scholz, 2017; Wittmayer \& Schäpke, 2014). At the same time, the Enlightenment ideal of science as a value-neutral description of reality still appears to receive broad support. In this context, scientific objectivity may be perceived as a proxy for political neutrality, whereas subjectivity in the scientific enterprise is dismissed as practicing advocacy rather than science (Milkoreit et al., 2015; T. R. Miller, 2013).

Third, normative and political concerns are raised with respect to the external factors shaping science for sustainability. Through funding and other incentive structures, influential societal actors may disproportionally influence scientific agendas and outcomes (Österblom, Jouffray, 
Folke, \& Rockström, 2017; Tschakert et al., 2016; van Kerkhoff \& Lebel, 2015; Chapter 5; Chapter 9). This is not necessarily an intentional process, but rather a consequence of the specific context in which science for sustainability is set. However, for socially relevant and urgent issues of global change and sustainability, the allocation of resources and focus of research can have important societal consequences (Fazey et al., 2018; Lacey et al., 2015). Given the risk of science uncritically reproducing dominant discourses, it is argued that sustainability researchers "must be willing, and able, to stir things up by actively mobilizing counter-discourses and by articulating values and options that do not fit with the hegemonic discourse" (Wesselink, Buchanan, Georgiadou, \& Turnhout, 2013). This requires structural orientation to the ways in which policy discourses and power structures affect scientific research, rather than assuming a power-free and policy neutral research context (Tschakert et al., 2016; Wesselink et al., 2013). Moreover, it requires attention to differently positioned stakeholders, including not only influential but also marginalised societal groups (Tschakert et al., 2016).

Table 7.1. Normative and political dimensions of science for sustainability

\begin{tabular}{|lll|}
\hline DIMENSION & KEY POINTS & RELEVANCE FOR RESEARCHERS \\
\hline $\begin{array}{l}\text { I. Normative and } \\
\text { political context }\end{array}$ & $\begin{array}{l}\text { Sustainability as a normative aspiration } \\
\text { Context of competing interests and } \\
\text { power asymmetries }\end{array}$ & $\begin{array}{l}\text { Values and politics as part of problem } \\
\text { identification and analysis }\end{array}$ \\
$\begin{array}{l}\text { II. Standpoint and } \\
\text { values of researcher }\end{array}$ & $\begin{array}{l}\text { Knowledge claims are socially situated } \\
\text { and partial } \\
\text { Standpoint of researcher influences } \\
\text { research process and outcomes }\end{array}$ & $\begin{array}{l}\text { Awareness of epistemic and normative } \\
\text { positionality } \\
\text { Importance of transparency and } \\
\text { reflexivity }\end{array}$ \\
\hline $\begin{array}{l}\text { III. Power structures } \\
\text { and asymmetries }\end{array}$ & $\begin{array}{l}\text { Power asymmetries in society affect } \\
\text { scientific knowledge production }\end{array}$ & $\begin{array}{l}\text { Influence on research agendas and } \\
\text { outcomes } \\
\text { Risk of reproducing dominant } \\
\text { discourses }\end{array}$ \\
\hline $\begin{array}{l}\text { IV. (Epistemic) power } \\
\text { of scientific knowledge }\end{array}$ & $\begin{array}{l}\text { Science influences societal and political } \\
\text { debates in complex and important ways }\end{array}$ & $\begin{array}{l}\text { Responsibility of researchers } \\
\text { Reflexive of societal role }\end{array}$ \\
\hline
\end{tabular}

Finally, fourth, the (epistemic) power of scientific knowledge affects how we understand and act upon the world around us (Lövbrand, Stripple, \& Wiman, 2009; Turnhout et al., 2016; Wesselink et al., 2013). Several studies show how science influences societal and political debates in complex and important ways, for example by constructing categories such as ecosystem services that hence become amenable for governance (Turnhout, Hisschemöller, \& Eijsackers, 2007) or by conditioning an imaginary of climate change as a global-scale environmental problem in need of effective governance (Demeritt, 2001; C. A. Miller \& Edwards, 2001). Science supports and helps shape certain problem framings and policy discourses, attracts particular actors as target audience and may privilege certain solutions over others (Turnhout et al., 2016; Wesselink et al., 2013). In this context, scholars have identified sustainability researchers as political actors that are engaged in the process of changing and 
shaping society (Jahn, Bergmann, \& Keil, 2012; Turnhout et al., 2016; Wittmayer \& Schäpke, 2014). As argued by several scholars, given this tight embrace between knowledge and power, it is important that researchers have a reflexive attitude concerning the political choices implicit in the discourses they work within and help establish (Fazey et al., 2018; Wesselink et al., 2013).

To sum up, normative and political aspects are entangled in science for sustainability through the value-laden context of research, the standpoint and values of researchers, the societal structures and power asymmetries that shape the research landscape, and the epistemic power of science. These dimensions do not represent strictly separated categories but rather interlinked aspects of scientific knowledge production for sustainability. Here, they are used heuristically as a way to capture the different aspects of science for sustainability and structure the empirical analysis.

\subsection{MATERIALS AND METHODS}

The normative and political dimensions of science for sustainability distinguished above are further explores through a survey among sustainability researchers. The survey approach was adopted in order to provide insight in different patterns of thought and their spread across the community, and, by doing so, give an empirical context to thus far largely theoretical and conceptual debates on the normative and political dimensions of science for sustainability.

\subsubsection{Case study: Future Earth}

Context for the survey is the global research platform Future Earth: research for global sustainability. This research platform, launched in 2012, brings together researchers from multiple scientific disciplines and different countries globally around the common theme of global sustainability. Future Earth aims to support interdisciplinary, inclusive, co-produced and solutions-oriented science for sustainability. The research network includes researchers working on issue areas ranging from atmospheric chemistry to land-use change to environmental governance. Given the ambitious objective of Future Earth to inform and shape transformations towards global sustainability, questions about normative and political dimensions touch upon its core.

\subsubsection{Survey design}

The survey included statements related to the ideal of transformative and solutions-oriented research for sustainability, as well as statements for each of the four normative and political dimensions of science for sustainability distinguished through the literature review. The survey statements reflect different ways in which researchers perceive and believe they should act with respect to the normative and political dimensions of their work. The set of statements includes items reflecting individual believes and attitudes as well as collective responsibilities. This diversity of statements was chosen in order to capture a wide range of views. Formulation of the statements was informed by earlier surveys addressing related topics (Hoppe, 2009; Rudd, 2015; Spruijt, Knol, Petersen, \& Lebret, 2016). The statements were tested during three roundtable discussions at a Future Earth meeting in Bern, Switzerland (June 2016) and adjusted based on feedback provided by the participants. 
Survey respondents were asked to indicate their (dis)agreement with these statement on a fivepoint Likert scale (ranging from strongly disagree to strongly agree). At the end of each set of statements, respondents were asked to provide written comments. In addition, the survey included questions about the role of researchers in society and background questions, such as age, discipline, career level and region of residence.

Table 7.2 Survey response

\begin{tabular}{|ll|}
\hline GENDER & N \\
Male & \\
Female & 133 \\
No answer & 131 \\
\hline CAREER LEVEL & 20 \\
\hline PhD/junior researcher & \\
Post-doctoral researcher & 94 \\
Senior researcher & 25 \\
Full professor & 77 \\
Other & 38 \\
No answer & 41 \\
\hline DISCIPLINE & 9 \\
Natural sciences & \\
Social sciences & 70 \\
Interdisciplinary sciences & 77 \\
Professional or applied sciences & 91 \\
Other & 16 \\
No answer & 20 \\
\hline REGION OF RESIDENCE & 10 \\
Europe & \\
North America & 118 \\
Latin America and Caribbean & 18 \\
Asia & 29 \\
Africa & 13 \\
Oceania & 29 \\
No answer & 21 \\
\hline TOTAL & $\mathbf{2 8 4}$ \\
\hline
\end{tabular}

\subsubsection{Survey distribution and response}

A request to participate in the survey was posted on Future Earth's website, and the survey was distributed through Future Earth's social media channels. In addition, the survey was circulated by the various research projects, regional networks and other initiatives operating under the umbrella of Future Earth. Responses were collected during October and November 2016 using SurveyMonkey software. 
A total of 284 respondents completed the survey. The sample is self-selected and statistically non-representative of the population of researchers engaged in Future Earth ${ }^{20}$. Nevertheless, a diverse set of respondents was reached, reflecting different disciplinary perspective on science for sustainability, as well as different geographical regions and career-levels. From the 43 active projects operating under the umbrella of Future Earth at the time of the survey, 39 projects were represented in the survey sample by at least 2 respondents. The geographical composition of the sample, including the dominance of researchers from the Global North, is similar to the geographical spread of researchers participating in Future Earth's online platform (Future Earth, 2016a). Characteristics of the sample are provided in Table 7.2.

\subsubsection{Analysis of survey data}

The data analysis combines quantitative analysis of survey responses with a qualitative analysis of written comments. The quantitative part of the analysis consisted of a cluster analysis of the response to 24 statements on transformative research and its normative and political dimensions. Cluster analysis is a well-established method in the social sciences to classify observations into groups and has been used across a wide variety of fields (Barr, Shaw, \& Coles, 2011; De Witt, de Boer, Hedlund, \& Osseweijer, 2016; Feola \& Nunes, 2014; Graham, Barnett, Fincher, Hurlimann, \& Mortreux, 2014; Reyes-García et al., 2014; Turner et al., 2014). The aim of the cluster analysis was to identify similarities in response patterns, which can be more insightful than analysing responses to each statement separately. The validity of a cluster analysis depends largely on the survey items used as input for the analysis. The selected items should be sufficiently comprehensive and diverse to capture the various dimensions of the investigated phenomenon. The set of 24 statements used in this analysis was, as explained above, derived through a literature review with the aim to capture different normative and political dimensions of science for sustainability. Moreover, the statements were formulated in such a way as to allow for a broad variety of responses.

The cluster analysis consisted of several steps. First, a hierarchical clustering was conducted using Ward's approach with a squared Euclidean distance measure. Based on an initial review of the results, the four cluster solution was selected for further analysis as it produced clearly distinguishable groups of respondents with distinct responses to the selected statements. Second, the cluster solution was optimised by using the cluster means from the hierarchical clustering as input for a K-means cluster analysis. This combination of hierarchical and Kmean cluster methods minimises within cluster variance while maximising variance between clusters (see for example Ramm et al., 2017 and De Witt et al., 2016). The third step was to distinguish the characteristics of the respondents in each cluster and identify significant

\footnotetext{
${ }^{20}$ The exact composition of the community of researchers engaged in Future Earth is unclear, making it impossible to determine whether the researchers reached with this survey are representative of the network. In some of its external communication, Future Earth refers to a community of 50.000 researchers (Future Earth, n.d.). However, no comprehensive database of this community exists. Probably a better reference is formed by the 2778 followers on Facebook, 2700 followers on Twitter, and 3000+ individuals signed up to Future Earth online platform called the 'Open Network' (Future Earth, 2017).
} 
differences between the clusters using Chi-square tests. The analysis was conducted using SPSS 24 for Windows.

In addition, written responses to the open questions in the survey were analysed to enrich the cluster interpretation and provide additional insights on the way researchers perceive and experience the normative and political dimensions of their work. A total of 312 written comments were received, provided by 143 out of 284 respondents. Written responses were first organised per cluster and then analysed thematically using the qualitative data analysis software NVivo 11 for Windows. The coding scheme was based on the literature and included relevant sub-codes for each of the four dimensions (Table 7.1). The results of the coding process informed the cluster interpretation. Additionally, three core tensions were identified with respect to the role of sustainability researchers in societal transformations, the possibility and desirability of scientific independence and impartiality, and the appropriate relationship between science and politics (discussion in Section 7.5).

Overall, researchers engaged in Future Earth and participating in the survey support the objective of transformative research for sustainability. Most respondents strongly agree (42\%) or agree $(43 \%)$ that scientists should actively seek solutions for sustainability challenges through their research. Likewise, most respondents strongly agree (44\%) or agree (43\%) that it is their responsibility as a researcher to contribute to societal change towards sustainability. Less than $10 \%$ of respondents disagreed with either or both of these statements. Responses are more diverse when it comes to perspectives on the normative and political dimensions of transformative research. In particular, respondents hold different views with respect to the way researchers should engage with political debates and societal controversies around sustainability. Although most respondents recognised the importance of being transparent about their values and interests, ideas about the possibility and desirability of impartiality differed. Overall, respondents were least outspoken on the statements concerning external power structures. While responses to the statements on the (epistemic) power of scientific knowledge again reflect diverse perspectives (see Table 7.3 for an overview of the response to all statements). 


\begin{tabular}{|c|c|c|c|c|c|c|}
\hline & & \multicolumn{5}{|c|}{ 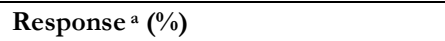 } \\
\hline \multicolumn{2}{|r|}{ STATEMENTS ON TRANSFORMATIVE SUSTAINABILITY RESEARCH } & 1 & 2 & 3 & 4 & 5 \\
\hline 1 & It is my responsibility as a scientist to contribute to societal change towards sustainability & 2,5 & 3,2 & 9,2 & 41,5 & 43,6 \\
\hline 2 & Through my research, I actively seek solutions for sustainability challenges & 1,8 & 3,9 & 9,3 & 43,1 & 42,0 \\
\hline 3 & As scientists, we need to be humble about the capacity of our research to provide solutions for sustainability challenges & 3,2 & 12,1 & 13,2 & 42,5 & 28,9 \\
\hline 4 & My job as a scientist does not stop at producing rigorous science, it also includes the implementation of knowledge in society & 1,4 & 8,6 & 13,3 & 46,6 & 30,1 \\
\hline \multicolumn{7}{|c|}{ STATEMENTS ON NORMATIVE AND POLITICAL DIMENSIONS OF SUSTAINABILITY RESEARCH } \\
\hline \multicolumn{7}{|c|}{ I. Normative and political context of sustainability research } \\
\hline 5 & When addressing complex problems of sustainability, science cannot isolate itself from politics & 0,4 & 9,6 & 10,0 & 46,3 & 33,8 \\
\hline 6 & As a scientist you risk producing irrelevant knowledge if you ignore the political context of your research & 4,9 & 19,8 & 15,2 & 37,5 & 22,6 \\
\hline 7 & In a situation of societal controversy, it is impossible for scientists to take an independent position & 6,1 & 33,1 & 22,7 & 32,4 & 5,8 \\
\hline 8 & Science's job is to clarify the facts based on which political decisions can be made & 5,0 & 11,0 & 19,1 & 44,3 & 20,6 \\
\hline 9 & Good scientific solutions are too often spoiled by politics & 1,8 & 16,8 & 27,6 & 35,5 & 18,3 \\
\hline \multicolumn{7}{|c|}{ II. Standpoint and values of researcher } \\
\hline 10 & In the value-laden context of sustainability research, scientists need to be open about their own values and interests & 1,1 & 2,5 & 11,3 & 52,7 & 32,4 \\
\hline 11 & The research process is never free from personal biases & 1,8 & 7,2 & 10,8 & 50,7 & 29,5 \\
\hline 12 & My personal values do not affect the way I conduct my research & 18,3 & 42,8 & 18,7 & 16,9 & 3,2 \\
\hline 13 & I find it important to keep an impartial position on the issues I address in my research & 1,1 & 18,2 & 24,4 & 43,6 & 12,7 \\
\hline 14 & I do not advocate specific societal changes, as this would undermine my credibility as a scientist & 20,4 & 48,9 & 17,1 & 12,1 & 1,4 \\
\hline \multicolumn{7}{|c|}{ III. Power structures and asymmetries } \\
\hline 15 & Scientists must be careful not to reaffirm dominant world views & 0,4 & 8,8 & 34,9 & 36,4 & 19,5 \\
\hline 16 & To get my research funded, I make sure that it aligns with current policy agendas & 5,9 & 18,6 & 37,2 & 30,5 & 7,8 \\
\hline 17 & I am hesitant to accept funding from private funding agencies as this may harm my independent position as a scientist & 5,2 & 28,1 & 39,6 & 20,4 & 6,7 \\
\hline 18 & I believe it is my responsibility as a scientist to encourage the participation of marginal societal groups in my research & 3,3 & 10,3 & 23,6 & 43,5 & 19,2 \\
\hline 19 & To make a difference in society, I believe it is important to work together with influential societal actors & 0,4 & 3,3 & 17,2 & 58,2 & 20,9 \\
\hline \multicolumn{7}{|c|}{ IV. (Epistemic) power of scientific knowledge } \\
\hline 20 & Scientists are political actors engaged in the process of shaping and changing society & 3,5 & 13,1 & 21,6 & 43,5 & 18,4 \\
\hline 21 & Science's ability to speak truth to power makes it a valuable factor in the transition to sustainability & 2,5 & 7,4 & 12,4 & 49,3 & 28,4 \\
\hline 22 & In my work as a scientist, I aim to be policy relevant but not prescriptive & 1,4 & 13,5 & 22,8 & 47,3 & 14,9 \\
\hline 23 & Only knowledge produced by the scientific method can provide an objective perspective on the situation at hand & 16,7 & 33,7 & 21,9 & 22,6 & 5,2 \\
\hline 24 & The value of lay and practitioner knowledge in addressing sustainability problems is often underestimated & 0,0 & 2,2 & 15,9 & 48,9 & 33,0 \\
\hline
\end{tabular}

Response: strongly disagree (1), disagree (2), neither agree nor disagree (3), agree (4), strongly agree (5) 


\subsection{RESULTS}

\subsubsection{Cluster solution}

Based on the cluster analysis, four groups of respondents are identified (see Figure 7.1). The chosen method assigns each respondent to one of the four clusters based on the similarity of responses across the 24 statements. The identified clusters are discussed in turn below and illustrated with quotes derived from the open questions in the survey.

\section{Cluster 1: Transformative research by speaking truth to power}

This first cluster is the largest of the four identified clusters with 104 respondents. Researchers in this cluster strongly agree with the objectives of transformative research for sustainability. That is, respondents aim to contribute to societal change, seek solutions for sustainability challenges and contribute to the implementation of scientific knowledge in society. In particular, respondents point to the need for scientists to take an active role in providing the scientific knowledge base for political decision-making.

[] t's important to understand one's limitations, but there is also a problem of scientists not wanting to speak out about general problems because they only consider themselves knowing a bit of it. Most times a bit of scientific knowledge, although not allencompassing, is better than policy without any fact base at all.

While most respondents in this cluster agree that researchers in sustainability need to be transparent about their personal values and interests, they also find it important to seek an impartial position. In particular, respondents appear to make a distinction between the way normative decisions affect their selection of research topics, and the way normative aspects affect the research process. While respondents recognise the value-laden decisions that shape research agendas, the research process - in the view of respondents - should be free from normative aspects to the greatest extent possible.

I design research projects in response to the information needs of others, but the methods I use and results I report are unaffected by external factors.

[1] believe that it is possible to be rigorous in not allowing bias to taint your work, while maintaining strong personal views and opinions.

There is strong overall agreement that science's ability to speak truth to power makes it a valuable factor in the transition to sustainability. Most respondents agree that science should be policy relevant but not prescriptive.

I am doing research to have credibility in the political arena. I think it's important to speak truth to power, and as a part of that [change the] system from the inside. I hope to use my research to affect political change.

I specifically try to remain policy relevant and not policy prescriptive. For example, if we (we broadly, a city, nation or the world) are aiming to achieve something like the 2 degree target, there are any number of ways that this could be achieved $[. .$.$] as a scientist I can$ 
provide information as to the implications of any of these options, but which one is chosen is a matter of politics.

Finally, working with (influential) societal actors is perceived as an important aspect of transformative research for sustainability. Respondents point out that working with societal actors establishes trust, which is considered of particular importance when addressing valueladen issues of sustainability. Moreover, respondents in this cluster focus on working with actors that have an influence 'on-the-ground' in order to enhance the impact of research in society.

Overall, researchers in this cluster, while acknowledging the social, normative and political dimensions of sustainability, tend to draw a line between the domains of science and politics. This is reflected in the societal role they see for themselves ('speaking truth to power') and the importance that is placed on scientific norms of independence and impartiality.

\section{Cluster 2: Transformative research as political act}

Similar to cluster one, the 88 respondents in this cluster strongly agree with the objectives of transformative research for sustainability. They also agree that science cannot isolate from politics when addressing sustainability issues and worry that science will produce irrelevant knowledge if the political context of research is ignored. However, unlike respondents in the first cluster, respondents in this cluster emphasise the political nature of scientific knowledge production.

Science has vested interests and ideologies just the same as any aspect of society, including politics. It is not possible to draw distinct lines between where science and policy start and finish, it is blurred and fluid.

Once you step into arenas where you are engaging with social or political change as a scientist you are engaging with politics. [It is] better to acknowledge [that] than to pretend otherwise.

Whereas respondents in the first cluster were generally concerned about the way values influence their work and said to strive towards neutrality and impartiality, researchers in this second cluster commented that impartiality is not only impossible to achieve, but also undesirable in the context of urgent sustainability problems. Rather than striving for impartiality, researchers should be stepping up and making a statement against unsustainable practices and systems. Respondents stressed the need to build such actions on rigorous science but are not generally concerned that advocating specific societal changes would affect their scientific credibility.

Sustainability in the face of catastrophic environmental change [is] not an impartial issue if one values the present and future of humanity on Earth. To me, avoiding discussion of values would be biasing the research!

The social consequences of sustainability research are so great it is impossible to be completely detached, and nor should we be. At the same time, it is important to ensure 
(and to demonstrate) that the actual research is conducted rigorously. Openness and transparency [are] important here.

More than for other clusters, researchers in this cluster are concerned about power structures and asymmetries shaping scientific research. Respondents commented on the way research funding, and the context of research more generally, is heavily influenced by politics. In particular, respondents commented on the role of research funding shaping research directions in ways that might not be the most meaningful or relevant to societal transformations.

[Funding decisions] tie science to the currently dominant and fashionable perspectives in society [which] risks damaging the value of science for the longer run.

Moreover, respondents in this cluster believe that it is their responsibility as researchers to enable the participation of societal actors in scientific research. Respondents commented in particular on the need to encourage and enable the participation of actors that are less commonly heard and represented in sustainability debates and processes of change. Finally, respondents in this cluster most strongly agree that the value of lay and practitioner knowledge in addressing sustainability problems is often underestimated. The statement that only knowledge produced by the scientific method can provide an objective perspective on the situation at hand is strongly dismissed.

Altogether, this cluster is characterised by strong overall agreement with the notion of scientists as political actors engaged in the process of shaping and changing society. Respondents perceive the domains of science and politics as blurred and identify important implications for the practice of sustainability researchers.

\section{Cluster 3: Responsibility for rigorous science}

Although the 44 respondents in the third cluster generally agree with the objectives of transformative research for sustainability, agreement is less strong than for the previous two clusters. In particular, respondents show reservation with respect to the responsibility of researchers for the implementation of scientific knowledge in society.

Other than in the previous two clusters, researchers in this cluster are hesitant when it comes to direct engagement with the normative and political dimension of sustainability. Instead, they stress the responsibility of researchers to do their work with 'rigour' and 'honesty'. There appear to be different views on the extent to which science can operate fully independent, yet respondents share the perspective that science cannot provide a satisfactory answer to normative and political concerns. Although scientific research can provide an important input for transformations to sustainability, discussion of norms and values, as stressed by respondents in this cluster, belong in the public sphere.

I see myself as someone who tries to do science with the highest possible rigor and honesty to inform policy, but I am neither fully independent nor political. 
Science can tell us the "what is" or "how things are" but what should be or how things should be belongs in the public process of subjective, democratic deliberation (but founded on sound facts).

Engaging with extra-scientific actors is perceived as a way to make available different perspectives beyond those of the researcher. In this way, the researcher can stimulate a normative discussion, without becoming directly engaged in normative decisions herself. Researchers in this cluster are least inclined to express their own values and interest when working on contested sustainability issues.

I think the results of my research can raise awareness of the different dimensions a problem entails (social, ecological, short-vs. long term, effects for different groups of the population and different scales). It points towards the system dynamics. [However,] the implementation and specific solution/decision is up to the people acting in these socioecological systems.

Overall, researchers in this cluster do not see scientists as political actors. Rather, they stress the value of scientific knowledge to inform normative discussion and political debates, while researchers themselves should strive for rigour, honesty and impartiality to the largest extent possible.

\section{Cluster 4: Humility on solutions potential}

The 48 respondents in this fourth and final cluster generally agree with the objectives of transformative research for sustainability, but, as for cluster three, they express multiple concerns. In particular, what stands out for this cluster is the perspective that scientists should be humble about the capacity of research to provide solutions for sustainability challenges. Some respondents shared the concern that they lack the necessary skills, time, training or experience to contribute directly to sustainability solutions. Others point out that scientists have no special privileged position when it comes to making societal decisions about how to resolve sustainability problems.

Science is one form of knowledge, that is occasionally useful; with other knowledge it interacts with values and institutions in society to shape new institutions [and] guide behaviours.

I think my - and any other sustainability science contribution - can only deliver partial solutions to sustainability problems. [...] Impact - in terms of societal change/transition - cannot be traced back to single projects. It is embedded into a network of impulses, research is only one.

Respondents in this cluster agree that research on sustainability cannot operate in isolation of normative and political concerns. Similar to cluster two, respondents are conscious about the way epistemic and normative values influence not only the selection of research topics but also the research process and outcomes. Moreover, and again similar to cluster two, the importance of transparency is stressed. 
Sustainability science is fundamentally normative, even if you don't recommend specific societal changes, advocating (or helping stimulate) societal change (of any form) is not neutral. Credibility comes from being transparent about the normative dimension of science, not pretending it has none.

In line with this perspective, respondents question the notion of objective knowledge and scientific facts. They stress that (scientific) solutions are always constructed, partial and political. This puts a responsibility on the researcher seeking societal change to work in partnership with other societal actors. Moreover, and consistent with the importance placed on humility, respondents in this cluster emphasise the need to recognise and value other types of knowledge contributing to sustainability. They see scientific knowledge as one among many ways of knowing and acting that are important when it comes to questions of sustainability.

$[\mathrm{F}]$ acts are temporary, conditional context specific beliefs that can hopefully be verified and replicated. Facts do not transcend contexts and [are] almost always partial in any decision problem.

$[\mathrm{N}] \mathrm{o}$ science is objective; it may be more repeatable in a controlled context, but other knowledge may provide a more accurate (contextually appropriate) perspective on an issue.

Thus, respondents in this cluster emphasise the complex entanglements between scientific, normative and political concerns and value humility in the engagement of science for sustainability. 

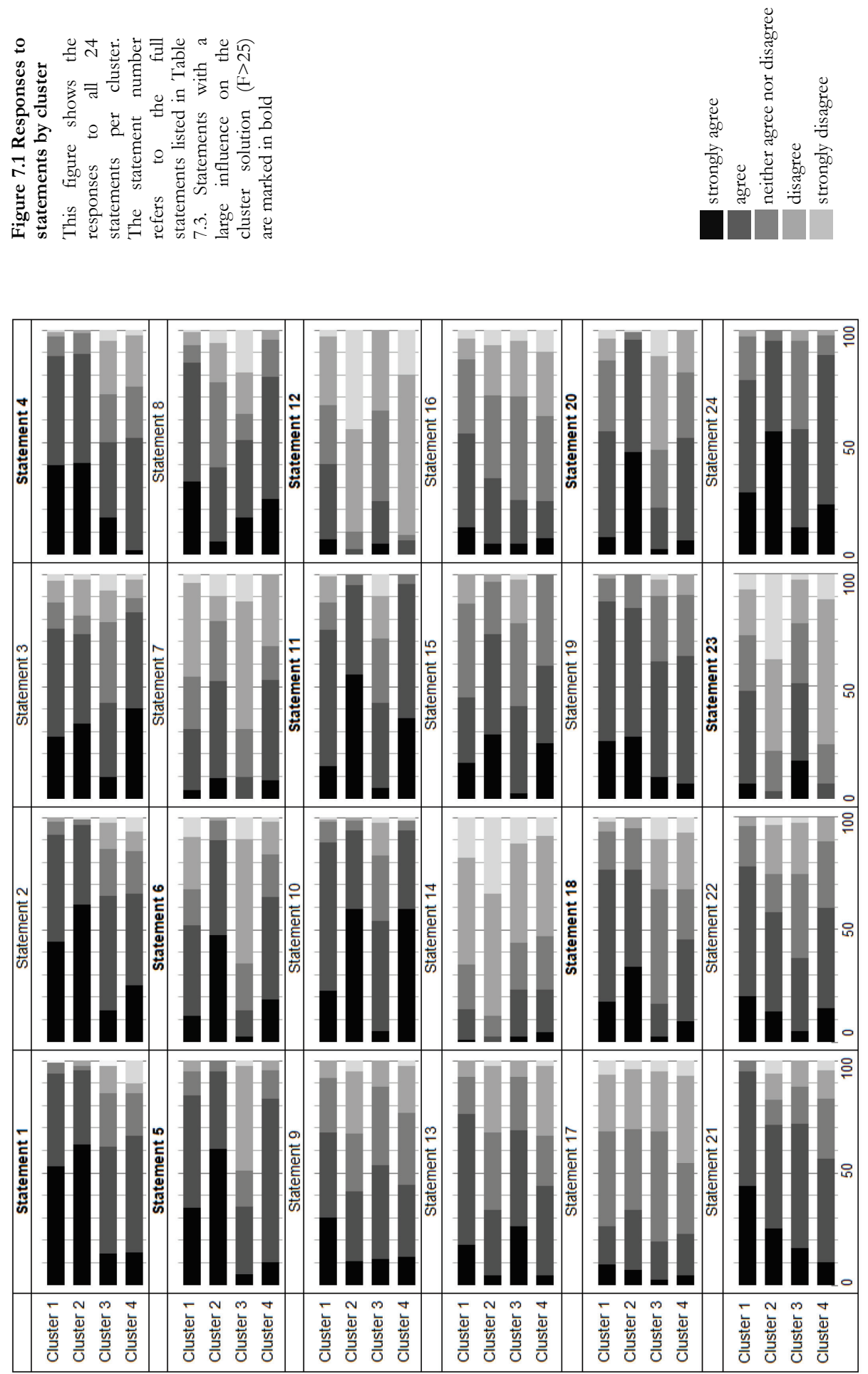


\subsubsection{Comparing cluster composition}

The community of sustainability researchers is diverse, including researchers at different career-levels and with different disciplinary and geographical backgrounds. How do these characteristics relate to the four identified clusters? In terms of gender, age and career level, no significant difference in cluster composition was found. This suggests that the identified clusters represent perspectives that are spread across the community rather than reflecting the views of particular groups of researchers. There are significant differences in disciplinary orientation per clusters $\left(\chi^{2}(12)=55,24, p=<0.001\right)$. These differences are presented in Table 7.4 and briefly discussed below. Differences between geographical regions appeared not significant after testing for co-variance with disciplinary-orientation.

Table 7.4 Disciplines by cluster

\begin{tabular}{|c|c|c|c|c|c|c|c|c|c|c|}
\hline & \multicolumn{2}{|c|}{$\begin{array}{l}\text { SOCIAL } \\
\text { SCIENCES } \\
(\mathrm{N}=77)\end{array}$} & \multicolumn{2}{|c|}{$\begin{array}{l}\text { NATURAL } \\
\text { SCIENCES } \\
(\mathrm{N}=70)\end{array}$} & \multicolumn{2}{|c|}{$\begin{array}{l}\text { INTER- } \\
\text { DISCIPLINARY } \\
\text { SCIENCES } \\
(\mathrm{N}=91) \\
\end{array}$} & \multicolumn{2}{|c|}{$\begin{array}{l}\text { PROFESSIONAL } \\
\text { AND APPLIED } \\
\text { SCIENCES } \\
(\mathrm{N}=16)\end{array}$} & \multicolumn{2}{|c|}{$\begin{array}{l}\text { OTHER/ } \\
\text { MISSING } \\
(\mathrm{N}=30)\end{array}$} \\
\hline & $\mathbf{N}$ & $\%$ & $\mathbf{N}$ & $\%$ & $\mathbf{N}$ & $\%$ & $\mathbf{N}$ & $\%$ & $\mathbf{N}$ & $\%$ \\
\hline Cluster 1 & 27 & 35 & 36 & 51 & 21 & 23 & 7 & 44 & 13 & 43 \\
\hline Cluster 2 & 29 & 38 & 4 & $\underline{6}$ & 42 & 46 & 4 & $\underline{25}$ & 9 & 30 \\
\hline Cluster 3 & 5 & $\underline{6}$ & 22 & 31 & 11 & 12 & 3 & 19 & 3 & $\underline{10}$ \\
\hline Cluster 4 & 16 & 21 & 8 & 11 & 17 & 19 & 2 & $\underline{13}$ & 5 & 17 \\
\hline
\end{tabular}

Note. Percentages relative to total number of respondents per discipline. Values higher than expected are marked in bold, values lower than expected are underlined (compared to equal distribution across clusters).

With respect to the disciplinary composition, researchers in the social sciences more often share the views reflected in cluster one and two, and to a lesser extent in cluster four. Natural scientists tend to share the views of the first and third clusters, while researchers with an interdisciplinary background predominantly share the perspectives represented in the second cluster. This different orientation of researchers is perhaps not surprising and could be seen to reflect the different methodological and epistemological focus of their respective disciplinary training. The first and third cluster reflect values of scientific objectivity and neutrality, most often associated with a positivist epistemological position common in the natural sciences. The second and fourth clusters, on the other hand, acknowledge the situated character of scientific research and the deep entanglement of science and politics. Such perspectives reflect an interpretivist epistemology common in the qualitative social sciences. It is interesting to note that perspectives of interdisciplinary researchers tend to be more similar to their social sciences than their natural sciences peers. In particular, the large share of interdisciplinary researchers in the second cluster (Transformative research as political act) is remarkable.

\subsection{Discussion}

The four clusters identified in this chapter represent different perspectives on science for sustainability and its normative and political dimensions. Respondents in the first cluster see 
the value of science in its ability to support societal change towards more sustainable futures by speaking truth to power. Respondents in the second cluster see researchers themselves as political actors engaged in shaping and changing society. Respondents in the third cluster are more hesitant when it comes to role of science as change agent for sustainability while recognising opportunities for science to stimulate normative debates. Respondents in the fourth cluster, finally, particularly stress the complex web of actors, interests and perspectives when it comes to questions of sustainability and emphasise the need for science to be humble with respect to its societal role.

In various ways, the identified perspectives combine historically developed norms of scientific knowledge production with new perspectives on the transformative, normative and political role of science for sustainability. Altogether, the results from the analysis point to some important tensions and ambiguities both within and across the identified clusters. Three interrelated tensions stand out. The first tension relates to the transformative potential of science for sustainability, tension two is about the possibility and desirability of independence and impartiality, and tensions three concerns the relationship between science and politics. The next sections discuss these tensions and their relevance for current debates about transformative research for sustainability.

\subsubsection{Transformative potential of science for sustainability}

First, researchers hold different views on the transformative potential of science for sustainability and the extent to which researchers should actively seek solutions for sustainability problems. The results from the survey indicate that the ideal of transformative research is widely supported. While not all researchers are comfortable with the notion of science providing solutions for sustainability challenges or becoming actively engaged in the implementation of scientific knowledge in society (in particular researchers in cluster 3), in general sustainability researchers support these objectives. This echoes the observation of Fazey et al. (2018) that an 'opening up' of science is pertinent, where activities traditionally confined to the domain of practice, such as the implementation of scientific knowledge, are increasingly accepted as inherently entangled with scientific knowledge production.

Yet, this research also illustrates the existence of different perspectives on what transformative and solutions-oriented research entails. Some researchers (represented in cluster 2), accept the explicit involvement in societal change processes as a new role for sustainability researchers, following the model of scientists as 'change agents' (T. R. Miller, 2013; Wittmayer \& Schäpke, 2014). For other researchers (represented in cluster 1), the ideal of the neutral, reflective scientist transferring knowledge to policy makers remains the core model of the relationship between science and societal change (Pregernig \& Böcher, 2012). Yet another group of sustainability researchers emphasise the way science interacts with other institutions in affecting societal change, while rejecting a privileged position of researchers in shaping sustainability solutions (represented in cluster 4). Thus, even though the ideal of transformative research for societal change is broadly supported, sustainability researchers give shape to this ideal in profoundly different ways. Whereas the literature on transformative and solutions- 
oriented research stresses the necessity to transcend current patterns and practices of scientific knowledge production and seek new societal roles (Fazey et al., 2018; Wittmayer \& Schäpke, 2014), such changes are not always acknowledged in perspectives on transformative and solutions-oriented science for sustainability.

\subsubsection{Possibility and desirability of independence and impartiality}

Second, what stands out from this analysis are tensions around the importance that researchers place on principles of independence and impartiality when engaging with value-laden and contested issues of sustainability. Miller (2013) describes the 'normative limitation' of science for sustainability as "its potential inability to recognise the degree to which supposedly valuefree science is in fact value-laden and how scientific analyses can influence necessary and important political debates in society in complex ways" (Miller, 2013). Also other studies have pointed to the lack of awareness among sustainability researchers of the normative and political dimensions of their work (Rosendahl et al., 2015; Wittmayer \& Schäpke, 2014). At first sight, findings from this research appear to be in contrast with those observations. The analysis reveals that researchers generally acknowledge the multiple external, epistemic and personal factors shaping scientific research as well as strong agreement that it is important to be transparent about these pertinent factors of science for sustainability.

Yet, perspectives differ with respect to the desirability of impartiality and independence. Some researchers perceive it as not only impossible but also undesirable to separate normative and value-laden questions from science for sustainability (represented in cluster 2 and 4). They stress the importance to act on scientific knowledge about major and urgent sustainability challenges and find that in doing so, science cannot keep an impartial position but rather becomes directly engaged in normative and political processes of shaping sustainable futures. Others, however, claim that researchers should strive for independence and impartiality to the greatest extent possible (represented in cluster 1 and 3). Although full independence or complete impartiality are generally considered impossible, far from all sustainability researchers are willing to "actively acknowledge and build normative aspects into research programmes" (Fazey et al., 2018). Instead, the 'myth' of scientific objectivity and associated political neutrality continues to receive support (Milkoreit et al., 2015).

\subsubsection{Idealised separation between science and politics}

Finally, tensions exist with regard to the relationship between science and politics in science for sustainability. This study identified a subset of sustainability researchers that embrace the political power of scientific knowledge and its ability to advance societal change (represented in cluster 2 in particular, cf. Milkoreit et al., 2015). At the same time, the findings reveal some deeply entrenched ideas about the appropriate relationship between science and politics. In particular, the notions of 'being policy relevant but not prescriptive' and 'speaking truth to power' are strongly supported by sustainability researchers. In essence, both these notions draw a boundary between what is considered 'scientific' and what is considered 'political'. An increasing body of scholarship points out that such a separation cannot be upheld in practice, especially when it comes to complex and value-laden issues of sustainability (K. Braun \& 
Kropp, 2010; Turnhout et al., 2016). This separation also appears at odds with the overall response to the survey which indicates that most sustainability researchers recognise the relationship between science and politics as considerably more complex. It is thus puzzling why the idealised distinction between science and politics, or truth and power, as implied by the before mentioned statements, remains to receive such strong support. One possible explanation could be the prominence of above-mentioned perspectives in discourses of scientific assessment bodies such as the IPCC (Fazey et al., 2018). The strong support for these statements raises questions of how researchers might bring these idealised notions into practice in different ways in relation to the perspective they hold on transformative sustainability research.

\subsubsection{Limitations and directions for further research}

This study has several limitations that deserve to be mentioned. First, the study is based on a non-representative sample of respondents. Although considerable effort was made to reach a diverse set of researchers engaged in Future Earth, it is likely that researchers that are more concerned about the issues covered in this survey were more inclined to participate. This might have resulted in an overrepresentation of more outspoken perspectives on transformative research for sustainability and its normative and political dimensions. At the same time, the survey did receive responses from researchers with different disciplinary and topical backgrounds and at different career levels, making it possible to draw careful conclusions about the way perspectives are spread across the community, although the results of the statistical tests need to be interpreted with caution. A related issue is that the survey was only available in English. This might have discouraged non-English speaking researchers to participate and might also have caused issues with the interpretation of questions and statements. Within the sample of survey respondents, certain geographical regions are more strongly represented than others. Although this is consisted with the research community engaged in Future Earth, the lower number of responses for certain regions made it difficult to draw clear conclusions about geographical differences. The link between national, institutional and political cultures and researchers' perspectives on transformative research is an important avenue for further research.

Second, the survey approach necessarily reduces complexity. Multifaceted normative and political questions had to be translated to simple statements that could be included in the survey format. As explained in the methodology, the reason for doing so was to gain insight in the different perspectives across a large and diverse community of researchers. At the same time, it should be realised that important nuances are inevitably lost in the process. Respondents were asked to provide a single response to statements that they might value differently depending on situation and context. Moreover, The specific formulation of statements might have elicited a certain response. Complementing the quantitative analysis of survey date with qualitative analysis of written responses allowed for interpretation of the differences and tensions across the identified perspectives. However, further in-depth qualitative research is needed to better understand the meaning of these differences and 
tensions in the way sustainability researchers perceive the normative and political dimensions of their work.

Finally, the three identified tensions highlight important dimensions for further research. In particular, the study raises questions of how the identified perspectives and tensions relate to actual research practices and outcomes. What does it mean for researchers to incorporate normative and political dimensions in their research practices? How do sustainability researchers give shape to different societal roles in correspondence with their beliefs about the appropriate relationship between science and politics? And in what way are different perspectives and practices enabled or constrained by the social, institutional and political context in which researchers work? Moreover, it raises questions of the competencies and skills that sustainability researchers need in order to openly, honestly and effectively engage with value-laden and political questions of sustainability. And finally, the question emerges how such openness and reflexivity can be supported institutionally, both within local institutions and global research networks.

\subsection{CONCLUSION}

This study set out to make explicit the normative and political dimension of science for sustainability and investigate the attitudes of sustainability researchers towards these dimensions of their profession. There is no single answer to the question how sustainability researchers can and should engage with the values and politics inherent to societal transformations to sustainability. It is clear, though, that this question can no longer be ignored. The ideal of global sustainability is filled with normative and political choices concerning possible and desirable futures as well as the pathways of getting there (Patterson et al., 2016, 2018). With science for sustainability taking an increasingly active and explicitly interventionist perspective on achieving sustainable futures, questions of values and politics thus become an inevitable component of research. Ignoring such dimensions restricts the ability of science for sustainability to make a meaningful contribution to society. Moreover, failing to recognise questions of values and politics brings along the very real risk of research "unintentionally reproducing unfavourable market settings, social inequalities and exploitive institutional relations" (Fazey et al., 2018). Only when conversations about values and politics become a central part of the everyday practice of sustainability researcher can we expect a meaningful and reflexive contribution of science to sustainability transformations. This requires not only commitment from individual researchers but also institutional support. There is a clear opportunity for research networks such as Future Earth to explicitly address questions of values and politics and support deliberation on the roles of science in transformations to sustainability. 


\section{8 - The authority of science in sustainability governance}


This chapter turns the focus to the relationship between science and governance for sustainability. The chapter presents a structured comparison of six science institutions engaged with the Sustainable Development Goals. It unpacks the material and rhetorical strategies by which these science institutions seek to acquire authority in sustainability governance. The chapter highlights the emerging solutions-oriented mode of science engagement. Science institutions characterised by this mode of engagement claim relevance based on the promise of providing solutions for global sustainability, seek credibility by invoking support of the scientific community, and foster legitimacy through a strategy of participation. Yet, while the solutionsoriented mode of science engagement is increasingly prominent in rhetoric, science institutions continue to rely on more established assessment and advisory modes of science engagement. Based on this analysis, we provide a framework for reflection on the claims and strategies of science institutions and their role and responsibility in sustainability governance.

Published $a^{21}$ :

van der Hel, Sandra \& Frank Biermann. 2017. The Authority of Science in Sustainability Governance: A Structured Comparison of Six Science Institutions Engaged with the Sustainable Development Goals. Environmental Science and Policy 77: 211-20. http://dx.doi.org/10.1016/j.envsci.2017.03.008

\footnotetext{
${ }^{21}$ This co-authored chapter uses the pronoun 'we'. Sandra van der Hel conducted the data collection and analysis, both authors contributed to the conceptualisation and writing of the chapter.
} 


\subsection{INTRODUCTION}

Over the past decades, scientists and science institutions have undoubtedly become highly active participants in global sustainability governance. And yet, today's role of scientists and science institutions - notably in the 2012 United Nations Conference on Sustainable Development in Rio de Janeiro and the subsequent intergovernmental negotiations for the Sustainable Development Goals - is much bigger in both quality of influence and quantity of representation than ever before (UN DESA, 2014). Numerous science institutions have become actively engaged in formulating the Sustainable Development Goals, and many will have a prominent role in monitoring and measuring the impact of the goals and seek to contribute to their implementation (Biermann, Kanie, \& Kim, 2017; Griggs et al., 2013; Lu, Nakicenovic, Visbeck, \& Stevance, 2015; Lubchenco, Barner, Cerny-chipman, \& Reimer, 2015; Stafford-Smith, 2014). Overall, many major science institutions turn towards what has been termed "solutions-oriented science engagement", that is, a way of operation that aims to inform and shape solutions for global sustainability (Edenhofer \& Kowarsch, 2015; Lee, 2015).

Yet, the current high participation of scientists in global sustainability governance is also contested and has given rise to criticism regarding the usefulness and effectiveness of science institutions. For that reason, science institutions and their managers today seek to carefully construct and safeguard their authority in political processes in order to be able to continue to play an active role in sustainability governance. In this chapter, we embark from the assumption that to construct and safeguard this authority, science institutions will aim to strengthen the salience, credibility and legitimacy of their work with policy audiences (drawing here on the well-established framework by Cash et al., 2003 and Mitchell et al., 2006). Salience is here defined as the perceived relevance of science institutions and the knowledge they provide; credibility as the perceived scientific adequacy of scientific products and arguments; and legitimacy as the perceived fairness of knowledge production and assessment, respecting divergent values, interests and believes (Cash et al., 2003).

There are, however, no simple formulas for constructing and safeguarding salience, credibility and legitimacy with policy audiences. Instead, institutions can seek to pursue these qualities in different ways, building on divergent strategies to claim authority in the crowded space of science engagement for sustainable development. The first aim of this chapter is hence to elucidate the variant strategies that science institutions employ to foster salience, credibility and legitimacy in governance for sustainability. The framework that we develop based on this exercise contributes to the second aim of this chapter - to support critical reflection on the strategies for authority pursued by science institutions engaged in sustainability governance.

We employ the broad concept of science institutions to include various forms of science-based initiatives operating at the interface between science and sustainability governance. This includes global environmental assessments (GEAs) but also advisory bodies and other forms of science networks and platforms. It is important to point out that science institutions are diverse in their institutional design and the context in which they operate, and that these institutions themselves are typically complex, multi-layered entities. Nevertheless, the common 
focus of science institutions on informing, monitoring and implementing the Sustainable Development Goals warrants a comparison on the ways in which authority is sought.

This chapter proceeds as follows. In the next section, we briefly introduce the academic literature on salience, credibility and legitimacy - particularly in relation to the strategies that science institutions may pursue to achieve these attributes - and present our research design, which is based on a structured comparison of six international science institutions engaged in formulating, implementing and monitoring the Sustainable Development Goals. In Sections 8.3 to 8.5 we discuss the different strategies that science institutions pursue to enhance and safeguard perceptions of salience, credibility and legitimacy among governance actors. We then point out three overarching modes of engagement by which science institutions aim to assure authority in sustainability governance and conclude by providing a framework to support reflection on the various strategies and their implementation.

\subsection{RESEARCH DESIGN}

Over the past decades, global environmental assessments and other science networks and institutions have become an important part of the international governance landscape for sustainable development (Biermann, 2014; Gupta et al., 2012). As a result, science institutions can be seen as a (potential) source of authority in global politics (C. A. Miller \& Edwards, 2001). The authority of science in a dynamic political environment is to a large extent contested and negotiated, and crucially depends on the practical and rhetorical tools that scientists use to establish perceptions of trustworthiness among governance actors (Kunseler \& Tuinstra, 2017; Lidskog \& Löfmarck, 2015; Turnhout et al., 2007).

Scholars of environmental politics have identified perceived salience, credibility and legitimacy as prerequisites for receptiveness of governance actors to scientific institutions and the knowledge they provide (Cash et al., 2003; Mitchell et al., 2006). In parts of this literature, the term "effectiveness" is used as the dependent variable to assess the eventual influence of science institutions. We rather conceptualise the key impact as scientific authority, which we see as fundamental for effective science-based political action. The attributes of salience, credibility and legitimacy have been applied to understand the influence of scientific knowledge and assessments (Cash et al., 2003; Mitchell et al., 2006), as well as other institutions operating at the science-policy interface (e.g. Reinecke, 2015; Sarkki et al., 2015). In this chapter, we assume that science institutions, implicitly or explicitly, will attempt to increase perceptions of salience, credibility and legitimacy in order to establish and maintain their authority among governance actors.

However, there are no simple avenues for fostering perceptions of salience, credibility and legitimacy (Keller, 2009; C. A. Miller \& Edwards, 2001; Reinecke, 2015). Reinecke (2015), for instance, lists several rhetorical strategies and institutional mechanisms that are employed to pursue these qualities, including the translation of research findings into policy messages to enhance salience, formal procedures for assuring the quality of knowledge to safeguard credibility, and transparency of the initiative to foster perceptions of legitimacy. Other studies 
point to formalised rules of engagement as beneficial to salience and credibility (Keller, 2009), emphasise how scientists establish credibility by claiming membership of the broader scientific community (Keller, 2009; Lidskog and Löfmarck 2015), and identify stakeholder participation as an increasingly popular strategy for generating salient, credible and legitimate science engagement (Kunseler et al., 2015; Sarkki et al., 2015; van Enst, Runhaar, \& Driessen, 2016).

More broadly, salience, credibility and legitimacy mean different things in different sociopolitical and cultural contexts, making it difficult to secure these attributes among often highly diverse audiences (Biermann, 2002; Jasanoff, 2005). Moreover, science institutions may place different emphasis on the attributes of salience, credibility and legitimacy (Reinecke, 2015). Several studies have pointed to trade-offs between salience, credibility and legitimacy, and the balancing act for assuring these qualities accross different actors (Kunseler et al., 2015; Sarkki et al., 2014). Finally, science institutions have been shown to pursue different startegies at once across different sites or levels of the institution (Keller, 2009; Kunseler \& Tuinstra, 2017).

Our study contributes to this literature by distilling common strategies pursued across different science institutions in sustainability governance and by critically reflecting on the related claims for salience, credibility and legitimacy. We use here the broad concept of "strategies", by which we include organisational strategies and institutional mechanisms - ranging from informal mechanism to formal rules and procedures (Keller, 2009) - as well as rhetorical strategies (Reinecke, 2015). As discussed above, science engagement in sustainability governance is complex, and science institutions themselves are multi-layered. As such, we do not expect to find unequivocal strategies for pursuing perceptions of salience, credibility and legitimacy. Instead, we assume that science institutions apply a multitude of different rhetorical claims, tools and mechanisms in pursuit of these qualities. These "strategies" might be implicit or explicit, actual or rhetoric, and in various degrees related to the institutional mandate or design. By using the broad concept of "strategy", we aim to grasp the diversity of institutional, organisational and rhetorical instruments and mechanisms used to pursue authority in sustainability governance.

The chapter draws on a structured comparison of six science-based initiatives engaged in sustainability governance. These six science institutions work according to different logics of operation, yet all share the goal of contributing scientific knowledge and expertise to the development and implementation of the Sustainable Development Goals, agreed upon in 2015 by the UN General Assembly. They are all also similar in their overall assessment function, that is, they all aim to 1) bring together scientific knowledge on a particular issue and 2) provide input in a policy process. Our six cases include scientific assessments in a more traditional understanding as well as other forms of science institutions with an assessment function, such as scientific advisory boards and international research networks. 
Box 8.1: Cases

\section{SCIENTIFIC AND TECHNOLOGICAL MAJOR GROUP}

The Scientific and Technological Major Group is one of nine Major Groups formalised in Agenda 21 as main channel for the participation of stakeholders. The organising partners of this Major Group are the International Council for Science (ICSU), the International Social Science Council (ISSC) and the World Federation of Engineering Organizations (WFEO). The Scientific and Technological Major Group formally represent the perspective of science and technology in UN processes on sustainable development.

\section{FUTURE EARTH: RESEARCH FOR GLOBAL SUSTAINABILITY}

Future Earth is an international research platform bringing together researchers from various natural and social science disciplines working on issues of sustainability. Future Earth was launched at the 2012 United Nations Conference on Sustainable Development. It aims to inform and guide societal transformations to global sustainability. Several subprojects focus specifically on the Sustainable Development Goals.

\section{SCIENTIFIC ADVISORY BOARD OF THE UN SECRETARY-GENERAL}

The Scientific Advisory Board of the UN SecretaryGeneral was created in 2013 at the request of the UNSecretary General to ensure "that up-to-date and rigorous science is appropriately reflected in high-level policy discussions within the UN system" (Scientific Advisory Board, 2016, p. 14). The Scientific Advisory Board consists of 26 scientists from around the world and is chaired by Irina Bokova, Director-General of UNESCO $^{22}$.

\section{GLOBAL ENVIRONMENTAL OUTLOOK}

The Global Environmental Outlook is an integrated environmental assessment periodically produced by the United Nations Environment Programme (UNEP). The Global Environmental Outlook was initiated in response to environmental reporting requirements listed in Agenda 21. The sixth Global Environmental Outlook (2019) has a specific focus on the Sustainable Development Goals.

\section{SUSTAINABLE DEVELOPMENT SOLUTIONS NETWORK}

The Sustainable Development Solutions Network is a network of experts and institutions from academia, business, civil society, and the public sector, chaired by Professor Jeffrey Sachs. The Network was launched in 2012 by UN Secretary-General Ban Ki-moon and aims to amplify the voices of science in global debates and contribute to sustainable solutions.

\section{GLOBAL SUSTAINABLE DEVELOPMENT REPORT}

The Global Sustainable Development Report is an assessment of assessments led by the United Nations Division for Sustainable Development. The report responds to the mandate of the High-Level Political Forum (HLPF) to strengthen the science-policy interface on issues of sustainability. Three reports have been published to date - a prototype edition in 2014, and full reports in 2015 and $2016 . .^{23}$

Four characteristics are particularly pertinent for understanding how science institutions can foster perceptions of salience, credibility and legitimacy: their structure; their objectives and function; their internal processes; and their intended outcomes (Sarkki et al., 2015). We have hence selected the six cases that we study for their diversity on these four characteristics. We do not claim to have included all relevant institutions. The selected cases rather present a diverse sample of science institutions engaged in sustainability governance, allowing us to investigate different strategies for pursuing salience, credibility and legitimacy in sustainability

\footnotetext{
22 The Scientific Advisory Board was closed at the end of Ban Ki-moon's tenure as UN Secretary General in 2016.

23 At the 2016 annual meeting of the HLPF, it was decided that the Global Sustainable Development Report will henceforth be published on a quadrennial basis, and drafted by a group of 15 independent scientists (Earth Negotiations Bulletin, 2016). This paper takes into account developments up to the publication of the third Global Sustainable Development Report in 2016.
} 
governance. We briefly introduce our cases in Box 8.1. (see Chapter 4 for an overview of our cases based on Sarkki et al.'s (2015) framework).

Our case comparison is based on a structured document analysis. We include both official strategy documents and representations on websites, in interviews, and other informal sources (documents are listed in Appendix C). To elucidate the strategies that science institutions employ to foster salience, credibility and legitimacy we chose an inductive research design, which allowed us to detect patterns and regularities across the six case studies. We coded the selected documents for statements making implicit or explicit claims for salience, credibility and legitimacy. Based on a comparison of these claims, we distinguished common strategies within our selected cases. Our analysis focuses on the rhetorical and institutional strategies of organisations as they are represented in documentary material. We do not offer claims about the actual implementation of these strategies. Instead, we critically reflect on and deconstruct the strategies pursued by our cases and provide a framework for further reflection on the rationales and implementation of each strategy. In the next sections, we discuss these strategies for salience (Section 8.3), credibility (Section 8.4) and legitimacy (Section 8.5).

\subsection{STRATEGIES FOR SALIENCE}

We distinguish three types of strategies by which science institutions aim to foster perceptions of salience among governance actors. We label these as salience through integration, salience through solutions, and salience through independent advice (see Table 8.1 for an overview).

\subsubsection{Salience through integration}

A first strategy for fostering salience is that of integration. Science institutions that employ this strategy claim salience based on the comprehensive and integrated nature of their products. They typically survey a large amount of scientific literature with the aim of providing a comprehensive report of the state of science for consideration by governance actors. In that sense, they follow the classical model of global environmental assessments. An example of this strategy is the Global Environmental Outlook, which claims to turn "the best available scientific knowledge into information relevant for decision makers" (UNEP, 2012, p. xix). Similarly, the Global Sustainable Development Report aims to integrate all available scientific knowledge relevant for the High-Level Political Forum, their direct policy audience. The Report takes the form of an "assessment of assessments" that builds on existing assessments and brings together dispersed information in a "comprehensive, authoritative global sustainable development report” (UN DESA, 2014, p. 26).

The question arises, however, what type of knowledge is considered relevant? When does knowledge become "scientific knowledge" worth being integrated in a comprehensive assessment? Traditionally, scientific assessments have relied strongly on peer-reviewed knowledge in established publishing outlets, notably academic journals. However, increasing acknowledgement that knowledge relevant for decision-makers might be found outside of formal scientific disciplines requires science institutions to look beyond the peer-reviewed literature. Indeed, upcoming reports from both the Global Environmental Outlook and the 
Global Sustainable Development Report are anticipated to draw on a more diverse knowledge base, including along with peer-reviewed scientific literature also grey literature and indigenous and local knowledge. However, to date, although elaborate mechanisms exists for assessing peer-reviewed knowledge, procedures for including local knowledge and grey literature are largely absent.

\subsubsection{Salience though independent advice}

Second, some science institutions claim salience based on the promise of providing independent advice. Institutions that follow this strategy are often linked to an ongoing policy process or body and thus have a direct audience to which they address their recommendations. One example is the Scientific Advisory Board that advises the United Nations SecretaryGeneral and the executive heads of UN organisations. Importantly, it was stressed at the inaugural meeting that this Board "should express not only what governments ask and want to hear but should hear, from a scientific perspective" (SAB, 2014a, p. 3 emphasis in original). A related role for the Scientific Advisory Board is to "elevate the role of science in policymaking" and strengthen the science-policy-society interface (SAB, 2014a, p. 3)

Another example is the Scientific and Technological Major Group, which represents, as part of the UN major group system, the scientific community in UN processes on sustainable development. Members of the group coordinate input from the scientific community "in order to ensure an informed and objective perspective on progress against the achievement of the SDGs" (ICSU, ISSC, \& Future Earth, 2015). For instance, a report by the two core member organisations that reviewed the targets of the Sustainable Development Goals was branded as "the science perspective" and "the first independent scientific review" of the Sustainable Development Goals (ICSU \& ISSC, 2015)

Here, the question arises what can be considered "the science perspective" in the case of complex issues dealt with in sustainability governance. Which disciplines, issue areas, theoretical perspectives and methodological approaches should be included? The institutions considered here are both essentially people-driven (as discussed in Section 7.4), making their input dependent on the qualifications, insights, understanding and possibly also normative preferences of the individual scientists involved.

Central to the advice in both cases is a broader emphasis on the important role of science, in general, for sustainable development. By virtue of its role and institutionalisation in the UN system, the Scientific and Technological Major Group seeks to represent the entire scientific community as "stakeholder" in international sustainability governance. Also the Scientific Advisory Board aims to promote the role of science in the UN system, as reflected in several publications stressing the "crucial role of science" for sustainable development (SAB, 2014b). We argue that more reflection is needed on the meaning and potential tensions of this dual role as independent advisor and advocate for science.

\subsubsection{Salience through solutions}

A third strategy that some science institutions use to claim salience is the promise of solutions for complex sustainability challenges. Moving away from a focus on assessing the problems of 
environmental change, these institutions aim to contribute to solutions for sustainable development.

This solutions-oriented strategy is strongly reflected in the narrative of both the Sustainable Development Solutions Network and Future Earth. As the name of the first network reflects, providing solutions for sustainability is its main ambition. Core to the strategy of the Sustainable Development Solutions Network are "solution-initiatives" that intend to promote new technologies, models and policies to accelerate progress towards sustainable development. The solutions-focus is also central in Future Earth, as reflected in the network's core mission of "research for global sustainability". Future Earth sees solutions-oriented science as a new type of science which, through integration of multiple disciplinary perspectives and coproduction with societal partners, is expected to enable "fundamental societal transitions to global sustainability" (Future Earth, 2013, p. 13).

To a lesser extent, the Global Environmental Outlook and the Global Sustainable Development Report also turn towards a solutions-oriented direction. The Global Environmental Outlook provides an analysis of "policy-options" and "priority solutions" in its fifth report, and promises to "[assist] member states to position themselves on the most effective pathways for transitions towards a sustainable future" through "enhanced policy analysis" (UNEP, 2015, p. 1). Similarly, the Global Sustainable Development Report brings in a solutions-oriented focus through its section on "emerging issues", which aims to inform policy makers of new risks as well as opportunities, policy options and solutions related to sustainable development. Yet, neither institution appears fully comfortable with this approach, using careful wording when it comes to "policy options" and "solutions" with the added qualification that science should point out the costs and benefits of policy options yet cannot make decisions.

In general, it is often unclear what exactly is meant by "solutions-orientation". Future Earth calls for "actionable scientific knowledge" (Future Earth, 2016b), whereas the Sustainable Development Solutions Network aims to promote and participate in "practical problem solving for sustainable development" (SDSN, 2015b). Yet, the type and form of solutions coming from science is generally not specified, nor are there many tangible examples of the solutions that these networks bring for sustainable development. More broadly, the fundamental question arises for whom science should provide solutions? Here, we see that the Global Environmental Outlook and the Global Sustainable Development Report primarily speak to governments and intergovernmental organisations, whereas the Sustainable Development Solutions Network and Future Earth also explicitly reach out to private sector actors. 
Table 8.1 Strategies for salience and case examples

\begin{tabular}{|c|c|c|c|}
\hline & $\begin{array}{l}\text { SALIENCE THROUGH } \\
\text { INTEGRATION }\end{array}$ & $\begin{array}{l}\text { SALIENCE THROUGH } \\
\text { INDEPENDENT ADVICE }\end{array}$ & $\begin{array}{l}\text { SALIENCE THROUGH } \\
\text { SOLUTIONS }\end{array}$ \\
\hline $\begin{array}{l}\text { Main } \\
\text { claims }\end{array}$ & $\begin{array}{l}\text { - Assessing the best } \\
\text { available knowledge } \\
\text { - Integration and } \\
\text { comprehensiveness }\end{array}$ & $\begin{array}{l}\text { Providing the/a science } \\
\text { perspective in ongoing } \\
\text { policy processes } \\
\text { - Independence of political } \\
\text { interests }\end{array}$ & $\begin{array}{l}\text { - } \quad \text { Contributing to solutions } \\
\text { for sustainability } \\
\text { challenges } \\
\text { - } \quad \text { Informing policy options }\end{array}$ \\
\hline Examples & $\begin{array}{l}\text { Global Environmental } \\
\text { Outlook; Global Sustainable } \\
\text { Development Report }\end{array}$ & $\begin{array}{l}\text { Scientific Advisory Board; } \\
\text { Major Group }\end{array}$ & $\begin{array}{l}\text { Sustainable Development } \\
\text { Solutions Network; Future } \\
\text { Earth }\end{array}$ \\
\hline
\end{tabular}

\subsection{STRATEGIES FOR CREDIBILITY}

We now turn to credibility. We distinguish here three types of strategies by which science institutions aim to foster a perception of credibility among political actors, which we label as credibility by peer review, credibility by community and credibility by individual credentials (see Table 8.2 for an overview).

\subsubsection{Credibility by peer review}

The mechanism of peer review is a well-established strategy to provide credibility to scientific knowledge. This strategy is at the heart of scientific assessments such as the Global Environmental Outlook, which emphasises its rigorous and comprehensive review process in official documentations (UNEP, 2012). Through its nature as an "assessment of assessments", the Global Sustainable Development Report also appeals to formal mechanisms associated with assessments, including peer review (UN DESA, 2014). Indirectly, the other cases considered here also build on peer review as a mechanism upholding the credibility and trustworthiness of the scientific communities they represent (see Section 7.4.3 'Credibility by community').

Notwithstanding the prominence of peer review as a strategy for attaining credibility, mechanisms of peer review are not undisputed. Who, for example, are considered credible "peers" for science institutions in global sustainability governance, and which mechanisms enable the participation of these peers in the review process? Where the review process of the Global Environmental Outlook includes an internal review by UN staff, an external review by scientific experts, and a governmental review, other institutions restrict peer review to the scientific community. The prototype of the Global Sustainable Development Report discusses the option of an open, multi-stakeholder peer review process. Yet, for the three reports published to date, no comprehensive peer review process was developed, with some chapter reviews conducted by a single expert (hence appealing to credibility by the credentials of this expert, rather than peer review as a mechanism). 


\subsubsection{Credibility by individual credentials}

A second strategy for establishing credibility is based on the individual credentials of members. The most prominent example is the Scientific Advisory Board, which is composed of 26 "eminent scientists", whose knowledge and experience form the foundation of the Board's science advice (Scientific Advisory Board, 2016). In a similar vein, the Sustainable Development Solutions Network appeals to the credentials of its "remarkable Leadership Council” (SDSN, 2015a, p. 17). Also Future Earth's governance structure includes a Science Committee composed of individual scientists who are expected to "ensure scientific quality" (Future Earth, 2013, p. 17). Finally, the Global Environmental Outlook applies this strategy in its selection of "world-renowned experts" as lead authors and members of its Scientific Advisory Panel, tasked with safeguarding the credibility of the assessment (UNEP, 2014, p. 1).

We might ask, however, which actors are in fact chosen to uphold the credibility of a scientific institution. Member of the Scientific Advisory Board are described as "leaders in their field, [including] Nobel Prize winners and heads of major national and international science institutions" (SAB, 2016, p. 13). Yet the processes through which this seniority is established, and the criteria used, remain unclear, and its outcome could hence be questioned. Whereas the Scientific Advisory Board is exclusively composed of scientists, the Leadership Council of the Sustainable Development Solutions Network includes other types of experts from multiple sectors of society, including science, civil society, business, government, and international organisations. Future Earth and the Global Environmental Outlook also include bodies representing societal actors. Yet both organisations rely on an exclusively scientific body (the Science Committee and Scientific Advisory Panel respectively) to uphold the scientific quality and credibility of their work. But also here, the criteria for selection and establishing seniority are unclear, and open for debate.

\subsubsection{Credibility by community}

Credibility by community is a third strategy for fostering a perception of credibility among governance actors. This strategy is utilised by the Major Group, Future Earth and the Sustainable Development Solutions Network, who all appeal to the combined expertise, trustworthiness and authority of "the scientific community" in their claims for credibility.

The Major Group formally represents the scientific community within UN processes on sustainable development, speaking on behalf of science within this institutional setting. Input from the Major Group is coordinated by ICSU, ISSC and the World Federation of Engineering Organisations, themselves membership organisations representing national academies of science and international scientific union members in their respective domain. The Sustainable Development Solutions Network and Future Earth also appeal to the combined strengths of the scientific community. The Solutions Network, as a membership organisation, points to the trustworthiness and authority of its members in its claim for credibility; membership is limited to "accredited" universities, research centres, and other knowledge institutions with "a strong track record" working on sustainable development (Sustainable Development Solutions Network, 2013). Future Earth does not have a formal 
membership structure but claims to represent and coordinate input from a large and interdisciplinary scientific community working on issues of global change and sustainability. Its outreach material points to the 50,000 scientists that have supposedly been mobilised by Future Earth, working across the world as part of more than 20 global research projects (Future Earth, n.d.). Yet it is difficult to establish to what extent Future Earth's own decisionmaking processes and outcomes really represent the views, insights, and perspectives of 50,000 scientists in the field.

The question arises who those communities are, and whether they feel part of and represented by the science institutions that claim credibility based on their behalf. The Major Group, for example, has been criticised for inadequately representing the scientific community (Zondervan, 2015). In the case of the Sustainable Development Solutions Network, the relative visibility of the selective and high-level Leadership Council has spurred critique of the exclusive nature of the network. For Future Earth, finally, recurrent calls for better involvement of relevant disciplines and research groups reflects that parts of the "community" do not feel represented in the network (Lövbrand et al., 2015).

Table 8.2 Strategies for credibility and case examples

\begin{tabular}{|c|c|c|c|}
\hline & $\begin{array}{l}\text { CREDIBILITY THROUGH } \\
\text { PEER REVIEW }\end{array}$ & $\begin{array}{l}\text { CREDIBILITY THROUGH } \\
\text { INDIVIDUAL CREDENTIALS }\end{array}$ & $\begin{array}{l}\text { CREDIBILITY THROUGH } \\
\text { COMMUNITY }\end{array}$ \\
\hline $\begin{array}{l}\text { Main } \\
\text { claims }\end{array}$ & $\begin{array}{l}\text { Building on the } \\
\text { combined expertise of } \\
\text { peers } \\
\text { - Formal procedures to } \\
\text { ensure scientific quality }\end{array}$ & $\begin{array}{l}\text { Distinguished individuals } \\
\text { uphold the institution's } \\
\text { scientific credibility }\end{array}$ & $\begin{array}{l}\text { - Speaks on behalf of the } \\
\text { scientific community }\end{array}$ \\
\hline Examples & $\begin{array}{l}\text { Global Environmental } \\
\text { Outlook; Global Sustainable } \\
\text { Development Report }\end{array}$ & $\begin{array}{l}\text { Scientific Advisory Board; } \\
\text { Sustainable Development } \\
\text { Solutions Network; Future } \\
\text { Earth }\end{array}$ & $\begin{array}{l}\text { Sustainable Development } \\
\text { Solutions Network; Future } \\
\text { Earth; Major Group }\end{array}$ \\
\hline
\end{tabular}

\subsection{STRATEGIES FOR LEGITIMACY}

Finally, we distinguish three types of strategies by which science institutions aim to foster a perception of legitimacy among governance actors, which we label as legitimacy through representation, legitimacy through formal recognition and legitimacy through participation (see Table 8.3 for an overview).

\subsubsection{Legitimacy through representation}

Science institutions claim legitimacy by stressing that they represent a multiplicity of relevant scientific fields. Additionally, geographical and gender balance are pursued as factors that enhance legitimacy.

A key example is the Scientific Advisory Board, whose board members, although appointed in their personal capacity, are presented as "representing all regions and many scientific disciplines relevant for sustainable development" (UNESCO, n.d.). Likewise, the procedures 
of the Global Environmental Outlook for selecting experts "aims to identify the best available expertise representing a range of disciplines, and geographical and gender balance, with particular emphasis on ensuring full representation from developing-country experts" (UNEP, 2014, p. 1). The Global Sustainable Development Report also stresses that it takes into account the perspectives of scientific communities across the globe and emphasises its open, inclusive and geographically balanced structure. Future Earth, in addition to pursuing gender, age and geographical balance among its committee members, is supported by a globally distributed secretariat, combined with a set of regional hubs, which are considered central to ensuring broader geographical representation.

Although the strategy of representation is widespread among science institutions engaged in sustainability governance, achieving the objective of disciplinary, geographical and gender balance often proofs difficult in practice. Contributors to the fifth Global Environmental Outlook, for example, are predominantly citizens of developed countries. The average Human Development Index score of the report's authors is 26, which is comparable to Luxembourg and considerably lower than the global average HDI of 94. Nevertheless, an external review notes that this might represent a standard that is "as good as it gets" (Rowe, Ng'eny, \& Carbon, 2014, p. 34). Future Earth similarly struggles with achieving an equal representation of geographical regions in its governance and membership structures, with the globally distributed secretariat and regional hubs based mostly in developed countries and the programme criticised for being Northern-oriented (Padma, 2014). Similarly, science institutions experience difficulties in achieving gender balance as well as a balanced representation of different disciplines. Only the Scientific Advisory Board appears to succeed relatively well in a balanced representation by its members. Yet, even when acceptable levels of representation are reached in numerical terms, we must ask to what extent voices from different disciplines, regions and genders are equally heard and able to shape science engagement in sustainability governance. All in all, legitimacy through representation, although often claimed, remains a strategy that requires much more careful consideration and targeted action in order to strengthen the practice of science engagement in sustainability governance.

\subsubsection{Legitimacy through formal recognition}

Second, legitimacy is claimed through formal recognition within the UN system. This is particularly important for the Global Sustainable Development Report, which was requested by governments at the 2012 UN Conference on Sustainable Development and directly responds to the mandate of the High-Level Political Forum to strengthen the science-policy interface. As such, it creates "an entry point for scientists across the world to be heard at the highest levels of the United Nations” (UN DESA, 2016, p. 1)

Another entry-point for scientists in the UN system is the Scientific and Technological Major Group. As one of nine "Major Groups" representing diverse stakeholders, the Scientific and Technological Major Group has been granted comprehensive participatory opportunities in UN processes on sustainable development. Members are keen to further extend this authority 
and argue that the Major Group "should be recognised as the specific consortium in charge of coordinating inputs by the scientific community in HLPF” (ICSU et al., 2015, p. 4).

The Scientific Advisory Board is also a formal component of the UN system, set up by UN Secretary-General Ban Ki-moon and reporting directly to executive heads of UN agencies and the Secretary-General. The Global Environmental Outlook is a formal publication of UNEP, and presented as "the UN's authoritative assessment of the state, trends and outlook of the global environment" (UNEP, 2012, p. xix). Future Earth and the Sustainable Development Solutions Network, finally, officially operate separately from the UN system. Yet, both aim to establish links with the UN. The Sustainable Development Solutions Network stresses its recognition within the UN, presenting itself as "a global initiative for the United Nations" (e.g. SDSN, 2015b). Two UN agencies - UNESCO and UNEP - are represented in the Governing Council of Future Earth.

Thus, we find intricate relationships between the science institutions studied here and various UN bodies and agencies. Science institutions tend to emphasis these links in their claims for legitimate engagement in sustainability governance. At the same time, all science institutions studied here also recurrently stress their independence of political processes. As such, a precarious balance is created between close engagement and distance from political processes by science institutions engaged in sustainability governance.

\subsubsection{Legitimacy through participation}

A more recent strategy for ensuring legitimacy in governance processes is through participation of non-academic actors in scientific institutions. We see this strategy reflected in the Leadership Council of the Sustainable Development Solutions Network, whose members represent not only academic institutions but also actors from business, civil society and the public sector. Future Earth institutionalises the role of extra-scientific actors in its separate Engagement Committee, which is an advisory body representing different stakeholders. Moreover, a core principle of the platform is that of co-design and co-production, stressing the importance of participatory knowledge production.

The Global Environmental Outlook is presented as a "consultative, participatory process that builds capacity for conducting integrated environmental assessments and reporting", and lists in addition to scientific institutions, governments and international organisations - NGOs, indigenous peoples' networks and the private sector as important partners (UNEP, n.d.). Likewise, he Global Sustainable Development Report envisions a participatory and multistakeholder approach for its future reports. For the three reports published to date, input was solicited through an open call for "crowdsourced science briefs". With the 2016 report going to press, 265 such briefs were received (UN DESA, 2016).

Yet, realities of participation do not always live up to the claims and expectations of science institutions. Crowdsourced briefs of the Global Sustainable Development Report, for example, were required to be based on peer-reviewed science (as discussed in Section 7.3.1 'Salience through integration'), thus largely limiting input to the scientific community. For the fifth Global Environmental Outlook, universities and research centres remained the main 
contributors, while multilateral organisations and national governments participated as reviewers and members of the advisory group (Rowe et al., 2014). Moreover, we might ask which societal actors are able and willing to participate in science institutions. Although Future Earth has voiced a strong ambition to co-produce knowledge with a diverse group of stakeholders, its governance structure remains dominated by science councils, funding agencies and, to a lesser extent, UN organisations. The Sustainable Development Solutions Network draws strongly on participation from private sector actors in its Leadership Council, but other groups of potential participants appear less strongly represented.

Table 8.3 Strategies for legitimacy and case examples

\begin{tabular}{|c|c|c|c|}
\hline & $\begin{array}{l}\text { LEGITIMACY THROUGH } \\
\text { REPRESENTATION }\end{array}$ & $\begin{array}{l}\text { LEGITIMACY THROUGH } \\
\text { FORMAL RECOGNITION }\end{array}$ & $\begin{array}{l}\text { LEGITIMACY THROUGH } \\
\text { PARTICIPATION }\end{array}$ \\
\hline $\begin{array}{l}\text { Main } \\
\text { claims }\end{array}$ & $\begin{array}{ll}\text { - } & \text { Gender balance } \\
\text { - } & \text { Geographical } \\
\text { - } & \text { representation } \\
\text { Disciplinary diversity }\end{array}$ & $\begin{array}{ll}\text { - } & \text { Formal relationship with } \\
\text { - UN agencies } \\
\text { Institutionalised role in } \\
\text { sustainability governance }\end{array}$ & $\begin{array}{l}\text { Participation of societal } \\
\text { actor in governing } \\
\text { bodies, advisory bodies } \\
\text { or research process }\end{array}$ \\
\hline Examples & $\begin{array}{l}\text { Global Environmental } \\
\text { Outlook; Scientific Advisory } \\
\text { Board; Future Earth; Global } \\
\text { Sustainable Development } \\
\text { Report }\end{array}$ & $\begin{array}{l}\text { Global Environmental } \\
\text { Outlook; Scientific Advisory } \\
\text { Board; Major Group; } \\
\text { Sustainable Development } \\
\text { Solutions Network; Future } \\
\text { Earth; Global Sustainable } \\
\text { Development Report }\end{array}$ & $\begin{array}{l}\text { Global Environmental } \\
\text { Outlook; Sustainable } \\
\text { Development Solutions } \\
\text { Network; Future Earth; } \\
\text { Global Sustainable } \\
\text { Development Report }\end{array}$ \\
\hline
\end{tabular}

\subsection{THREE MODES OF AUTHORITY}

We have presented a comparative case analysis of six science institutions engaged in the process of the developing, monitoring and implementing the Sustainable Development Goals, elucidating the strategies pursued by these institutions to enhance and safeguard scientific authority in sustainability governance.

Across our six case studies, we find that three sets of strategies are often combines. We see these sets of strategies as the foundation of three different modes of scientific authority in sustainability governance (see Figure 8.1). These modes of authority reflect different ways in which science institutions pursue salience, credibility and legitimacy, and hence authority, in sustainability governance. The first mode, which we call the assessment-oriented mode, combines a strategy of salience through integration, claiming relevance based on the comprehensive and integrated nature of scientific output, with credibility by peer review, asserting scientific quality through formal mechanisms of review. Legitimacy is sought here through representation of relevant disciplines, gender and geographical regions. This assessment-oriented mode can be seen as the traditional strategy by which global environmental assessments seek authority in sustainability governance. The Global Environmental Outlook and Global Sustainable Development Report best represent this mode, even though they increasingly appeal to 
additional strategies in order to assure salience, credibility and legitimacy among a diversity of governance actors.

Second, science institutions seek authority in sustainability governance based on an adviceoriented mode of engagement. This again more traditional mode of science engagement in governance appeals to salience through the promise of independent and timely science advice on ongoing governance processes. Credibility is typically sought based on the individual credentials of scientists engaged in the institution, whereas legitimacy is claimed based on formal recognition by governance actors. The Scientific Advisory Board is a classic example of this mode of science engagement in sustainability governance, while the Major Group also appeals to most of these strategies.

Finally, a third solutions-oriented mode of scientific authority in governance builds on the strategy of salience through solutions. Here, science institutions claiming relevance among governance actors based on the promise that science can contribute to solutions for global sustainability. Credibility is sought by appealing to the larger scientific community which is (supposedly) represented by the institution, while legitimacy is claimed based on a strategy of participation, by which extra-scientific actors are invited to participate in the process of knowledge assessment and production. This mode for seeking authority in sustainability governance is reflected in the Sustainable Development Solutions Network and Future Earth, although we find other institutions in our sample increasingly appeal to the solutions-oriented mode as well.

Thus, we distinguish three modes of engagement by which science institutions seek authority in sustainability governance: the assessment-oriented mode, the advice-oriented mode and the solutions-oriented mode. Our observations point out that the solutions-oriented mode is gaining increasing prominence, with science institutions promising to deliver "actionable scientific knowledge" and contribute to "practical problem solving". And yet, the type and form of solutions coming from science are generally not specified. Moreover, science institutes differ substantially with respect to the actor groups that they claim to represent and that are able to participate in the search for science-derived solutions for sustainability. Notwithstanding claims of inclusiveness, actors and knowledge from the global South remain underrepresented. This is particularly worrisome in the case of the Sustainable Development Goals, as it risks undermining the legitimacy of science institutions operating in a global context. At the same time, although the focus is still predominantly on governmental and intergovernmental organisations, science institutions increasingly seek engagement of local and private sector actors. In several institutions, we see that extra-scientific actors have obtained a formal role. Nevertheless, strategies for credibility remain strongly focused on academic quality assurance through peer review or individual credentials. In general, our analysis reveals that although the solutions-oriented mode of authority is increasingly dominant in rhetoric, science institutions continue to rely on more established strategies for acquiring credibility and legitimacy in sustainability governance. 

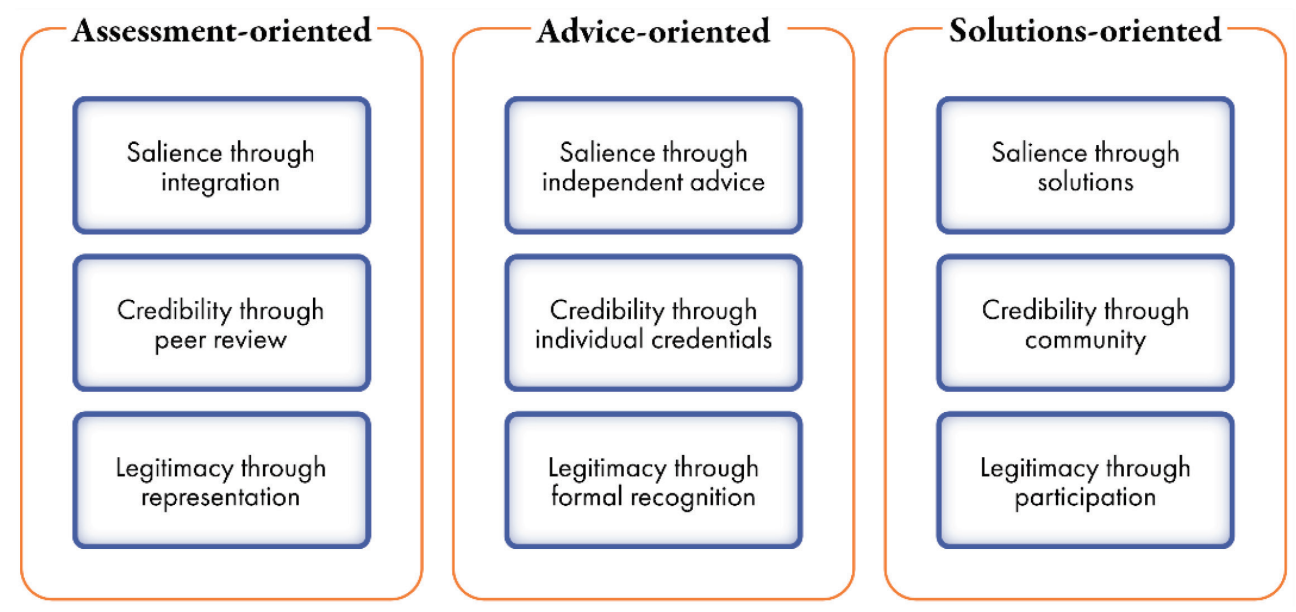

Figure 8.1 Modes of authority and associated strategies for salience, credibility and legitimacy

Whereas an earlier study found that strategies for legitimacy where underrepresented (Reinecke, 2015), our study shows that strategies for legitimacy, at least in rhetoric, are welldeveloped across science institutions engaged in sustainability governance, with most cases pursuing legitimacy through multiple different strategies, seeking recognition and participation from an increasingly diverse set of actors. At the same time, science institutions appear to struggle to bring ambitions of representation and participation into practice. We also find, in line with earlier studies (e.g. Sarkki et al., 2014), several potential trade-offs between salience, credibility and legitimacy. In particular, our study points out that the specific strategies by which authority is pursued lie at the heart of such trade-offs. For example, credibility when pursued through a strategy of peer review tends to inhibit legitimacy through participation, when the peer review system lacks formal procedures for including extra-scientific knowledge. Another potential tension lies between the strategy of salience through independent advice and legitimacy through formal recognition, as this combination of strategies positions science institutions as both part of and independent from the political system.

The reality of science engagement is clearly more complex than the three ideal typical modes presented here. In fact, most cases included in our analysis combine aspects of more than one mode, building on multiple strategies in seeking authority in sustainability governance. Another complicating factor is the interaction between these institutions. Among our sample of cases, ICSU and ISSC, partners of the Scientific and Technological Community Major Group, are also represented in the Governing Council of Future Earth. Members of Future Earth, in turn, have spoken on behalf of the Major Group in UN meetings on sustainable development. The Sustainable Development Solutions Network is part of Future Earth's Governing Council, while the two institutions have also recently confirmed their partnership for cooperation on the Sustainable Development Goals (Sustainable Development Solutions Network, 2016). Two other members of the Future Earth Governing Council, UNESCO and UNEP, respectively 
host the secretariat of the Scientific Advisory Board and publish the Global Environmental Outlook. Finally, the Global Environmental Outlook, Major Group and Future Earth provide input for the Global Sustainable Development Report. Thus, we can see science engagement in the process of designing, implementing and monitoring the Sustainable Development Goals as a complex system of relationships and overlap between institutions. Nevertheless, we find it important and relevant to focus on the individual institutions and their various strategies for ensuring salience, credibility and legitimacy, as this helps to understand and deconstruct the (claims for) authority of science in sustainability governance.

\subsection{CONCLUSION}

Based on our analysis, we advance a framework that specifies the modes of authority and the strategies for salience, credibility and legitimacy as they are pursued by science institutions in sustainability governance (Figure 8.1). We see two complementary uses of this framework. First, as an analytical framework, it can serve as a starting point for further empirical analysis of the implementation of particular strategies for pursuing authority of science in sustainability governance. Second, the framework can aid science institutions, and the individuals working in the context of these institutions, to better reflect on their role and responsibility in sustainability governance. To this end, we further developed the framework into a framework for reflection (see Table 8.4).

The main objective of this framework for reflection is to support deliberation and contemplation with respect to the strategies for authority pursued by science institutions in sustainability governance. The questions that we used in our analysis to deconstruct and critically reflect on the claims and strategies for salience, credibility and legitimacy are provided in the framework. By posing these questions, we aim, first of all, to support explicit reflection on the intentions and rationales for pursuing certain strategies in support of salience, credibility or legitimacy. As our analysis points out, strategies for salience, credibility and legitimacy often remain hidden or implicit; only by explicating these strategies is further reflection on their implementation and effects possible.

Second, questions posed in the framework focus on the potential discrepancy between the claims of science institutions and their implementation in practice. Our analysis points out numerous instances in which claims and reality lie far apart. However, also in cases where these discrepancies appear less obvious, we contend that reflection on the particular way in which a strategy becomes implemented can yield surprising new insights.

Finally, we aim to support sensitivity to inequalities and power imbalances that might inhibit the implementation of strategies, or could, unintendedly, follow from the pursuit of particular strategies. This is particularly important with respect to the emerging mode of solutionsoriented science engagement, which is characterised by claims for inclusiveness and participation. Our study as well as other empirical research of inclusiveness and participation point out that the rationales shaping these strategies are diverse, and that their implementation in practice requires further careful scrutiny in order to avoid reproducing dominant structures, 
and to actually allow for and support inclusive participation in science for sustainability (Esguerra et al., 2017; Lövbrand et al., 2015; Chapter 5).

In conclusion, our framework does not propose a particular "right" way for science-based initiatives to engage in sustainability governance. The questions we pose are rather meant as a starting point. We do not claim to be comprehensive in covering all dimensions of science authority, but hope that our framework will stimulate debate, raise new questions, and support further reflection in order to improve the quality of science engagement in sustainability governance. 
Table 8.4 A framework for reflection

\begin{tabular}{|c|c|c|}
\hline ASSESSMENT-ORIENTED & ADVICE-ORIENTED & SOLUTIONS-ORIENTED \\
\hline $\begin{array}{l}\text { Rationale and intention } \\
\text { - Why is integration of (scientific) } \\
\text { knowledge important? What are } \\
\text { possible drawbacks of } \\
\text { integration? } \\
\text { Which knowledge should be } \\
\text { integrated? Why is this } \\
\text { knowledge relevant? For what } \\
\text { purpose? For whom? } \\
\text { Implementation } \\
\text { How are different forms and } \\
\text { sources of knowledge included } \\
\text { in the assessment? } \\
\text { What procedures } \\
\text { support/inhibit the inclusion of } \\
\text { different types of knowledge? } \\
\text { Can the promise of } \\
\text { comprehensiveness be fulfilled? } \\
\text { Are certain perspectives, issue } \\
\text { areas or approaches omitted? }\end{array}$ & $\begin{array}{l}\text { Rationale and intention } \\
\text { - What kind of advice is needed } \\
\text { from science? } \\
\text { Who can speak on behalf of } \\
\text { - Wcience? } \\
\text { Which disciplines, issue areas } \\
\text { or approaches should be } \\
\text { included in a science } \\
\text { perspective? } \\
\text { Implementation } \\
\text { - Which knowledge is included } \\
\text { in the advice? } \\
\text { Who speaks on behalf of } \\
\text { science? } \\
\text { What potential tensions come } \\
\text { with the dual role of } \\
\text { independent advisor and } \\
\text { advocate for the role of science } \\
\text { in governance? }\end{array}$ & $\begin{array}{l}\text { Rationale and intention } \\
\text { - What kind of solutions can } \\
\text { science provide? } \\
\text { For whom should solutions } \\
\text { be developed? At which level? } \\
\text { For which actors? } \\
\text { Implementation } \\
\text { - Which actors are asked to } \\
\text { participate in the development } \\
\text { of solutions? Which are left } \\
\text { out? } \\
\text { What kinds of solutions are } \\
\text { developed? At which level? } \\
\text { For which problems? Who } \\
\text { benefits? Who loses? }\end{array}$ \\
\hline Credibility through peer review & $\begin{array}{l}\text { Credibility through individual } \\
\text { credentials }\end{array}$ & Credibility through community \\
\hline $\begin{array}{l}\text { Rationale and intention } \\
\text { - What is the main purpose of } \\
\text { peer review? What are possible } \\
\text { drawbacks of peer review? } \\
\text { Who should be allowed to } \\
\text { conduct peer review? Who is } \\
\text { considered a credible peer? }\end{array}$ & $\begin{array}{l}\text { Rationale and intention } \\
\text { - When can someone be a } \\
\text { - } \quad \text { Tonsidered a credible expert? } \\
\text { experts speak for (a field of) } \\
\text { science? }\end{array}$ & $\begin{array}{l}\text { Rationale and intention } \\
\text { - When and how can a scientific } \\
\text { community provide credibility } \\
\text { to science institutions? } \\
\text { - How is the community } \\
\text { defined? Who is part of it? } \\
\text { Who is not? }\end{array}$ \\
\hline $\begin{array}{l}\text { Implementation } \\
\text { - Is the peer review process } \\
\text { comprehensive and in-depth? } \\
\text { Who is allowed and able to take } \\
\text { part in peer review? Whose } \\
\text { perspective and expertise are } \\
\text { included? } \\
\text { Does the peer review process } \\
\text { support/inhibit input from } \\
\text { particular perspectives? }\end{array}$ & $\begin{array}{l}\text { Implementation } \\
\text { - Which individuals are } \\
\text { considered capable of } \\
\text { upholding the credibility of } \\
\text { science institutions? Why? } \\
\text { Based on which rationales is a } \\
\text { certain (group of) expert(s) } \\
\text { selected? } \\
\text { What is the role of these } \\
\text { individuals within in the } \\
\text { institution? Are they active } \\
\text { participants or do they have an } \\
\text { advisory or symbolic role? }\end{array}$ & $\begin{array}{l}\text { How should this community } \\
\text { be represented? What } \\
\text { mechanisms or procedures } \\
\text { support community } \\
\text { representation? } \\
\text { Implementation } \\
\text { - How are the expertise and } \\
\text { perspectives of 'the } \\
\text { community' represented? } \\
\text { Does the defined community } \\
\text { feel part of the initiative? } \\
\text { What can be done to better } \\
\text { represent the community? } \\
\text { Are claims to speak on behalf } \\
\text { of the community justifiable? } \\
\text { Why (not)? }\end{array}$ \\
\hline
\end{tabular}


Table 8.4 A framework for reflection (continued)

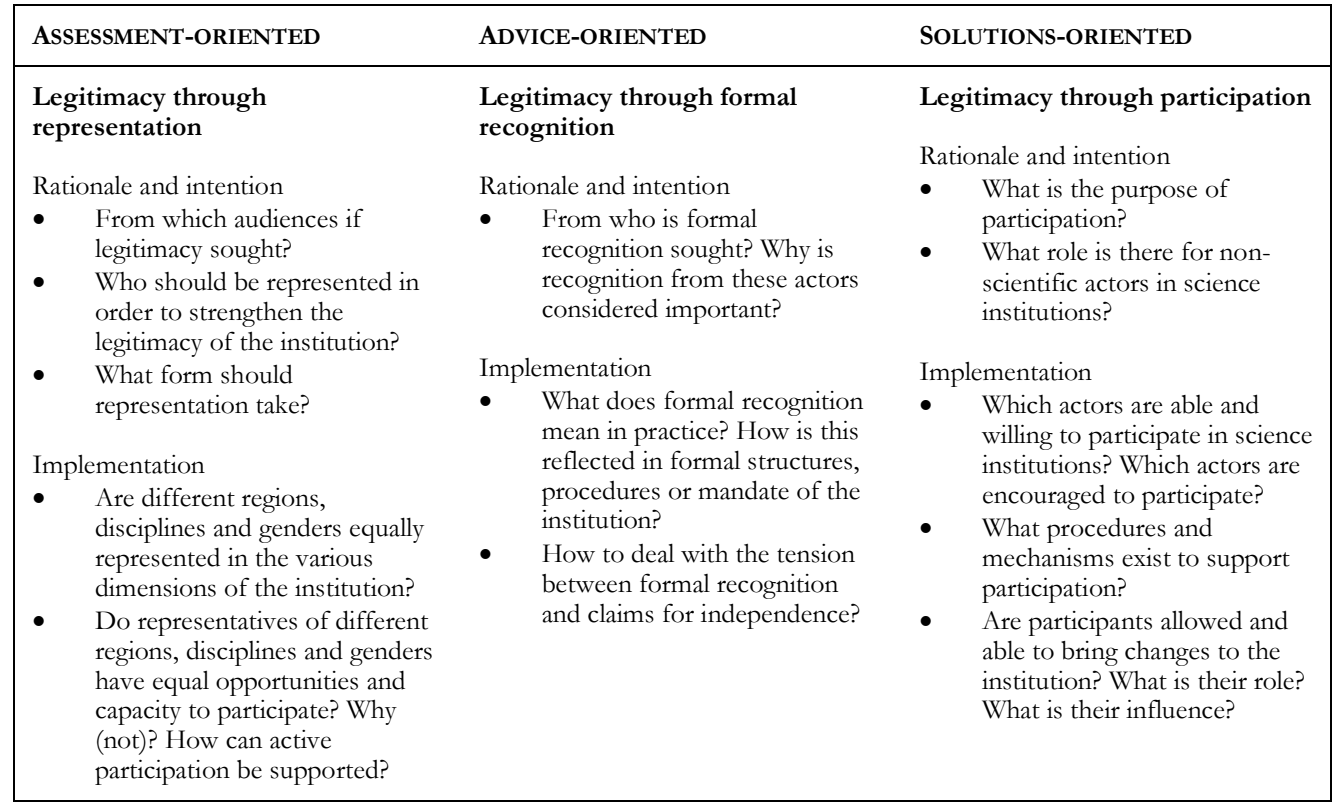




\section{9 - Epistemic authority and institutional design}

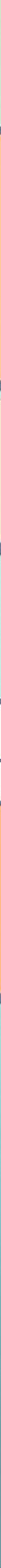


This chapter brings together insights on institutional design of co-production and epistemic authority in sustainability governance. The chapter is based on a comparison of IPBES and Future Earth. Both knowledge platforms aim to institutionalise participation at the global level. The comparison shows that the institutionalisation of participation is shaped by the way in which these knowledge platforms seek epistemic authority (specifically from whom), which in turn shapes whose and which knowledge is presented as legitimate in global environmental politics. It thus highlights the politics of institutionalising participatory ambitions. Institutional designs of participation allow for the inclusion of a wider set of knowledge and experiences. Yet, in seeking epistemic authority knowledge platforms also reinforce existing power structures by redrawing boundaries that protect scientific autonomy and privilege relationships with elite actors.

Accepted for publication ${ }^{24}$ :

Esguerra, Alejandro \& Sandra van der Hel. 2021. Participatory Designs and Epistemic Authority in Knowledge Platforms for Sustainability. Global Environmental Politics. (in press)

\footnotetext{
${ }^{24}$ This co-authored chapter uses the pronoun 'we'. The chapter is based on equal contribution by the authors.
} 


\subsection{INTRODUCTION}

Global environmental politics deals with highly complex issues, which makes knowledge an integral part of environmental governance (Dooley \& Gupta, 2017; Lidskog \& Sundqvist, 2015; Littoz-Monnet, 2017). States, firms and international organisations follow the advice of expert organisations ${ }^{25}$ because of their epistemic authority - their authoritative claim to relevant knowledge (Haas, 2017). In the ozone regime, for example, like-minded experts successfully supported policy-makers in the development of the Montreal Protocol (Haas, 1992). In the climate regime, the Intergovernmental Panel for Climate Change (IPCC) provides scientific evidence the risks of climate change (Beck \& Mahony, 2018). Yet, expert organisations are increasingly criticised for failing to deal effectively with the urgent, complex and contested challenges of global change (Haas \& Stevens, 2011) and for neglecting to include knowledge sources from outside of elite science (Stirling, 2008). In response, scholars and practitioners alike call for "opening up" (Stirling, 2008) expert organisations by expanding participation in order to enhance the relevance of expertise for addressing environmental problems and supporting sustainability transformations (De Pryck \& Wanneau, 2017; Garard \& Kowarsch, 2017; Opgenoorth et al., 2014; Turnhout et al., 2012).

In this chapter, we present an empirical comparison of two new expert organisations that claim to innovate expertise by adopting the imperative of participation - the Intergovernmental Platform for Biodiversity and Ecosystem Services (IPBES) and the research platform Future Earth: research for global sustainability. Founded in 2012, IPBES is an intergovernmental organisation that aims to provide policymakers with state-of-the-art knowledge regarding biodiversity, as well as tools and methods to protect and sustainably use natural assets. Future Earth, founded also in 2012, is a research organisation that strives to integrate and coordinate solutions-oriented science for sustainability. These organisations differ in their foundations as assessment versus knowledge-generating institutions, yet they share an explicit commitment to participation at the global level. As such, they form two contrasting institutionalisations of the "participatory turn" (Bäckstrand, 2003) in global knowledge production. To conceptualise this development, we introduce the notion of knowledge platforms for sustainability as a new type of expert organisation that not only rhetorically embraces, but also attempts to institutionalise the norm of stakeholder participation.

Institutionalising stakeholder participation requires innovation in the institutional design of expert organisations. The design of expert organisations has long been guided by principles of consensus, autonomy and policy relevance without being prescriptive (Beck \& Mahony, 2018; Haas, 2017; Keller, 2010). These principles are challenged by the inclusion of new actors and

\footnotetext{
25 This chapter uses the term expert organisation which is a common term in the IR and STS literature. The term expert organisation largely overlaps with the use of the term science institution in this thesis. The term science institution specifically draws attention to institutions with their roots in the scientific community, while the term expert organisation can be understood as broader, including expert organisations in different domains. The term institutions as used in this thesis goes beyond organisational elements alone, and includes also informal norms and procedures. Here, we draw attention to the institutional design of expert organisations.
} 
multiple perspectives in environmental knowledge making. Thus, while stakeholder participation in knowledge platforms for sustainability promises to increase the legitimacy of global environmental knowledge, it also challenges the conventional foundations of epistemic authority. This apparent tension inspired us to examine empirically how epistemic authority is constructed and maintained (Beck et al., 2017; Kunseler \& Tuinstra, 2017). Therefore, we ask how and with what effects do knowledge platforms for sustainability strive for epistemic authority?

More specifically, we consider three dimensions of the relationship between epistemic authority, participation and the design of knowledge platforms for sustainability. First, we consider how seeking epistemic authority shapes the institutional design of knowledge platforms. Here, we pay attention to the various participatory designs proposed and the negotiations over design choices. Second, we consider how design choices, in turn, shape how participation is enacted, i.e. who can participate in knowledge platforms and in what way. Third, we ask how institutional designs of participation affect epistemic authority. That is, we consider both whose and which knowledge comes to be considered true and relevant for sustainability, and which actors are likely to accept these knowledge claims. In other words, we investigate how epistemic authority is both a driver and an outcome of the way participation is institutionalised in knowledge platforms for sustainability (Figure 9.1).

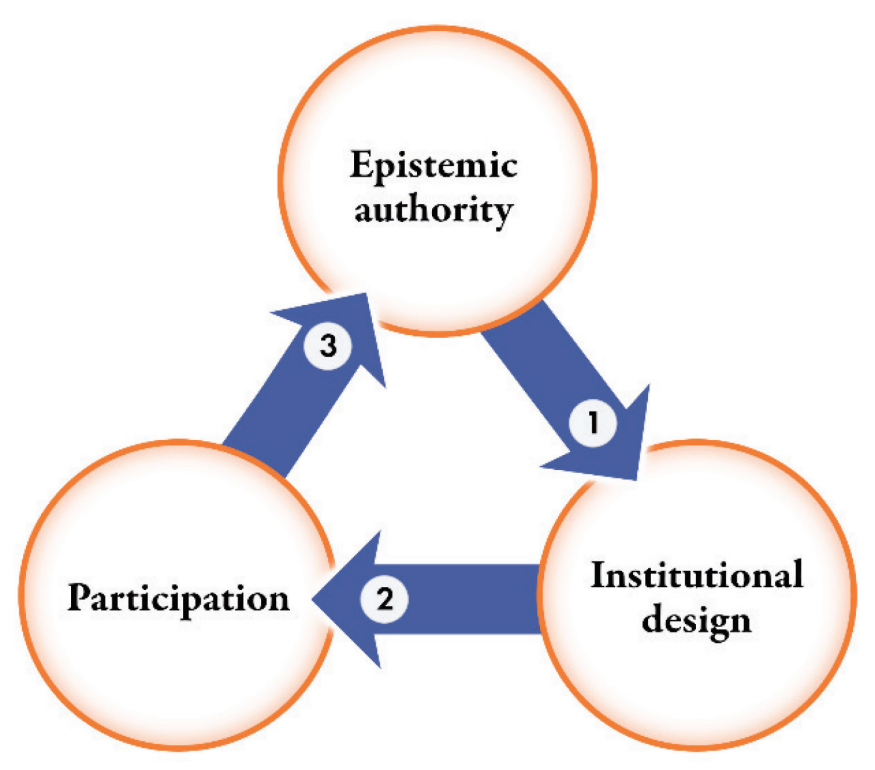

Figure 9.1 The relationship between epistemic authority, institutional design and participation in knowledge platforms for sustainability (1) Seeking epistemic authority affects institutional design; (2) Institutional design affects who can participate in knowledge platforms for sustainability and in what way; (3) Participation affects whose and which knowledge comes to be considered as true and relevant. 
The next section introduces the notion of knowledge platforms for sustainability. Subsequently, we argue for a dynamic perspective on authority based on three literatures in International Relations (IR) and Science and Technology Studies (STS) and operationalise an institutional design perspective that focuses on epistemic authority in the making. The empirical section presents two cases of knowledge platforms for sustainability - IPBES and Future Earth - and highlights ongoing negotiations and contestations over different elements of these platforms' institutional designs. We discuss these findings in the conclusion and outline the implications for global environmental politics.

\subsection{KNOWLEDGE PLATFORMS FOR SUSTAINABILITY}

With the "participatory turn" in knowledge making, a specific type of expert organisation has emerged, which we call knowledge platforms for sustainability. They adopt the principle of participation at the global level (Esguerra et al., 2017; van der Hel, 2016). Knowledge platforms for sustainability differ from other expert organisations in their ambition to advance a participatory format which includes a broad array of experts and stakeholders. They assess state-of-the-art knowledge as well as catalyse efforts to generate new knowledge for sustainability and provide this knowledge to various audiences in order to guide societal transformation (Garard \& Kowarsch, 2017; De Pryck \& Wanneau, 2017; Beck \& Forsyth, 2019). Their platform character aims at facilitating connections between knowledge holders and decision-makers, including both public and private actors (Gustafson \& Lidskog, 2018).

These new tasks and roles create tensions between conventional forms of epistemic authority and novel forms of legitimising that authority through the participation and inclusion of different knowledge systems (Haas, 2017). First, the imperative of participation questions the exclusive relationship between states and expert organisations. This relationship, which forms the basis of "politically delegated epistemic authority," is, for example, foundational to the IPCC, which is commissioned by governments to provide an authoritative assessment of the state of climate knowledge (Zürn et al., 2012, 91). With the opening up to non-state actors as both intended audience and participants in knowledge production and assessment, knowledge platforms for sustainability challenge this privileged relationship between science and state. Second, knowledge platforms challenge the exclusive access of scientists to preside over the pursuit and interpretation of scientific findings. For example, the IPCC is considered successful in speaking "on behalf of global science with one voice, thereby acquiring a reputation as the epistemic authority in matters of climate policy" (Beck et al., 2014, p. 80). The effort to open up involves expanding the number of contributors, rethinking what forms of knowledge are legitimate, and thus, calling into question the exclusive position of science. Together, this dual challenge creates a need for knowledge platforms for sustainability to rethink the relationship between science and politics. 


\subsection{EPISTEMIC AUTHORITY IN GLOBAL ENVIRONMENTAL POLITICS}

Our aim is to explain how and with what effect knowledge platforms for sustainability strive for epistemic authority. We define epistemic authority as the authoritative interpretation of relevant knowledge for governance. In this definition we use the term knowledge instead of science to indicate that we are interested in the multiple forms of knowledge that are potentially mobilised by knowledge platforms for sustainability. Moreover, we use the term governance instead of policy-making to indicate that we focus on multiple actors, including policy-makers as well as other public and private actors that make up potential 'audiences' of knowledge platforms for sustainability (similar to e.g. Beck et al., 2017).

Different analytical traditions have developed concepts on epistemic authority. First, in global environmental politics scholars have drawn from the foundational work of Peter Haas (1992) on epistemic communities. Epistemic communities - networks of scientific experts within a specific policy area - may affect states' behaviour because of their authoritative claim to consensual, policy-relevant knowledge. For Haas, expert organisations "rely on willing deference by their audiences" given the "absence of conventional material capabilities for inducing (...) others to adhere to their analysis" (Haas, 2017, p. 221). Their epistemic authority ultimately rests on the legitimacy of scientific communities and assessments as perceived by states, international organisations, and private actors. That is, when expert organisations are regarded as legitimate, they carry authority. This perspective largely aligns with the literature on global environmental assessments (GEAs) that puts forward salience, credibility and legitimacy as three important conditions for effectiveness (Cash et al., 2003; Mitchell et al., 2006). Thus, this perspective advances an understanding of epistemic authority based on a set of principles that expert organisations can or should achieve. Epistemic authority, in other words, is the causal variable that explains why states or firms defer to scientific claims and may ultimately change their behaviour.

Second, a different take on epistemic authority comes from STS. Whereas the approaches above understand epistemic authority as the explanans (that which explains), the STS perspective, in contrast, focuses on the construction of epistemic authority itself so that authority turns into the explanandum (that which should be explained) (see Hajer \& Pelzer 2018, p. 223). This approach examines epistemic authority as 'in the making', which is to ask how the authoritative claim to relevant knowledge for governance comes about. Rather than thinking of epistemic authority as built on a specific set of principles, attention is placed on the practices through which authority is acquired, protected, challenged and expanded. An STS perspective on epistemic authority raises questions about, "who belongs within the relevant expert collective, and hence is entitled to speak for it, as well as who does not belong" (Beck et al., 2017, p. 1068). Conflicts over epistemic authority are mainly about who has the right to speak for science. That right is potentially challenged by the participatory turn in scientific knowledge production. As Sheila Jasanoff has argued, "[t]horoughgoing changes in the production of science cannot but affect the foundations of scientific authority" (Jasanoff, 2005, p. 213). From 
this perspective, it thus becomes relevant to ask how participation in scientific knowledge production affects the making of epistemic authority.

Third, conceptualising epistemic authority as 'in the making' resonates with recent advances in IR on authority in global governance (Krisch, 2017; Sending, 2017). This scholarship recognises that authority "is often contested and has to be regained in competition and cooperation" (Krisch, 2017, p. 245). Ole Jacob Sending in particular has challenged IR scholarship to provide analytical tools to explain how consensus emerged within an epistemic community, "and how this particular group prevailed over others to become recognised as an authority” (Sending, 2015, p. 4). According to Sending, epistemic communities, international organisations and, in extension, knowledge platforms compete with other actors for recognition as authorities in the interpretation of relevant knowledge (Sending, 2015).

In this chapter, we suggest that all three analytical traditions agree that epistemic authority is about the authoritative interpretation of relevant knowledge for governance, including its exclusive and selective effects (Haas, 2017; Beck et al., 2017). We expand Haas' work by examining epistemic authority in the making. The integration of STS and recent IR approaches allows us to inquire how epistemic authority is made, contested and reinvented (Allan, 2017; Lidskog \& Sundqvist, 2015). In particular, we are interested in how, in response to changes in the conditions and demands made of global environmental politics, knowledge platforms strive for epistemic authority (Sending, 2017). They do so by interacting with people and groups inside and outside of the expert community (Lidskog \& Sundqvist, 2018) and by negotiating the institutional designs that shape the making of environmental knowledge (Beck et al., 2017; Montana, 2019).

\subsection{STUDYING INSTITUTIONAL DESIGNS OF PARTICIPATION}

We operationalise this dynamic perspective on epistemic authority by investigating how actors negotiate the institutional designs of knowledge platforms for sustainability as a means to strive for recognition. Scholars in STS have been particularly vocal in stressing that "expertise does not simply lie in specific exercises of knowledge-making" but also in "the institutional dynamics in which knowledge is rendered authoritative" (Beck et al., 2017, p. 1069). Institutional designs define the power relations between participants and bring about specific knowledge products (Montana, 2019). From this perspective, we regard design choices as the locus where the dynamic and contested nature of epistemic authority becomes visible (Miller \& Wyborn, 2019).

Studying the ways in which knowledge platforms for sustainability reconfigure epistemic authority, we compare the participatory design choices of IPBES and Future Earth. We inquire how and why IPBES and Future Earth struggle and differ in their attempts to institutionalise participation. More specifically, we first consider (a) why in each organisation actors have suggested institutionalising principles of participation. Then, we investigate how the imperative of participation becomes institutionalised as part of (b) the organisational structures as well as (c) the conceptual frameworks of each case. Both items are key components of the negotiated 
institutional designs that seek to establish the authoritative knowledge of a phenomenon such as biodiversity or sustainability. Finally, we examine (d) the participation strategy that determines who participates and with what rights. With this operationalisation of the why, how, and who, we investigate the struggles over how the making of knowledge is organised in seeking epistemic authority in global governance.

We used rich empirical material to build a comparison of both cases in three stages. First, we conducted document analysis of the IISD reporting service (IPBES), negotiation documents (IPBES and Future Earth) and vision and design documents (IPBES and Future Earth) from 2012 to 2018. Then, we built our analysis on our experience as participant observers at IPBES Plenary Sessions in 2013 and 2015 as well as meetings of Future Earth in 2012 and 2016. Finally, we analysed opinion pieces in scientific journals that lobby for distinct designs and refer to the relevant academic literature. Using these different types of materials allowed for a rich understanding of the various proposals for institutional designs, the justifications for design choices, and the negotiations through which the eventual organisational structures, conceptual frameworks and participation strategies of the platforms materialised.

\subsection{INSTITUTIONAL DESIGNS OF PARTICIPATION IN IPBES AND FUTURE EARTH}

\subsubsection{Participatory ambition of IPBES and Future Earth}

Seeking to position themselves as relevant knowledge actors in the domain of sustainable development, both IPBES and Future Earth present themselves as participatory platforms that contribute to solutions for sustainability challenges. In supporting these ambitions, both platforms seek to innovate the institutional design of expert organisations. The resulting design choices are the products of extensive negotiations with many design options on the table.

For IPBES, a gap analysis in the early negotiation phase indicated "the need to include other, non-formal types of knowledge” (UNEP/IPBES/2/2 2009, p. 22). This participatory ambition was also reflected in the actor composition: IPBES started as a multi-stakeholder initiative involving actors as diverse as conservation and indigenous peoples' organisations, prominent scientists involved in global environmental assessments, Multilateral Environmental Agreements and state representatives. IPBES had to position itself in the controversies over the adequate institutional design of expert organisations as well as how a new organisation would fit into the already existing structure of science-policy organisations. Proponents in favour of copying the institutional design of the IPCC argued for an intergovernmental organisation with a global design, staffed by natural scientists and relying on their expertise (Nature, 2010). In contrast, others argued in favor of a multi-stakeholder organisation with a more regional orientation that would take into account diverse knowledge systems including that of indigenous and local communities as well as the humanities. Such a multi-stakeholder organisation, it was argued, would be better fitted to support the ambition to integrate participation not only in matters of politics but also of science and technology (Turnhout et al., 2012). 
Similar to IPBES, Future Earth presents itself as a global, participatory and inclusive knowledge platform. Future Earth was officially launched, also in 2012, at the major academic conference 'Planet under Pressure' (London, March 2012) as well as at the Rio+20 United Nations Conference on Sustainable Development (Rio de Janeiro, June 2012). This dual launch reflects the ambition to play a role in global governance for sustainable development. Future Earth developed on the foundation of several large international research programmes in global environmental change. One of the core principles that distinguishes Future Earth from its predecessors is that of co-production ${ }^{26}$. Co-production of knowledge with societal actors is presented as a new mode of knowledge production essential to addressing the challenges of global sustainability. Co-production, thus, is the way in which Future Earth takes up the imperative of participation. Actors involved in developing the research platform agreed that supporting this ambition called for an innovative institutional design (Future Earth, 2013). However, the process of developing a new global research platform involved considerable discussion about what such a platform should look like, which design would best support the objectives of co-production and participation, and who should be involved in what way. In particular, tensions centred around the role of existing research projects versus new initiatives designed to support co-production and participation. Central to the discussion was a search for the appropriate balance between 'curiosity-driven' research and participatory, co-produced and action-oriented knowledge (Leemans, 2016; Strohschneider, 2016).

Thus, in both cases the ambition of participation forms an important justification for becoming recognised as an epistemic authority. The platforms seek to position themselves as relevant actors in societal transformations toward sustainability and in this endeavour they encounter frictions between their participatory ambitions and conventional ways of producing and assessing authoritative knowledge.

\subsubsection{Organisational structure of IPBES and Future Earth}

Organisational structure formed a main point of debate for actors involved in the development of IPBES and Future Earth. In both cases, discussions centred on how extra-scientific actors would participate and whether they would be observers, advisers, or allowed actual decisionmaking power.

In 2010, state and non-state actors decided to design IPBES as a permanent, intergovernmental organisation open to all member states of the United Nations (UNEP/IPBES/3/3 2010). This came with the hope that governments would take IPBES' deliverables into account since they define procedural rules as well as commission and approve official outputs such as biodiversity assessments. While this reasoning resonates with established notions of expert organisations, it only partially reflects IPBES' origin as a multi-

\footnotetext{
${ }^{26}$ We use the term co-production as an empirical concept - i.e. as an objective advanced by Future Earth. This interpretation differs from the analytical understanding of co-production developed in STS that examines the constant co-production of science and social order (see Chapter 2 and Miller \& Wyborn, 2019).
} 
stakeholder initiative that attempts to involve traditionally underrepresented actors such as indigenous peoples and local communities.

Specific elements of IPBES' organisational structure depart from the established path of organisational designs for expert organisations. For instance, IPBES' knowledge-generating body, the MEP, is referred to as an expert body as opposed to a science body. ${ }^{27}$ This shift from scientist to expert reflects an inclusion of more diverse knowledge systems. Natural sciences should be complemented by the social sciences and humanities; holders of indigenous knowledge should balance the often Western, white, male, "scientific" perspective. To realise this shift, IPBES has introduced rules for the appointment of 25 experts that aims for a balance of representation in region, gender and discipline, and includes indigenous knowledge (IPBES, 2012; Kovács \& Pataki, 2016). However, IPBES has so far not succeeded in fully realising this balance. Critics have called upon IPBES to "play by [the] rules" it set for itself, and to do a better job in involving "non-elite actors" (Opgenoorth et al., 2014). Yet governments barred the creation of an institutional sub-body of IPBES in which stakeholders would oversee their contributions to the organisation. Instead, stakeholders are invited to organise themselves in an open-ended network that has no formal role in the institutional architecture of the organisation.

Whereas IPBES is set in an intergovernmental context, Future Earth developed in a research landscape with a clear focus on advancing science. in which societal engagement was of secondary importance. In the transition from global change research programmes to Future Earth, a major point of discussion concerned the elaboration of an organisational structure that would support stronger engagement with, and the involvement of, societal stakeholders. Eventually, a dual advisory structure was established consisting of a Science Committee and an Engagement Committee with equal status (Future Earth, 2013). The Science Committee brought together internationally respected scientists from a variety of disciplines, whereas the Engagement Committee consisted of societal stakeholders. A core argument for this dual structure was that it would give extra-scientific stakeholders a strong position in the platform, while also guaranteeing scientific rigor and nimbleness (Leemans, 2016). Yet, the advisory structure was also criticised, not least by its own members, for not living up to the participatory ambition of Future Earth. The critique suggested that the dual structure of both a Science Committee and an Engagement Committee effectively separated the 'science' of Future Earth from external influence by limiting the counsel of extra-scientific actors to matters of engagement. After a few years of operation, the two committees were succeeded by a single Advisory Committee. The Advisor Committee comprises of 'high-level representatives of scientific and stakeholder communities,' most of whom hold high-level positions at public and

\footnotetext{
${ }^{27}$ The MEP operationalise and integrate governments' requests as well as oversee the selection of expert groups that are tasked to carry out IPBES deliverables.
} 
private organisations and have strong scientific track records (Future Earth, 2018a) ${ }^{28}$. As such, responsibility for Future Earth's scientific agenda and output remains deeply rooted with experts who have earned their scientific credentials. The main decision-making power in Future Earth, however, lies with its Governing Council.

The Governing Council is the main decision-making body of Future Earth and is responsible for setting strategic directions. It was initially envisioned as a multi-stakeholder body "of scientists, policymakers, development actors, representatives of business and industry, civil society and other stakeholders" (Future Earth, 2013, p. 44). However, when Future Earth became operational the role of the Governing Council was taken on by the alliance of international science councils, science funders and UN organisations that had instigated the platform. As such, rather than opening up the platform to external stakeholders, the role of these initiating actors and sponsors was reinforced. In 2018, however, the Governing Council was formally opened up to include three types of voting members: representatives of 'supporting partners'; representatives of 'international organisations'; and 'strategic leaders' in sustainability transformations (Future Earth, 2018b). The platform thus seeks further support of and recognition from key actors in international environmental governance by attracting 'international organisations' and 'strategic leaders' to its governing body. At the same time, the decision-making role of funders of global sustainability research ('supporting partners') remains prominent.

Taken together, we find ongoing struggles over the organisational design of IPBES and Future Earth. The (de)institutionalisation of designs reflects the tensions between different perspectives on the participation of stakeholders in knowledge platforms for sustainability. Instead of simply implementing a ready-made model, platforms experiment, muddle through, and call for more participation, while dealing with concerns for recognition by states and the science community.

\subsubsection{Conceptual framework of IPBES and Future Earth}

The conceptual frameworks of knowledge platforms reflect how they establish knowledge of phenomena such as biodiversity and sustainability, and what knowledge is considered relevant. For IPBES and Future Earth, the ambition to include different ways of knowing forms a driving force behind the development of and contestations over their conceptual frameworks.

IPBES' innovative conceptual framework operates as a guiding, "simplified model of the complex interactions between the natural world and human societies" and structures IPBES' current and future work program (Díaz et al., 2015). The process of negotiating this framework revealed a tension between two competing positions on ways of knowing biodiversity. (Borie \& Hulme, 2015; Hughes \& Vadrot, 2019). One focuses on the concept of “ecosystem

\footnotetext{
${ }^{28}$ Of the thirteen members of the Advisory Committee (November 2018), twelve members hold a doctorate degree. Ten members of the committee, including the two co-chairs, have a professorship and hold or have held leadership positions in academia.
} 
services". This concept has become influential in operationalising nature or biodiversity as goods and services. For the proponents of this concept, there is nothing suspect about the approach since it links scientific knowledge on biodiversity with policy-making by the identification of goods and the assignment of value to them. The notion of value can be stretched to include non-economic values such as recreational activities. The other position has been most prominently articulated by the Bolivian delegation. Bolivia demanded that the conceptual framework be organised around the notion of Mother Earth (iisd, 2013a). This underlines the importance of indigenous knowledge and more broadly, other knowledge systems. Advocates of this position join critics of the ecosystem services approach in suggesting that the very notion of ecosystem services is a manifestation of nature's commodification (Turnhout et al., 2013). They argue against the idea that ecosystem services are a neutral vehicle for engaging with policy-makers and assert, instead, that these services are as deeply political as the notion of Mother Earth.

Both camps in the negotiations accused the other of arguing politically over knowledge-making processes. A compromise was developed that allows both framings to be true and is illustrated with a color-coding of the framework. It recognises "ecosystem services," indicated with green as well as a holistic notion of biodiversity in the concept of "Mother Earth," indicated with blue (Figure 9.2). This demonstrates that the recognition of plural views on nature and biodiversity have become an integral part of the discourse that structures IPBES (Borie \& Hulme, 2015). Yet, the recognition of "contrasting rationalities, diverging ontological claims, and different criteria for knowledge validation" remains to be realised (Löfmarck \& Lidskog 2017, p. 28). Two worlds of knowing biodiversity are presented side by side without a vision for integrating them. 


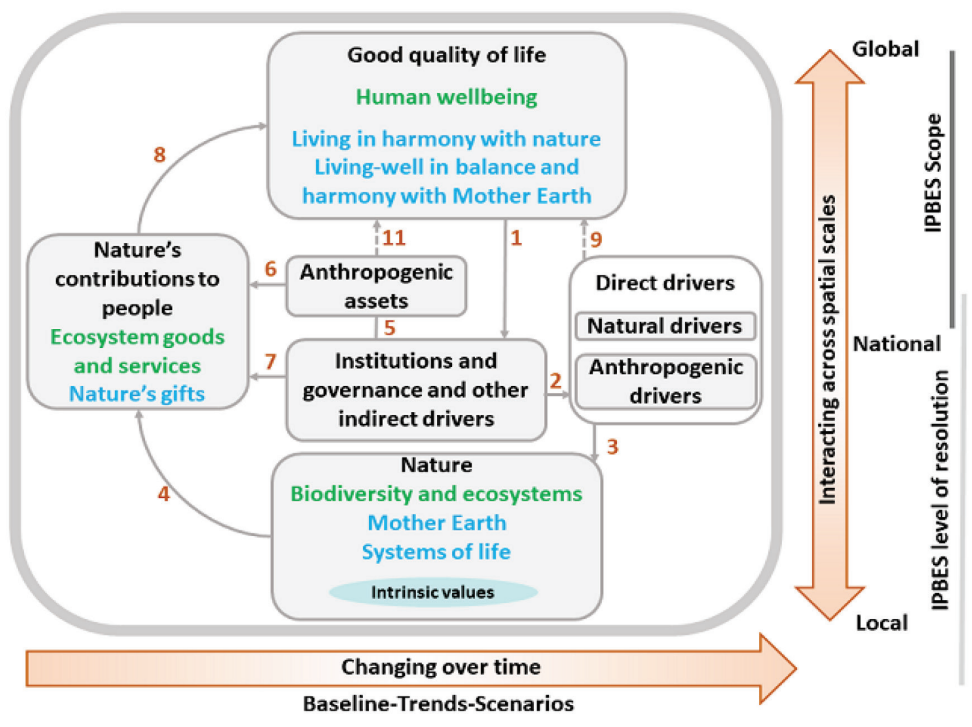

Figure 9.2 The IPBES Conceptual Framework-connecting nature and people (Diaz et al., 2015)

An initial conceptual framework for Future Earth was developed during a two-year visioning process, the aim of which was to "explore options and propose implementation steps for a holistic strategy on Earth system research" (ICSU 2010, p. 2). This strategy and research agenda would have to reflect knowledge and experiences from a diversity of disciplines, including the natural sciences as well as the social sciences and humanities (De Pryck \& Wanneau, 2017). One of the main outcomes of the visioning process was the identification of five grand challenges - forecasting, observing, confining, responding and innovating (Figure 9.3) - as the main rationale for the new research platform. These challenges, and those of forecasting and observing in particular, reflect the strengths of earth system science, based in the natural sciences, as developed in the previous decades of global change research. During the visioning process, scholars from the social sciences and humanities in particular suggested that the notion of responding should be prioritised as the main aim of the platform, thereby informing other challenges (Lahsen, 2016). This discussion was, however, not reflected in the final model. The five grand challenges were presented as a core justification for why a large integrated research platform such as Future Earth was needed, thus reinforcing a relatively narrow relevance rationale based on natural science research.

Yet, during the subsequent development of Future Earth, the grand challenges framework retreated to the background and was largely replaced by a conceptual framework building on the "fundamental interconnections between natural and human drivers of change" (Future Earth 2013, p. 12). This model of global sustainability research is presented as an innovation that foregrounds the 'social heart' of global environmental change research (Hackmann et al., 2014; Castree, 2015). It forms the basis of Future Earth's three main research themes: dynamic planet, global development and transformations toward sustainability (Future Earth, 2013). 


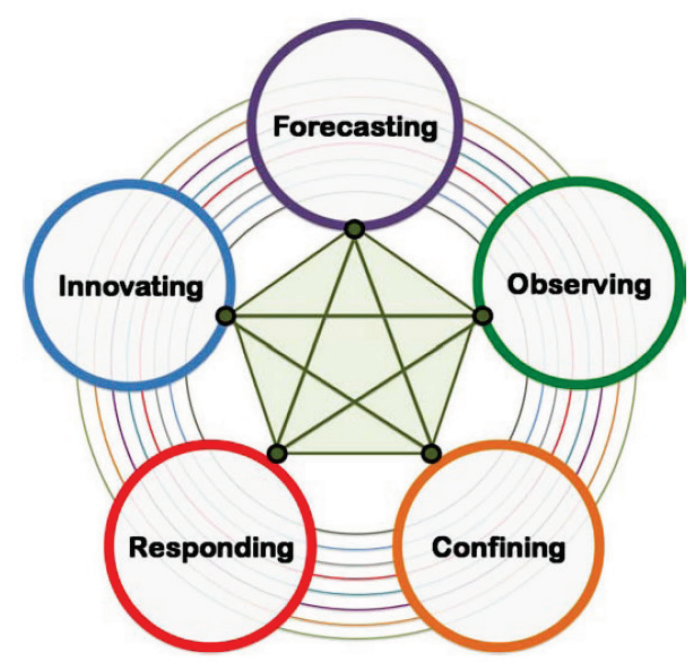

Figure 1: Grand Challenges in Earth System Science for Global Sustainability. The concentric circles represent the disciplinary research needed in the social, natural, health and engineering sciences and the humanities that must be carried out alongside interdisciplinary and transdisciplinary research in order to address the challenges. The lines linking the grand challenges show that progress in addressing any challenge will require progress in addressing each of the others.

Figure 9.3 Grand Challenges conceptual model developed as part of the visioning process that preceded the development of Future Earth (ICSU, 2010)

Overall, IPBES' and Future Earth's conceptual frameworks present different perspectives on the knowledge and actors that they represent as well as the objects of knowledge that are created as a result of their design. IPBES' conceptual framework reflects ongoing controversies about the precise definition of terms and their political implications (Hughes \& Vadrot, 2019). The changes in Future Earth's conceptual framework illustrate developments in the way the platform seeks to position itself and the knowledge it generates as relevant and legitimate in addressing major sustainability challenges.

\subsubsection{Participatory strategies of IPBES and Future Earth}

Participatory ambitions of knowledge platforms for sustainability are put into practice through the formation of participatory strategies. For both IPBES and Future Earth, the question of who participates and on what grounds was highly debated. Eventually, both platforms developed their own unique institutional strategies for realising their participatory ambitions.

In 2013, relevant stakeholders were invited to develop, in consultation with IPBES sub-bodies, a stakeholder engagement strategy (IPBES, 2013) out of which arose a first set of controversies concerning issues of representation. The plenary had delegated the facilitation of the process to two major NGOs, the International Council for Science (ICSU) and the International Union for the Conservation of Nature (IUCN). Although most organisations agreed with this process, some indigenous organisations stressed that ICSU and IUCN cannot speak for all stakeholders and underlined the need to "recognize the diversity of [stakeholder] groups collaborating with the Platform" (iisd, 2013b). In addition, sub-bodies of IPBES frequently changed the drafts prepared by stakeholders. In one extreme case, the secretariat rewrote the participation strategy, resulting in stakeholder resistance. Those who objected argued that only the strategy 
developed by the stakeholders themselves would enjoy any legitimation due to the extensive consultative process (IUCN et al., 2014).

Throughout the process, the notion of stakeholder remained an essentially contested category. ICSU and IUCN claimed that "stakeholders should be seen as a relationship of partners and not just unspecified generic 'stakeholders' (ICSU \& IUCN, 2013). Similarly, the indigenous peoples' representative demanded that "IPBES ... must recognize ....indigenous peoples and local communities, as knowledge-holders, rights-holders, and partners, and recognize our distinct contribution to the platform" (Carino, 2013). Notions of rights-holders and partners appeared throughout the drafting process, but IPBES sub-bodies filtered out these categories because a rights-based terminology would grant non-state actors rights within the intergovernmental setting. Most states try to prevent such a situation.

The resulting adopted strategy defines stakeholders as "(a) Contributors: scientists, knowledge holders and practitioners and (b) End users: policymakers" (IPBES, 2014, p. 3). This terminology suggests that stakeholders are invited as knowledge holders with an instrumental, rather than a democratic, vision of stakeholder participation (Garard \& Kowarsch, 2017). In practice, the notion of stakeholders refers mostly to environmental, conservationist, indigenous peoples and business NGOs as well as Multilateral Environmental Agreements that link IPBES to the UN systems. Stakeholder organisations can access the process of knowledge making by nominating up to twenty percent of the experts for the IPBES deliverables. They are invited to submit review comments on draft documents as well as participate directly as experts or authors. Yet, they hold no formal governing power.

Future Earth's main institutional innovation for supporting participation at the research level are so-called Knowledge Actions Networks. They are presented as the main channel for implementing Future Earth's core principles of co-design and co-production through collaborative knowledge development between scientists and societal partners (Future Earth, 2016b). According to Leemans (2016), many of the global change research initiatives that have transitioned to Future Earth "... were critical on the actual co-design and co-production, a research approach which was often feared as an intrusion on scientific independence” (p. 108). Knowledge Action Networks were meant to signal a departure from the structure of global change research projects, which are based foremost on academic collaboration (Hadley Kershaw, 2018). By September 2018, nine Knowledge Action Networks were at different levels of development, addressing topics ranging from urban issues to oceans to health.

Future Earth refers to participants in Knowledge Action Networks as 'experts within and outside of academia' and aims to 'bring together researchers and experts in policy, business, civil society and more' (Future Earth, 2016b). The role of experts is thus, by design, not reserved for scientific experts alone. The modus operandi of Knowledge Action Networks "is that of generating high quality actionable scientific knowledge through the integration of research and the involvement of societal partners" (Future Earth, 2016b). Actionable and highquality scientific knowledge is here presented as a shared responsibility of scientists and stakeholders. Yet, in the absence of rules and procedures for balancing academic and non- 
academic leadership and participation, participation often remains restricted to scientific actors by default. Moreover, the primacy of scientific knowledge as both starting point and output of Knowledge Actions Networks limits the interest and potential contribution of non-academic stakeholders. This might explain why, in contrast to the presented ambitions, the development of Knowledge Action Networks has been slow in practice. While they present a new and innovative structure, it is one that remains disproportionally populated by actors traditionally involved in global change science.

Altogether, the participation strategies of IPBES and Future Earth present a mixed picture. There are indicators that resonate with the metaphor of "opening up" (Stirling, 2008). Stakeholders populate the intergovernmental negotiations of IPBES as observers, deliver statements in the Plenary, and even access the process of knowledge making. Similarly, Future Earth's Knowledge Action Networks provide spaces for collaborative knowledge making beyond science. At the same time, we observe an absence of institutional rules that would allow for more formal representation (IPBES), or indeed attract other societal actors (Future Earth).

\subsection{CONCLUSION}

Our study of IPBES and Future Earth shows that knowledge platforms for sustainability seek epistemic authority by institutionalising participation at the global level. Our findings reveal how seeking epistemic authority affects institutional design; how design choices shape and enact participation; and how participation, in turn, affects epistemic authority of knowledge platforms for sustainability. Here we discuss our findings and relate them to the literature on epistemic authority in global environmental politics.

We introduced the conceptualisation of knowledge platforms for sustainability in order to examine the trend toward more participatory designs across different types of expert organisations (Garard \& Kowarsch, 2017; van der Hel, 2016; Esguerra et al., 2017). Often, scholarship in global environmental politics takes the IPCC or other global environmental assessments as the main reference point for interaction between science and politics. We argue, with others, that a deeper understanding of global environmental politics requires an expansion of empirical focus as well as a new theoretical approach (Gustafsson \& Lidskog, 2018; Montana, 2019). This presents a shift in perspective for the study of epistemic authority in global environmental politics. Instead of assuming that expert organisations enjoy authority by way of delegation, we show how expert organisations strive for recognition and innovate their institutional designs to connect to different audiences.

How does seeking epistemic authority affect institutional design? As novel expert organisations that seek epistemic authority, both IPBES and Future Earth evoke rhetorical strategies of inclusive participation. We observe that actors in the development of both platforms vividly discussed institutional design choices in support of divergent visions of participation. As recent literature on global environmental assessments suggests, participatory ambitions create tension between conventional and novel foundations of epistemic authority (Haas, 2017). Our analysis makes 
visible that the ambitions of participation are only partly supported by developments in institutional design. This tension between the ambition of participation and other modes of supporting epistemic authority (i.e. based on scientific consensus or state-delegation) is reflected in the development of and contestation over different designs. We show how resulting design decisions depend on interactions with various audiences from which knowledge platforms seek recognition (Gustafsson \& Lidskog, 2018; Sending, 2017). Knowledge platforms are strongly embedded in the existing scientific and intergovernmental contexts of world politics and seeking recognition in different contexts calls for different designs IPBES seeks recognition in the intergovernmental context making it more restrictive regarding membership. Future Earth seeks recognition as relevant actor in sustainability transformations and opens up its design to authoritative governance actors in public and private settings. These findings have implications for research on epistemic communities and GEAs (Mitchell et ., 2006; Haas, 2017). While most of this literature examines institutional design to account for influence, we show how seeking influence affects institutional design. In other words, prominent categories of the GEA literature such as salience, credibility and legitimacy are by no means neutral; instead, they are the product of complex negotiations over who speaks legitimately about the Earth (Lövbrand et al., 2016).

How do design choices shape participation? We utilise a perspective that takes design choices as an inroad into how environmental knowledge is produced, i.e. the contested rules and procedures by which it is made (Beck et al., 2017). From this perspective, institutional designs represent power relations in that they determine who can participate in knowledge making and in what ways (Montana, 2019). We find that the organisational design of IPBES follows an intergovernmental model that limits room for participation by non-state actors. Future Earth's organisational design departs from a conventional model of scientific autonomy by formalising the role of stakeholders in its advisory structure and governing body. However, decisionmaking power is granted mostly to those actors - science councils, funders and UN organisations - with previously established authority in sustainability governance, while the potential for other actors to challenge and shape authoritative knowledge on sustainability remains limited. These design choices restrict access for less prominent or privileged stakeholders to shape authoritative knowledge. The conceptual framework of IPBES is where we find institutional innovation (Borie \& Hulme, 2016; Hughes \& Vadrot, 2019). It institutionalises a new way of knowing biodiversity, based on the holistic notion of 'Mother Earth,' alongside the more conventional science of ecosystem services. Future Earth's conceptual framework also moves beyond the dominant natural science mode of understanding global change and sustainability, but does not (as with the conceptual model of IPBES) explicitly acknowledge knowledge that challenges conventional scientific understandings. The participatory strategies of IPBES and Future Earth present a mixed picture with some instances of opening up as well as a tendency to limit the participation of elite actors. These findings resonate with STS and IR scholarship on epistemic authority in showing that the practices and designs by which authority is acquired, protected, challenged and expanded have important selective effects (Sending, 2015; Beck et al., 2017). Overall, we find 
that both platforms support participation on instrumental grounds (i.e. supporting the legitimacy of the platform and enhancing its impact) rather than by opening up to a diversity of stakeholders in the development of relevant knowledge for biodiversity and sustainability (Beck \& Forsyth, 2019).

How does the design of participation affect epistemic authority? Design choices affect whose and which knowledge claims are presented as true and relevant by knowledge platforms for sustainability. Innovations in design show that relevant knowledge for biodiversity and sustainability is no longer the exclusive domain of the natural sciences. IPBES opens up alternative understandings of biodiversity through its conceptual model. Future Earth invites extrascientific actors to shape relevant knowledge for sustainability as part of its participation strategy. As a result, there is a proliferation of ontologies of environmental knowledge. This "opening up" of knowledge platforms for sustainability challenges conventional foundations of epistemic authority. Conventional wisdom holds that knowledge is powerful when it is consensual, that is, when science speaks with one voice (Haas, 1992). In contrast, participatory designs are more likely to create competing knowledge claims and not consensual knowledge. This diversified knowledge comes about partly through democratic norms such as contestation and accountability rather than conventional scientific norms (Beck et al., 2014; Turnhout et al., 2012). In this model, knowledge can become powerful when it is diverse and multiple (Esguerra, 2015). However, our findings also point in another direction. The opening up of knowledge platforms is limited by the organisational structures and contexts of both organisations. The dynamics of seeking authority continue to reinforce the dominance of actors already involved in global environmental politics, rather than support less powerful stakeholders to inform or challenge knowledge claims.

In conclusion, the power to shape relevant knowledge on biodiversity and sustainability remains with actors with well-established authority in science and governance for sustainability. Even in knowledge platforms for sustainability, scientific autonomy and consensus remain strong foundations for epistemic authority in the conventional sense. And yet, we find instances of participatory design that challenge the model of autonomous, consensus-based and delegated epistemic authority. We see this tension between conventional and novel foundations of epistemic authority as a defining feature of knowledge platforms for sustainability. In the changing landscape of environmental knowledge making and governance, expert organisations will continue to be under pressure to reinvent their designs in order to become recognised and maintain recognition as authoritative voices in the politics of sustainability. 
10 - Conclusion, discussion and future directions

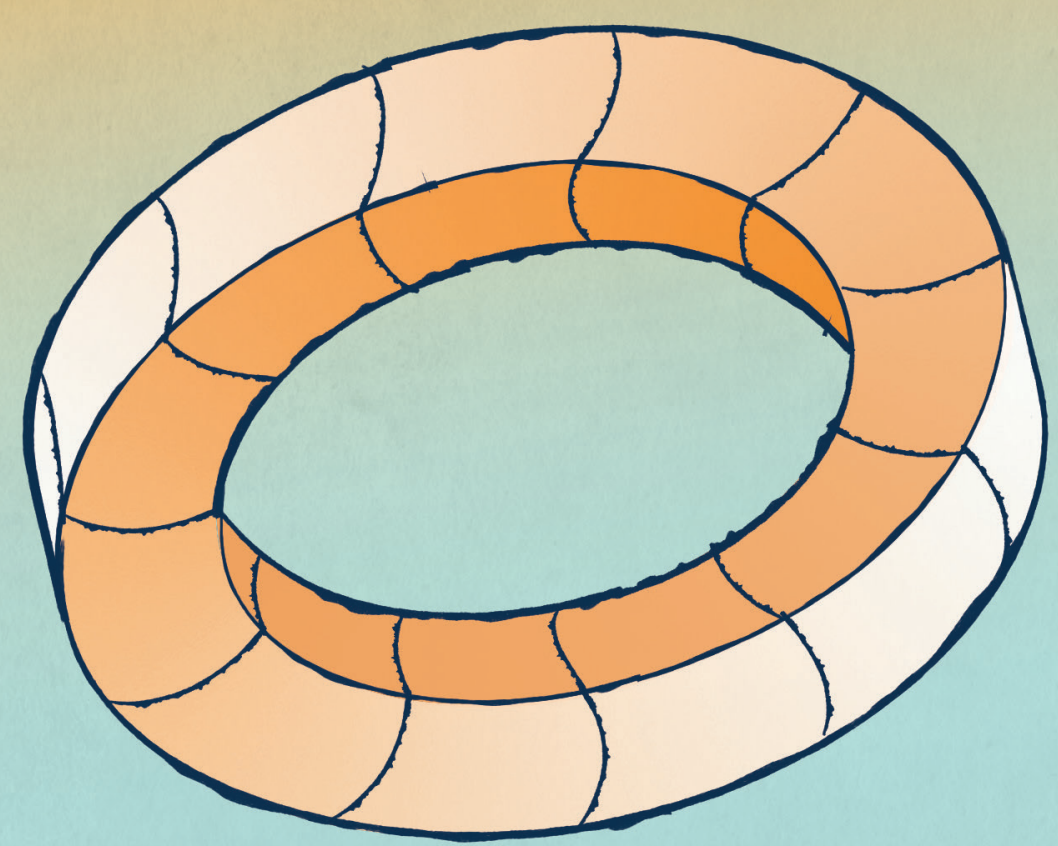




\subsection{INTRODUCTION}

When science transforms from being driven by a desire to understand to being driven by a desire to change, new challenges emerge that go to the heart of science itself. It raises questions about what science is, what science is for and how science relates to governance and societal change. In this final chapter, I draw together insights from the preceding chapters in order to shed light on the institutionalisation and politics of what has become known as science for sustainability.

The ideal of science for sustainability advances a new mode of knowledge production that promises to be better equipped to address complex, urgent and contested challenges of sustainability. Science for sustainability is based on principles of co-production, interdisciplinarity, inclusiveness and solutions-orientation. Supported by a coalition of funders, science councils and intergovernmental organisations, these principles of science for sustainability have moved from the margins to the centre of discussions about the organisation of research at the global level. This trend is captured in the main case study of this thesis: the research platform Future Earth. Future Earth sets forth an ambitious mission - internally referred to as an 'Apollo project' - of fundamentally restructuring global knowledge systems towards 'new science for global sustainability' (Chapter 4). In doing so, it positions principles of science for sustainability at the heart of research on global change and sustainability. Yet, what new science for sustainability should look like exactly, who should be involved and how it could best be supported is subject to much debate. These debates are not confined to Future Earth, but rather represent a broader trend of restructuring research for sustainability that involves universities, research institutes, funding agencies, science-policy organisations and other actors involved in science and governance for sustainability.

In this thesis, I studied Future Earth as a paradigmatic case that gives insight into the broader phenomenon of new science for sustainability and its institutionalisation and politics. Moreover, I compared the development of Future Earth to other global science institutions that take up principles of science for sustainability in seeking to give shape to their ambition to support sustainability transformations.

This thesis was guided by the following main research question:

How are new principles of science for sustainability institutionalised and how does this shape the relationship between science and governance for sustainability?

In response to this question, I found that new principles of science for sustainability form an important rationale shaping Future Earth and other global science institutions on sustainability. Yet, principles of science for sustainability are pursued in support of different aims, which leads to contestations over the appropriate design of science institutions. One broadly shared aim is to inform and shape sustainability transformations, which puts forward an ideal of science as active governance partner in steering societal change. However, the design of science institutions for sustainability also reinforces boundaries between science and politics by rebuilding the myth of neutral and independent science in governance for sustainability. This is 
problematic because it hides the inevitable politics involved in the ambitions, institutions and effects of science for sustainability.

Before further unpacking these claims, I am first returning to the four sub-questions that guided this thesis. In the next section, I will provide an answer to each sub-question by drawing together insights from the relevant chapters (Section 10.2). Based on these building blocks, I will then unpack my response to the main research question (Section 10.3), followed by a discussion of how this thesis contributes to academic debates about the politics of science for sustainability (Section 10.4). Subsequently, I will reflect on the research approach of this thesis and draw out some limitations (Section 10.5). To conclude, I will put forward contributions of this thesis for practice (Section 10.6) and I will place the insights of this thesis in the context of current calls for science to respond to the crisis of unsustainability (Section 10.7).

\subsection{SUMMARY OF FINDINGS FOR RESEARCH SUB-QUESTIONS}

\section{Research question 1: How do new principles of science for sustainability shape global science institutions?}

The first question addresses the institutionalisation of science for sustainability in global science institutions. In my answer to this question, I focussed specifically on the principle of co-production and related ideals of participation in knowledge production for sustainability. I studied how the principle of co-production shaped the design of Future Earth (Chapter 5). Moreover, I compared the institutionalisation of co-production in Future Earth to the institutionalisation of participation in IPBES (Chapter 9).

I found that while the principle of co-production forms an important justification for the development of Future Earth, its institutionalisation in Future Earth was subject to much contestation. The coalition of actors that initiated Future Earth - which includes science councils, funding agencies and intergovernmental organisations - presented co-production as a novel approach to science for sustainability and as the main principle on which the design of the new research platform should be based. Yet, discussions on the organisational structure, rules and procedures that would support co-production in Future Earth brought out tensions between different aims and practices. Some actors in Future Earth presented co-production as a way to respond to societal needs (accountability logic); others emphasised the possibility to affect societal change (impact logic), whereas yet others stressed attentiveness to different forms of knowledge in understanding and addressing sustainability challenges (humility logic). This flexibility of the concept is one of the reasons why co-production could become a central principle for Future Earth. It allowed actors with different ideas about science and its role in society to find a common ground. However, the different logics of co-production involve different ideas about how co-production should be practiced and, importantly, how coproduction could and should become part of global science institutions. These differences pertain to the purpose of co-production, the actors that should be involved and the role of both scientists and extra-scientific actors in co-production of knowledge (Chapter 5). 
The comparison with IPBES in Chapter 9 showed how participation, the foundational idea of co-production, is also taken up by other global science institutions. Similar to Future Earth, IPBES struggled with how to design an institutional structure that would support the principle of participation. These struggles centred on who should be involved, and in what role, and on who has the authority to speak for science. In IPBES, stakeholders eventually settled on an intergovernmental model of science advice, yet with some important institutional innovations that allowed for deviation from a dominant natural sciences approach (Chapter 9). For Future Earth, eventual design choices demonstrate the prominence of accountability and impact logics of co-production. That is, Future Earth developed as a platform oriented towards shaping and informing action for societal change, where co-production serves the primarily instrumental aims of responding to societal demands and implementing scientific knowledge in society. Other potentials of co-production, including the support for plural forms of knowledge, are less prominently reflected in institutional designs (Chapter 5; Chapter 9).

Thus, new principles of science for sustainability, and the principle of co-production specifically, shape the design of global science institutions. However, for Future Earth, a relatively narrow instrumental understanding of co-production limits the potential for 'doing science differently' (Chapter 5; Chapter 9). This presents a paradox: institutional support for new principles of knowledge production falls short for those practices that deviate most from conventional scientific norms, even though these unconventional practices require this support the most (Chapter 5; Chapter 9).

\section{Research question 2: What is the influence of global science institutions on scientific knowledge production?}

Where the first research question is about the design of global science institutions, the second question asks whether global science institutions actually matter for the way scientific knowledge gets produced. In response to this question, I focused specifically on the principles of interdisciplinarity and inclusiveness (Chapter 6).

Future Earth, and the network of science councils, funding agencies and intergovernmental organisations by which the programme is supported, attempts to coordinate knowledge production by setting a new research agenda and redefining the objectives and practices of research for sustainability. While Future Earth has only been fully operational for a short while, the practice of science coordination through formal research programmes is not new, and lessons can be drawn from previous experiences. Global science institutions, and formal research programmes specifically, function as coordination mechanisms that have the potential to shape knowledge production by setting a common research agenda, mobilising capacity, facilitating collaboration and shaping funding priorities. The global change programmes that preceded Future Earth, and Future Earth itself, follow a model of coordination by administration, with a secretariat set up to manage and coordinate activities and, in the case of Future Earth, a governing council with decision-making power (Chapter 6).

Interdisciplinarity and inclusiveness form two core challenges for science coordination in global change and sustainability research. These principles had been on the agenda of IGBP 
and IHDP - two of Future Earth's predecessors - throughout their years of operation. My scientometric analysis of IGBP and IHDP illustrates the potential of research programmes to support collaboration across disciplinary boundaries. The research output of both research programmes became more interdisciplinary over time - sometimes ahead of developments towards interdisciplinarity in the respective research domains. In contrast, efforts to support geographical inclusiveness did not meet the set objectives. IGBP and IHDP have had limited success in involving researchers from a wide range of countries globally, specifically with respect to inclusiveness of researchers from the Global South (Chapter 6). This somewhat sobering conclusion stands in contrast to the major ambitions of global science coordination through Future Earth and calls for careful reflection on the potential of global science coordination to transform research practices towards science for sustainability.

Research question 3: What are the perspectives of researchers on the transformative ambition and politics of science for sustainability?

The third question moves the focus from the design of global science institutions to the shared understanding of researchers working under the umbrella of Future Earth. In my response to this question, I focused specifically on the principle of solutions-orientation and the transformative ideal of science for sustainability (Chapter 7).

Future Earth puts forward a vision and mission of research that contributes to global sustainability. Its principle of solutions-orientation reflects this ideal. The type of solutions pursued, at least in rhetoric, are transformative solutions that inform and shape systemic societal change towards sustainability. My research confirms that Future Earth's visions of transformative research receives broad support among sustainability researchers (Chapter 7). Yet, there are important differences in perspectives on what it means to do transformative research, specifically when it comes to dealing with normative and political concerns. One dimension of difference between perspectives is about the role of sustainability researchers in society. Some researchers support the idea of an active role of science in shaping societal transformations, whereas others are more hesitant and rather see researchers in the role of facilitator or critical participant in supporting societal change. Another important dimension of difference between perspectives concerns the possibility and desirability of scientific independence from normative and political concerns. Whereas some researchers support the ideal of a neutral, reflective science transferring knowledge to societal actors, others see scientific knowledge production as a political act that not neutrally informs but actively shapes how sustainability problems are understood and addressed. For the latter, the question arises how the politics of research can be actively acknowledged, practiced and built into research programmes. Overall, I find that sustainability researchers, while supporting the transformative ambition of science for sustainability, struggle to reconcile historically developed norms of scientific knowledge production and new perspectives on the transformative, normative and political role of sustainability research in society (Chapter 7). 
Research question 4: How does science for sustainability affect epistemic authority in sustainability governance?

The fourth question focuses on the relationship between science and governance for sustainability. I studied how the four principles of co-production, interdisciplinarity, inclusiveness and solutions-orientation shape strategies by which global science institutions seek epistemic authority (Chapter 8) and the way in which seeking epistemic authority shapes the design of science institutions for sustainability (Chapter 9).

I found that strategies of global science institutions to acquire social and political influence are increasingly shaped by principles of science for sustainability. I distinguished three strategies by which global science institutions seek authority in sustainability governance (Chapter 8). Firstly, some science institutions lean towards the classical model of global environmental assessments. They seek relevance by bringing together state-of-the-art scientific knowledge on a given issue, seek credibility through formal mechanisms of review and legitimacy through representation of relevant disciplines and geographical regions (assessment-oriented mode). Secondly, some science institutions build on a model of independent science advice. These institutions are often directly linked to UN agencies, which provides them with legitimacy among policy audiences. They seek salience through the promise of independent and timely science advice, while credibility is allegedly derived through the credentials of individual scientists involved (advice-oriented mode). Both the assessment- and advice-oriented modes represent institutionalised norms of science and its role in society, such as independence and impartiality (Chapter 8). Yet, the effectiveness of these models is frequently questioned, and science institutions increasingly appeal to different strategies in seeking relevance, credibility and legitimacy (Chapter 8; Chapter 9). This is reflected in the third and increasingly prominent mode by which science institutions seek authority: the solutions-oriented mode of science engagement. Institutions that fit in this model claim relevance by promising to deliver 'actionable scientific knowledge' and contributing to 'practical problem-solving'. Credibility claims are based on the diverse community of researchers that these institutions allegedly represent, while legitimacy is sought through a strategy of participation. Future Earth best fits within this category (Chapter 8).

The solutions-oriented mode for acquiring authority represents a dominant trend in science engagement for sustainability. This alludes to a changing role of science institutions and researchers, from independent referees presenting and protecting scientific knowledge to active partners in steering society to sustainable futures. The institutionalisation of science for sustainability is guided by the desire to become recognised as epistemic authority in governance for sustainability. This involved creating platforms that bring together science and other kinds of knowledge relevant for sustainability (Chapter 8; Chapter 9). Yet, the eventual institutionalisation of science for sustainability is largely shaped by actors traditionally involved in the organisation of research and governance for sustainability, such as funding agencies, science councils and intergovernmental organisations (Chapter 5; Chapter 8; Chapter 9). Other stakeholders, such as representatives of non-governmental organisations and interest groups, but also researchers themselves, are included in an advisory without formal decision- 
making power. Eventual design choices thus grant power to organisations and individuals with established authority in shaping science and governance on sustainability. As a result, the potential for new voices and practices to acquires epistemic authority in sustainability governance is limited.

\subsection{ANSWER TO MAIN RESEARCH QUESTION}

Together, the insights acquired by the answers to these four research questions form the building blocks of my response to the main question of this thesis:

How are new principles of science for sustainability institutionalised and how does this shape the relationship between science and governance for sustainability?

New principles of science for sustainability form an important rationale shaping Future Earth and other global science institutions. Yet, as I have shown in this thesis, there is also contestation over these principles and the appropriate design of science institutions for sustainability (Chapter 5; Chapter 8; Chapter 9). The process of defining and institutionalising principles of science for sustainability involves decisions over what counts as relevant knowledge, what determines credible expertise and who are legitimate actors in science for sustainability. Thus, the stakes over how to define and shape science for sustainability are high. In Future Earth, researchers, research managers, science councils, funders and intergovernmental actors negotiate the conditions of science for sustainability (Chapter 5; Chapter 9). They are engaged in discussions over what 'new science for global sustainability' should look like and how it can be achieved. These discussions were sometimes heated, especially in the early phase of the design of Future Earth, when the existing system of global change programmes and projects was disrupted, and different possibilities for shaping a new system of research collaboration were on the table (Chapter 4; Chapter 5; Chapter 9).

One broadly shared aim of science for sustainability is to inform and shape sustainability transformations (Chapter 5; Chapter 7). Seen from this perspective, principles of science for global sustainability challenge conventional understandings of the practice and purpose of science. Firstly, the principle of solutions-orientation - by calling for transformative science that supports societal change towards sustainability - challenges the norms of disinterested and impartial science (Chapter 7). Secondly, the principle of co-production - by seeking to involve extra-scientific actors in the process of knowledge production - challenges the norms of independent and autonomous science (Chapter 5; Chapter 9). Thirdly, the principles of interdisciplinarity and inclusiveness - by calling attention to the importance of different disciplinary and geographical perspectives - challenge the idea of value-free science that provides a neutral view of global problems (Chapter 6; Chapter 8). Together, these principles put forward a new perspective on the practices and organisation of science that deviates from historically developed norms shaping science and its role in society. The ideal of science for sustainability presents scientific actors as governance partners in addressing complex, urgent and contested challenges of global change, rather than distant and neutral observers. Science 
for sustainability is - at least in rhetoric - concerned with shaping and steering societal change, and thus becomes directly involved in sustainability transformations.

This transformative mission of science for sustainability contradicts institutionalised boundaries between science and politics. Through its aim to shape and steer societal change, science for sustainability is interwoven with normative and political questions of what sustainable futures look like and how they can be achieved. I found that while sustainability researchers acknowledge these normative and political dimensions of their work, designs of global science institutions tend to conceal what is normative and political about science for sustainability (Chapter 5; Chapter 7; Chapter 8; Chapter 9). Among sustainability researchers, the ideal of transformative science for sustainability is widely supported. There is also broad awareness of the normative and political dimensions of science for sustainability, although perspectives on what this means for research practices and relationships with extrascientific actors vary (Chapter 7). In contrast, global science institutions for sustainability tend to uphold historically developed norms and structures of scientific knowledge production, including the separation of science from normative and political concerns (Chapter 5; Chapter 8; Chapter 9). This is evident in the institutional design of co-production in Future Earth, which aims to protect scientific independence and autonomy by carefully designing spaces in which extra-scientific stakeholders are allowed to participate (Chapter 5). It is also evident in the rhetorical strategies by which science institutions seek authority, particularly where they rely on scientific independence to invoke relevance, credibility, and legitimacy (Chapter 8). Moreover, I found that global science institutions get shaped by actors with authoritative positions in science and governance for sustainability (Chapter 5; Chapter 9). For Future Earth, this means that alliances are established between science councils, funders and intergovernmental organisations, while further engagement is sought from 'strategic leaders' in sustainability transformations. There is little possibility for other actors to shape the design of Future Earth or inform what comes to be seen as relevant, legitimate and credible knowledge for societal transformations (Chapter 5; Chapter 9).

Thus, while the transformative mission of science for sustainability makes that science becomes directly involved with normative and political concerns, science institutions tend to reinforce boundaries between science and politics and rebuild the myth of neutral and independent science in governance for sustainability. This is problematic because it hides the inevitable politics involved in the ambitions, institutionalisation and effects of science for sustainability. As I have shown throughout the chapters of this thesis, the institutionalisation of science for sustainability is a process shaped by values and politics, and in turn shapes which normative and political positions influence knowledge production for sustainability. Yet, as these political choices are hidden, the potential of science for sustainability to support systemic societal changes for sustainability transformations is limited. 


\subsection{THE POLITICS OF TRANSFORMATIVE SCIENCE FOR SUSTAINABILITY}

This thesis contributes to emerging discussions about the politics of transformative science for sustainability. The previous chapters showed that science for global sustainability is not only a scientific project, it is also an institutional and political project that shapes the conditions, possibilities and outcomes of science for sustainability. I brought together academic literature at the intersection of science for sustainability, social studies of science and science in environmental governance (Chapter 2). An important common thread that runs through these three bodies of literature is that they draw attention to the politics of science for sustainability, albeit in different ways. I combined insights from these three bodies of literature in a nested conceptualisation of the politics of science for sustainability. This conceptualisation is based on three lenses for studying science institutions for sustainability. Each lens has a different focal point where it makes visible what is political about science. The first lens is about the transformative ambition of science for sustainability, which is inevitably entangled with normative and political concerns. The second lens is about the politics of institutionalising science for sustainability in global science institutions. The third lens is about the relationship between science and governance for sustainability transformations (Figure 10.1). Here, I reflect on the contributions of the thesis within and across these lenses and distinguish questions for further research.

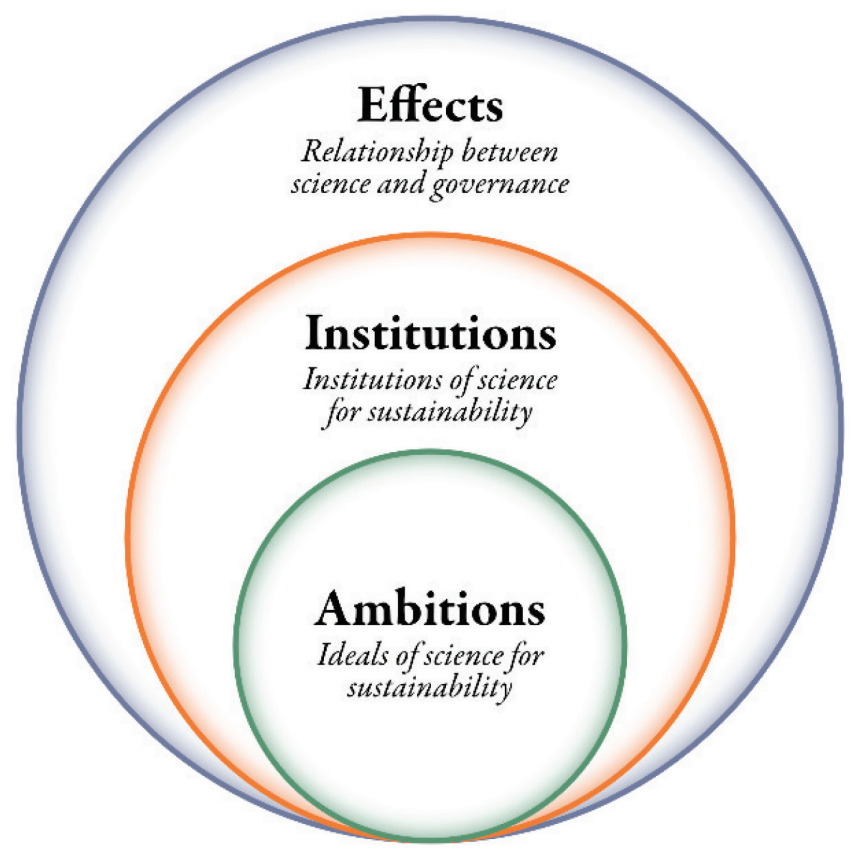

Figure 10.1 Nested conceptualisation of the politics of science for sustainability (see also Chapter 2) 
Firstly, this thesis contributes to discussions about the transformative ambition of science for sustainability. For an increasing number of researchers engaged in science for sustainability, the responsibility of science lies not only in understanding the causes and consequences of unsustainability, but also in contributing to sustainability transformations (Chapter 7). This transformative aim of science for sustainability makes that matters of fact become inseparable from matters of concern (Latour, 2004; Schmieg et al., 2017; van Poeck, Goeminne, \& Vandenabeele, 2016). Science for sustainability is directly concerned with action and interventions for sustainability transformations, moving beyond a linear idea of scientific knowledge informing decision-making and rather attending to the co-production of knowledge and societal change (Norström et al., 2020; West et al., 2019; Wyborn et al., 2019). If ever it was possible to separate facts from values or truth from power, this distinction is increasingly found unhelpful in addressing urgent, complex and contested sustainability challenges (Kläy et al., 2015; Lahn, 2018; T. R. Miller, 2013; Popa et al., 2014; Schneider et al., 2019). The subject matter of sustainability transformations is inseparable from normative and political concerns. Moreover, for science to contribute to sustainability transformations, it cannot do so from neutral grounds; it has to get directly engaged with questions of values and politics (Fazey et al., 2018; Patterson et al., 2018; Tschakert et al., 2016).

And yet, sustainability researchers struggle to deal with normative and political dimensions of their work (Chapter 7). Engaging in transformations to sustainability demands new roles from researchers which are out of the 'comfort zone' of conventional scientific practices (Bansard, Hickmann, \& Kern, 2019; Cash et al., 2003; Knaggård, Ness, \& Harnesk, 2018; Petersen, Cath, Hage, Kunseler, \& van der Sluijs, 2010; Wittmayer \& Schäpke, 2014). In this context, sustainability researchers may choose to continue to support the 'noble myth' of objective science as neutral input to normative and political processes of societal change (Milkoreit, 2016; Hoppe, 2009; Wiek, 2012; Pohl, 2010). My research partly revealed the presence of this phenomenon. I found that principles of independence, autonomy and neutrality are indeed deeply engrained in norms and structures shaping science for sustainability. However, I also showed that few sustainability researchers actually hold the perspective that science for sustainability can be separated from normative and political concerns. Rather, sustainability researchers struggle with ways to reconcile demands of transformative science with historically developed norms and structures of scientific knowledge production (Chapter 7). This finding resonates with recent contributions to the literature on science for sustainability that call on sustainability researchers to "engage more deeply with normative challenges despite their reservations" (Nielsen et al., 2019, p. 4). Rather than leaving questions of values to the realm of politics, "science must find a way of addressing them and incorporating them in a systematic and reflexive way" (Schneider et al., 2019, p. 4). How sustainability researchers can do so is a question that demand further reflection as well research.

Secondly, this thesis contributes to discussions about the institutionalisation of science for sustainability. The science for sustainability literature recurrently calls for institutional change to support new modes of knowledge production (e.g. Yarime et al., 2012). Yet, a lack of empirical research and theoretical reflections leaves questions about the process, outcome and 
effects of institutionalising science for sustainability largely undiscussed. This thesis makes a contribution through its empirical investigation of the process and outcome of institutionalising science for sustainability. I have shown that institutionalising science for sustainability in global science institutions is not a neutral act - as calls for institutionalisation often appear to assume - but rather involves debate and negotiations over the kinds of knowledge and practices that can legitimately contribute to sustainability (Chapter 5; Chapter 9; Montana, 2019). In this process, it matters which actors have a seat at the table to discuss institutional designs of science for sustainability. A core question here is who is allowed and able to shape science for sustainability (Lövbrand et al., 2015). Future Earth as well as other global science institutions claim to 'open up' science to a broad variety of stakeholders, and yet, as other scholars have also found, there is limited support for proactively giving voice to actors who have historically had limited direct influence on science and governance of sustainability, be it local community groups, indigenous communities or scholars from the Global South (Chapter 9; Chilisa, 2017; Klenk \& Hickey, 2012, 2013; Sénit, 2019; Tschakert et al., 2016). As a result, actors with already dominant positions in science and governance come to shape institutional designs and practices of science for sustainability.

My findings support the perspective that the institutionalisation of science for sustainability in (global) science institutions tends to be instrumental rather than transformative (Daly \& Dilling, 2019; Felt \& Fochler, 2010; Maasen \& Lieven, 2006; Schneidewind \& Augenstein, 2012; Turnhout et al., 2013). This means that - contrary to the rhetoric of a fundamentally different way of practicing science in support of transformations to sustainability - institutions of science for sustainability support modes of scientific knowledge production and relationships between scientific and extra-scientific actors that deviate little from historically institutionalised practices of science. While individual projects arguably find ways of 'doing science differently' (de Bremond et al., 2019; Nielsen et al., 2019), I did not find evidence for the substantial institutional changes that scholars argue are needed to support sustainability transformations (Kueffer et al., 2012; Schneidewind \& Augenstein, 2012; Yarime et al., 2012). Instead, it appears that institutions of science for sustainability fail to acknowledge the level and depth of change required to live up to the promises of transformative research (Fazey et al., 2018; Musch \& von Streit, 2020). This thesis suggests that part of the reason for this lack of change is the challenge of moving beyond established relationships between science and politics. Instead, the myth of independent science is rebuilt in global science institutions (Sundqvist et al., 2018). As such, there is limited institutional support for sustainability researchers that seek to find reflexive ways of engaging with the values and politics of sustainability transformations (Popa et al., 2014).

Thirdly, this thesis contributes to discussions about the relationship between science and governance for societal transformations. Reflections on transformative science for sustainability from the perspective of this lens highlight the importance of addressing politics and power in science for sustainability. Sustainability transformations, according to the expanding literature on the topic, are about structural societal changes. Transformations involve challenging the power structures that uphold the systems and structures of society as 
we know it (Feola, 2015; Patterson et al., 2016; I. C. Scoones, Newell, \& Leach, 2015). It follows that, to be transformative, science needs to address deeper socio-economic and political arrangements (Blythe et al., 2018; Fazey et al., 2018; Patterson et al., 2018; Wyborn et al., 2019). And yet, what is presented as solutions-oriented or transformative research often fails to challenge current dominant practices and structures in science and society (Blühdorn, Butzlaff, Deflorian, \& Hausknost, 2018; Daly \& Dilling, 2019; Jagannathan et al., 2019; Kueffer, Schneider, \& Wiesmann, 2019; Nightingale et al., 2019; Turnhout, Metze, Wyborn, Klenk, \& Louder, 2020). This includes persistent neutrality towards capitalism in sustainability transitions research (Asara, Otero, Demaria, \& Corbera, 2015; Feola, 2019), a dominance of technical fixes in responding to climate change (Hulme, 2009; Nightingale et al., 2019; Wesselink et al., 2013) and inattention to power relationships and knowledge politics in coproduction of knowledge and outcomes for sustainability (Daly \& Dilling, 2019; Jagannathan et al., 2019; Turnhout et al., 2020). Where scientific activities that support the status quo can easily be presented as neutral, independent and a-political, scientific activities that aim to transform societal arrangements and power structures do not have this luxury. Yet, also when presented as value-free, the construction of knowledge for sustainability is a political act that carries consequences for the kind of sustainability transformations that are made possible and governable (Gupta \& Möller, 2019; Turnhout et al., 2016).

Jagannathan and colleagues (2019) make a distinction between the actionable ambition of science for sustainability to produce practical, proximate and tangible knowledge, and the transformative ambition that involves structural, long-term, time-intensive and deliberative practices and relationships. Actionable knowledge may support transformative change, but it could also undermine it, especially when existing institutional and political barriers and power inequalities remain unaddressed. Taking on the transformative ambition is challenging because it requires reshaping relationships between science and society. Several studies have shown that sustainability research projects that do not explicitly address politics and power are likely to support the status quo (Daly \& Dilling, 2019; Sarkki, Ficko, Grunewald, Kyriazopoulos, \& Nijnik, 2017). This thesis illustrates this at the institutional level, with science institutions seeking partnerships from authoritative actors in science and governance (Chapter 8; Chapter 9). Nevertheless, science institutions, perhaps more than individual research projects, hold the potential to address the challenges of transformative research for sustainability by attending to societal change across different scales and societal institutions Jagannathan et al., 2019; Wyborn et al., 2019). Yet, most importantly, for science for sustainability to achieve its mission of sustainability transformations, science institutions need to open their perspective to the power and politics of societal change (Fazey et al., 2018; Marshall, Dolley, \& Priya, 2018; Nightingale et al., 2019; Wyborn et al., 2019). Without explicitly addressing politics and power in science for sustainability, science institutions risk reproducing existing power structures and fall short of supporting structural societal transformations (Blythe et al., 2018; Fazey et al., 2018; Jagannathan et al., 2019; Nightingale et al., 2019).

Overall, this thesis thus points to the importance of reconsidering politics in science for sustainability. Representing science as a-political caries negative consequences across all three 
levels discussed here: it keeps researchers from engaging more deeply with normative dimensions of sustainability transformations (Nielsen et al., 2019; Schneider et al., 2019); it hides the politics that shape science institutions for sustainability (Lövbrand et al., 2015; T. R. Miller, Muñoz-Erickson, \& Redman, 2011); and it provides a barrier to the transformative mission of science for sustainability (Fazey et al., 2018). In recent years, with sustainability scholars increasingly reflecting on the role of science in societal transformations, questions of values and politics in science start to receive more attention (Nightingale et al., 2019). Scholars, for example, have pointed to the importance of addressing normative dimensions of science and practice in supporting the 2030 Agenda for Sustainable Development (Schneider et al., 2019). Authors of the Global Sustainable Development Report argue that the Sustainable Development Goals can form a moral compass for transformative sustainability science, while scholars should also recognise and work with the competing development agendas, different interests and power imbalances in seeking to support actors to achieve this agenda (Messerli et al., 2019). These developments are promising steps in supporting further reflexive engagement with the transformative mission of science institutions for sustainability.

\subsection{REFLECTIONS ON THE RESEARCH APPROACH}

In this thesis, I have tried to elucidate the processes of sense making, negotiating and structuring that shape institutions of science for global sustainability. The thesis itself reflects my own process of sense making of a complex and multi-facetted phenomenon. I have drawn on multiple theoretical traditions and applied a variety of methods. These theoretical perspectives and methods provided different insights on the main object of this study: science institutions for global sustainability. The different theoretical perspectives allowed me to look at science institutions from different angles: as research programmes that coordinate scientific fields; as constellations of formal and informal rules, norms and values shaping scientific knowledge production; and as actors engaged in governance for sustainability. These perspectives are not fully harmonious. For example, my study of the influence of research programmes takes a relatively narrow perspective on institutions as organisations (Chapter 6) while other chapters highlight the complex web of formal and informal rules, norms and values that shape scientific knowledge production (Chapter 5; Chapter 9). In some chapters, I considered science institutions as actors in sustainability governance (Chapter 8; Chapter 9), where it is important to keep in mind that science institutions are not unitary actors speaking with one voice - even though this is sometimes claimed - but rather networks of actors and activities that relate to sustainability governance in a variety of ways. These different perspectives on science institutions for sustainability are derived from the three bodies of literature that I build on in this thesis - literature on science for sustainability, literature from the social studies of science and literature on science in environmental governance (Chapter 2). Here, again, it is important to note that these heterogenous bodies of literature build on different ontological and epistemological traditions. While being mindful of the differences in the ways in which these bodies of literature conceptualise principles of science for sustainability, science institutions and science-society relationships, I found common ground 
in the attention to the politics of science for sustainability across these different bodies of literature. Rather than presenting an integrated perspective, I highlighted how these bodies of literature provide different lenses for studying and reflecting on the politics of science institutions for sustainability. Triangulation of methods, likewise, allowed me to study the phenomenon of new science for sustainability from multiple angles. Insights from the different methods supported each other, with, for example, expert interviews and document analysis providing a starting point for the survey, which in turn showed which ideas from expert interviews were supported by the broader community. If I would have focused on a single theoretical perspective or method, I could have explored these in more depth. Yet, overall, I believe that drawing together insights from multiple perspectives allowed me to build a rich picture of science institutions for sustainability.

In making sense of science for sustainability, I focused on the case of Future Earth. Future Earth, as I argued in Chapter 3, provides a paradigmatic case for studying transformations towards science for global sustainability. The challenges and tensions observed are not unique to Future Earth; rather, they represent the broader phenomenon of science for sustainability and its institutionalisation across different settings, organisations and scales. Nevertheless, the specific case of Future Earth of course shaped this study. To aid in interpreting these findings and explore whether particular observations were unique to Future Earth, or presented a broader phenomenon, I contrasted insights gained from the case analysis of Future Earth with comparative cases. For these other cases, I could not conduct the in-depth analysis as I did for Future Earth. Yet, they did provide a good benchmark for considering what is unique about Future Earth and which observations present broader trends. A specific challenge stemming from the case study of Future Earth was that it meant studying a research programme in the making. This provided an opportunity to observe discussions about principles of knowledge production and the role of science in society that are generally taken for granted. At the same time, it also brought up questions of whether observed developments were significant or merely affairs with little long-term effects. I had two ways to deal with this. Firstly, by looking at the impact of research programmes that preceded Future Earth (Chapter 6) and, secondly, by focusing not only on developments at the organisational level but also on perspectives of sustainability researchers (Chapter 7). My view is that Future Earth is significant in its attempt to restructure global change research into research for global sustainability. That is, it takes new ideas about science and society and brings these to the centre of discussions about science for sustainability. Whether the platform will also be significant in its outcomes and contribute to long-term changes remains an open question.

\subsection{PRACTICAL SIGNIFICANCE}

This thesis has argued that in science for sustainability a strict separation between science and politics is not only impossible but also undesirable. This does not mean that anything goes. Rather, it provides a challenge to rethink the relationship between science and politics. I believe that insights from this thesis are relevant for researchers, research managers and funders involved in science for sustainability. Specifically, I hope that this thesis sparks 
reflection on the politics of new principles of knowledge production and their institutionalisation in science for sustainability. To support this, I conclude this thesis with a reflection on what it means to consider politics in science institutions for sustainability.

Confronting the politics of science in sustainability research requires reflexivity. Many sustainability scholars have proposed reflexivity as an important quality of sustainability research (Knaggård et al., 2018; Popa et al., 2014). Reflexivity involves transparency about the values, assumptions and power structures that shape scientific research (Milkoreit et al., 2015; Wittmayer \& Schäpke, 2014) and actively seeking change in research practices and knowledge systems based on individual and collective reflection about the position and role of science in society (Popa et al., 2014; Schneider \& Buser, 2017; Wijsman \& Feagan, 2019). Scoones and colleagues argue (2015) that sustainability researchers have a responsibility not only to be accurate but also to be reflexive, specifically of the inevitably multiple and contested pathways of sustainability transformations (Scoones et al., 2015). For Temper and colleagues (2019), reflexivity means that sustainability research must meet not only standards of scientific rigour but also standards of political rigour. This involves attention for "the transformative aims and desired political impacts of research projects" and "accountability for practical and political outcomes” (Temper, McGarry, \& Weber, 2019, p. 106379). Other researchers point to the need to support 'deliberative contestation' at the intersection of normative judgement and scientific knowledge (Pickering \& Persson, 2019). Overall, reflexivity acknowledges that making a meaningful contribution to societal change involves moving beyond the deeply engrained assumption that scientific knowledge is and should be independent from politics.

Reflexivity is generally called for as a responsibility of individual researchers or research projects. Based on this research, I am arguing for the need and opportunity to think about reflexivity at the institutional level. Reflexive approaches to science for sustainability require not only researchers and research projects but especially institutions of science to become more reflexive on their interlinkage with politics and explore alternative ways of giving shape to this relationship in support of societal transformations to sustainability. That is, reflexivity vis-à-vis the values, politics and transformative potential of science for sustainability should be embraced as a quality of institutions operating between science and governance for sustainability (K. Braun \& Kropp, 2010). First of all, global science institutions should make the normative and political choices involved in research agendas, partnerships and funding structures explicit as a first step in rendering these dimensions of science for sustainability open to political contestation and change (Beck, 2019; Beck et al., 2014; Fazey et al., 2018; Wynne, 1993). Secondly, science institutions can facilitate reflexivity among researchers and research projects operating under their umbrella by providing support to design more overtly political approaches to sustainability transformations (Fazey et al., 2018; Pereira et al., 2019). This can be encouraged by conversations between solutions-oriented and critical approaches to help rethink how science relates to and may support societal change, including by questioning prevailing practices and institutions and breaking down incumbent power structures (Jerneck et al., 2011; Wijsman \& Feagan, 2019). And finally, science institutions can support and encourage practices that purposefully generate political contestation and draw attention to 
dimensions of urgency as well as equity and justice in sustainability transformations (Lahn, 2018; Temper et al., 2019). Doing so will move science for sustainability outside of its comfortable position of neutrality and impartiality and into a messy but potentially productive realm of political action for societal change.

\subsection{CONCLUDING REFLECTION}

Researchers at universities across the world are increasingly vocal in declaring climate, biodiversity and other sustainability emergencies (Chaplin et al., 2019; Faez, 2020; Lenton, 2020; Ripple, Wolf, Newsome, Barnard, \& Moomaw, 2020; Steinberger, 2019). This makes the question what science institutions can and should do in responding to urgent, complex and contested sustainability challenges ever more pressing. It is clear that more knowledge of sustainability challenges and potential solutions alone will not lead to the actions and transformations required. In this thesis, I have argued that the answer to addressing sustainability challenges lies not in more knowledge, better integration across disciplines or involvement of more stakeholders, but rather in rethinking relationships between science and politics for sustainability. Science institutions can take the lead in responding to sustainability challenges and enacting societal change. This requires embracing the politics of science for sustainability. For science to be truly transformative, researchers, research projects and institutions need to recognise and work with the inevitable politics of sustainability transformations. 


\section{References}

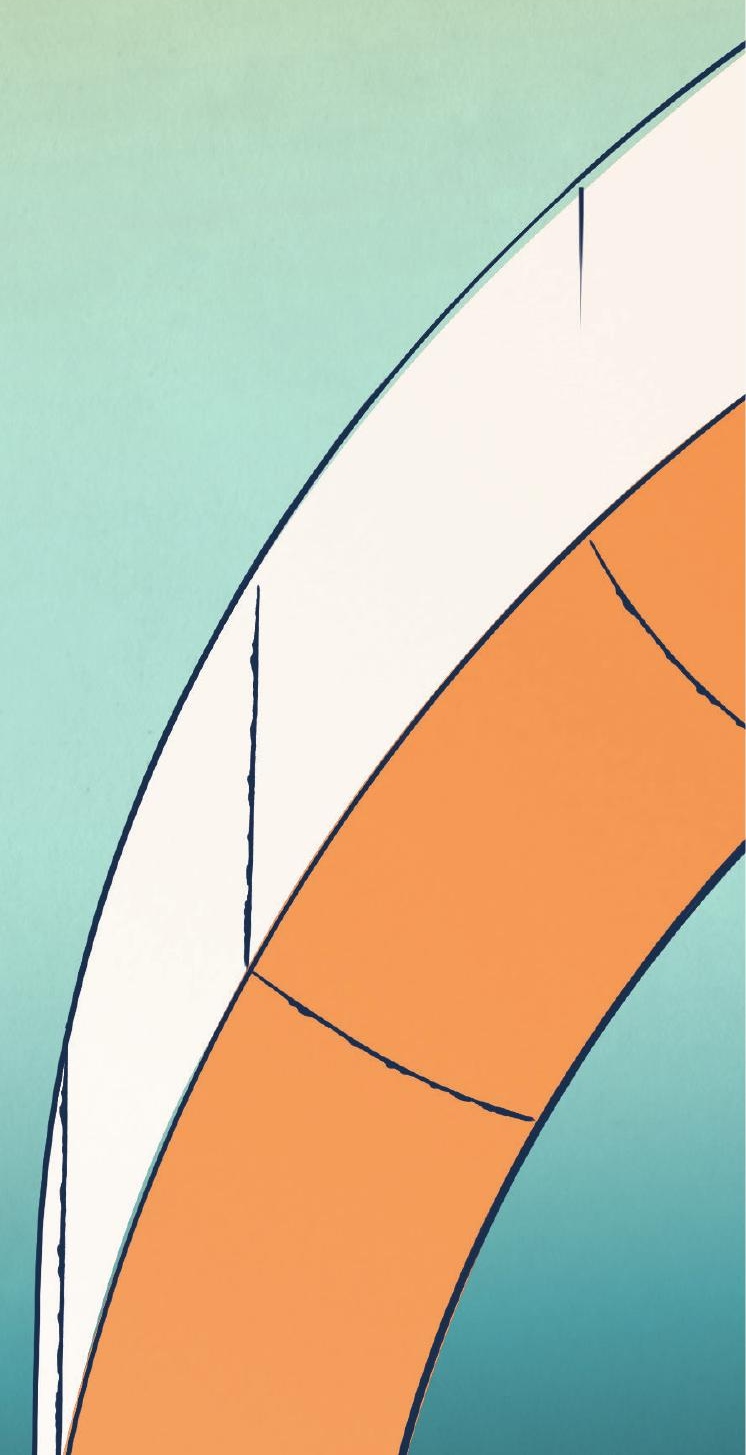


Adler, E., \& Haas, P. M. (1992). Conclusion: epistemic communities, world order, and the creation of a reflective research program. International Organization, 46(1), 367. https://doi.org/10.1017/S0020818300001533

Allan, B. B. (2017). Producing the Climate: States, Scientists, and the Constitution of Global Governance Objects. International Organization, 71(1), 131-162. https://doi.org/10.1017/S0020818316000321

Anderson, M. W., Teisl, M. F., \& Noblet, C. L. (2016). Whose values count: is a theory of social choice for sustainability science possible? Sustainability Science, 11(3), 373-383. https://doi.org/10.1007/s11625-015-0345-1

Asara, V., Otero, I., Demaria, F., \& Corbera, E. (2015). Socially sustainable degrowth as a social-ecological transformation: repoliticizing sustainability. Sustainability Science, 10(3), 375-384. https://doi.org/10.1007/s11625-015-0321-9

Bäckstrand, K. (2003). Civic Science for Sustainability: Reframing the Role of Experts, Policy-Makers and Citizens in Environmental Governance. Global Environmental Politics, 3(4), $24-41$. https://doi.org/10.1162/152638003322757916

Bäckstrand, K. (2004). Scientisation vs. civic expertise in environmental governance: Eco-feminist, eco-modern and post-modern responses. Environmental Politics, 13(4), 695-714. https://doi.org/10.1080/0964401042000274322

Bansard, J. S., Hickmann, T., \& Kern, K. (2019). Pathways to urban sustainability: How science can contribute to sustainable development in cities. Gaia, 28(2), 112-118. https://doi.org/10.14512/gaia.28.2.9

Barr, S., Shaw, G., \& Coles, T. (2011). Times for (Un)sustainability? Challenges and opportunities for developing behaviour change policy. A case-study of consumers at home and away. Global Environmental Change, 21(4), 1234-1244. https://doi.org/10.1016/j.gloenvcha.2011.07.011

Barry, A., \& Born, G. (2013). Interdisciplinarity: Reconfigurations of the Social and Natural Sciences. In A. Barry \& G. Born (Eds.), Interdisciplinarity: Reconfigurations of the Social and Natural Sciences (p. 296). London, UK: Routledge.

Barry, A., Born, G., \& Weszkalnys, G. (2008). Logics of interdisciplinarity. Economy and Society, 37(1), $20-49$. https://doi.org/10.1080/03085140701760841

Bauer, S., \& Stringer, L. C. (2009). The Role of Science in the Global Governance of Desertification. The Journal of Environment \& Development, 18(3), 248-267. https://doi.org/10.1177/1070496509338405

Beck, S. (2019). Coproducing Knowledge and Politics of the Anthropocene: The Case of the Future Earth Program. In Anthropocene Encounters: New Directions in Green Political Thinking (pp. 191-211). https://doi.org/10.1017/9781108646673.010

Beck, S., Borie, M., Chilvers, J., \& Esguerra, A. (2014). Towards a Reflexive Turn in the Governance of Global Environmental Expertise. GALA, 144(2), 80-87. https://doi.org/10.14512/gaia.23.2.4

Beck, S., Forsyth, T., Kohler, P., Lahsen, M., \& Mahony, M. (2017). The Making of Global Enviornmental Science and Politics. In U. Felt, R. Fouche, C. A. Miller, \& L. Smith-Doerr (Eds.), The Handbook of Science and Technology Studies. (4th ed., pp. 1059-1086). Cambridge, MA: MIT Press.

Beck, S., \& Mahony, M. (2017). The IPCC and the politics of anticipation. Nature Climate Change, 7(5), 311-313. https://doi.org/10.1038/nclimate3264

Beck, S., \& Mahony, M. (2018). The IPCC and the new map of science and politics. Wiley Interdisciplinary Reviews: Climate Change, 9(6), 1-16. https://doi.org/10.1002/wcc.547

Belmont Forum. (2011). The Belmont Challenge: A Global, Environmental Research Mission for Sustainability. Retrieved from https://www.igfagcr.org/sites/default/files/documents/belmont-challenge-white-paper.pdf

Belmont Forum, ICSU, \& ISSC. (2011). Towards a 10 year Earth System Research initiative for Global Sustainability: A joint statement of intent from the Belmont Forum, ICSU and the ISSC. 30GA/8.5. Retrieved from http://www.icsu.org/future-earth/media-centre/relevant_publications/JointStatementMay2011.pdf

Bensaude-Vincent, B. (2014). The politics of buzzwords at the interface of technoscience, market and society: The case of "public engagement in science." Public Understanding of Science, 23(3), 238-253. https://doi.org/10.1177/0963662513515371

Berkhout, F. (2014). What does coordination achieve? Retrieved August 5, 2016, from http://www.futureearth.org/blog/2014-may-30/what-does-coordination-achieve

Bernard de Raymond, A. (2018). 'Aligning activities': coordination, boundary activities, and agenda setting in interdisciplinary research. Science and Public Policy, 45(March), 1-13. https://doi.org/10.1093/scipol/scx087

Bettencourt, L. M. A., \& Kaur, J. (2011). Evolution and structure of sustainability science. Proceedings of the National Academy of Sciences, 108(49), 19540-19545. https://doi.org/10.1073/pnas.1102712108

Biermann, F. (2001). Big science, small impacts—in the South? The influence of global environmental assessments on expert communities in India. Global Environmental Change, 11(4), 297-309. https://doi.org/10.1016/S09593780(01)00008-5 
Biermann, F. (2002). Institutions for Scientific Advice: Global Environmental Assessments and Their Influence in Developing Countries. Global Governance, 8, 195-219.

Biermann, F. (2014). Earth System Governance: World Politics in the Anthropocene. Cambridge, MA: MIT Press.

Biermann, F., Bai, X., Bondre, N., Broadgate, W., Arthur Chen, C. T., Dube, O. P., ... Seto, K. C. (2016). Down to Earth: Contextualizing the Anthropocene. Global Environmental Change, 39, 341-350. https://doi.org/10.1016/j.gloenvcha.2015.11.004

Biermann, F., Betsill, M. M., Burch, S., Dryzek, J., Gordon, C., Gupta, A., ... Scobie, M. (2019). The Earth System Governance Project as a network organization: a critical assessment after ten years. Current Opinion in Environmental Sustainability, 39, 17-23. https://doi.org/10.1016/j.cosust.2019.04.004

Biermann, F., Kanie, N., \& Kim, R. E. (2017). Global governance by goal-setting: the novel approach of the UN Sustainable Development Goals. Current Opinion in Environmental Sustainability, 26-27(November), 26-31. https://doi.org/10.1016/j.cosust.2017.01.010

Bjurström, A., \& Polk, M. (2011). Physical and economic bias in climate change research: a scientometric study of IPCC Third Assessment Report. Climatic Change, 108(1-2), 1-22. https://doi.org/10.1007/s10584-011-0018-8

Blicharska, M., Smithers, R. J., Kuchler, M., Agrawal, G. K., Gutiérrez, J. M., Hassanali, A., ... Mikusiński, G. (2017). Steps to overcome the North-South divide in research relevant to climate change policy and practice. Nature Climate Change, 7(1), 21-27. https://doi.org/10.1038/nclimate3163

Blühdorn, I., Butzlaff, F., Deflorian, M., \& Hausknost, D. (2018). Transformation Research and Academic Responsibility. The social theory gap in narratives of radical change (IGN-In- terventions). Vienna, Austria.

Blythe, J., Silver, J., Evans, L., Armitage, D., Bennett, N. J., Moore, M. L., .. Brown, K. (2018). The Dark Side of Transformation: Latent Risks in Contemporary Sustainability Discourse. Antipode, 50(5), 1206-1223. https://doi.org/10.1111/anti.12405

Bogner, A., Menz, W., \& Littig, B. (2009). Expert Interviews - An Introduction to a New Methodological Debate. In A. Bogner, B. Littig, \& W. Menz (Eds.), Interviewing Experts (pp. 1-16). Basingstoke, UK: Palgrave Macmillan. https://doi.org/10.1057/9780230244276

Borie, M., Mahony, M., \& Hulme, M. (2015). Somewhere between everywhere and nowhere: the institutional epistemologies of IPBES and the IPCC. Resource Politics 2015, 33.

Braun, D. (2003). Lasting tensions in research policy-making - a delegation problem. Science and Public Policy, 30(5), 309-321.

Braun, K., \& Kropp, C. (2010). Beyond Speaking Truth? Institutional Responses to Uncertainty in Scientific Governance. Science, Technology \& Human Values, 35(6), 771-782. https://doi.org/10.1177/0162243909357916

Bremer, S., \& Meisch, S. (2017). Co-production in climate change research: reviewing different perspectives. Wiley Interdisciplinary Reviews: Climate Change, e482. https://doi.org/10.1002/wcc.482

Bridgewater, P. (2015). The Man and Biosphere programme of UNESCO: rambunctious child of the sixties, but was the promise fulfilled ? Current Opinions in Environmental Sustainability, 19, 1-6. https://doi.org/10.1016/j.cosust.2015.08.009

Brown, M. B. (2015). Politicizing science: Conceptions of politics in science and technology studies. Social Studies of Science, 45(1), 3-30. https://doi.org/10.1177/0306312714556694

Burch, S., Gupta, A., Inoue, C. Y. A., Kalfagianni, A., Persson, A., Gerlak, A. K., ... Zondervan, R. (2019). New directions in earth system governance research. Earth System Governance, 1, 100006. https://doi.org/10.1016/j.esg.2019.100006

Caniglia, G., Schäpke, N., Lang, D. J., Abson, D. J., Luederitz, C., Wiek, A., ... von Wehrden, H. (2017). Experiments and evidence in sustainability science: A typology. Journal of Cleaner Production, 169, 39-47. https://doi.org/10.1016/j.jclepro.2017.05.164

Carino, J. (2013). Statement delivered by Joji Carino from the Forest Peoples Programme on behalf of the International Indigenious Forum on Biodiversity and Ecosystem Services at IPBES-2.

Carson, R. (1962). Silent Spring. Anniversary edition (2002). Boston, MA: Houghton Mifflin Company.

Cash, D. W., Clark, W. C., Alcock, F., Dickson, N. M., Eckley, N., Guston, D. H., ... Mitchell, R. B. (2003). Knowledge systems for sustainable development. Proceedings of the National Academy of Sciences of the United States of America, 100(14), 8086-8091. https://doi.org/10.1073/pnas.1231332100

Castree, N. (2015). Geography and Global Change Science: Relationships Necessary, Absent, and Possible. Geographical Research, 53(1), 1-15. https://doi.org/10.1111/1745-5871.12100

Castree, N. (2017). Speaking for the 'people disciplines': Global change science and its human dimensions. The Anthropocene Review, 205301961773424. https://doi.org/10.1177/2053019617734249 
Castree, N., Adams, W. M., Barry, J., Brockington, D., Büscher, B., Corbera, E., ... Wynne, B. (2014). Changing the intellectual climate. Nature Climate Change, 4(9), 763-768. https://doi.org/10.1038/nclimate2339

Chaplin, J., Conroy, C., Engell, J., Greene, V., Hall, N., Marglin, S., ... Watson, N. K. (2019). Harvard's Response to the Climate Crisis. Retrieved from https://harvardfacultydivest.com/fas-whitepaper-2019/

Chilisa, B. (2017). Decolonising transdisciplinary research approaches: an African perspective for enhancing knowledge integration in sustainability science. Sustainability Science, 12(5), 813-827. https://doi.org/10.1007/s11625-017$0461-1$

Clark, W. C. (2007). Sustainability science: A room of its own. Proceedings of the National Academy of Sciences.

Clark, W. C., \& Dickson, N. M. (2003). Sustainability science: the emerging research program. Proceedings of the National Academy of Sciences, 100(14), 8059-8061. https://doi.org/10.1073/pnas.1231333100

Clark, W. C., van Kerkhoff, L. E., Lebel, L., \& Gallopin, G. C. (2016). Crafting usable knowledge for sustainable development. Proceedings of the National Academy of Sciences, 113(17), 4570-4578. https://doi.org/10.1073/pnas.1601266113

Cornell, S., Berkhout, F., Tuinstra, W., Tàbara, J. D., Jäger, J., Chabay, I., .. Van Kerkhoff, L. E. (2013). Opening up knowledge systems for better responses to global environmental change. Environmental Science \& Policy, 28, 6070. https://doi.org/10.1016/j.envsci.2012.11.008

Cummings, J. N., \& Kiesler, S. (2007). Coordination costs and project outcomes in multi-university collaborations. Research Policy, 36(10), 1620-1634. https://doi.org/10.1016/j.respol.2007.09.001

Daly, M., \& Dilling, L. (2019). The politics of "usable" knowledge: examining the development of climate services in Tanzania. Climatic Change. https://doi.org/10.1007/s10584-019-02510-w

de Bremond, A., Ehrensperger, A., Providoli, I., \& Messerli, P. (2019). What role for global change research networks in enabling transformative science for global sustainability? A Global Land Programme perspective. Current Opinion in Environmental Sustainability, 38, 95-102. https://doi.org/10.1016/j.cosust.2019.05.006

De Pryck, K., \& Wanneau, K. (2017). (Anti)-boundary work in global environmental change research and assessment. Environmental Science and Policy, (July 2016). https://doi.org/10.1016/j.envsci.2017.03.012

De Witt, A., de Boer, J., Hedlund, N., \& Osseweijer, P. (2016). A new tool to map the major worldviews in the Netherlands and USA, and explore how they relate to climate change. Environmental Science and Policy, 63, 101112. https://doi.org/10.1016/j.envsci.2016.05.012

Dedeurwaerdere, T. (2013). Transdisciplinary Sustainability Science at Higher Education Institutions: Science Policy Tools for Incremental Institutional Change. Sustainability, 5(9), 3783-3801. https://doi.org/10.3390/su5093783

Demeritt, D. (2001). The Construction of Global Warming and the Politics of Science. Annals of the Association of American Geographers, 91(2), 37-41. https://doi.org/10.1111/0004-5608.00245

Demeritt, D. (2006). Science studies, climate change and the prospects for constructivist critique. Economy and Society, 35(3), 453-479. https://doi.org/10.1080/03085140600845024

Desmond, M. (2004). Methodological challenges posed in studying an elite in the field. Area, 36(3), 262-269. https://doi.org/10.1111/j.0004-0894.2004.00223.x

Díaz, S., Demissew, S., Carabias, J., Joly, C., Lonsdale, M., Ash, N., ... Zlatanova, D. (2015). The IPBES Conceptual Framework - connecting nature and people. Current Opinion in Environmental Sustainability, 14, 1-16. https://doi.org/10.1016/j.cosust.2014.11.002

Dooley, K., \& Gupta, A. (2016). Governing by expertise: the contested politics of (accounting for) land-based mitigation in a new climate agreement. International Environmental Agreements: Politics, Law and Economics, 17(4), 483-500. https://doi.org/10.1007/s10784-016-9331-z

Edenhofer, O., \& Kowarsch, M. (2015). Cartography of pathways: A new model for environmental policy assessments. Environmental Science and Policy, 51, 56-64. https://doi.org/10.1016/j.envsci.2015.03.017

Edwards, P. N. (2010). A V ast Machine: Computer Models, Climate Data, and the Politics of Global Warming. Cambridge, MA: MIT Press.

Edwards, P. N., Jackson, S. J. S., Chalmers, M. M. K., Bowker, G. C., Borgman, C. L., Ribes, D., ... Calvert, S. (2013). Knowledge infrastructures: Intellectual frameworks and research challenges. Ann Arbor: Deep Blue. http://hdl.handle.net/2027.42/97552.

Eimer, T. R. (2014). Philosopher-kings in real life: The epistemic community on biodiversity in Brazil and India. Global Society, 28(2), 131-150. https://doi.org/10.1080/13600826.2014.887555

Engels, A., \& Ruschenburg, T. (2008). The uneven spread of global science: patterns of international collaboration in global environmental change research. Science and Public Policy, 35(5), 347-360. https://doi.org/10.3152/030234208X317160 
Esguerra, A. (2015). Toward two narratives of knowledge. Innovation, 28(1), 3-10. https://doi.org/10.1080/13511610.2014.943164

European Science Foundation. (2012). Responses to Environmental and Societal Challenges for our Unstable Earth (RESCUE). ESF-COST 'Frontier of Science' joint initiative. European Science Foundation, Strasbourg (FR) and European Cooperation in Science and Technology, Brussels (BE).

Faez, S. (2020). Are Dutch universities ready to address the climate crisis? ScienceGuide. Retrieved from https://www.scienceguide.nl/2020/01/are-dutch-universities-ready-to-address-the-climate-crisis/

Fazey, I., Bunse, L., Msika, J., Pinke, M., Preedy, K., Evely, A. C., ... Reed, M. S. (2014). Evaluating knowledge exchange in interdisciplinary and multi-stakeholder research. Global Environmental Change, 25(1), 204-220. https://doi.org/10.1016/j.gloenvcha.2013.12.012

Fazey, I., Schäpke, N., Caniglia, G., Patterson, J. J., Hultman, J., van Mierlo, B., ... N, C. W. (2018). Ten essentials for action-oriented and second order energy transitions, transformations and climate change research. Energy Research and Social Science, 40(November 2017), 54-70. https://doi.org/10.1016/j.erss.2017.11.026

Felt, U., \& Fochler, M. (2010). Machineries for Making Publics: Inscribing and De-scribing Publics in Public Engagement. Minerva, 48, 219-238. https://doi.org/10.1007/s11024-010-9155-x

Felt, U., Igelsböck, J., Schikowitz, A., \& Völker, T. (2012). Challenging Participation in Sustainability Research. International Journal of Deliberative Mechanisms in Science, 1(1), 3-34. https://doi.org/10.4471/demesci.2012.01

Feola, G. (2015). Societal transformation in response to global environmental change: A review of emerging concepts. Ambio, 44(5), 376-390. https://doi.org/10.1007/s13280-014-0582-z

Feola, G. (2019). Capitalism in sustainability transitions research: Time for a critical turn? Environmental Innovation and Societal Transitions, (July 2018), 1-10. https://doi.org/10.1016/j.eist.2019.02.005

Feola, G., \& Nunes, R. (2014). Success and failure of grassroots innovations for addressing climate change: The case of the transition movement. Global Environmental Change, 24(1), 232-250. https://doi.org/10.1016/j.gloenvcha.2013.11.011

Flyvbjerg, B. (2001). Making Social Science Matter. Making Social Science Matter. Cambridge University Press. https://doi.org/10.1017/cbo9780511810503

Frickel, S., \& Moore, K. (2006). The New Political Sociology of Science: Institutions, Networks, And Power. Madison, WI: University of Wisconsin Press.

Funtowicz, S., \& Ravetz, R. (1993). Science for the post-normal age. Futures, 25(7), 739-755. https://doi.org/10.1016/0016-3287(93)90022-L

Future Earth. (n.d.). Future Earth. Research for Global Sustainability [leaflet]. Retrieved April, 2016, from http://www.futureearth.org/who-we-are.

Future Earth. (2013). Future Earth Initial Design: Report of the Transition Team. Paris, France. International Council for Science (ICSU).

Future Earth. (2014a). Engagement Committee Call for Applications. Paris, France: International Council for Science (ICSU). Retrieved from http://www.icsu.org/news-centre/news/call-for-applications-for-future-earthengagement-committee

Future Earth. (2014b). Engagement in Future Earth: Aims, rationales and a strategy. A Green Paper for consultation with Future Earth Core Projects [Unpublished].

Future Earth. (2014c). Future Earth 2025 Vision. Paris, France. International Council for Science (ICSU).

Future Earth. (2014d). Future Earth and WCRP affirm strong partnership. Retrieved October 14, 2014, from http://www.futureearth.org/news/future-earth-and-wcrp-affirm-strong-partnership

Future Earth. (2014e). Strategic Research Agenda. Paris, France. International Council for Science (ICSU).

Future Earth. (2016a). Future Earth ‘Open Network’ map. Retrieved June 20, 2012, from https://network.futureearth.org/home

Future Earth. (2016b). Knowledge $\rightleftarrows$ Action Networks Framing and Operationalisation. Version 1.0.1. Retrieved from http:// futureearth.org/sites/default/files/framing_and_operationalisation_kans_version_1.0.1.pdf

Future Earth. (2017). Future Earth Annual Report 2016 - 2017. Retrieved from https:// futureearth.org/wpcontent/uploads/2019/08/annual_report_2017_digital_final_p1_7-1.pdf

Future Earth. (2018a). Call for application Future Earth governing council. Retrieved from http:// futureearth.org/news/2018-call-application-future-earth-governing-council

Future Earth. (2018b). Future Earth names inaugural members to its Advisory Committee. Retrieved from http://www.futureearth.org/news/ future-earth-names-inaugural-members-its-advisory-committee 
Garard, J., \& Kowarsch, M. (2016). If at first you don't succeed: Evaluating stakeholder engagement in global environmental assessments. Environmental Science and Policy, (online first). https://doi.org/10.1016/j.envsci.2017.02.007

Garard, J., \& Kowarsch, M. (2017). Objectives for Stakeholder Engagement in Global Environmental Assessments. Sustainability, 9(9), 1571. https://doi.org/10.3390/su9091571

Garner, J. G., Porter, A. L., Newman, N. C., \& Crowl, T. A. (2012). Assessing research network and disciplinary engagement changes induced by an NSF program. Research Evaluation, 21(2), 89-104. https://doi.org/10.1093/reseval/rvs004

Garrett-Jones, S., Turpin, T., Burns, P., \& Diment, K. (2005). Common purpose and divided loyalties: the risks and rewards of cross-sector collaboration for academic and government researchers. $\mathrm{R}$ and D Management, 35(5), 535-544. https://doi.org/10.1111/j.1467-9310.2005.00410.x

Georghiou, L. (1998). Global cooperation in research. Research Policy, 27, 611-626. https://doi.org/10.1016/S00487333(98)00054-7

Gibbons, M., Limoges, C., Nowotny, H., Schwartzman, S., Scott, P., \& Trow, M. (1994). The New Production of Knowledge: The Dynamics of Science and Research in Contemporary Societies. London, UK: SAGE.

Gieryn, T. F. (1999). Cultural Boundaries of Science: Credibility on the Line. University of Chicago Press.

Gläser, J., \& Laudel, G. (2016). Governing Science. European Journal of Sociology, 57(1), 117-168. https://doi.org/10.1017/s0003975616000047

Graham, S., Barnett, J., Fincher, R., Hurlimann, A., \& Mortreux, C. (2014). Local values for fairer adaptation to sealevel rise: A typology of residents and their lived values in Lakes Entrance, Australia. Global Environmental Change, 29, 41-52. https://doi.org/10.1016/j.gloenvcha.2014.07.013

Griggs, D., Stafford-Smith, M., Gaffney, O., Rockström, J., Ohman, M. C., Shyamsundar, P., ... Noble, I. (2013). Sustainable development goals for people and planet. Nature, 495(7441), 305-307. https://doi.org/10.1038/495305a

Gupta, A., Andresen, S., Siebenhüner, B., \& Biermann, F. (2012). Science networks. In F. Biermann \& P. Pattberg (Eds.), Global Environmental Governance Reconsidered (pp. 69-93). Cambridge, MA: MIT Press. https://doi.org/10.7551/mitpress/9232.003.0008

Gupta, A., \& Möller, I. (2019). De facto governance: how authoritative assessments construct climate engineering as an object of governance. Environmental Politics, 28(3), 480-501. https://doi.org/10.1080/09644016.2018.1452373

Gustafsson, K. M., \& Lidskog, R. (2018). Boundary organizations and environmental governance: Performance, institutional design, and conceptual development. Climate Risk Management. https://doi.org/10.1016/j.crm.2017.11.001

Haas, P. M. (1989). Do regimes matter? Epistemic communities and Mediterranean pollution control. International Organization, 43(3), 377. https://doi.org/10.1017/S0020818300032975

Haas, P. M. (1992). Banning chlorofluorocarbons: epistemic community efforts to protect stratospheric ozone. International Organization, 46(1), 187-224.

Haas, P. M. (2004). When does power listen to truth? A constructivist approach to the policy process. Journal of European Public Policy, 11(4), 569-592. https://doi.org/10.1080/1350176042000248034

Haas, P. M. (2017). The epistemic authority of solution-oriented global environmental assessments. Environmental Science and Policy, 77, 221-224. https://doi.org/10.1016/j.envsci.2017.03.013

Haas, P. M., \& Stevens, C. (2011). Organized Science, Usable Knowledge, and Multilateral Environmental Governance. In R. Lidskog \& G. Sundqvist (Eds.), Governing the Air: The Dynamics of Science, Policy, and Citizen Interaction (pp. 125-161). Cambridge, MA.: MIT Press.

Hackett, E. J., Parker, J. N., Vermeulen, N., \& Penders, B. (2017). The social and epistemic organization of scientific work. In U. Felt, R. Fouché, C. A. Miller, \& L. Smith-Doerr (Eds.), Handbook of Science and Technology Studies (4th ed., pp. 733-764). Cambridge, MA: MIT Press.

Hadley Kershaw, E. (2017). Leviathan and the hybrid network: Future Earth, co-production and the experimental life of a global institution. In B. Nerlich, S. Hartley, S. Raman, \& A. Smith (Eds.), Science and the politics of openness Here be monsters (pp. 107-130). Manchester, UK: Manchester University Press.

Hadorn, G. H., Biber-Klemm, S., Grossenbacher-Mansuy, W., Hoffmann-riem, H., Joye, D., Pohl, C., ... Zemp, E. (2008). The Emergence of Transdisciplinarity as a Form of Research. In G. Hirsch Hadorn, H. HoffmannRiem, S. Biber-Klemm, W. Grossenbacher-Mansuy, D. Joye, C. Pohl, ... E. Zemp (Eds.), Handbook of Transdisciplinary Research (pp. 19-39). Springer. 
Haider, J., Hentati-Sundberg, J., Giusti, M., Goodness, J., Hamann, M., Masterson, V., ... Sinare, H. (2017). The undisciplinary journey: Early-career perspectives in sustainability science. Sustainability Science. https://doi.org/10.1007/s11625-017-0445-1

Hajer, M. A. (1995). The Politics of Environmental Discourse: Ecological Modernization and the Policy Process. Oxford, UK: Oxford University Press.

Hajer, M. A., \& Pelzer, P. (2018). 2050-An Energetic Odyssey: Understanding 'Techniques of Futuring' in the transition towards renewable energy. Energy Research and Social Science, 44(May), 222-231. https://doi.org/10.1016/j.erss.2018.01.013

Hassan, S. U., Haddawy, P., \& Zhu, J. (2014). A bibliometric study of the world's research activity in sustainable development and its sub-areas using scientific literature. Scientometrics (Vol. 99). https://doi.org/10.1007/s11192-013-1193-3

Hegger, D., Lamers, M., Van Zeijl-Rozema, A., \& Dieperink, C. (2012). Conceptualising joint knowledge production in regional climate change adaptation projects: success conditions and levers for action. Environmental Science and Policy, 18, 52-65. https://doi.org/10.1016/j.envsci.2012.01.002

Hellsten, I., \& Leydesdorff, L. (2015). The Construction of Interdisciplinarity: The development of the knowledge base and programmatic focus of the journal Climatic Change, 1977-2013. Journal of the Association of Information Science and Technology.

Hess, D. J. (1997). Science Studies: An Advanced Introduction. NYU Press.

Hessels, L. K. (2013). Coordination in the Science System: Theoretical Framework and a Case Study of an Intermediary Organization. Minerva, 51(3), 317-339. https://doi.org/10.1007/s11024-013-9230-1

Hessels, L. K., \& van Lente, H. (2008). Re-thinking new knowledge production: A literature review and a research agenda. Research Policy, 37(4), 740-760. https://doi.org/10.1016/j.respol.2008.01.008

Hessels, L. K., van Lente, H., \& Smits, R. (2009). In search of relevance: The changing contract between science and society. Science and Public Policy, 36(5), 387-401. https://doi.org/10.3152/030234209X442034

Hessels, L. K., Wardenaar, T., Boon, W. P. C. C., \& Ploeg, M. (2014). The role of knowledge users in public-private research programs: An evaluation challenge. Research Evaluation, 23(2), 103-116. https://doi.org/10.1093/reseval/rvu007

Hird, M. D., \& Pfotenhauer, S. M. (2016). How complex international partnerships shape domestic research clusters: Difference-in-difference network formation and research re-orientation in the MIT Portugal Program. Research Policy, 46(3), 557-572. https://doi.org/10.1016/j.respol.2016.10.008

Holm, P., Goodsite, M. E., Cloetingh, S., Agnoletti, M., Moldan, B., Lang, D. J., ... Zondervan, R. (2013). Collaboration between the natural, social and human sciences in Global Change Research. Environmental Science and Policy, 28, 25-35. https://doi.org/10.1016/j.envsci.2012.11.010

Hoppe, R. (2009). Scientific advice and public policy: Expert advisers' and policymakers' discourses on boundary work. Poiesis Und Praxis, 6(3-4), 235-263. https://doi.org/10.1007/s10202-008-0053-3

Hordijk, L., Marcus, T., Pearman, G. I., Sinha, J. B. P., \& Torrey, B. B. (2006). External assessment of the International Human Dimension on Global Environmental Change programme. Retrieved from https://council.science/wp-content/uploads/2017/05/IHDP_Review.pdf

Horlick-Jones, T., \& Sime, J. (2004). Living on the border: knowledge, risk and transdisciplinarity. Futures, 36(4), 441456. https://doi.org/10.1016/j.futures.2003.10.006

Hughes, H. R. (2012). Practices of Power and Knowledge in the Intergovernmental Panel on Climate Change (IPCC). Aberystwyth University.

Hughes, H. R., \& Vadrot, A. B. M. (2019). Weighting the World: IPBES and the Struggle over Biocultural Diversity. Global Environmental Politics, 19(2), 14-37. https://doi.org/10.1162/GLEP

Hulme, M. (2009). Why We Disagree About Climate Change. Why We Disagree About Climate Change. Cambridge University Press. https://doi.org/10.1017/cbo9780511841200

Hulme, M. (2010). Problems with making and governing global kinds of knowledge. Global Environmental Change, 20(4), 558-564. https://doi.org/10.1016/j.gloenvcha.2010.07.005

Hulme, M. (2015). Changing what exactly, and from where? A response to Castree. Dialogues in Human Geography, 5(3), 322-326. https://doi.org/10.1177/2043820615613227

ICSU-IGFA. (2008). ICSU-IGFA Review of the Earth System Science Partnership (ESSP). Paris, France: International Council for Science (ICSU). Retrieved from http://www.icsu.org/publications/reports-and-reviews/esspreview/ESSP_Review.pdf

ICSU-IGFA. (2009). Review of the International Geosphere-Biosphere Programme (IGBP). Paris, France: International Council for Science (ICSU). Retrieved from http://www.icsu.org/publications/reports-and-reviews/igbpreview/IGBP_Review_2009.pdf 
ICSU. (2010). Earth System Science for Global Sustainability: The Grand Challenges. Paris, France. International Council for Science (ICSU).

ICSU. (2011a). Earth System Research for Global Sustainability: A New 10-Year Research Initiative. Paris, France: International Council for Science (ICSU).

ICSU. (2011b). Establishment of a Transition Team: Terms of Reference. Paris, France: International Council for Science (ICSU). Retrieved from http://www.icsu.org/future-earth/who/transition-team/ToRsforTransitionTeam.pdf

ICSU, \& ISSC. (2015). Review of Targets for the Sustainable Development Goals: The Science Perspective. Paris, France: International Council for Science (ICSU).

ICSU, ISSC, \& Future Earth. (2015). Key messages proposed by the Science and Technology community for the Post-2015 Outcome Document. Paris, France: International Council for Science (ICSU).

ICSU, \& IUCN. (2013). Statements on behalf of ICSU, the International Council for Science, and IUCN, the International Union for Conservation of Nature, on items 7(b).

Ignaciuk, A., Rice, M., Bogardi, J., Canadell, J. G., Dhakal, S., Ingram, J., ... Rosenberg, M. (2012). Responding to complex societal challenges: A decade of Earth System Science Partnership (ESSP) interdisciplinary research. Current Opinions in Environmental Sustainability, 4(1), 147-158. https://doi.org/10.1016/j.cosust.2011.12.003

iisd. (2013a). Summary of the First Plenary Meeting of the Intergovernmental Platform on Biodiversity and Ecosystem Services. 21-26 January 2013. Earth Negotiations Bulletin 31(6).

iisd. (2013b). IPBES-2 Highlights. 11 December 2013. Earth Negotiations Bulletin 31(10).

IPBES. (2012). Functions, operating principles and institutional arrangements of the Intergovernmental Science-Policy Platform on Biodiversity and Ecosystem Services. Adopted by the second session of the plenary meeting to determine the modalities and institutional arra.

IPBES. (2013). IPBES/2/13 Communication and stakeholder engagement: Stakeholder engagement strategy. Draft stakeholder engagement strategy for supporting the implementation of the Platform's work programme.

IPBES. (2014). Revised draft stakeholder engagement strategy: deliverable 4 (d). IPBES/3/16.

IPCC. (1990). Climate Change: The IPCC Scientific Assessment. Report prepared for IPCC by Working Group I. [J.T.Houghton, G.J.Jenkins and J.J.Ephraums, Eds.]. Intergovernmental Panel on Climate Change (IPCC). Cambridge, UK: Cambridge University Press.

IUCN, ICSU, \& NEFO. (2014). Outline of a second version of the IPBES Stakehlder Engagement Strategy.

Jagannathan, K., Arnott, J. C., Wyborn, C., Klenk, N. L., Mach, K. J., Moss, R. H., \& Sjostrom, K. D. (2019). Great expectations? Reconciling the aspiration, outcome, and possibility of coproduction. Current Opinion in Environmental Sustainability, 42. https://doi.org/10.1016/j.cosust.2019.11.010

Jäger, J. (2003). The International Human Dimensions Programme on Global Environmental Change (IHDP). Global Environmental Change, 13(1), 69. https://doi.org/10.1016/S0959-3780(02)00083-3

Jahn, T., Bergmann, M., \& Keil, F. (2012). Transdisciplinarity: Between mainstreaming and marginalization. Ecological Economics, 79, 1-10. https://doi.org/10.1016/j.ecolecon.2012.04.017

Janssen, M. A., \& Ostrom, E. (2006). Resilience, vulnerability, and adaptation: A cross-cutting theme of the International Human Dimensions Programme on Global Environmental Change. Global Environmental Change, 16(3), 237-239. https://doi.org/10.1016/j.gloenvcha.2006.04.003

Janssen, M. A., Schoon, M. L., Ke, W., \& Börner, K. (2006). Scholarly networks on resilience, vulnerability and adaptation within the human dimensions of global environmental change. Global Environmental Change, 16(3), 240-252. https://doi.org/10.1016/j.gloenvcha.2006.04.001

Jappe, A. (2009). International collaboration in global environmental research: a comparison of the International Geosphere Biosphere Program and the International Hydrological Program. Science and Public Policy, 36(3), 183197. https://doi.org/10.3152/030234209X427086

Jasanoff, S. (2003). Technologies of humility: citizen participation in governing science. Minerva, 41, $223-244$. https://doi.org/10.1023/A:1025557512320

Jasanoff, S. (2004). States of Knowledge: The Co-Production of Science and Social Order. London, UK: Routledge.

Jasanoff, S. (2005). Judgement Under Siege: The Three-Body Problem of Expert Legitimacy. In S. Maasen \& P. Weingart (Eds.), Democratization of Expertise? Exploring Novel Forms of Scientific Advice in Political Decision-Making (Vol. 24, pp. 209-224). Springer Netherlands.

Jasanoff, S., \& Martello, M. L. (2004). Eartbly Politics: Local and Global in Environmental Governance. MIT Press.

Jerneck, A., Olsson, L., Ness, B., Anderberg, S., Baier, M., Clark, E., ... Lövbrand, E. (2011). Structuring sustainability science. Sustainability Science, 6(1), 69-82. https://doi.org/10.1007/s11625-010-0117-x 
Johnson, J. C., Christian, R. R., Brunt, J. W., Hickman, C. R., \& Waide, R. B. (2010). Evolution of Collaboration within the US Long Term Ecological Research Network. BioScience, 60(11), 931-940. https://doi.org/10.1525/bio.2010.60.11.9

Kajikawa, Y., Tacoa, F., \& Yamaguchi, K. (2014). Sustainability science: the changing landscape of sustainability research. Sustainability Science, 431-438. https://doi.org/10.1007/s11625-014-0244-x

Karlsson, S., Srebotnjak, T., \& Gonzales, P. (2007). Understanding the North-South knowledge divide and its implications for policy: a quantitative analysis of the generation of scientific knowledge in the environmental sciences. Environmental Science and Policy, 10(7-8), 668-684. https://doi.org/10.1016/j.envsci.2007.04.001

Kates, R. W. (2011). What kind of a science is sustainability science? Proceedings of the National Academy of Sciences of the United States of America, 108(49), 19449-19450. https://doi.org/10.1073/pnas.1116097108

Kates, R. W., Clark, W. C., Corell, R., Hall, M., Jaeger, C. C., Lowe, I., ... Svedin, U. (2001). Sustainability Science. Science, 292(5517), 641-642.

Kauffman, J., \& Arico, S. (2014). New directions in sustainability science: promoting integration and cooperation. Sustainability Science, 9(4), 413-418. https://doi.org/10.1007/s11625-014-0259-3

Keenan, M., Cutler, P., Marks, J., Meylan, R., Smith, C., \& Koivisto, E. (2012). Orienting international science cooperation to meet global "grand challenges." Science and Public Policy, 39(2), 166-177. https://doi.org/10.1093/scipol/scs019

Keller, A. C. (2009). Science in Environmental Policy: The Politics of Objective Advice. Cambridge, MA: MIT Press.

Keller, A. C. (2010). Credibility and relevance in environmental policy: Measuring strategies and performance among science assessment organizations. Journal of Public Administration Research and Theory, 20(2), 357-386. https://doi.org/10.1093/jopart/mup001

Kläy, A., Zimmermann, A. B., \& Schneider, F. (2015). Rethinking science for sustainable development: Reflexive interaction for a paradigm transformation. Futures, 65, 72-85. https://doi.org/10.1016/j.futures.2014.10.012

Klein, Julie Thompson. (2001). The Discourse of Transdisciplinarity: An Expanding Global Field. In J. T. Klein, W. Grossenbacher-Mansuy, R. Haberli, A. Bill, R. W. Scholz, \& M. Welti (Eds.), Transdisciplinarity: Joint Problem Solving among Science, Technology, and Society (pp. 35-44). Basel, Switzerland: Birkhauser Berlag.

Klein, Julie Thompson. (2014). Discourses of transdisciplinarity: Looking Back to the Future. Futures, 63, 68-74. https://doi.org/10.1016/j.futures.2014.08.008

Klenk, N. L., \& Hickey, G. M. (2012). Improving the social robustness of research networks for sustainable natural resource management: Results of a delphi study in Canada. Science and Public Policy, 39(3), 357-372. https://doi.org/10.1093/scipol/scs024

Klenk, N. L., \& Hickey, G. M. (2013). How can formal research networks produce more socially robust forest science? Forest Policy and Economics, 37, 44-56. https://doi.org/10.1016/j.forpol.2012.05.006

Klenk, N. L., Hickey, G. M., \& MacLellan, J. I. (2010). Evaluating the social capital accrued in large research networks: The case of the Sustainable Forest Management Network (1995-2009). Social Studies of Science, 40(6), 931-960. https://doi.org/10.1177/0306312710374130

Klenk, N. L., \& Meehan, K. (2015). Climate change and transdisciplinary science: Problematizing the integration imperative. Environmental Science and Policy, 54, 160-167. https://doi.org/10.1016/j.envsci.2015.05.017

Klerkx, L., \& Leeuwis, C. (2008). Delegation of authority in research funding to networks: experiences with a multiple goal boundary organization. Science and Public Policy, 35(3), 183-196. https://doi.org/10.3152/030234208X299053

Kloet, R. R., Hessels, L. K., Zweekhorst, M. B. M., Broerse, J. E. W., \& Buning, T. de C. (2013). Understanding Constraints in the Dynamics of a Research Programme Intended as a Nich Innovation. Science and Public Policy, 40(2), 206-218. https://doi.org/10.1093/scipol/scs081

Knaggård, A., Ness, B., \& Harnesk, D. (2018). Finding an academic space: Reflexivity among sustainability researchers. Ecology and Society, 23(4). https://doi.org/10.5751/ES-10505-230420

Kohler, P. M. (2019). Science Advice and Global Environmental Governance: Expert Institutions and the Implementation of International Environmental Treaties. London, UK: Anthem Press.

Koier, E., \& Horlings, E. (2015). How accurately does output reflect the nature and design of transdisciplinary research programmes? Research Evaluation , 24(1), 37-50. https://doi.org/10.1093/reseval/rvu027

Kowarsch, M., \& Jabbour, J. (2017). Solution-oriented global environmental assessments: Opportunities and challenges. Environmental Science and Policy, 77, 1-6. https://doi.org/10.1016/j.envsci.2017.08.013

Krisch, N. (2017). Liquid authority in global governance. International Theory, 9(2), 1-25. https://doi.org/10.1017/S1752971916000269 
Kueffer, C., Schneider, F., \& Wiesmann, U. (2019). Addressing sustainability challenges with a broader concept of systems, target, and transformation knowledge. GAIA - Ecological Perspectives for Science and Society, 28(4), 386388. https://doi.org/10.14512/gaia.28.4.12

Kueffer, C., Underwood, E., Hirsch Hadorn, G., Holderegger, R., Lehning, M., Pohl, C., ... Edwards, P. (2012). Enabling Effective Problem-oriented Research for Sustainable Development. Ecology and Society, 17(4). https://doi.org/10.5751/ES-05045-170408

Kunseler, E. M., \& Tuinstra, W. (2017). Navigating the authority paradox: Practising objectivity in environmental expertise. Environmental Science and Policy, 67, 1-7. https://doi.org/10.1016/j.envsci.2016.10.001

Kunseler, E. M., Tuinstra, W., Vasileiadou, E., \& Petersen, A. C. (2015). The reflective futures practitioner: Balancing salience, credibility and legitimacy in generating foresight knowledge with stakeholders. Futures, 66, 1-12. https://doi.org/10.1016/j.futures.2014.10.006

Kwa, C. (2006). The programming of interdisciplinary research through informal science-policy interactions. Science and Public Policy, 33(6), 457-467. https://doi.org/0302-3427/06/060457-11

Lacey, J., Howden, S. M., Cvitanovic, C., \& Dowd, A. M. (2015). Informed adaptation: Ethical considerations for adaptation researchers and decision-makers. Global Environmental Change, 32, 200-210. https://doi.org/10.1016/j.gloenvcha.2015.03.011

Lahn, B. (2018). In the light of equity and science: scientific expertise and climate justice after paris. International Environmental Agreements: Politics, Law and Economics, 18(1), 29-43. https://doi.org/10.1007/s10784-017-9375-8

Lahsen, M. (2016). Toward a Sustainable Future Earth: Challenges for a Research Agenda. Science Technology and Human Values, 41(5), 876-898. https://doi.org/10.1177/0162243916639728

Lahsen, M., Mathews, A., Dove, M. R., Orlove, B., Puri, R., Barnes, J., ... Yager, K. (2015). Strategies for changing the intellectual climate. Nature Climate Change, 5(5), 391-392. https://doi.org/10.1038/nclimate2596

Lang, D. J., Wiek, A., Bergmann, M., Stauffacher, M., Martens, P., Moll, P., ... Thomas, C. J. (2012). Transdisciplinary research in sustainability science: practice, principles, and challenges. Sustainability Science, 7(1), 25-43. https://doi.org/10.1007/s11625-011-0149-x

Latour. (2004). Why Has Critique Run out of Steam? From Matters of Fact to Matters of Concern. Critical Inquiry, 30(2), 225. https://doi.org/10.2307/1344358

Latour, B. (1987). Science in Action: How to Follow Scientists and Engineers Through Society. Cambridge, MA: Harvard University Press.

Lee, H. (2015). Turning the focus to solutions. Science, 350(6264), 1007. https://doi.org/10.1126/science.aad8954

Leemans, R. (2016). The lessons learned from shifting from global-change research programmes to transdisciplinary sustainability science. Current Opinions in Environmental Sustainability, 19, 103-110. https://doi.org/10.1016/j.cosust.2016.01.001

Leemans, R., Asrar, G., Busalacchi, A., Canadell, J., Ingram, J., Larigauderie, A., ... Young, O. (2009). Developing a common strategy for integrative global environmental change research and outreach: the Earth System Science Partnership (ESSP). Current Opinions in Environmental Sustainability, 1(1), 4-13. https://doi.org/10.1016/j.cosust.2009.07.013

Lemos, M. C., \& Morehouse, B. J. (2005). The co-production of science and policy in integrated climate assessments. Global Environmental Change, 15(1), 57-68. https://doi.org/10.1016/j.gloenvcha.2004.09.004

Lengwiller, M. (2007). Participatory Approaches in Science and Technology: Historical Origins and Current Practices in Critical Perspective. Science, Technology \& Human Values, 33(2), 186-200. https://doi.org/10.1177/0162243907311262

Lenton, T. M. (2020). Tipping positive change. Philosophical Transactions of the Royal Society of London. Series B, Biological Sciences, 375(1794), 20190123. https://doi.org/10.1098/rstb.2019.0123

Lidskog, R. (2008). Scientised citizens and democratised science. Re-assessing the expert-lay divide. Journal of Risk. Research, 11(1), 69-86. https://doi.org/10.1080/13669870701521636

Lidskog, R. (2014). Representing and regulating nature: boundary organisations, portable representations, and the science-policy interface. Environmental Politics, 23(4), 670-687. https://doi.org/10.1080/09644016.2013.898820

Lidskog, R., \& Löfmarck, E. (2015). Managing uncertainty: Forest professionals' claim and epistemic authority in the face of societal and climate change. Risk Management, 17(3), 145-164. https://doi.org/10.1057/rm.2015.10

Lidskog, R., \& Sundqvist, G. (2015). When Does Science Matter? International Relations Meets Science and Technology Studies. Global Environmental Politics, 15, 1-20. https://doi.org/10.1162/GLEP

Lima, M. G. B., \& Gupta, J. (2013). Studying Global Environmental Meetings. Global Environmental Politics, 13 , $46-64$. https://doi.org/10.1162/GLEP

Litfin, K. (1994). Ozone discourses: science and politics in global environmental cooperation. Columbia University Press. 
Littoz-Monnet, A. (2017). The Politics of Expertise in International Organizations: How International Bureaucracies Produce and Mobilize Knowledge. New York, NY: Routledge.

Löfmarck, E., \& Lidskog, R. (2017). Bumping against the boundary: IPBES and the knowledge divide. Environmental Science and Policy, 69, 22-28. https://doi.org/10.1016/j.envsci.2016.12.008

Lövbrand, E. (2011). Co-producing European climate science and policy: a cautionary note on the making of useful knowledge. Science and Public Policy, 38(3), 225-236. https://doi.org/10.3152/030234211X12924093660516

Lövbrand, E., Beck, S., Chilvers, J., Forsyth, T., Hedrén, J., Hulme, M., .. Vasileiadou, E. (2015). Who speaks for the future of Earth? How critical social science can extend the conversation on the Anthropocene. Global Environmental Change, 32, 211-218. https://doi.org/10.1016/j.gloenvcha.2015.03.012

Lövbrand, E., Stripple, J., \& Wiman, B. (2009). Earth System governmentality. Global Environmental Change, 19(1), 7-13. https://doi.org/10.1016/j.gloenvcha.2008.10.002

Lu, Y., Nakicenovic, N., Visbeck, M., \& Stevance, A.-S. (2015). Five priorities for the UN Sustainable Development Goals. Nature, 520, 432-433. https://doi.org/10.1038/520432a

Lubchenco, J. (1998). Entering the Century of the Environment: A New Social Contract for Science. Science, 279, 491497.

Lubchenco, J., Barner, A. K., Cerny-chipman, E. B., \& Reimer, J. N. (2015). Sustainability rooted in science. Nature, 8(10), 741-745. https://doi.org/10.1038/ngeo2552

Luks, F., \& Siebenhüner, B. (2007). Transdisciplinarity for social learning? The contribution of the German socioecological research initiative to sustainability governance. Ecological Economics, 63(2-3), 418-426. https://doi.org/10.1016/j.ecolecon.2006.11.007

Luukkonen, T. (2001). Old and new strategic roles for the European Union Framework Programme. Science and Public Policy, 28(3), 205-218.

Lyall, C., Bruce, A., Marsden, W., \& Meagher, L. (2013). The role of funding agencies in creating interdisciplinary knowledge. Science and Public Policy, 40(1), 62-71. https://doi.org/10.1093/scipol/scs121

Maasen, S., \& Dickel, S. (2019). Normative answers - epistemic questions. Updating the science-society contract. In D. Simon, S. Kuhlmann, \& J. Stamm (Eds.), Handbook on Science and Public Policy (pp. 49-66). Edward Elgar Publishing.

Maasen, S., \& Lieven, O. (2006). Transdisciplinarity: a new mode of governing science? Science and Public Policy, 33(6), 399-410. https://doi.org/10.3152/147154306781778803

Mahony, M., \& Hulme, M. (2016). Epistemic geographies of climate change: Science, space and politics. Progress in Human Geography, 1-30. https://doi.org/10.1177/0309132516681485

Marshall, F., Dolley, J., \& Priya, R. (2018). Transdisciplinary research as transformative space making for sustainability: Enhancing propoor transformative agency in Periurban contexts. Ecology and Society, 23(3). https://doi.org/10.5751/ES-10249-230308

Martinez-Harms, M. J., Gelcich, S., Krug, R. M., Maseyk, F. J. F., Moersberger, H., Rastogi, A., ... Pascual, U. (2018). Framing natural assets for advancing sustainability research: translating different perspectives into actions. Sustainability Science, 13(6), 1519-1531. https://doi.org/10.1007/s11625-018-0599-5

Mauser, W., Klepper, G., Rice, M., Schmalzbauer, B. S., Hackmann, H., Leemans, R., \& Moore, H. (2013). Transdisciplinary global change research: the co-creation of knowledge for sustainability. Current Opinions in Environmental Sustainability, 1-12. https://doi.org/10.1016/j.cosust.2013.07.001

Meadows, D. H., Meadows, D. L., Randers, J., \& Behrens III, W. W. (1972). The Limits to Growth: A Report for the Club of Rome's Project on the Predicament of Mankind. New York, NY: Universe Books.

Messerli, P., Kim, E. M., Lutz, W., Moatti, J.-P., Richardson, K., Saidam, M., .. Furman, E. (2019). Expansion of sustainability science needed for the SDGs. Nature Sustainability, 2, 892-894. https://doi.org/10.1038/s41893019-0394-z

Miettinen, R. (1998). Object Construction and Networks in Research Work:: The Case of Research on Cellulose-Degrading Ensymes. Social Studies of Science (Vol. 28). https://doi.org/10.1177/030631298028003003

Milkoreit, M., Bansard, J., \& van der Hel, S. (2020). Agency and knowledge in environmental governance: a thematic review. In M. M. Betsill, T. M. Benney, \& A. K. Gerlak (Eds.), Agency in Earth system Governance (pp. 86-96). Cambridge, UK: Cambridge University Press.

Milkoreit, M., Moore, M. L., Schoon, M., \& Meek, C. L. (2015). Resilience scientists as change-makers. Growing the middle ground between science and advocacy? Environmental Science and Policy, 53(B), 87-95. https://doi.org/10.1016/j.envsci.2014.08.003

Miller, C. A., \& Edwards, P. N. (2001). Changing the Atmosphere: Expert Knowledge and Environmental Governance. Cambridge, MA: MIT Press. 
Miller, C. A., \& Wyborn, C. (2018). Co-production in global sustainability: Histories and theories. Environmental Science and Policy, (October 2017). https://doi.org/10.1016/j.envsci.2018.01.016

Miller, T. R. (2013). Constructing sustainability science: Emerging perspectives and research trajectories. Sustainability Science, 8(2), 279-293. https://doi.org/10.1007/s11625-012-0180-6

Miller, T. R., Muñoz-Erickson, T., \& Redman, C. L. (2011). Transforming knowledge for sustainability: towards adaptive academic institutions. International Journal of Sustainability in Higher Education, 12(2), 177-192. https://doi.org/10.1108/14676371111118228

Miller, T. R., Wiek, A., Sarewitz, D., Robinson, J., Olsson, L., Kriebel, D., \& Loorbach, D. (2014). The future of sustainability science: a solutions-oriented research agenda. Sustainability Science, 9(2), 239-246. https://doi.org/10.1007/s11625-013-0224-6

Mitchell, R. B., Clark, W. C., Cash, D. W., \& Dickson, N. M. (2006). Global Environmental Assessments: Information and Influence. Cambridge, MA: MIT Press.

Montana, J. (2017). Accommodating consensus and diversity in environmental knowledge production: Achieving closure through typologies in IPBES. Environmental Science and Policy, 68, 20-27. https://doi.org/10.1016/j.envsci.2016.11.011

Montana, J. (2019). Co-production in action: perceiving power in the organisational dimensions of a global biodiversity expert process. Sustainability Science, 14(6), 1581-1591. https://doi.org/10.1007/s11625-019-00669-w

Mooney, H. A., Duraiappah, A., \& Larigauderie, A. (2013). Evolution of natural and social science interactions in global change research programs. Proceedings of the National Academy of Sciences of the United States of America, 110(Suppl 1), 3665-3672. https://doi.org/10.1073/pnas.1107484110

Moore, B., Underdal, A., Lemke, P., \& Loreau, M. (2001). The Amsterdam Declaration on Global Change. In W. Steffen, J. Jäger, D. Carson, \& . Bradshaw (Eds.), Challenges of a Changing Earth: Proceedings of the Global Change Open Science Conference. Amsterdam, The Netherlands, 10-13 July 2001, Springer-Verlag (2001) (pp. 207-208). IGBP Global Change Series.

Moore, K. (2008). Disrupting ScienceDisrupting Science: Social Movements, American Scientists, and the Politics of the Military, 1945-1975. Princeton, NJ: Princeton University Press.

Moser, S. C. (2016). Can science on transformation transform science? Lessons from co-design. Current Opinions in Environmental Sustainability, 20, 106-115. https://doi.org/10.1016/j.cosust.2016.10.007

Mukhtarov, F. (2016). Reflexivity, positionality and normativity in the ethnography of policy translation. In T. Berger \& A. Esguerra (Eds.), World Politics in Translation Power, Relationality, and Difference in Global Cooperation. London, UK: Routledge.

Musch, A. K., \& von Streit, A. (2020). (Un)intended effects of participation in sustainability science: A criteria-guided comparative case study. Environmental Science and Policy, 104(October 2019), 55-66. https://doi.org/10.1016/j.envsci.2019.10.004

Nature. (2010). Wanted: an IPCC for biodiversity. Nature, 465(7298), 525-525.

Newig, J., Jahn, S., Lang, D. J., Kahle, J., \& Bergmann, M. (2019). Linking modes of research to their scientific and societal outcomes. Evidence from 81 sustainability-oriented research projects. Environmental Science and Policy, 101, 147-155. https://doi.org/10.1016/j.envsci.2019.08.008

Nielsen, J., de Bremond, A., Roy Chowdhury, R., Friis, C., Metternicht, G., Meyfroidt, P., ... Thomson, A. (2019). Toward a normative land systems science. Current Opinion in Environmental Sustainability, 38, 1-6. https://doi.org/10.1016/j.cosust.2019.02.003

Nightingale, A. J., Eriksen, S., Taylor, M., Forsyth, T., Pelling, M., Newsham, A., ... Joslyn, A. (2019). Beyond Technical Fixes: climate solutions and the great derangement. Climate and Development, 12(4), 343-352. https://doi.org/10.1080/17565529.2019.1624495

Norström, A. V, Cvitanovic, C., Löf, M. F., West, S., Wyborn, C., Balvanera, P., .. Österblom, H. (2020). Principles for knowledge co-production in sustainability research. Nature Sustainability, 9. https://doi.org/10.1038/s41893-019-0448-2

Nowotny, H., Scott, P., \& Gibbons, M. (2001). Re-Thinking Science: Knowledge and the Public in an Age of Uncertainty. Maiden, MA: Blackwell Publishers.

Nowotny, H., Scott, P., \& Gibbons, M. (2003). 'Mode 2' Revisited: The New Production of Knowledge. Minerva, 41(3), 179-194.

O’Brien, K. (2011). Global environmental change II: From adaptation to deliberate transformation. Progress in Human Geography, 36(5), 667-676. https://doi.org/10.1177/0309132511425767

O'Brien, K. (2012). Global environmental change III: Closing the gap between knowledge and action. Progress in Human Geography, 37(4), 587-596. https://doi.org/10.1177/0309132512469589 
Opgenoorth, L., Hotes, S., \& Mooney, H. (2014). IPBES: Biodiversity panel should play by rules. Nature, 506(7487), 159-159.

Österblom, H., Jouffray, J.-B., Folke, C., \& Rockström, J. (2017). Emergence of a global science-business initiative for ocean stewardship. Proceedings of the National Academy of Sciences, (August), 201704453. https://doi.org/10.1073/pnas.1704453114

Padma, T. V. (2014). Future Earth's 'global' secretariat under fire. SciDevNet. Retrieved from http://www.scidev.net/global/sustainability/news/future-earth-global-secretariat.html

Pasgaard, M., Dalsgaard, B., Maruyama, P. K. P. K., Sandel, B., \& Strange, N. (2015). Geographical imbalances and divides in the scientific production of climate change knowledge. Global Environmental Change, 35, 279-288. https://doi.org/10.1016/j.gloenvcha.2015.09.018

Pasgaard, M., Van Hecken, G., Ehammer, A., \& Strange, N. (2017). Unfolding scientific expertise and security in the changing governance of Ecosystem Services. Geoforum, 84(October), 354-367. https://doi.org/10.1016/j.geoforum.2017.02.001

Patterson, J. J., Schulz, K., Vervoort, J., van der Hel, S., Widerberg, O., Adler, C., ... Barau, A. (2016). Exploring the governance and politics of transformations towards sustainability. Environmental Innovation and Societal Transitions, 24,1-16. https://doi.org/10.1016/j.eist.2016.09.001

Patterson, J. J., Thaler, T., Hoffmann, M., Hughes, S., Oels, A., Chu, E., ... Jordan, A. A. (2018). Political feasibility of $1.5^{\circ} \mathrm{C}$ societal transformations: the role of social justice. Current Opinions in Environmental Sustainability, 31, 1-9. https://doi.org/10.1016/j.cosust.2017.11.002

Pereira, L., Frantzeskaki, N., Hebinck, A., Charli-Joseph, L., Drimie, S., Dyer, M., ... Vervoort, J. M. (2019). Transformative spaces in the making: key lessons from nine cases in the Global South. Sustainability Science, 15(1), 161-178. https://doi.org/10.1007/s11625-019-00749-x

Petersen, A. C., Cath, A., Hage, M., Kunseler, E. M., \& van der Sluijs, J. P. (2010). Post-Normal Science in Practice at the Netherlands Environmental Assessment Agency. Science, Technology \& Human Values, 36(3), 362-388. https://doi.org/10.1177/0162243910385797

Pickering, J., \& Persson, Å. (2019). Democratising planetary boundaries: experts, social values and deliberative risk evaluation in Earthsystem governance. Journal of Environmental Policy and Planning, $0(0), 1-13$. https://doi.org/10.1080/1523908X.2019.1661233

Pielke, R. A. (2007). The honest broker: Making sense of science in policy and politics. Cambridge, UK: CUP.

Pinheiro, R., \& Stensaker, B. (2013). Designing the Entrepreneurial University: The Interpretation of a Global Idea. Public Organization Review, 1-20. https://doi.org/10.1007/s11115-013-0241-z

Pohl, C. (2008). From science to policy through transdisciplinary research. Environmental Science and Policy, 11(1), 46-53. https://doi.org/10.1016/j.envsci.2007.06.001

Pohl, C., Rist, S., Zimmermann, A., Fry, P., Gurung, G. S., Schneider, F., ... Wiesmann, U. (2010). Researchers' roles in knowledge co-production: experience from sustainability research in Kenya, Switzerland, Bolivia and Nepal. Science and Public Policy, 37(4), 267-281. https://doi.org/10.3152/030234210X496628

Popa, F., Guillermin, M., \& Dedeurwaerdere, T. (2014). A pragmatist approach to transdisciplinarity in sustainability research: From complex systems theory to reflexive science. Futures, 65, 45-56. https://doi.org/10.1016/j.futures.2014.02.002

Pregernig, M., \& Böcher, M. (2012). Normative and analytical perspectives on the role of science and expertise in environmental governance. Environmental Governance: The Challenge of Legitimacy and Effectiveness, 199-219. https://doi.org/10.4337/9781849806077.00020

Rafols, I., Leydesdorff, L., O’Hare, A., Nightingale, P., \& Stirling, A. (2012). How journal rankings can suppress interdisciplinary research: A comparison between Innovation Studies and Business \& Management. Research Policy, 41(7), 1262-1282. https://doi.org/10.1016/j.respol.2012.03.015

Reinecke, S. (2015). Knowledge brokerage designs and practices in four european climate services: A role model for biodiversity policies? Environmental Science and Policy, 54, 513-521. https://doi.org/10.1016/j.envsci.2015.08.007

Reyes-García, V., Aceituno-Mata, L., Calvet-Mir, L., Garnatje, T., Gómez-Baggethun, E., Lastra, J. J., ... Pardo-deSantayana, M. (2014). Resilience of traditional knowledge systems: The case of agricultural knowledge in home gardens of the Iberian Peninsula. Global Environmental Change, 24(1), 223-231. https://doi.org/10.1016/j.gloenvcha.2013.11.022

Rice, M. (2013). Spanning disciplinary, sectoral and international boundaries: a sea change towards transdisciplinary global environmental change research? Current Opinions in Environmental Sustainability, 5, 1-11. https://doi.org/10.1016/j.cosust.2013.06.007 
Rip, A. (2011). Protected Spaces of Science: Their Emergence and Further Evolution in a Changing World. In M. Carrier \& A. Nordmann (Eds.), Science in the Context of Application (pp. 197-220). Dordrecht, NL: Springer Netherlands. https://doi.org/10.1007/978-90-481-9051-5

Ripple, W. J., Wolf, C., Newsome, T. M., Barnard, P., \& Moomaw, W. R. (2020). World Scientists' Warning of a Climate Emergency. BioScience, 70(1), 100-100. https://doi.org/10.1093/biosci/biz152

Robinson, J. (2008). Being undisciplined: Transgressions and intersections in academia and beyond. Futures, 40(1), 7086. https://doi.org/10.1016/j.futures.2007.06.007

Rockström, J. (2016). Future earth. Science, 351(6271), 319. https://doi.org/10.1126/science.aaf2138

Rosendahl, J., Zanella, M. A., Rist, S., \& Weigelt, J. (2015). Scientists' situated knowledge: Strong objectivity in transdisciplinarity. Futures, 65, 17-27. https://doi.org/10.1016/j.futures.2014.10.011

Rowe, A., Ng'eny, N., \& Carbon, M. (2014). Terminal Evaluation of the Project. Fifth Global Environmental Outlook: Integrated Environmental Assessment. Nairobi, Kenia: United Nations Environment Programme (UNEP).

Rudd, M. A. (2015). Scientists' framing of the ocean science - policy interface. Global Environmental Change, 33, 44-60. https://doi.org/10.1016/j.gloenvcha.2015.04.006

SAB. (2014a). Report of the Inaugural meeting. Berlin, Germany: Scientific Advisory Board of the UN Secretary-General. UNESCO.

SAB. (2014b). The Crucial Role of Science for Sustainable Development and the Post-2015 Development Agenda. Scientific Advisory Board of the UN Secretary-General. UNESCO. Retrieved from https://en.unesco.org/unsab/content/documents

SAB. (2016). Press kit: United Nations Secretary General's Scientific Advisory Board, 5th meeting Trieste, Italy, 24-25 May 2016. Scientific Advisory Board of the UN Secretary-General. UNESCO. Retrieved from http://en.unesco.org/un$\mathrm{sab} /$ sites/un-sab/files/Press_kit_SAB5.pdf

Sarewitz, D. (2011). Political Effectiveness in Science and Technology. In M. Carrier \& A. Nordmann (Eds.), Science in the Context of Application. Dordrecht, NL: Springer Netherlands. https://doi.org/10.1007/978-90-481-9051-5

Sarkki, S., Ficko, A., Grunewald, K., Kyriazopoulos, A. P., \& Nijnik, M. (2017). How pragmatism in environmental science and policy can undermine sustainability transformations: the case of marginalized mountain areas under climate and land-use change. Sustainability Science, 12(4), 549-561. https://doi.org/10.1007/s11625-016-0411-3

Sarkki, S., Tinch, R., Niemelä, J., Heink, U., Waylen, K., Timaeus, J., ... van den Hove, S. (2015). Adding 'iterativity' to the credibility, relevance, legitimacy: A novel scheme to highlight dynamic aspects of science-policy interfaces. Environmental Science and Policy, 1-10. https://doi.org/10.1016/j.envsci.2015.02.016

Sayer, L. (2014). “Co-design for relevance and usefulness" - Q\&A with Melissa Leach. Future Earth Blog. Retrieved from http://www.futureearth.org/blog/2014-jul-23/co-design-relevance-and-usefulness-qa-melissa-leach

Schlaile, M., Urmetzer, S., Blok, V., Andersen, A., Timmermans, J., Mueller, M., .. Pyka, A. (2017). Innovation Systems for Transformations towards Sustainability? Taking the Normative Dimension Seriously. Sustainability, 9(12), 2253. https://doi.org/10.3390/su9122253

Schmieg, G., Meyer, E., Schrickel, I., Herberg, J., Caniglia, G., Vilsmaier, U., ... Lang, D. (2017). Modeling normativity in sustainability: a comparison of the sustainable development goals, the Paris agreement, and the papal encyclical. Sustainability Science, (October). https://doi.org/10.1007/s11625-017-0504-7

Schneider, F., \& Buser, T. (2017). Promising degrees of stakeholder interaction in research for sustainable development. Sustainability Science. https://doi.org/10.1007/s11625-017-0507-4

Schneider, F., Kläy, A., Zimmermann, A. B., Buser, T., Ingalls, M., \& Messerli, P. (2019). How can science support the 2030 Agenda for Sustainable Development? Four tasks to tackle the normative dimension of sustainability. Sustainability Science, (0123456789). https://doi.org/10.1007/s11625-019-00675-y

Schneidewind, U., \& Augenstein, K. (2012). Analyzing a transition to a sustainability-oriented science system in Germany. Environmental Innovation and Societal Transitions, 3, 16-28. https://doi.org/10.1016/j.eist.2012.04.004

Schneidewind, U., Singer-Brodowski, M., Augenstein, K., \& Stelzer, F. (2016). Pledge for a transformative science: a conceptual framework. Wuppertal papers. https://doi.org/ISSN 0949-5266

Scholz, R. W. (2017). The normative dimension in Transdisciplinarity, Transition Management, and Transformation Sciences: New roles of science and universities in sustainable transitioning. Sustainability, 9(6). https://doi.org/10.3390/su9060991

Schoolman, E. D., Guest, J. S., Bush, K. F., \& Bell, A. R. (2011). How interdisciplinary is sustainability research? Analyzing the structure of an emerging scientific field. Sustainability Science, 7(1), 67-80.

https://doi.org/10.1007/s11625-011-0139-z 
Schröder, S., Welter, F., Leisten, I., Richert, A., \& Jeschke, S. (2014). Research performance and evaluation-Empirical results from collaborative research centers and clusters of excellence in Germany. Research Evaluation, 23(3), 221-232. https://doi.org/10.1093/reseval/rvu010

Scoones, I. C., Newell, P., \& Leach, M. (2015). The green transformation imperative - and its politics. In I. Scoones, M. Leach, \& P. Newell (Eds.), The politics of Green Transformations. London, UK: Routledge.

Scott, W. R. (2014). Institutions and organizations: ideas, interests and identities. Los Angeles, CA: SAGE Publications.

SDSN. (2015a). Getting Started with the Sustainable Development Goals. A Guide for Stakeholders. New York, NY: Sustainable development Solutions Network (SDSN).

SDSN. (2015b). SDSN Factsheet: A brief overview of the SDSN and its work. New York, NY: Sustainable Development Solutions Network. Retrieved from http://unsdsn.org/wp-content/uploads/2013/05/SDSN-brochureWEB.pdf

Seitzinger, S. P., Gaffney, O., Brasseur, G., Broadgate, W., Ciais, P., Claussen, M., ... Uematsu, M. (2015). International Geosphere-Biosphere Programme and Earth system science: Three decades of co-evolution. Anthropocene, 12(2015), 3-16. https://doi.org/10.1016/j.ancene.2016.01.001

Sending, O. J. (2015). The Politics of Expertise: Competing for Authority in Global Governance. University of Michigan Press.

Sending, O. J. (2017). Recognition and liquid authority. International Theory, 9(2), 311-328. https://doi.org/10.1017/S1752971916000282

Sénit, C. A. (2019). Leaving no one behind? The influence of civil society participation on the Sustainable Development Goals. Environment and Planning C: Politics and Space, 1-20. https://doi.org/10.1177/2399654419884330

Shove, E. (2003). Principals, agents, actors and research programmes. Science and Public Policy, 30(5), 371-381. https://doi.org/10.3152/147154303781780308

Shove, E., \& Redclift, M. (2001). Steering research towards policy: the case of social science and environmental change. In M. Hisschemöller, R. Hoppe, W. N. Dunn, \& J. R. Ravetz (Eds.), Knowledge, Power, and Participation in Environmental Policy Analysis. Taylor \& Francis.

Shrivastava, P., Raivio, K., Kasuga, F., Tewksbury, J., Haines, A., \& Daszak, P. (2016). Future Earth Health Knowledge-Action Network. Public Health Reviews, 37(1), 25. https://doi.org/10.1186/s40985-016-0039-y

Smith, A. M., Lai, S. Y., Bea-Taylor, J., Hill, R. B. M. M., \& Kleinhenz, N. (2016). Collaboration and change in the research networks of five Energy Frontier Research Centers. Research Evaluation, 25(4), 472-485. https://doi.org/10.1093/reseval/rvw006

Spangenberg, J. H. (2011). Sustainability science: a review, an analysis and some empirical lessons. Environmental Conservation, 38(03), 275-287. https://doi.org/10.1017/S0376892911000270

Spruijt, P., Knol, A. B., Petersen, A. C., \& Lebret, E. (2016). Differences in views of experts about their role in particulate matter policy advice: Empirical evidence from an international expert consultation. Environmental Science and Policy, 59, 44-52. https://doi.org/10.1016/j.envsci.2016.02.003

Stafford-Smith, M. (2014). UN sustainability goals need quantified targets. Nature, 513(7518), 281. https://doi.org/10.1038/513281a

Steffen, Will, Sanderson, A., Tyson, P. D., Jäger, J., Matson, P. A., Moore III, B., ... Wasson, R. J. (2004). Global change and the earth system: a planet under pressure. IGBP Science Series (Vol. 4). New York, NY: Springer.

Steinberger, J. K. (2019). A Postmortem for Survival: on science, failure and action on climate change. Medium. Retrieved from https://medium.com/age-of-awareness/a-postmortem-for-survival-on-science-failure-andaction-on-climate-change-35636c79971e

Stirling, A. (2007). A general framework for analysing diversity in science, technology and society. Journal of the Royal Society, 4(15), 707-719. https://doi.org/10.1098/rsif.2007.0213

Stirling, A. (2008). "Opening Up" and "Closing Down" power, participation, and pluralism in the social appraisal of technology. Science, Technology, \& Human Values, 33(2), 262-294. https://doi.org/10.1177/0162243907311265

Stirling, A. (2014). Emancipating Transformations: from controlling "the transition" to culturing plural radical progress. STEPS Centre Working Paper series. London, UK: Routledge.

Strohschneider, P. (2014). Zur Politik der Transformativen Wissenschaft. In A. Brodocz, D. Herrmann, R. Schmidt, D. Schulz, \& J. S. Wessel (Eds.), Die Verfassung des Politischen (pp. 175-192). Springer: Wiesbaden, Germany. https://doi.org/10.1007/978-3-658-04784-9

Sundqvist, G., Gasper, D., St.Clair, A. L., Hermansen, E. A. T., Yearley, S., Øvstebø Tvedten, I., \& Wynne, B. (2018). One world or two? Science-policy interactions in the climate field. Critical Policy Studies, 12(4), 448-468. https://doi.org/10.1080/19460171.2017.1374193 
Suni, T., Juhola, S., Korhonen-Kurki, K., Käyhkö, J., Soini, K., \& Kulmala, M. (2016). National Future Earth platforms as boundary organizations contributing to solutions-oriented global change research. Current Opinions in Environmental Sustainability, 23, 63-68. https://doi.org/10.1016/j.cosust.2016.11.011

Tàbara, J. D., Jäger, J., Mangalagiu, D., \& Grasso, M. (2019). Defining transformative climate science to address highend climate change. Regional Environmental Change, 19(3), 807-818. https://doi.org/10.1007/s10113-018-1288-8

Talwar, S., Wiek, A., \& Robinson, J. (2011). User engagement in sustainability research. Science and Public Policy, 38(5), 379-390. https://doi.org/10.3152/030234211X12960315267615

Temper, L., McGarry, D., \& Weber, L. (2019). From academic to political rigour: Insights from the 'Tarot' of transgressive research. Ecological Economics, 164(January), 106379. https://doi.org/10.1016/j.ecolecon.2019.106379

Trencher, G. P., Yarime, M., \& Kharrazi, A. (2013). Co-creating sustainability: Cross-sector university collaborations for driving sustainable urban transformations. Journal of Cleaner Production, 50, 40-55. https://doi.org/10.1016/j.jclepro.2012.11.047

Tschakert, P., Tuana, N., Westskog, H., Koelle, B., \& Afrika, A. (2016). TCHANGE: The role of values and visioning in transformation science. Current Opinions in Environmental Sustainability, 20, 21-25. https://doi.org/10.1016/j.cosust.2016.04.003

Turner, R. A., Fitzsimmons, C., Forster, J., Mahon, R., Peterson, A., \& Stead, S. M. (2014). Measuring good governance for complex ecosystems: Perceptions of coral reef-dependent communities in the Caribbean. Global Environmental Change, 29, 105-117. https://doi.org/10.1016/j.gloenvcha.2014.08.004

Turnhout, E., Bloomfield, B., Hulme, M., Vogel, J., \& Wynne, B. (2012). Conservation policy: Listen to the voices of experience. Nature, 488(7412), 454-455.

Turnhout, E., Dewulf, A., \& Hulme, M. (2016). What does policy-relevant global environmental knowledge do? The cases of climate and biodiversity. Current Opinions in Environmental Sustainability, 18, 65-72. https://doi.org/10.1016/j.cosust.2015.09.004

Turnhout, E., Hisschemöller, M., \& Eijsackers, H. (2007). Ecological indicators: Between the two fires of science and policy. Ecological Indicators, 7(2), 215-228. https://doi.org/10.1016/j.ecolind.2005.12.003

Turnhout, E., Hisschemöller, M., \& Eijsackers, H. (2008). Science in Wadden Sea policy: from accommodation to advocacy. Environmental Science and Policy, 11(3), 227-239. https://doi.org/10.1016/j.envsci.2007.07.004

Turnhout, E., Metze, T., Wyborn, C., Klenk, N. L., \& Louder, E. (2020). The politics of co-production: participation, power, and transformation. Current Opinion in Environmental Sustainability, 42(2018), 15-21. https://doi.org/10.1016/j.cosust.2019.11.009

Turnhout, E., Stuiver, M., Klostermann, J., Harms, B., \& Leeuwis, C. (2013). New roles of science in society: Different repertoires of knowledge brokering. Science and Public Policy, 40(3), 354-365. https://doi.org/10.1093/scipol/scs114

Turpin, T. (1997). CRCs and Transdisciplinary Research: What are the Implications for Science? Prometheus, 15(2), 253265. https://doi.org/10.1080/08109029708632074

Turpin, T., Garrett-Jones, S., Woolley, R., Garret-Jones, S., \& Woolley, R. (2011). Cross-sector research collaboration in Australia: the Cooperative Research Centres Program at the crossroads. Science and Public Policy, 38(2), 87-97. https://doi.org/10.3152/030234211x12924093660354

Uhrqvist, O. (2014). Seeing and Knowing the Earth as a System An Effective History of Global Environmental Change Research as Scientific and Political Practice. Linköping Studies in Arts and Sciences No. 631.

Uhrqvist, O., \& Lövbrand, E. (2013). Rendering global change problematic: the constitutive effects of Earth System research in the IGBP and the IHDP. Environmental Politics, 23(2), 1-18. https://doi.org/10.1080/09644016.2013.835964

UN DESA. (2014). Prototype Global Sustainable Development Report. New York, NY: United Nations Department of Economic and Social Affairs, Division for Sustainable Development.

UN DESA. (2016). Call for contributions to the UN Global Sustainable Development Report 2016. New York, NY: United Nations Department of Economic and Social Affairs. Retrieved from https://sustainabledevelopment.un.org/content/documents/8541Call_for_briefs_2016_ENGLISH_rev4.pdf

UNEP. (n.d.). Guidelines for ensuring Scientific Credibility and Policy Relevance of the GEO-5 Assessment. Nairobi, Kenia: United Nations Environment Programme (UNEP). Retrieved from http://www.unep.org/geo/pdfs/geo5/Guidelines_for_science_\&_policy_GEO-5.pdf

UNEP. (2012). Global Environmental Outlook (GEO-5). Nairobi, Kenia: United Nations Environment Programme (UNEP).

UNEP. (2014). Global Environmental Outlook: Keeping the Global Environment Under Review. Retrieved July 27, 2016, from http://www.unep.org/geo/ 
UNEP. (2015). GEO Matters. Nairobi, Kenia: United Nations Environment Programme (UNEP). Retrieved from http://www.unep.org/geo/pdfs/GEO_matter_sept2015.pdf

UNESCO. (n.d.). Scientific Advisory Board of the UN Secretary-General. Retrieved July 27, 2015, from http://en.unesco.org/un-sab/content/scientific-advisory-board

van der Leeuw, S., Wiek, A., Harlow, J., Buizer, J., Leeuw, S. Van Der, Wiek, A., ... Buizer, J. (2012). How much time do we have? Urgency and rhetoric in sustainability science. Sustainability Science, 7(S1), 115-120. https://doi.org/10.1007/s11625-011-0153-1

van der Molen, F., van der Windt, H. J., \& Swart, J. A. A. (2016). The interplay between knowledge and governance: Insights from the governance of recreational boating in the Dutch Wadden Sea area, 1981-2014. Environmental Science and Policy, 55, 436-448. https://doi.org/10.1016/j.envsci.2015.02.012

van Enst, W. I., Runhaar, H. A. C. C., \& Driessen, P. P. J. (2016). Boundary organisations and their strategies: Three cases in the Wadden Sea. Environmental Science and Policy, 55, 416-423. https://doi.org/10.1016/j.envsci.2015.08.016

van Kerkhoff, L. E., \& Lebel, L. (2006). Linking Knowledge and Action for Sustainable Development. Annual Review of Environment and Resources, 31(1), 445-477. https://doi.org/10.1146/annurev.energy.31.102405.170850

van Kerkhoff, L. E., \& Lebel, L. (2015). Coproductive capacities: Rethinking science-governance relations in a diverse world. Ecology and Society, 20(1), 14. https://doi.org/10.5751/ES-07188-200114

van Poeck, K., Goeminne, G., \& Vandenabeele, J. (2016). Revisiting the democratic paradox of environmental and sustainability education: sustainability issues as matters of concern. Environmental Education Research, 22(6), 806826. https://doi.org/10.1080/13504622.2014.966659

Vasileiadou, E., Heimeriks, G., \& Petersen, A. C. (2011). Exploring the impact of the IPCC Assessment Reports on science. Environmental Science \& Policy, 14(8), 1052-1061. https://doi.org/10.1016/j.envsci.2011.07.002

Vaughan, D. (1999). The Role of the Organisation in the Production of Techno-Scientific Knowledge. Social Studies of Science, 29(6), 913-943.

von Falkenhayn, L., Rechkemmer, A., \& Young, O. R. (2011). The International Human Dimensions Programme on Global Environmental Change - Taking Stock and Moving Forward. In H. G. Brauch, Ú. O. Spring, C. Mesjasz, J. Grin, P. Kameri-Mbote, B. Chourou, ... Jörn Birkmann (Eds.), Coping with Global Environmental Change, Disasters and Security (pp. 1221-1233). Berlin, Heidelberg: Springer. https://doi.org/10.1007/978-3-64217776-7_75

Wagner, C. S., Roessner, J. D., Bobb, K., Klein, J. T., Boyack, K. W., Keyton, J., .. Börner, K. (2011). Approaches to understanding and measuring interdisciplinary scientific research (IDR): A review of the literature. Journal of Informetrics, 5(1), 14-26. https://doi.org/10.1016/j.joi.2010.06.004

Wang, C. Y., Zhou, T. J., Lin, Z., \& Jin, N. (2015). Future Earth activities in China: Towards a national sustainable development. Advances in Climate Change Research, 6(2), 84-91. https://doi.org/10.1016/j.accre.2015.09.008

Wardenaar, T., Jong, S. P. L. De, \& Hessels, L. K. (2014). Varieties of research coordination: A comparative analysis of two strategic research consortia. Science and Public Policy, 41, 1-13. https://doi.org/10.1093/scipol/scu008

WCED. (1987). Our Common Future. Brussels, Belgium: World Commission on Environment and Development (WCED).

Weaver, C. P., Mooney, S., Allen, D., Beller-Simms, N., Fish, T., Grambsch, A. E., .. Winthrop, R. (2014). From global change science to action with social sciences. Nature Climate Change, 4(8), 656-659. https://doi.org/10.1038/nclimate2319

Wesselink, A., Buchanan, K. S., Georgiadou, Y., \& Turnhout, E. (2013). Technical knowledge, discursive spaces and politics at the science-policy interface. Environmental Science and Policy, 30, 1-9. https://doi.org/10.1016/j.envsci.2012.12.008

West, S. (2016). Meaning and Action in Sustainability Science: Interpretive approaches for social-ecological systems research. Stockholm University, Sweden. https://doi.org/10.13140/RG.2.2.32127.10406

West, S., van Kerkhoff, L., \& Wagenaar, H. (2019). Beyond "linking knowledge and action": towards a practice-based approach to transdisciplinary sustainability interventions. Policy Studies, 40(5), 534-555. https://doi.org/10.1080/01442872.2019.1618810

Wiek, A., Farioli, F., Fukushi, K., \& Yarime, M. (2012). Sustainability science: bridging the gap between science and society. Sustainability Science, 7(1), 1-4. https://doi.org/10.1007/s11625-011-0154-0

Wiek, A., \& Kay, B. (2015). Learning while transforming: solution-oriented learning for urban sustainability in Phoenix , Arizona. Current Opinions in Environmental Sustainability, 16, 29-36.

https://doi.org/10.1016/j.cosust.2015.07.001 
Wijsman, K., \& Feagan, M. (2019). Rethinking knowledge systems for urban resilience: Feminist and decolonial contributions to just transformations. Environmental Science and Policy, 98, 70-76. https://doi.org/10.1016/j.envsci.2019.04.017

Withycombe Keeler, L., Wiek, A., Lang, D. J., Yokohari, M., van Breda, J., Olsson, L., ... Evans, J. (2015). Utilizing International Networks for Accelerating Research and Learning in Transformational Sustainability Science. Sustainability Science, 11(5), 749-762. https://doi.org/10.1007/s11625-016-0364-6

Wittmayer, J. M., \& Schäpke, N. (2014). Action, research and participation: roles of researchers in sustainability transitions. Sustainability Science, 9(4), 483-496. https://doi.org/10.1007/s11625-014-0258-4

Wixted, B., \& Holbrook, J. A. (2012). Environmental complexity and stakeholder theory in formal research network evaluations. Prometheus, 30(3), 291-314. https://doi.org/10.1080/08109028.2012.727276

Wyborn, C., Datta, A., Montana, J., Ryan, M., Leith, P., Chaffin, B., ... van Kerkhoff, L. E. (2019). Co-Producing Sustainability: Reordering the Governance of Science, Policy, and Practice. Annual Review of Environment and Resources, 44(1), 319-346. https://doi.org/10.1146/annurev-environ-101718-033103

Wynne, B. (1993). Public uptake of science: a case for institutional reflexivity. Public Understanding of Science, 2(4), 321337. https://doi.org/10.1088/0963-6625/2/4/003

Yamineva, Y. (2017). Lessons from the Intergovernmental Panel on Climate Change on inclusiveness across geographies and stakeholders. Environmental Science \& Policy, (April), 1-8. https://doi.org/10.1016/j.envsci.2017.04.005

Yarime, M., Takeda, Y., \& Kajikawa, Y. (2010). Towards institutional analysis of sustainability science: a quantitative examination of the patterns of research collaboration. Sustainability Science, 5(1), 115-125. https://doi.org/10.1007/s11625-009-0090-4

Yarime, M., Trencher, G., Mino, T., Scholz, R. W., Olsson, L., Ness, B., .. Rotmans, J. (2012). Establishing sustainability science in higher education institutions: towards an integration of academic development, institutionalization, and stakeholder collaborations. Sustainability Science, 7(1), 101-113. https://doi.org/10.1007/s11625-012-0157-5

Zhou, W.-L. L., Jin, N., Lin, Z., Wu, G.-X. X., Wen-ling, Z., Nan, J. I. N., ... Wu, G.-X. X. (2015). From global change to Future Earth in China. Advances in Climate Change Research, 6(2), 1-9. https://doi.org/10.1016/j.accre.2015.10.001

Zondervan, R. (2015). Fine tuning the Science and Technology Major Group. SciDevNet, Retrived from http://www.scidev.net/asia-pacific/m.

Zürn, M., Binder, M., \& Ecker-Ehrhardt, M. (2012). International authority and its politicization. International Theory, 4(1), 69-106. https://doi.org/10.1017/S1752971912000012 
Appendices

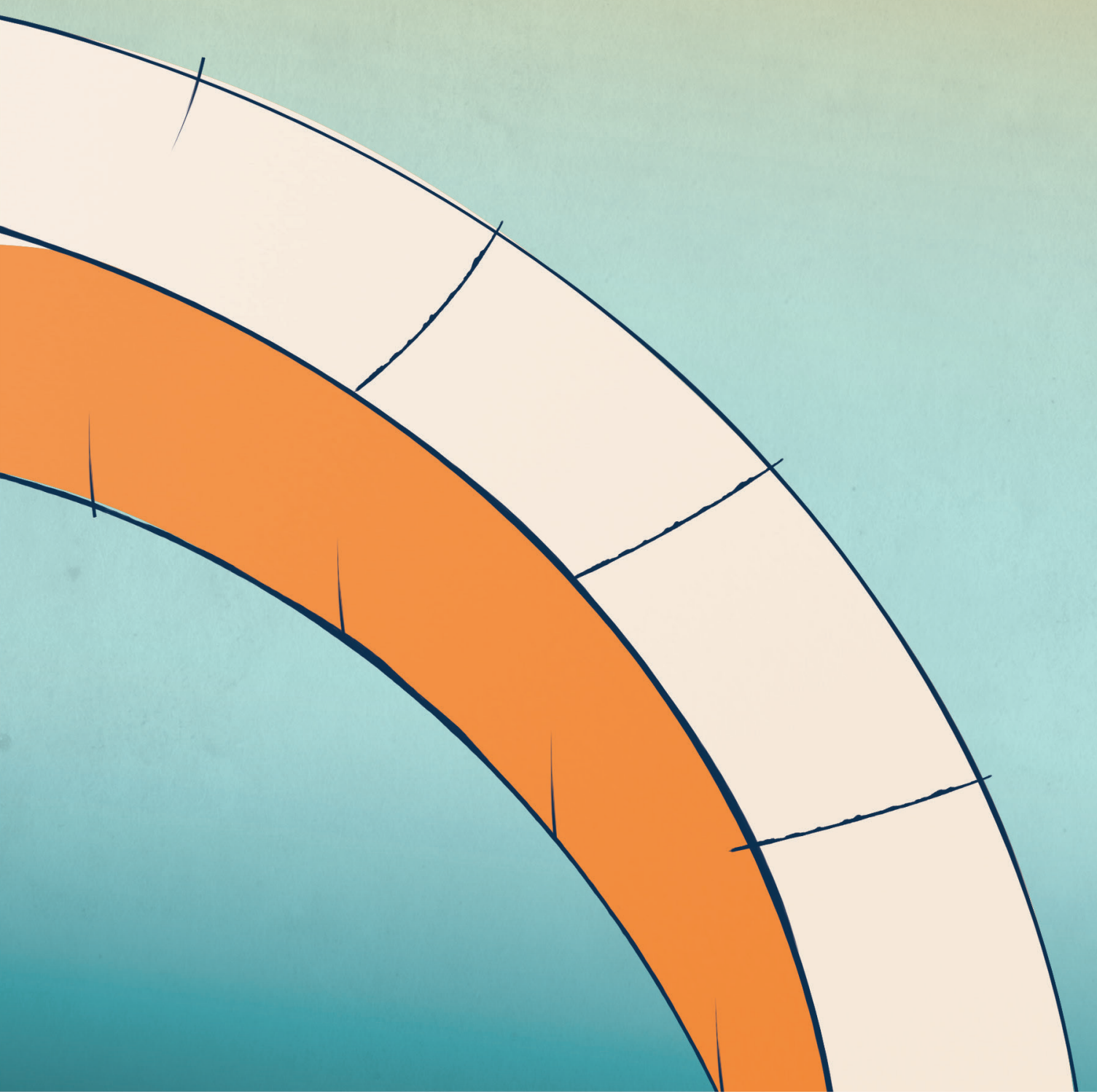


Appendices

APPENDIX A: INTERVIEW RESPONDENTS

APPENDIX B: INTERVIEW PROTOCOL

APPENDix C: CONSUlted DOCUMENTS

SUMMARY

SAMENVATTING

ACKNOWLEDGEMENT 


\section{APPENDIX A: INTERVIEW RESPONDENTS}

This list includes the interviews conducted as part of the empirical analysis presented in Chapter 5 (interview $1-18$ ) as well as additional interviews that contributed to the case description in Chapter 4 (interview 19 - 22). Interviews were conducted in person or via Skype and lasted between 45 minutes and 2 hours. All interviews were recorded and transcribed. All interviewees agreed to be listed by name. Directed quotes used in this thesis were verified with the respective respondents. For each respondent, current (at the time of the interview) and previous positions at international programmes and organisations in global change research are provided.

1. Prof. Dr Rik Leemans. Executive Member, Transition Team for Future Earth; Former Chair, Earth System Science Partnership (ESSP). Wageningen, The Netherlands, 24 April 2014

2. Dr Martin Rice. Former Executive Officer, Earth System Science Partnership (ESSP). Skype, 13 May 2014

3. Prof. Dr Sybil Seitzinger. Executive Director, International Geosphere-Biosphere Programme (IGBP); Former Member, Scientific Committee, International Geosphere-Biosphere Programme (IGBP). Skype, 19 May 2014

4. Dr Albert van Jaarsveld. Chief Executive Officer, South African National Research Foundation; Co-Chair, Belmont Forum. Skype, 29 May 2014

5. Prof. Dr Thomas Rosswall. Former Executive Director, International Council for Science (ICSU); Former Executive Director, International Geosphere-Biosphere Programme (IGBP); Former Executive Director Global Change System for Analysis, Research and Training (START). Skype, 29 May 2014

6. Prof. Dr Anne Larigauderie. Former Executive Director, DIVERSITAS. Skype, 10 June 2014

7. Prof. Dr Sander van der Leeuw. Former Member, Scientific Committee, International Human Dimensions Programme (IHDP). Utrecht, The Netherlands, 11 June 2014

8. Prof. Dr Jill Jäger. Former Executive Director, International Human Dimensions Programme (IHDP). Skype, 20 June 2014

9. Prof. Dr Oran Young. Former Chair, Scientific Committee, International Human Dimensions Programme (IHDP). Norwich, United Kingdom, 30 June 2014

10. Prof. Dr Corinne le Quéré. Member, Science Committee, Future Earth. United Kingdom, 4 July 2014

11. Prof. Dr Peter Liss. Executive Member, Transition Team for Future Earth; Former Chair, Scientific Committee, International Geosphere-Biosphere Programme (IGBP). Norwich, United Kingdom, 4 July 2014

12. Prof. Dr Will Steffen. Former Executive Director, International GeosphereBiosphere Programme (IGBP). Skype, 22 July 2014

13. Dr Heide Hackmann. Executive Director, International Social Science Council (ISSC). Skype, 24 July 2014 
14. Dr John Ingram. Former Executive Officer, Global Environmental Change and Food Systems project (GECAFS). Skype, 14 October 2014

15. Dr Carthage Smith. Deputy-Director, International Council for Science (ICSU). Skype, 17 October 2014

16. Prof. Dr Diana Liverman. Co-Chair, Transition Team for Future Earth. Skype, 28 October 2014

17. Dr John Marks. Former Chair, International Group of Funding Agencies (IGFA); Former Executive Director, International Geosphere-Biosphere Programme (IGBP). Leiden, The Netherlands, 28 November 2014

18. Mr Farooq Ullah. Member, Engagement Committee, Future Earth. Skype, 2 March 2015

19. Dr João Morais. Former Social Science Officer, International Geosphere-Biosphere Programme (IGBP). Stockholm, Sweden, May 2013

20. Owen Gaffney. Director of Communications, International Geosphere-Biosphere Programme (IGBP). Stockholm, Sweden, May 2013

21. Ninad Bondre. Senior Science Editor and Advisor, International GeosphereBiosphere Programme (IGBP). Stockholm, Sweden, May 2013

22. Wendy Broadgate Deputy Director, Natural Sciences, International GeosphereBiosphere Programme (IGBP). Stockholm, Sweden, May 2013 


\section{APPENDIX B: INTERVIEW PROTOCOL}

Example of interview protocol. The interview protocol was adjusted based on the background and expertise of each respondent.

\section{$\underline{\text { Interview details }}$}

Number of interview:

Date of interview:

Respondent:

Location of interview:

Agreed to use name: $\quad$ yes/no

Recorded: yes/no

Transcribed: yes/no

Summarised yes/no

Analysed: yes/no

Agreed for follow up: yes/no

Follow up on date:

\section{Interview scheme}

\section{Introduction}

- Introducing myself

- The aim or this research project is to understand institutional change in science for sustainability, with Future Earth as main case study.

- The purpose of this interview is to learn from your experience in this research field and your perspective on the emergence and development of Future Earth.

\section{Formalities}

(this information was also sent to participant before the interview)

- The interview will take 60 minutes

- With your permission, the interview will be audio-taped to accurately record the information you provide. The recoding will be used for transcription purposes only.

- Direct quotes from the interview might be included in publications resulting from this study. To avoid misunderstanding, I will give you the opportunity to verify quotes or other remarks referencing to you before they will be included in publications.

- If you choose to remain anonymous, your identity will be concealed in any publications resulting from this study. 


\section{Interview questions}

Questions about respondent's background and involvement in Future Earth

1. Could you start by telling me how you came to work at [organisation] and what motivated you to take on this position?

2. What is your role in [Future Earth or other organisation]? How are you involved in the development of Future Earth?

3. What motivated you to engage in (the development of) Future Earth?

Questions about the design principles

4. Future Earth advances a solutions-oriented approach to global change issues. What considerations led to the centrality of the solutions-oriented approach in Future Earth's design?

5. Co-design and co-production are central principles in the design of Future Earth. Could you explain why these principles have been given such a central role? What is needed to ensure co-production in Future Earth?

6. Another principle that is central within Future Earth is inclusiveness. Could you explain why inclusiveness is so important for Future Earth? What is needed to ensure inclusiveness in Future Earth?

7. The fourth principle that is central to Future Earth is interdisciplinarity. In what way is Future Earth's approach to interdisciplinarity similar to that of previous global change initiatives? In what way is it different? What is needed to ensure interdisciplinarity in Future Earth?

Questions about expectations for Future Earth

8. In what way do you expect Future Earth to change the global change research field, if at all?

9. What do you see as the main pitfalls for Future Earth?

10. When would you consider Future Earth to be a success? (10 years from now)

\section{Wrapping up}

Thank you. We have come to the end of my questions.

- Is there anything you would like to add?

- Do you happen to know anybody that would be interested to participate in this study?

- May I contact you with follow-up questions?

Thank you again for your time and interest in this project. I will keep you informed with the results of the study. 


\section{APPENDIX C: CONSULTED DOCUMENTS}

List of documents consulted for this thesis. The list includes public reports (PR), formal documents (FD), unpublished documents (UD), news items (NI) and scientific publications (SP). Full references for cited sources are included in the reference list.

\begin{tabular}{|c|c|c|c|}
\hline AUTHOR(s) & YEAR & TITLE & TYPE \\
\hline Belmont Forum & 2011 & $\begin{array}{l}\text { The Belmont Challenge: A Global, Environmental Research Mission for } \\
\text { Sustainability }\end{array}$ & FD \\
\hline $\begin{array}{l}\text { Belmont Forum; } \\
\text { ICSU; ISSC }\end{array}$ & 2011 & $\begin{array}{l}\text { Towards a } 10 \text { year Earth System Research initiative for Global } \\
\text { Sustainability. A joint statement of intent from the Belmont Forum, ICSU, } \\
\text { and the ISSC. }\end{array}$ & FD \\
\hline Berkhout, F. & 2014 & What Does Coordination Achieve? (Source: futureearth.org) & NI \\
\hline $\begin{array}{l}\text { Brito, L. ; M. } \\
\text { Stafford Smith }\end{array}$ & 2012 & $\begin{array}{l}\text { State of the Planet Declaration (statement by the Co-Chairs of the Planet } \\
\text { under Pressure Conference, supported by the conference Scientific } \\
\text { Organizing Committee) }\end{array}$ & PR \\
\hline Cornell, S. et al. & 2013 & $\begin{array}{l}\text { Opening up knowledge systems for better responses to global } \\
\text { environmental change. (Source: Environmental Science and Policy, 28, pp } \\
60-70 \text { ) }\end{array}$ & $\mathrm{SP}$ \\
\hline $\begin{array}{l}\text { de Vries, R.S.D. } \\
\text { et al. }\end{array}$ & 2012 & $\begin{array}{l}\text { Planetary Opportunities: A Social Contract for Global Change Science to } \\
\text { Contribute to a Sustainable Future. (Source: Bioscience } 62 \text { pp. 603-606) }\end{array}$ & $\mathrm{SP}$ \\
\hline $\begin{array}{l}\text { Duraiappah, } \\
\text { A.K.; D.S. } \\
\text { Rogers }\end{array}$ & 2011 & $\begin{array}{l}\text { IHDP Survey of Social Sciences Scholars on Engagement in Global } \\
\text { Environmental Change Research }\end{array}$ & FD \\
\hline ECOSOC & 2014 & $\begin{array}{l}\text { Options for the scope and methodology for a global sustainable } \\
\text { development report. Report of the Secretary-General. E/2014/87 }\end{array}$ & FD \\
\hline ECOSOC & 2016 & $\begin{array}{l}\text { Background note for consultations on the scope, methodology and } \\
\text { frequency of the Global Sustainable Development Report (GSDR). }\end{array}$ & FD \\
\hline ESSP & 2012 & ESSP final communique: ESSP Transitions into 'Future Earth' & FD \\
\hline Future Earth & 2013 & Future Earth Interim Engagement Committee Terms of Reference & FD \\
\hline Future Earth & 2013 & $\begin{array}{l}\text { Minutes Future Earth Science Committee Meeting, 19-21 November 2013, } \\
\text { Mgaliesburg, Gauteng, South Africa }\end{array}$ & UD \\
\hline Future Earth & 2013 & $\begin{array}{l}\text { Preparation document Future Earth Science Committee Meeting, 19-21 } \\
\text { November 2013, Mgaliesburg, Gauteng, South Africa }\end{array}$ & UD \\
\hline Future Earth & 2013 & $\begin{array}{l}\text { Process to establish the permanent secretariat of Future Earth. Call for } \\
\text { expression of interest }\end{array}$ & FD \\
\hline Future Earth & 2014 & Future Earth 2025 Vision & PR \\
\hline Future Earth & 2014 & Future Earth Engagement Committee Call for applications & FD \\
\hline Future Earth & 2014 & $\begin{array}{l}\text { Minutes Science Committee (SC) and interim Engagement Committee (iEC) } \\
\text { Teleconference } 11-16\end{array}$ & UD \\
\hline Future Earth & 2014 & Supporting the development of the SDGs: Future Earth Policy Brief \#1 & FD \\
\hline Future Earth & $\begin{array}{l}2013- \\
2014\end{array}$ & Minutes Science Committee (SC) Teleconference 1 - 10 & UD \\
\hline Future Earth & $\begin{array}{l}2013- \\
2015\end{array}$ & Reports of Webinar 1 - 14: GEC projects and Future Earth & UD \\
\hline Future Earth & n.d. & Future Earth. Research for global sustainability [Leaflet] & PR \\
\hline Future Earth & 2013 & Defining 'engagement' in Future Earth [draft for consultation] & UD \\
\hline Future Earth & 2013 & $\begin{array}{l}\text { Memorandum of Understanding between Future Earth and Core Projects } \\
\text { [draft for completion by Core Projects] }\end{array}$ & FD \\
\hline Future Earth & 2013 & $\begin{array}{l}\text { Q\&A with Mark Stafford Smith, Science Committee Chair (Source: } \\
\text { futureearth.org) }\end{array}$ & NI \\
\hline
\end{tabular}


Appendices

\begin{tabular}{|c|c|c|c|}
\hline Future Earth & 2013 & Transition Guidance for Core Projects & FD \\
\hline Future Earth & 2014 & $\begin{array}{l}\text { Engagement in Future Earth: Aims, rationales and a strategy. A Green } \\
\text { Paper for consultation with Future Earth Core Projects [draft for } \\
\text { consultation] }\end{array}$ & UD \\
\hline Future Earth & 2014 & $\begin{array}{l}\text { Future Earth's Globally Distributed Secretariat Designed to Be Flexible and } \\
\text { Diverse. (Source: futureearth.org) }\end{array}$ & NI \\
\hline Future Earth & 2014 & Research on Future Earth: requirements for researchers and students & UD \\
\hline Future Earth & 2014 & $\begin{array}{l}\text { Strategic Research Agenda 2014. Priorities for a global sustainability } \\
\text { research strategy }\end{array}$ & PR \\
\hline Future Earth & 2015 & Future Earth Core Project Guidelines & UD \\
\hline Future Earth & 2015 & Future Earth Governance & FD \\
\hline Future Earth & 2015 & $\begin{array}{l}\text { Q\&A with Paul Shrivastava, Executive Director of Future Earth (Source: } \\
\text { futureearth.org) }\end{array}$ & NI \\
\hline Future Earth & 2015 & $\begin{array}{l}\text { Sustainable Development Goals: scientists worldwide mobilised around } \\
\text { transformative agenda (Source: futureearth.org) }\end{array}$ & NI \\
\hline Future Earth & 2016 & Call for Applications Future Earth Engagement Committee & FD \\
\hline Future Earth & 2016 & Future Earth Annual Highlights: 2015 - 2016 & PR \\
\hline Future Earth & 2016 & Future Earth Engagement Principles and Practice & PR \\
\hline Future Earth & 2016 & $\begin{array}{l}\text { Future Earth Engagement Principles and Practice [internal document; draft } \\
\text { for consultation] }\end{array}$ & UD \\
\hline Future Earth & 2016 & Future Earth Global Research Projects: 2015 summary & PR \\
\hline Future Earth & 2016 & Future Earth Implementation Plan: 2016-2018. & PR \\
\hline Future Earth & 2016 & $\begin{array}{l}\text { Future Earth Implementation Plan: 2016-2018. Prepared in consultation } \\
\text { with the Future Earth Governing Council, Science and Engagement } \\
\text { Committees, Regional Centres and Offices and Core Projects and compiled } \\
\text { by the Secretariat [internal document] }\end{array}$ & FD \\
\hline Future Earth & 2017 & Future Earth Annual Report 2016-2017 & PR \\
\hline Future Earth & 2018 & Call for applications Future Earth Governing Council & FD \\
\hline Future Earth & 2018 & Future Earth Annual Report 2017-2018 & PR \\
\hline Future Earth & 2018 & $\begin{array}{l}\text { Future Earth Knowledge-Action Network on Systems of Sustainable } \\
\text { Consumption and Production. Research and Engagement Plan }\end{array}$ & PR \\
\hline Future Earth & 2018 & $\begin{array}{l}\text { Research and Engagement Plan for the Water-Energy-Food Knowledge- } \\
\text { Action Network, Report of the Development Team }\end{array}$ & PR \\
\hline Future Earth & $\begin{array}{l}2015- \\
2016\end{array}$ & $\begin{array}{l}\text { Knowledge-Action Networks. Framing and Operationalization [multiple } \\
\text { versions; draft for consultation] }\end{array}$ & UD \\
\hline $\begin{array}{l}\text { Future Earth } \\
\text { Finland }\end{array}$ & 2016 & Co-designing Research with Stakeholders - Examples \& Best Practices & FD \\
\hline $\begin{array}{l}\text { Future Earth; } \\
\text { IRDR; WCRP }\end{array}$ & 2017 & $\begin{array}{l}\text { Knowledge-Action Network (KAN) on Emergent Risks and Extreme } \\
\text { Events - Reducing Disaster Risks under Environmental Change }\end{array}$ & FD \\
\hline Gaffney, O. & 2014 & $\begin{array}{l}\text { Quiet green revolution starts to make some noise. (Source: Nature, } \\
\text { 505:7485) }\end{array}$ & $\mathrm{SP}$ \\
\hline Gilbert, N. & 2013 & International alliance will tackle global change (Source: Nature News) & NI \\
\hline Griggs, D. et al & 2013 & $\begin{array}{l}\text { Sustainable development goals for people and planet (Source: Nature, } \\
\text { 495:7441) }\end{array}$ & $\mathrm{SP}$ \\
\hline Griggs, D. et al & 2014 & $\begin{array}{l}\text { An integrated framework for sustainable development goals. (Source: } \\
\text { Ecology and Society, 19:4) }\end{array}$ & $\mathrm{SP}$ \\
\hline $\begin{array}{l}\text { Hackmann, } \mathrm{H} \text {. } \\
\text { et al. }\end{array}$ & 2014 & $\begin{array}{l}\text { The social heart of global environmental change. (Source: Nature Climate } \\
\text { Change 4, pp. 653-655) }\end{array}$ & $\mathrm{SP}$ \\
\hline $\begin{array}{l}\text { Hackmann, } \mathrm{H} \text {. } \\
\text { et al. }\end{array}$ & 2011 & $\begin{array}{l}\text { ISSC-Belmont Forum agenda setting workshop. Synthesis report and } \\
\text { resource document }\end{array}$ & PR \\
\hline
\end{tabular}




\begin{tabular}{|c|c|c|c|}
\hline Holm, P. et al., & 2013 & $\begin{array}{l}\text { Collaboration between the natural, social and human sciences in Global } \\
\text { Change Research (Source: Environmental Science and Policy 28, pp. 25-35) }\end{array}$ & $\mathrm{SP}$ \\
\hline Hordijk, L et al. & 2006 & $\begin{array}{l}\text { External assessment of the International Human Dimensions of Global } \\
\text { Change Programme (IHDP) }\end{array}$ & FD \\
\hline ICSU & 2009 & Press release: A Vision for Earth System Research: Have Your Say & NI \\
\hline ICSU & 2010 & $\begin{array}{l}\text { Regional Environmental Change: Human Action and Adaptation. What } \\
\text { does it take to meet the Belmont Challenge? }\end{array}$ & PR \\
\hline ICSU & 2011 & $\begin{array}{l}\text { Earth System Research for Global Sustainability: A New 10-Year Research } \\
\text { Initiative }\end{array}$ & FD \\
\hline ICSU & 2011 & Establishment of a Transition Team: Terms of Reference & UD \\
\hline ICSU & 2011 & ICSU Strategic Plan II, 2012-2017. & PR \\
\hline ICSU & 2011 & $\begin{array}{l}\text { Press Release: Research solutions for sustainability in a rapidly changing } \\
\text { world }\end{array}$ & NI \\
\hline ICSU & 2011 & Summary of the 3rd Earth System Visioning meeting & UD \\
\hline ICSU & 2012 & Future Earth. Research for global sustainability [Leaflet] & PR \\
\hline ICSU & 2012 & ICSU International Council for Science Annual Report 2012 & PR \\
\hline ICSU & 2012 & International Council for Science Annual Report & PR \\
\hline ICSU & 2012 & $\begin{array}{l}\text { Report on Future Earth Regional Workshop for Africa. } 31 \text { October-02 } \\
\text { November 2012. Cape Town, South Africa }\end{array}$ & FD \\
\hline ICSU & 2012 & $\begin{array}{l}\text { Report on Future Earth Regional Workshop for Asia and the Pacific. 21-23 } \\
\text { November 2012. Kuala Lumpur, Malaysia }\end{array}$ & FD \\
\hline ICSU & 2012 & $\begin{array}{l}\text { Report on Future Earth Regional Workshop for Europe. 13-14 May } 2013 . \\
\text { Paris, France }\end{array}$ & FD \\
\hline ICSU & 2012 & $\begin{array}{l}\text { Report on Future Earth Regional Workshop for Latin America and the } \\
\text { Caribbean. 3-4 December 2012. Mexico City, Mexico }\end{array}$ & FD \\
\hline ICSU & 2013 & $\begin{array}{l}\text { Report on Future Earth Regional Workshop for Middle East and North } \\
\text { Africa. 3-5 June 2013. Nicosia, Cyprus }\end{array}$ & FD \\
\hline ICSU & 2017 & A guide to SDG interactions: from science to implementation & PR \\
\hline ICSU & n.d. & $\begin{array}{l}\text { Organizing Partner Governance Reporting Form. Report for United } \\
\text { Nations Department of Economic and Social Affairs. Developed by } \\
\text { International Council for Science (ICSU), Co-organizing Partner of the } \\
\text { Scientific and Technological Community Major Group. }\end{array}$ & FD \\
\hline ICSU & 2012 & $\begin{array}{l}\text { Press release: Future Earth: New global platform for sustainability research } \\
\text { launched at Rio }+20\end{array}$ & NI \\
\hline ICSU & 2012 & $\begin{array}{l}\text { Press release: New Contract Between Science and Society Critical For } \\
\text { Ensuring Sustainability }\end{array}$ & NI \\
\hline ICSU; IGFA & 2008 & Review of the Earth System Science Partnership (ESSP) & PR \\
\hline ICSU; IGFA & 2009 & $\begin{array}{l}\text { Review of the International Geosphere-Biosphere Programme } \\
\text { (IGBP) }\end{array}$ & PR \\
\hline ICSU; ISSC & 2010 & Earth System Science for Global Sustainability: The Grand Challenges & PR \\
\hline ICSU; ISSC & 2015 & $\begin{array}{l}\text { Review of Targets for the Sustainable Development Goals: The Science } \\
\text { Perspective. }\end{array}$ & PR \\
\hline $\begin{array}{l}\text { ICSU; ISSC: } \\
\text { Future Earth }\end{array}$ & 2015 & $\begin{array}{l}\text { Key messages proposed by the Science and Technology community for the } \\
\text { Post- } 2015 \text { Outcome Document. }\end{array}$ & $\mathrm{PR}$ \\
\hline IGBP & 2006 & Science Plan and Implementation Strategy. IGBP Report No. 55. & PR \\
\hline IGBP & 2010 & $\begin{array}{l}\text { IGBP Strategic Vision: A vision for integrative global change research for a } \\
\text { sustainable future }\end{array}$ & FD \\
\hline $\begin{array}{l}\text { IGBP; IHDP; } \\
\text { WCRP; } \\
\text { Diversitas }\end{array}$ & 2001 & Amsterdam Declaration on Global Change & FD \\
\hline
\end{tabular}




\begin{tabular}{|c|c|c|c|}
\hline $\begin{array}{l}\text { Ignaciuk, A. et } \\
\text { al. }\end{array}$ & 2012 & $\begin{array}{l}\text { Responding to complex societal challenges: A decade of Earth System } \\
\text { Science Partnership (ESSP) interdisciplinary research (Source: } \\
\text { CurrentOpinion in Environmental Sustainability 4, pp. 147-158) }\end{array}$ & SP \\
\hline IHDP & 2007 & $\begin{array}{l}\text { Strategic Plan } 2007 \text { - 2015. Framing Worldwide Research on the Human } \\
\text { Dimensions of Global Environmental Change }\end{array}$ & $\mathrm{PR}$ \\
\hline IHDP & 2012 & $\begin{array}{l}\text { Annual Report of the International Human Dimensions Programme on } \\
\text { Global Environmental Change }\end{array}$ & PR \\
\hline $\begin{array}{l}\text { Ingram, J.; W. } \\
\text { Steffen; P. } \\
\text { Canadell }\end{array}$ & 2006 & $\begin{array}{l}\text { Envisioning Earth System Science for Societal Needs. The development of } \\
\text { Joint Projects and the Earth System Science Partnership (ESSP) }\end{array}$ & FD \\
\hline ISSC & 2010 & World Social Science Report 2010. Knowledge Divides & $\mathrm{PR}$ \\
\hline ISSC & 2011 & Transformative Cornerstones of Social Science Research for Global Change & $\mathrm{PR}$ \\
\hline ISSC & 2013 & World Social Science Report 2013. Changing Global Environments & PR \\
\hline ISSC & 2014 & Transformations to Sustainability Programme & FD \\
\hline Jäger, J. et al. & 2013 & $\begin{array}{l}\text { Responses to Environmental and Societal Challenges for our Unstable } \\
\text { Earth (Source: Environmental Science and Policy 28, pp. 1-2) }\end{array}$ & $\mathrm{SP}$ \\
\hline $\begin{array}{l}\text { Larigauderie, A. } \\
\text { et al. }\end{array}$ & 2012 & $\begin{array}{l}\text { Biodiversity and ecosystem services science for a sustainable planet: the } \\
\text { DIVERSITAS vision for 2012-20 (Source: Current Opinion in } \\
\text { Environmental Sustainability 4, pp. 101-105) }\end{array}$ & $\mathrm{SP}$ \\
\hline $\begin{array}{l}\text { Leemans, R. et } \\
\text { al. }\end{array}$ & 2009 & $\begin{array}{l}\text { Developing a common strategy for integrative global environmental change } \\
\text { research and outreach: the Earth System Science Partnership (ESSP) } \\
\text { (Source: Current Opinion in Environmental Sustainability 1, pp. 4-13) }\end{array}$ & SP \\
\hline $\begin{array}{l}\text { Leemans, R. et } \\
\text { al. }\end{array}$ & 2011 & $\begin{array}{l}\text { Research Agenda and Policy Input of the Earth System Science Partnership } \\
\text { for Coping with Global Environmental Change (Source: H.G. Brauch et al. } \\
\text { (eds.), Coping with Global Environmental Change, Disasters and Security, } \\
\text { Hexagon Series on Human and Environmental Security and Peace 5) }\end{array}$ & SP \\
\hline Mauser, W. et al. & 2013 & $\begin{array}{l}\text { Transdisciplinary global change research: the co-creation of knowledge for } \\
\text { sustainability (Source: Current Opinion in Environmental Sustainability } 5 \text {, } \\
\text { pp. } 1-12 \text { ). }\end{array}$ & $\mathrm{SP}$ \\
\hline $\begin{array}{l}\text { Mooney, H. et } \\
\text { al. }\end{array}$ & 2013 & $\begin{array}{l}\text { Evolution of natural and social science interactions in global change } \\
\text { research programs (Source: Proceedings of the National Academy of } \\
\text { Sciences } 110 \text {, pp. 3665-72) }\end{array}$ & $\mathrm{SP}$ \\
\hline $\begin{array}{l}\text { O'Brien, K. et } \\
\text { al. }\end{array}$ & 2013 & $\begin{array}{l}\text { You say you want a revolution? Transforming education and capacity } \\
\text { building in response to global change (Source: Environmental Science and } \\
\text { Policy 28, pp. 48-59) }\end{array}$ & $\mathrm{SP}$ \\
\hline $\begin{array}{l}\text { Pahl-Wostl, C. } \\
\text { et al. }\end{array}$ & 2013 & $\begin{array}{l}\text { Transition towards a new global change science: Requirements for } \\
\text { methodologies, methods, data and knowledge (Source: Environmental } \\
\text { Science and Policy 28, pp. 36-47) }\end{array}$ & SP \\
\hline Perkins, N.I. & 2016 & Q\&A: Leave no scientists behind (Source: SciDevNet) & NI \\
\hline Raupach, M.R. & 2012 & $\begin{array}{l}\text { Earth-System Science at a Crossroads (Source: IGBP Global Change } \\
\text { Magazine) }\end{array}$ & NI \\
\hline Reid, W.V. et al. & 2010 & $\begin{array}{l}\text { Earth System Science for Global Sustainability: Grand Challenges (Source: } \\
\text { Science, 330:6006, pp 916-917) }\end{array}$ & SP \\
\hline Rice, $M$. & 2013 & $\begin{array}{l}\text { Spanning disciplinary, sectoral and international boundaries: a sea change } \\
\text { towards transdisciplinary global environmental change research? (Source: } \\
\text { Current Opinion in Environmental Sustainability } 5, \mathrm{pp} .1-11 \text { ) }\end{array}$ & $\mathrm{SP}$ \\
\hline $\begin{array}{l}\text { Rivera-Ferre, } \\
\text { M.G.M. }\end{array}$ & 2013 & $\begin{array}{l}\text { A vision for transdisciplinarity in Future Earth : Perspectives from young } \\
\text { researchers (Source: Journal Agriculture, Food Systems, and Community } \\
\text { Development 3, pp. } 249-260 \text { ) }\end{array}$ & SP \\
\hline $\mathrm{SAB}$ & 2014 & Report of the Inaugural meeting. 30-31 January 2014, Berlin, Germany & FD \\
\hline $\mathrm{SAB}$ & 2014 & $\begin{array}{l}\text { The Crucial Role of Science for Sustainable Development and the Post- } \\
2015 \text { Development Agenda Reflection and Comments by the Scientific } \\
\text { Advisory Board of the UN Secretary-General to the ongoing discussions in } \\
\text { New York. }\end{array}$ & $\mathrm{PR}$ \\
\hline
\end{tabular}




\begin{tabular}{|c|c|c|c|}
\hline $\mathrm{SAB}$ & 2015 & $\begin{array}{l}\text { Science, Technology and Innovation: Critical Means of Implementation for } \\
\text { the SDGs. Reflections by the Scientific Advisory Board of the UN } \\
\text { Secretary-General. }\end{array}$ & $\mathrm{PR}$ \\
\hline $\mathrm{SAB}$ & 2015 & $\begin{array}{l}\text { Strengthening the High-Level Political Forum and the UN Global } \\
\text { Sustainable Development Report. Policy Brief by the Scientific Advisory } \\
\text { Board of the UN Secretary-General. }\end{array}$ & PR \\
\hline $\mathrm{SAB}$ & 2016 & $\begin{array}{l}\text { Press kit: United Nations Secretary General's Scientific Advisory Board, 5th } \\
\text { meeting Trieste, Italy, 24-25 May } 2016\end{array}$ & FD \\
\hline Sayer, L. & 2014 & $\begin{array}{l}\text { Co-Design for Relevance and Usefulness' - Q\&A with Melissa Leach } \\
\text { (Source: futureearth.org) }\end{array}$ & NI \\
\hline SDSN & 2012 & $\begin{array}{l}\text { United Nations Secretary-General Announces New Sustainable } \\
\text { Development Initiative (press release). }\end{array}$ & NI \\
\hline SDSN & 2013 & $\begin{array}{l}\text { Join the Sustainable Development Solutions Network. The benefits of } \\
\text { membership }\end{array}$ & FD \\
\hline SDSN & 2014 & $\begin{array}{l}\text { An Action Agenda for Sustainable Development: Report for the UN } \\
\text { Secretary-General. }\end{array}$ & PR \\
\hline SDSN & 2015 & $\begin{array}{l}\text { Getting Started with the Sustainable Development Goals. A Guide for } \\
\text { Stakeholders. }\end{array}$ & PR \\
\hline SDSN & 2015 & $\begin{array}{l}\text { Indicators and a Monitoring Framework for the Sustainable Development } \\
\text { Goals. Launching a data revolution for the SDGs. A report to the Secretary- } \\
\text { General of the United Nations by the Leadership Council of the Sustainable } \\
\text { Development Solutions Network }\end{array}$ & $\mathrm{PR}$ \\
\hline SDSN & n.d. & Bylaws for SDSN Members & FD \\
\hline SDSN & n.d. & The World's Knowledge Network for the Sustainable Development Goals & PR \\
\hline Sharma, Y. & 2012 & Global alliance to study planetary changes revealed (Source: SciDev.Net) & NI \\
\hline $\begin{array}{l}\text { Stafford-Smith, } \\
\text { M. }\end{array}$ & 2014 & $\begin{array}{l}\text { UN sustainability goals need quantified targets (Source: Nature, 315:7518, } \\
\text { pp 281) }\end{array}$ & SP \\
\hline $\begin{array}{l}\text { STC Major } \\
\text { Group }\end{array}$ & $\begin{array}{l}2012- \\
2017\end{array}$ & $\begin{array}{l}\text { Official statements of the Scientific and Technological Major Group } \\
\text { (Source: sustainabledevelopment.un.org) }\end{array}$ & FD \\
\hline Steffen, W. et al. & 2004 & Global Change and the Earth System: A Planet Under Pressure & PR \\
\hline Tatalović, M. & 2012 & UNESCO to set up UN science advisory board. (Source: SciDevNet) & NI \\
\hline $\begin{array}{l}\text { Transition Team } \\
\text { for Future Earth }\end{array}$ & 2011 & $\begin{array}{l}\text { Earth System Sustainability Initiative. Summary of the first Transition Team } \\
\text { meeting }\end{array}$ & UD \\
\hline $\begin{array}{l}\text { Transition Team } \\
\text { for Future Earth }\end{array}$ & 2011 & $\begin{array}{l}\text { Earth System Sustainability Initiative. Transition Team Working Group 1: } \\
\text { Draft Terms of Reference }\end{array}$ & UD \\
\hline $\begin{array}{l}\text { Transition Team } \\
\text { for Future Earth }\end{array}$ & 2011 & $\begin{array}{l}\text { Earth System Sustainability Initiative. Transition Team Working Group 2: } \\
\text { Draft Terms of Reference }\end{array}$ & UD \\
\hline $\begin{array}{l}\text { Transition Team } \\
\text { for Future Earth }\end{array}$ & 2011 & $\begin{array}{l}\text { Earth System Sustainability Initiative. Transition Team Working Group 3: } \\
\text { Draft Terms of Reference }\end{array}$ & UD \\
\hline $\begin{array}{l}\text { Transition Team } \\
\text { for Future Earth }\end{array}$ & 2011 & $\begin{array}{l}\text { Future Earth (Earth System Sustainability Initiative). Summary of the 2nd } \\
\text { Transition Team meeting }\end{array}$ & UD \\
\hline $\begin{array}{l}\text { Transition Team } \\
\text { for Future Earth }\end{array}$ & 2012 & $\begin{array}{l}\text { Future Earth: research for global sustainability. A Framework Document by } \\
\text { the Future Earth Transition Team }\end{array}$ & FD \\
\hline $\begin{array}{l}\text { Transition Team } \\
\text { for Future Earth }\end{array}$ & 2012 & $\begin{array}{l}\text { Governance framework and institutional mechanisms for Future Earth } \\
\text { [draft for consultation] }\end{array}$ & UD \\
\hline $\begin{array}{l}\text { Transition Team } \\
\text { for Future Earth }\end{array}$ & 2012 & Report on Future Earth's Institutional design [draft for consultation] & UD \\
\hline $\begin{array}{l}\text { Transition Team } \\
\text { for Future Earth }\end{array}$ & 2012 & Research framework for Future Earth [draft for consultation] & UD \\
\hline $\begin{array}{l}\text { Transition Team } \\
\text { for Future Earth }\end{array}$ & 2013 & Future Earth Initial Design Report & PR \\
\hline $\begin{array}{l}\text { Transition Team } \\
\text { for Future Earth }\end{array}$ & 2013 & Draft Terms of Reference for Engagement Committee & FD \\
\hline
\end{tabular}




\begin{tabular}{|c|c|c|c|}
\hline $\begin{array}{l}\text { Transition Team } \\
\text { for Future Earth }\end{array}$ & 2013 & Draft Terms of Reference for Science Committee & FD \\
\hline UN DESA & 2014 & Prototype Global Sustainable Development Report. & PR \\
\hline UN DESA & 2015 & $\begin{array}{l}\text { Call for contributions to the UN Global Sustainable Development Report } \\
2016\end{array}$ & FD \\
\hline UN DESA & 2015 & Global Sustainable Development Report & PR \\
\hline UN DESA & 2015 & $\begin{array}{l}\text { Report of the UN Expert Group Meeting for the Global Sustainable } \\
\text { Development Report: Emerging issues and peer review }\end{array}$ & FD \\
\hline UN DESA & 2016 & Global Sustainable Development Report & PR \\
\hline UN DESA & 2016 & $\begin{array}{l}\text { Report of the UN Expert Group Meeting for the Global Sustainable } \\
\text { Development Report: Emerging issues for the attention of policy makers }\end{array}$ & FD \\
\hline UNEP & 2012 & $\begin{array}{l}\text { The GEO-5 Process. (In: Global Environment Outlook (GEO-5), pp. 489- } \\
492 \text { ) }\end{array}$ & PR \\
\hline UNEP & 2014 & $\begin{array}{l}\text { Governments Set in Motion Vital New Assessment on the State of the } \\
\text { World's Environment (Source: UNEP News Centre) }\end{array}$ & NI \\
\hline UNEP & 2014 & Key roles and responsibilities in GEO-6 & FD \\
\hline UNEP & 2014 & Nomination Criteria for GEO-6 experts. & FD \\
\hline UNEP & 2014 & $\begin{array}{l}\text { Terminal Evaluation of the Project. Fifth GEO: Integrated Environmental } \\
\text { Assessment }\end{array}$ & FD \\
\hline UNEP & 2016 & $\begin{array}{l}\text { Summary of the Sixth Global Environment Outlook Regional Assessments: } \\
\text { Key Findings and Policy Messages }\end{array}$ & PR \\
\hline UNEP & n.d. & $\begin{array}{l}\text { Guidelines for ensuring Scientific Credibility and Policy Relevance of the } \\
\text { GEO-5 Assessment }\end{array}$ & FD \\
\hline Wilson, S. & 2012 & Science is key to our sustainable future (Source: Al Jazeera) & $\mathrm{NI}$ \\
\hline
\end{tabular}




\section{SUMMARY}

The urgency, complexity and contested nature of sustainability problems and potential solutions poses unprecedented challenges for both science and governance. Responding to these challenges, researchers seek to advance new ways of doing science that are more interdisciplinary, co-produced, inclusive and solutions-oriented. In this thesis, I show how such ambitions of science for sustainability become institutionalised, and what the implications are for the relationship between science and governance for sustainability.

Science for sustainability proposes an active role of science in shaping and steering sustainability transformations. As such, it challenges conventional understandings of science as neutral, disinterested and impartial. Principles of science for sustainability are increasingly adopted by researchers, science managers, funding agencies and policy-makers. This means that these principles are moving from the margin to the mainstream of research on sustainability. And yet, we do not know how these ideals and aspirations come to shape institutions of science for sustainability. The specific way in which science for sustainability becomes institutionalised matters for the kind of knowledge that gets produced and the relations between science and governance that get formed. Moreover, the institutionalisation of science for sustainability raises questions about appropriate and desirable engagement of science with the politics of sustainability transformations. Thus, it is important to understand how principles of science for sustainability become institutionalised and with what effects.

The question addressed in this thesis is as follows:

How are new principles of science for sustainability institutionalised and how does this shape the relationship between science and governance for sustainability?

In addressing this question, I bring together multiple theoretical traditions and empirical approaches. Chapter 2 discusses three strands of literature that form the conceptual foundation for this thesis. Literature on science for sustainability puts forward the ambition of science to support sustainability transformations. Literature from social studies of science emphasises the social, institutional and political processes that shape scientific knowledge production. Literature on science in environmental governance discusses how science influences environmental and sustainability governance. All three bodies of literature draw attention to the politics of science institutions for sustainability, albeit in different ways. I bring these insights together in a nested conceptualisation of ambitions, institutions and effects as entangled elements of the politics of science for sustainability.

The main empirical focus of this thesis is the global research platform Future Earth: research for global sustainability. Future Earth was launched in 2012 in response to calls to fundamentally change the practice, content and organisation of global change research. It provides an exemplary case of the institutionalisation of new principles of science for sustainability and an opportunity to study a global science institution in the making'. Chapter $\mathbf{3}$ discusses the methods of data collection and analysis used in this thesis. I employed a mixed-method 
approach, which allowed me to consider the phenomenon of science for sustainability and its institutionalisation from different angles. I combined document analysis, expert interviews, participant observation, scientometric analysis and a survey among researchers engaged in Future Earth. Chapter 4 discusses the organisational history and development of Future Earth. It highlights the ambitious mission of Future Earth to advance science that shapes societal transformations to sustainability. In the thesis, I contrast and compare Future Earth to eight other cases of science institutions in sustainability, including formal research programmes, global environmental assessments and scientific advisory bodies. This comparison allows for a better understanding of the extent to which the developments I observe for Future Earth reflect broader trends.

Chapters 5 to 9 present the empirical research of this thesis. Chapter $\mathbf{5}$ focuses on the institutionalisation of the principle of co-production in Future Earth. I distinguish three distinct rationales (logics) on the purpose and practice of co-production. These logics variously emphasise how co-production in Future Earth can ensure the accountability of science to its societal sponsors (logic of accountability), enhance the influence of science in society (logic of impact) or enrich scientific knowledge production with the knowledge, perspectives and experience of extra-scientific actors (logic of humility). This heterogenous conception of coproduction provides helpful ambiguity that allows actors with different perspectives on science and its role in society to engage in Future Earth. Yet, translating the aspirational principle of co-production into specific institutional structures, rules and procedures brought out tensions between the different logics. My research shows that the logics of impact and accountability are prominent in shaping the development of Future Earth, while the logic of humility plays a more marginal role.

Chapter 6 considers the influence of global science institutions on scientific knowledge production. In this chapter, I conceptualise science institutions as coordination mechanisms that aim to facilitate collaboration and might steer research in particular directions. Using a scientometric approach, I studied how two of Future Earth's predecessors, the International Geosphere-Biosphere Programme and the International Human Dimensions Programme on Global Environmental Change, shaped the disciplinary and geographical composition of research undertaken under their umbrellas. The analysis illustrates the potential of formal research programmes to foster interdisciplinary collaboration. At the same time, the ambition of inclusiveness and equal participation of researchers from countries in the Global South remains far from realised. This chapter thus calls for careful reflection on the potential of global science coordination to transform research practices towards science for sustainability.

Chapter 7 focuses on the perspectives of researchers engaged in science for sustainability. It thus takes the question of institutionalisation from the formal structures, rules and procedures of global science institutions to the shared norms and values of sustainability researchers. This chapter builds on a survey conducted among researchers engaged in Future Earth. The survey results highlight that Future Earth's vision of transformative research for sustainability receives broad support. Yet, there are important differences in perspectives on what it means to do 
transformative research, specifically when it comes to dealing with normative and political concerns. This chapter highlights that sustainability researchers struggle to reconcile historically developed norms of scientific knowledge production and new perspectives on the transformative, normative and political roles of sustainability research in society.

Chapter 8 turns the attention to the relationship between science and governance for sustainability. Global science institutions have become a well-established part of the global landscape of sustainability governance. This chapter reviews how six different science institutions seek authority in their engagement with the development of the Sustainable Development Goals. The chapter distinguishes multiple strategies by which science institutions aim to foster perceptions of salience, credibility and legitimacy among governance actors. This includes the emerging mode of solutions-oriented authority, where science institutions claim relevance based on the promise of contributing to solutions for sustainability challenges, while seeking credibility by invoking support of the scientific community and legitimacy through an emphasis on participation. This mode of authority stands in contrast to two more established modes of authority (assessment-oriented and advice-oriented) that emphasise autonomy and independence of science. The chapter concludes with a framework for reflection, which highlights the political choices embedded in the strategies by which science institutions seek authority.

Chapter 9 takes the discussion of authority further by unpacking how the pursuit of epistemic authority shapes the institutional design of science institutions. The chapter focuses on the relationship between epistemic authority, institutional design and participation. It compares the development of Future Earth and the Intergovernmental Platform for Biodiversity and Ecosystem Services (IPBES). While these two platforms are different in their organisational history and focus, they share an explicit commitment to participation at the global level. The comparison shows that institutional designs of participation allow for the inclusion of a wider set of knowledge and experiences. Yet, in seeking epistemic authority, both knowledge platforms also reinforce existing power structures by redrawing boundaries that protect scientific autonomy and privilege relationships with elite actors.

Together, the empirical chapters of this thesis draw out tensions that shape the institutionalisation of science for sustainability. In chapter 10, in answering the research question, I argue that principles of science for sustainability form an important rationale that shapes Future Earth and other science institutions. Yet, these principles are pursued in support of different aims, which leads to contestations over the appropriate design of science institutions. I show that the transformative ambition of science for sustainability contradicts with institutionalised boundaries between science and politics. Sustainability researchers find different ways to reconcile demands of transformative research and historically developed norms of scientific knowledge production. Yet, designs of global science institutions tend to conceal the inevitable politics involved in the ambitions, institutions and effects of science for sustainability. 
I conclude by presenting my thoughts on the need to rethink the relationship between science and politics for sustainability. I argue that a strict separation between science and politics in transformations to sustainability is not only impossible but also undesirable. Sustainability transformations are about normative visions of desirable futures which cannot be seen separate from the knowledge that informs and supports transformations. Moreover, transformations to sustainability inevitably involve changes in power structures that uphold existing practices and societal structures. Science institutions that obscure difficult discussions about the politics of science and sustainability risk reproducing the status quo. Overall, making a meaningful contribution to sustainability transformations involves moving beyond the deeply engrained assumption that scientific knowledge is and should be independent from politics. 


\section{SAMENVATTING}

De urgentie, complexiteit en het betwiste karakter van duurzaamheidsproblematiek vormen ongekende uitdagingen voor zowel wetenschap als politiek. In reactie op deze uitdagingen richten wetenschappers zich steeds vaker tot nieuwe vormen van wetenschap, hier samengevat met de term science for sustainability. Science for sustainability is gebaseerd op principes van interdisciplinariteit, coproductie, inclusiviteit en oplossingsgerichtheid. In dit proefschrift kijk ik naar de manier waarop deze principes geïnstitutionaliseerd worden in wetenschappelijke organisaties en netwerken en ga ik in op de implicaties voor de relatie tussen wetenschap en politiek.

De ambitie van science for sustainability is dat de wetenschap een actieve bijdrage levert aan maatschappelijke transformaties naar een duurzame toekomst. Het staat daarmee in contrast met conventionele opvattingen over wetenschap als waardevrij, belangeloos en onafhankelijk. Desondanks wordt het ideaal van science for sustainability in toenemende mate ondersteund door onderzoekers, wetenschapsmanagers, financierende instanties en beleidsmakers. Dit betekent dat deze manier van wetenschap steeds meer centraal wordt gesteld in het duurzaamheidsonderzoek. Het is echter onduidelijk hoe de ambities en principes van science for sustainability worden geïnstitutionaliseerd in wetenschappelijke organisaties en netwerken. Bovendien roept de institutionalisering van science for sustainability vragen op over de rol van wetenschap in duurzaamheidstransformaties. Het is dus belangrijk om te begrijpen hoe science for sustainability geïnstitutionaliseerd wordt in wetenschappelijke organisaties en netwerken, en welke effecten dit heeft voor de relatie tussen wetenschap en politiek.

De vraag die centraal staat in dit proefschrift is als volgt:

Hoe worden nieuwe principes van science for sustainability geïnstitutionaliseerd in wetenschappelijke organisaties en netwerken en hoe geeft dit vorm aan de relatie tussen wetenschap en politiek?

Bij het beantwoorden van deze vraag breng ik meerdere theoretische tradities en empirische benaderingen samen. Hoofdstuk 2 bespreekt de literatuur die de conceptuele basis vormt voor dit proefschrift. Literatuur over science for sustainability formuleert de ambitie om bij te dragen aan duurzaamheidstransformaties door middel van een nieuwe manier van wetenschap. Literatuur vanuit de social studies of science benadrukt de sociale, institutionele en politieke processen van wetenschappelijke kennisproductie. Literatuur over science in environmental governance bespreekt hoe wetenschap invloed heeft op duurzaamheidsbeleid. Alle drie de literatuurgebieden vestigen de aandacht op de relatie tussen wetenschap en politiek, zij het vanuit verschillende perspectieven.

Het internationale onderzoeksplatform Future Earth: research for global sustainability vormt de empirische casus voor dit onderzoek. Future Earth, gelanceerd in 2012, heeft de ambitie om de inhoud en organisatie van onderzoek naar duurzaamheid fundamenteel te veranderen. Het platform vormt dus een voorbeeld van de institutionalisering van nieuwe wetenschappelijke 
principes voor duurzaamheid. Hoofdstuk 3 bespreekt de wetenschappelijke methoden die in dit proefschrift worden gebruikt. Het proefschrift is gebaseerd op documentanalyse, expertinterviews, observaties tijdens bijeenkomsten van Future Earth, sciëntometrische analyse en een enquête onder duurzaamheidswetenschappers. Deze combinatie van methoden stelde me in staat de institutionalisering van science for sustainability vanuit verschillende invalshoeken te bestuderen. Hoofdstuk 4 bespreekt de ontwikkeling van Future Earth en benadrukt de missie van Future Earth om bij te dragen aan maatschappelijke transformaties. In het proefschrift vergelijk ik Future Earth met acht andere wetenschappelijke organisaties en netwerken op het gebied van duurzaamheid om inzicht te krijgen in de mate waarin de ontwikkelingen van Future Earth een weerspiegeling zijn van breder gedragen ideeën en trends.

Hoofdstuk 5 richt zich op de institutionalisering van het principe van coproductie in Future Earth. Coproductie gaat over het betrekken van niet-wetenschappers in het wetenschappelijke proces. Ik onderscheid drie verschillende beweegredenen (logics) met betrekking tot het doel en de praktijk van coproductie. Coproductie kan worden gezien als een manier waarop de wetenschap verantwoording aflegt aan haar maatschappelijke sponsors (logic of accountability), als een manier waarop de wetenschap haar invloed in de samenleving kan versterken (logic of impact), of als een verrijken van de wetenschap met de kennis, perspectieven en ervaring van niet-wetenschappers (logic of humility). Deze ambiguiteit zorgt er voor dat actoren met verschillende beweegredenen zich kunnen vinden in de ambitie van coproductie in Future Earth. Tegelijkertijd zorgt de vertaling van het principe van coproductie naar specifieke institutionele structuren, regels en procedures voor spanningen. Mijn onderzoek toont aan dat de logic of accountability en de logic of impact een prominente rol spelen in institutionele processen, terwijl de logic of humility minder nadrukkelijk wordt ondersteund.

Hoofdstuk 6 gaat in op de invloed van grootschalige wetenschappelijke organisaties en netwerken, zoals Future Earth. Met behulp van een sciëntometrische benadering heb ik onderzocht hoe twee van de voorlopers van Future Earth, het International GeosphereBiosphere Programme (IGBP) en het International Human Dimensions Programme on Global Environmental Change (IHDP), de interdisciplinariteit en inclusiviteit van wetenschappelijk onderzoek hebben beïnvloed. De analyse laat zien dat wetenschappelijke organisaties en netwerken interdisciplinaire samenwerking kunnen bevorderen. Tegelijkertijd blijft de ambitie van inclusiviteit, en dan met name de gelijke deelname van onderzoekers uit niet-Westerse landen, verre van gerealiseerd.

Hoofdstuk 7 focust op de perspectieven van wetenschappers binnen het netwerk van Future Earth. De resultaten van een enquête onder duurzaamheidswetenschappers laten zien dat de ambities van science for sustainability breed worden ondersteund. Toch zijn er belangrijke verschillen in perspectieven op de rol van wetenschap in duurzaamheidstransformaties, en dan met name over de vraag in hoeverre wetenschappers zich moeten mengen in normatieve en politieke vraagstukken. Duurzaamheidswetenschappers ervaren frictie tussen historisch 
ontwikkelde wetenschappelijke normen, zoals neutraliteit en onafhankelijkheid, en de meer politieke rol van wetenschap in duurzaamheidstransformaties.

Hoofdstuk 8 richt de aandacht op de relatie tussen wetenschap en internationaal beleid. Dit hoofdstuk bespreekt hoe zes verschillende wetenschappelijke organisaties en netwerken op het gebied van duurzaamheid zich mengen in de ontwikkeling van de Duurzame Ontwikkelingsdoelen van de Verenigde Naties. Het hoofdstuk onderscheidt verschillende strategieën waarmee wetenschappelijke organisaties en netwerken hun invloed en autoriteit trachten te bevorderen. Daarbij komt naar voren dat een nieuwe strategie, gericht op het aandragen van oplossingen en samenwerking met andere maatschappelijke actoren, steeds belangrijker wordt voor wetenschappelijke organisaties en netwerken die trachten bij te dragen aan duurzame ontwikkeling.

Hoofdstuk 9 gaat verder in op de discussie over autoriteit. Dit hoofdstuk onderzoekt hoe het streven naar autoriteit de institutionele structuur van wetenschappelijke organisaties en netwerken beïnvloedt. Hierbij wordt een vergelijking gemaakt tussen de ontwikkeling van Future Earth en het Intergovernmental Platform for Biodiversity and Ecosystem Services (IPBES). Uit de vergelijking blijkt de centrale positie van participatie binnen beide netwerken. Echter, in het streven naar autoriteit worden met name relaties met invloedrijke publieke en private actoren bevorderd. Minder prominente actoren kunnen wel deelnemen in de wetenschappelijke netwerken maar directe invloed op besluitvormingsprocessen is beperkt.

Hoofdstuk 10 geeft antwoord op de onderzoeksvraag. Ik betoog dat principes van science for sustainability een belangrijke grondgedachte vormen voor Future Earth en andere wetenschappelijke organisaties en netwerken. Deze principes worden echter nagestreefd ter ondersteuning van uiteenlopende doelen, wat leidt tot spanningen tussen verschillende perspectieven. Deze spanningen blijken uit de manier waarop principes van science for sustainability worden geïnstitutionaliseerd. Specifiek speelt er een spanning tussen de ambitie van science for sustainability om duurzaamheidstransformaties te bevorderen, waarbij gezocht wordt naar een meer actieve en sturende rol voor de wetenschap in maatschappelijke veranderingen, en geïnstitutionaliseerde grenzen tussen wetenschap en politiek. Duurzaamheidsonderzoekers vinden verschillende manieren om met deze contradictie om te gaan. Desondanks blijft de fictieve scheiding tussen wetenschap en politiek behouden in de manier waarop science for sustainability wordt geïnstitutionaliseerd.

Tot slot betoog ik dat een strikte scheiding tussen wetenschap en politiek bij transformaties naar duurzaamheid niet alleen onmogelijk maar ook ongewenst is. Duurzaamheidstransformaties gaan over normatieve visies en politieke keuzes. Deze aspecten zijn onlosmakelijk verbonden met de wetenschappelijke kennis die maatschappelijke transformaties informeert en ondersteunt. Om de ambities van science for sustainability in de praktijk te brengen is het dus noodzakelijk het diepgewortelde idee van een onafhankelijke en neutrale wetenschap los te laten. Een nieuw perspectief op de relatie tussen wetenschap en politiek kan een belangrijke bijdrage leveren aan de noodzakelijke maatschappelijke transformaties naar een duurzame toekomst. 
Appendices 


\section{ACKNOWLEDGEMENT}

This $\mathrm{PhD}$ was a journey with beautiful mountain tops and some daunting passages. Many people inspired, helped, encouraged and made me laugh along the way. I want to express my sincere thanks to you all!

First and foremost, my supervisors Frank Biermann and Arthur Petersen. You gave me the freedom to seek my own way and guided me with openness and interest. Frank, thank you for your relentless enthusiasm and honest advice. Our meetings always gave me inspiration and new energy to continue. You also taught me that the work of a PhD goes beyond the research and writing, and encouraged me to seek different experiences and develop myself in the broadest sense. Arthur, being at different universities, our conversations were intermittent but always rich and stimulating. I especially appreciate the opportunities to visit you at University College London and your visit to Arizona State University during my research stay there. I am grateful that I could count on your encouragement, critical view and attention for detail throughout this $\mathrm{PhD}$.

I would also like to thank the people that I had the pleasure to interview for this study and those with whom I had informal conversations that shaped my thinking. This includes representatives of Future Earth's research projects, advisory committees and secretariat staff. Thank you for your help and your interest in my work.

The foundational work for chapter six was conducted together with Eleftheria Vasileiadou. Eleftheria passed away, way too early, in April 2016. I wish I could have I told her how much I valued her critical engagement with my PhD. I am still triggered by her voice in my head telling me to figure out the answer to the question 'what kind of beast is Future Earth?'

The Science, Values and Environmental Governance cluster, led by Arthur and Eleftheria, provided a valuable foundation for reflection and discussion in the early stages of my $\mathrm{PhD}$. Thanks to you all for showing me joys of in-depth engagement with each other's work. In particular I would like to thank Eva Kunseler for ongoing conversations on the complexities of science in society.

Another group of people that I would like to thank are the members of the SENSE Honours Programme. We wrote our $\mathrm{PhD}$ proposals together and kept in touch along the different directions that this took us. I especially appreciate that we never let the competition for $\mathrm{PhD}$ grants overtake our collaborative spirit. With Jillian I developed a special friendship. Jillian, I am so glad we got to share this $\mathrm{PhD}$ journey together. Your positive energy helped me through difficult passages and you inspired me with the strength and commitment by which you completed your $\mathrm{PhD}$.

I started this PhD at the Institute for Environmental Studies (IVM) at VU Amsterdam. My former colleagues at the Environmental Policy Analysis (EPA) department generously shared their time to provide feedback on the initial steps of this $\mathrm{PhD}$. I especially would like to thank the (then) PhDs and junior researchers at IVM for providing a fun and social working 
environment. With Oscar Widerberg I got to organise several events on environmental governance which was a great pleasure. Thanks for that!

At the Copernicus Institute at Utrecht University, I found another group of inspiring colleagues. Thank you all for engaging conversations, encouragement and feedback on my work. I appreciate the close collaboration with many of you in writing, teaching and organising events. Special thanks to Bart, Elizabeth, Laura and Toon for making office 7.96 the best place to work, to Charlotte, Gustav, James, Karlijn and Lucas for moral support and fun times, and to Yu Yang for many cups of Chinese tea.

During this PhD I visited Arizona State University and was inspired by conversations with Marta Berbés-Blázquez, Matt Feagan, Clark Miller, Thad Miller, Dan Sarewitz and many others. Thank you for hosting me and introducing me to not only inspiring research but also the thrilling beauty of Arizona.

The Earth System Governance network forms my academic home. I especially enjoyed the stimulating conferences and other events over the years and would like to thank the many people that provided feedback on early drafts of the papers in this $\mathrm{PhD}$. Jennifer Bansard, Ina Möller and Carole-Anne Sénit became dear friends. I deeply appreciate how we support each other in our academic journeys.

My thanks also go to other inspiring people I met along the way. Ayşem Mert opened my eyes to critical theoretical work and was a mentor for me over the years. Carina Wyborn was a great conversation partner at Future Earth events and helped me reflect on the various dimensions of co-production. Alejandro Esguerra, my co-author for chapter 9, showed me the joys of writing together. Thank you all for your encouragement and support.

Outside of academic life, I would like to thank my close friends since high school, Daya, Nina and Liesbeth. You worried about me when I got to absorbed with work and laughed with me about my struggles in making decisions. Thanks for taking me out of my $\mathrm{PhD}$ bubble for highwines or camping trips whenever I needed it most.

I should also thank our houseboat for providing the perfect spot to break-up work sessions for a swim in the Amstel river. Of course, special places are shared with special people. Barend and Julie, Olav and Renee, Joachim and Ilse, Guus and Hanna, thank you for your friendship.

My friends also have mad skills. Barend Wilschut designed the cover and figures and illustrations in this book. Daya Berendse edited chapter 1 and chapter 10, and answered all my questions about language. Thank you both!

Another special place that shaped this $\mathrm{PhD}$ is Manege Geuzeneiland in Amsterdam. Here I could escape from writer's blocks and daunting reviews. Sometimes, working with horses and getting your hand dirty are the best medicine in life. Lieve allemaal, bedankt dat jullie me bebben opgenomen in de Geuzeneiland familie. Ik vind het heel bijzonder wat wij samen neerzetten. 
I am fortunate to have my family standing by my side. Mum, Dad and David, thanks for your ongoing support, care and trust in me. Paul and Jeanette, thank you for cheering me up and cheering me on.

Maarten, this $\mathrm{PhD}$ has been a journey for both of us, not only because we took every conference and research visit as an opportunity to travel to new places, but mostly because you joined me through all the ups and downs. The last months, working together at our kitchen table, were particularly special. Thank you for keeping me going. Let's make many more adventures together. 
reis ver, drink wijn, denk na,

lach hard, duik diep,

kom terug

- Spinvis 